ALEX SANDRO ROMEU DE SOUZA POLETTO

\title{
UM MODELO PARA PROJETO E IMPLEMENTAÇÃO DE BANCOS DE DADOS ANALÍTICO-TEMPORAIS
}

Tese apresentada à Escola Politécnica da Universidade de São Paulo para obtenção do título de Doutor em Engenharia Elétrica. 


\title{
UM MODELO PARA PROJETO E IMPLEMENTAÇÃO DE BANCOS DE DADOS ANALÍTICO-TEMPORAIS
}

\author{
Tese apresentada à Escola Politécnica \\ da Universidade de São Paulo para \\ obtenção do título de Doutor em \\ Engenharia Elétrica. \\ Área de Concentração: \\ Sistemas Digitais. \\ Orientador: Prof $^{\circ} \mathrm{Dr}^{\circ}$ \\ Jorge Rady de Almeida Junior
}


Este exemplar foi revisado e alterado em relação à versão original, sob responsabilidade única do autor e com a anuência de seu orientador.

São Paulo, 07 de janeiro de 2008.

Assinatura do autor

Assinatura do orientador

FICHA CATALOGRÁFICA

Poletto, Alex Sandro Romeu de Souza

Um modelo para projeto e implementação de bancos de dados analítico-temporais. Edição Revisada / A.S.R.S. Poletto. -São Paulo, 2008. $167 \mathrm{p}$.

Tese (Doutorado) - Escola Politécnica da Universidade de São Paulo. Departamento de Engenharia de Computação e Sistemas Digitais.

1.Banco de dados (Projeto; Modelagem) 2.Banco de dados ativos 3.Banco de dados temporais I.Universidade de São Paulo. Escola Politécnica. Departamento de Engenharia de Compu-tação e Sistemas Digitais II.t. 
Dedico este trabalho a minha esposa Flávia e ao meu filho Breno Augusto. 


\section{AGRADECIMENTOS}

A Deus, por permitir o cumprimento desta etapa em minha vida.

Agradeço ao Profo Dro Jorge Rady de Almeida Júnior, pela belíssima orientação, motivação e paciência, que certamente foram primordiais para a conclusão deste trabalho.

À Fundação Educacional do Município de Assis, pelo apoio e incentivo.

Ao meu amigo Luiz Ricardo Begosso, pelas valiosas contribuições.

Aos meus amigos funcionários do Centro de Pesquisas em Informática - CEPEIN, pela ajuda e compreensão, que certamente foram essenciais para a conclusão deste trabalho.

Aos meus pais, Alécio e Antônia pela constante motivação aos estudos, desde a infância.

Ao meu sogro e sogra, Vamil e Gedaíra, pelo apoio.

À Prof $^{\mathrm{a}} \mathrm{Dr}^{\mathrm{a}}$ Márcia Valério Seródio Carbone, pelas horas dedicadas para a revisão deste trabalho.

Em especial à minha esposa Flávia, pela compreensão, apoio e motivação, e ao meu filho Breno Augusto. 


\section{RESUMO}

O presente trabalho descreve um modelo para, a partir de Bancos de Dados Operacionais, projetar e implementar Bancos de Dados Analítico-Temporais, cujo principal objetivo é o de armazenar históricos de dados, os quais, por sua vez, visam servir de alicerce para, principalmente, auxiliar no processo de tomada de decisões de médio e longo prazo. O modelo é dividido em três atividades principais. $\mathrm{Na}$ primeira atividade o objetivo é mapear os Modelos de Dados Operacionais em um Modelo de Dados Unificado, sendo que este último modelo serve de base para a segunda atividade que é a geração do Modelo de Dados Analítico-Temporal. Para realizar essas duas primeiras atividades, foram elaborados alguns passos que englobam as principais características a serem verificadas e desenvolvidas. $\mathrm{Na}$ terceira atividade objetivou-se disponibilizar mecanismos que possibilitem a geração, o transporte e o armazenamento dos dados Analítico-Temporais. Para a realização dessa terceira atividade foram especificados gatilhos e procedimentos armazenados genéricos.

Palavras-chave: Bancos de Dados Analítico-Temporais. Bancos de Dados Operacionais. Gatilhos. Procedimentos Armazenados. Data Warehousing. 


\section{ABSTRACT}

This work describes a model whose main objective is to store historic data, resulting in the Analytic-Temporal Databases. The origins of the data are the Operational Databases. This model can aid in the design and implementation of the Analytic-Temporal Databases that constitutes a very adequate foundation to help in the medium and long time decision taking process. The model is divided into three main activities. In the first activity the objective is to map the Operational Data Models into a Unified Data Model. This last model is the base for the second activity, which is the generation of the Analytical-Temporal Data Model. Considering these two activities, there were elaborated some steps, which encompass the main characteristics to be evaluated and developed. In the third activity the objective is to make available mechanisms, allowing the generation, the transport and the storage of the Analytical-Temporal data. For this third activity, there were specified generic triggers and stored procedures.

Key Words: Analytical-Temporal Databases, Operational Databases, Triggers, Stored Procedures. Data Warehousing. 


\section{LISTA DE ILUSTRAÇÕES}

Figura 1 - Representação simplificada de um Sistema de Banco de Dados ............ 21

Figura 2 - Fases do Projeto de um Banco de Dados ............................................ 23

Figura 3 - Arquitetura de esquemas em três níveis para um banco de dados.......... 26

Figura 4 - Ilustração de um Ambiente de Data Warehousing .................................... 36

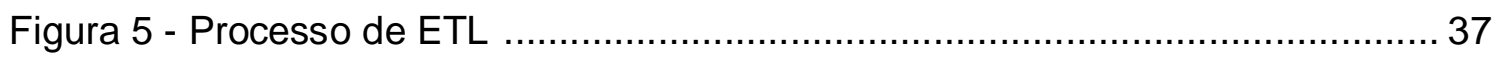

Figura 6 - Estrutura básica do modelo multidimensional ........................................ 38

Figura 7 - Diagrama Geral da Proposta de Modelagem e Implementação de Bancos de Dados Analítico-Temporais................................................................ 44

Figura 8 - Etapas da Proposta de Modelagem e Implementação de Bancos de Dados

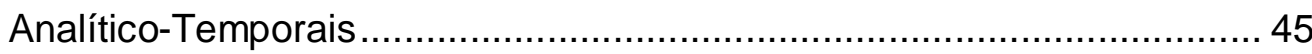

Figura 9 - Proposta de Modelagem e Implementação de Bancos de Dados AnalíticoTemporais $x$ Ambiente de Data Warehousing ....................................... 47

Figura 10 - Passos para a Geração Modelo de Dados Unificado ............................... 49

Figura 11 - Exemplo do Passo A1 .............................................................. 51

Figura 12 - Exemplo de Modelos de Dados Operacionais - Passo A2 …................. 52

Figura 13 - Exemplo do Passo A2 .............................................................. 52

Figura 14 - Exemplos de Entidades - Passo A3 …………………..................... 53

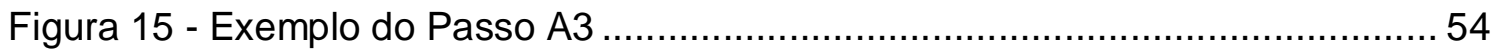

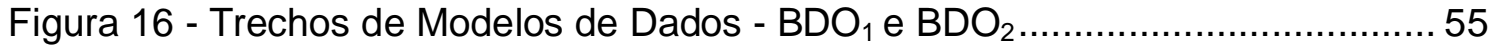

Figura 17 - llustração do uso das Chaves Primárias como Chaves Estrangeiras ... 57

Figura 18 - Passos para a Geração do Modelo de Dados Analítico-Temporal ......... 59

Figura 19 - Exemplo de aplicação do Passo B1 ................................................. 60

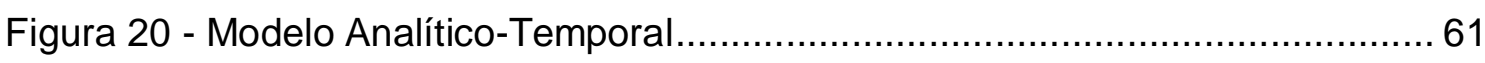

Figura 21 - Modelo de Dados Operacional entre FUNCIONÁRIO e CARGO ...........61 61

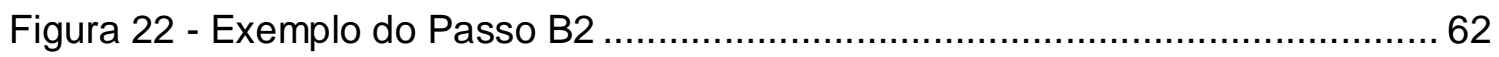

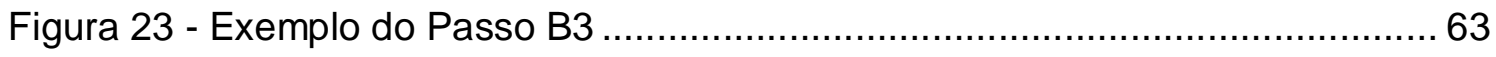

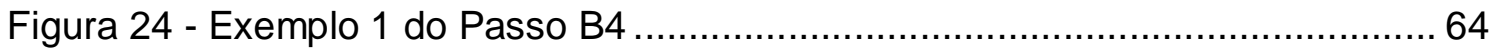

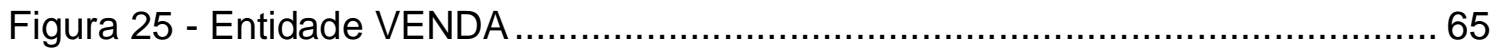

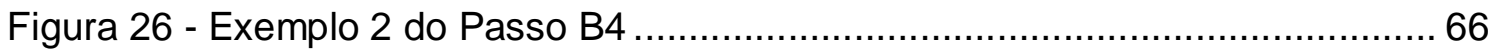

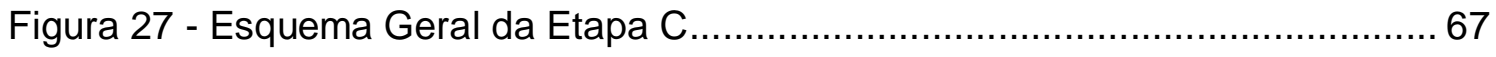

Figura 28 - Esquema de Comunicação - Cliente/Servidor e/ou Servidor/Servidor... 68 
Figura 29 - Fluxograma do Gatilho do Passo C1 …........................................ 70

Figura 30 - Especificação Genérica do Gatilho do Passo C1 ................................. 71

Figura 31 - Criação de Conjunto de Entidades ................................................... 72

Figura 32 - Fluxograma do Gatilho do Passo C2 ………................................... 73

Figura 33 - Especificação Genérica do Gatilho do Passo C2 ………………..... 74

Figura 34 - Fluxograma exemplo do Gatilho do Passo C2 ………….................. 74

Figura 35 - Fluxograma do Procedimento Armazenado do Passo C3 ..................... 75

Figura 36 - Especificação Genérica do Procedimento Armazenado do Passo C3 ... 76

Figura 37 - Fluxograma exemplo do Procedimento Armazenado do Passo C3 ....... 77

Figura 38 - Comparação com relação ao processo de tomada de decisão .............. 79

Figura 39 - Comparação com relação à forma de modelagem entre o banco de dados proposto e os Bancos de Dados Operacionais ........................... 80

Figura 40 - Comparação com relação à forma de modelagem entre o banco de dados proposto e os ambientes de Data Warehousing ....................... 81

Figura 41 - Comparação com relação à origem dos dados entre o banco de dados proposto e os ambientes de Data Warehousing ................................... 83

Figura 42 - Comparação com relação à origem e obtenção dos dados entre o banco de dados proposto e os ambientes de Data Warehousing.

Figura 43 - Comparação das ferramentas de consultas entre os três bancos de dados

Figura 44 - Modos de atualizações mais freqüentes nos três tipos de bancos de dados

Figura 45 - Parte do Modelo de Dados do Sistema de Folha de Pagamento ........... 96

Figura 46 - Parte do Modelo de Dados do Sistema Acadêmico ………………...... 97

Figura 47 - Estrutura de Comunicação entre os Bancos de Dados ........................... 98

Figura 48 - Modelo de Dados Operacional Unificado ........................................ 105

Figura 49 - Modelo de Dados BDAT_CARGO ………….................................... 108

Figura 50 - Modelo de Dados BDAT_CATEGORIA …….................................... 108

Figura 51 - Modelo de Dados BDAT_COORDENADORIA …................................ 109

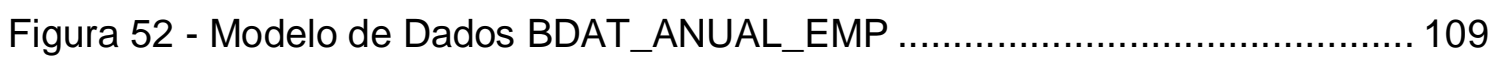

Figura 53 - Modelo de Dados BDAT_MEDIA.................................................... 110

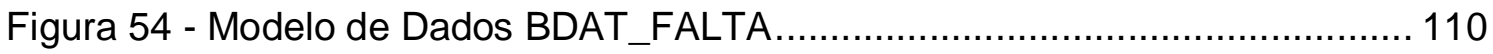

Figura 55 - Modelo de Dados BDAT_ENDER_EMPREGADO ……..................... 111

Figura 56 - Modelo de Dados BDAT_CARGO com Elementos de Tempo .............. 112 
Figura 57 - Modelo de Dados BDAT_CATEGORIA com Elementos de Tempo ..... 112

Figura 58 - Modelo de Dados BDAT_COORDENADORIA com dos Elementos de Tempo 112

Figura 59 - Modelo de Dados BDAT_MEDIA com Elemento de Tempo 113

Figura 60 - Modelo de Dados BDAT_ENDER_EMPREGADO com Elementos de

Tempo 113

Figura 61 - Modelo de Dados BDAT_MEDIA com Elemento Tempo e Atributos

Derivados 114

Figura 62 - Modelo de Dados BDAT_FALTA com atributo derivado 114

Figura 63 - Modelo de Dados BDAT_ANUAL_EMP com atributos derivados 115

Figura 64 - Modelo de Dados Analítico-Temporal 116

Figura 65 - Fluxograma do gatilho do PASSO_C1_BDAT_CARGO....................... 118

Figura 66 - Fluxograma do gatilho do PASSO_C1_BDAT_CAT1 ........................... 119

Figura 67 - Fluxograma do gatilho do PASSO_C1_BDAT_CAT2 ……………...... 120

Figura 68 - Fluxograma do gatilho do PASSO_C1_BDAT_COORDENADORIA .... 121

Figura 69 - Fluxograma do gatilho do PASSO_C1_BDAT_ENDER_EMP1 ........... 122

Figura 70 - Fluxograma do gatilho do PASSO_C1_BDAT_ENDER_EMP2 ........... 123

Figura 71 - Fluxograma do gatilho do PASSO_C2_BDAT_MEDIA ........................ 124

Figura 72 - Fluxograma do Procedimento Armazenado do PASSO_C2_BDAT_ANUAL_EMP 125

Figura 73 - Fluxograma do Procedimento Armazenado do PASSO_C2_BDAT_FALTA 126

Figura 74 - Modelos de Dados utilizados em testes 128 


\section{LISTA DE TABELAS}

Tabela 1 - Identificação de diferentes representações de valores .......................... 103

Tabela 2 - Seleção dos conjuntos de entidades …………………................... 107

Tabela 3 - Seleção dos conjuntos de relacionamento ......................................... 107 


\section{LISTA DE ABREVIATURAS E SIGLAS}

$\begin{array}{ll}\text { AUDESP } & \text { - Auditoria Eletrônica de Órgãos Públicos } \\ \text { BDO } & \text { - Banco de Dados Operacional } \\ \text { BDAT } & \text { - Banco de Dados Analítico-Temporal } \\ \text { ECA } & \text { - Evento-Condição-Ação (régra imposta aos gatilhos) } \\ \text { E-R } & \text { - Entidade-Relacionamento } \\ \text { ETL } & \text { - Extração, Transformação e Carga } \\ \text { FK } & \text { - Foreign Key } \\ \text { IDEF1X } & \text { - Integration Definition for Information Modeling } \\ \text { NIST } & \text { - National Institute of Standards and Technology } \\ \text { OLAP } & \text { - Online Analytic Processing } \\ \text { SGBD } & \text { - Sistema Gerenciador de Banco de Dados } \\ \text { SQL } & \text { - Structured Query Language } \\ \text { RHS } & \text { - Sistema de Recursos Humanos } \\ \text { TCP/IP } & \text { - Transmission Control Protocol/Internet Protocol } \\ \text { TF-ORM } & \text { - Temporal Functionality in Objetcs with Roles Model } \\ \text { TRM } & \text { - Temporal Relational Model } \\ \text { TVM } & \text { - Temporal Version Model } \\ \text { UML } & - \text { Unified Modeling Language } \\ \text { XML } & \text { - Extensive Markup Language } \\ & \end{array}$




\section{SUMÁRIO}

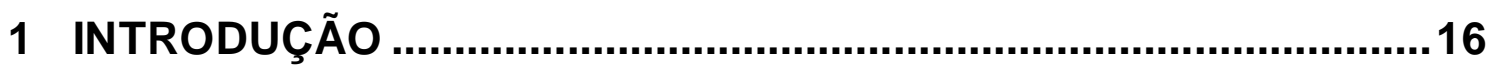

1.1 JUSTIFICATIVAS E MOTIVAÇÕES …………………………............16

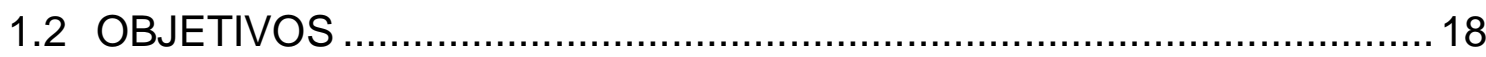

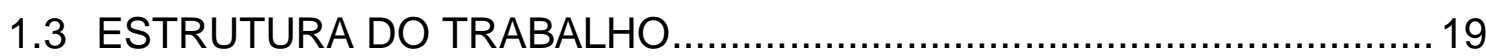

2 SISTEMAS DE BANCOS DE DADOS E DE DATA WAREHOUSING.

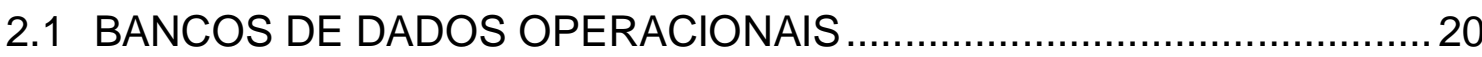

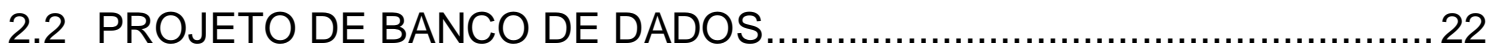

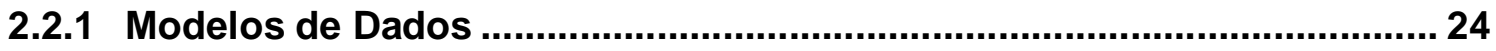

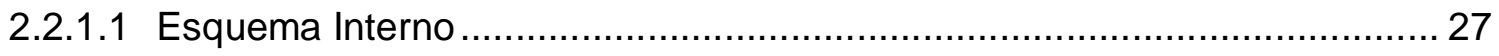

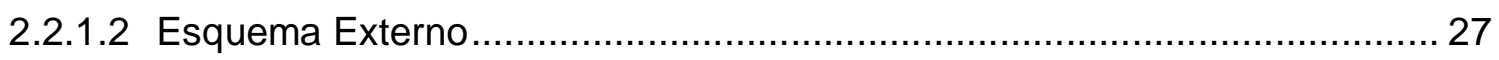

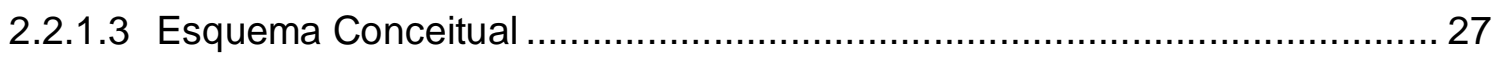

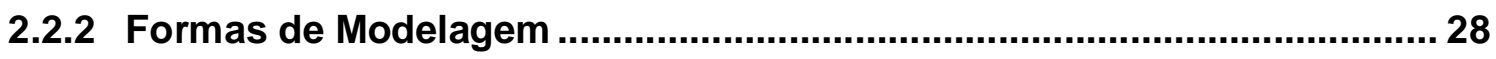

2.2.2.1 Diagramas Entidade-Relacionamento ……........................................... 28

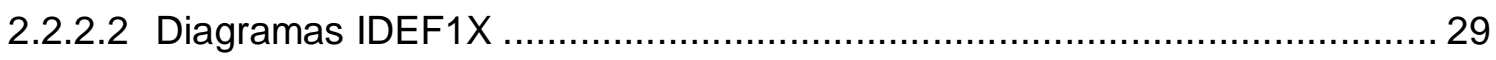

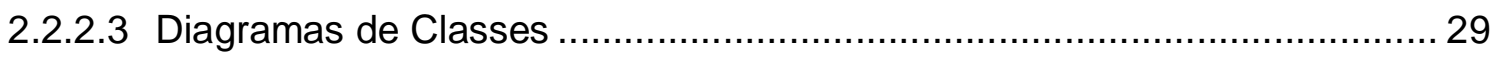

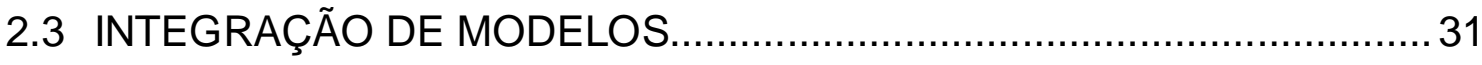

2.4 GATILHOS E PROCEDIMENTOS ARMAZENADOS …......................... 32

2.4.1 Procedimentos Armazenados..................................................................... 33

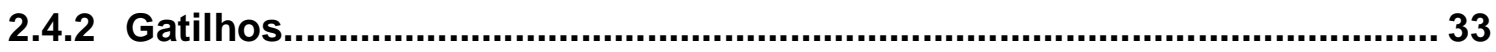

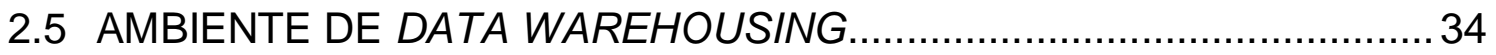

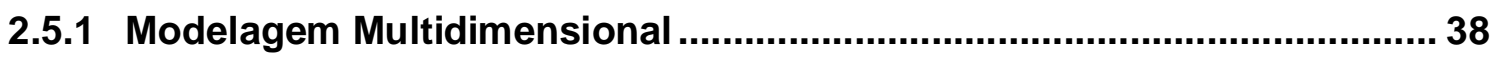

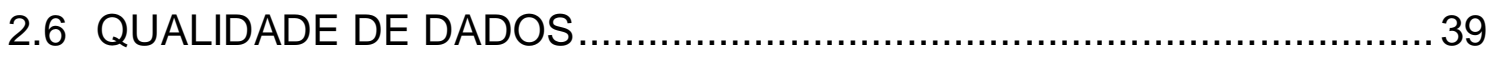

3 BANCOS DE DADOS ANALÍTICO-TEMPORAIS ................................41

3.1 BANCOS DE DADOS ANALÍTICO-TEMPORAIS .................................. 41

3.2 BANCO DE DADOS ANALÍTICO-TEMPORAL PROPOSTO ...................43

3.3 MAPEAMENTO DE DADOS ANALÍTICO-TEMPORAIS - ETAPAS A e B ..

3.3.1 Etapa A: Mapeamento dos Modelos de Dados Operacionais em um Modelo de Dados Unificado 
3.3.1.1 Passo A1: Renomeação de conjuntos de entidades com nomes iguais, mas com dados distintos.

3.3.1.2 Passo A2: Renomeação de conjuntos de entidades com nomes distintos, mas com dados comuns

3.3.1.3 Passo A3: Renomeação de atributos com nomes distintos, mas com dados comuns.

3.3.1.4 Passo A4: Transformação de atributos com dados comuns, mas com representação diferente de valores .......................................................... 54

3.3.1.5 Passo A5: Transformação de atributos chaves primárias ........................... 55

3.3.1.6 Passo A6: Transformação de atributos chaves estrangeiras ..................... 56

3.3.1.7 Passo A7: Geração do Modelo de Dados Unificado ................................. 57

\subsubsection{Etapa B: Mapeamento do Modelo de Dados Unificado em um Modelo de} Dados Analítico-Temporal..................................................................... 58

3.3.2.1 Passo B1: Seleção dos conjuntos de entidades e atributos para o Banco de Dados Analítico-Temporal 59

3.3.2.2 Passo B2: Criação dos conjuntos de entidades para o armazenamento dos dados analítico-temporais

3.3.2.3 Passo B3: Inclusão de elementos de tempo nos conjuntos de entidades ... 62

3.3.2.4 Passo B4: Inclusão de atributos derivados 64

3.3.2.5 Passo B5: Geração do Modelo de Dados Analítico-Temporal .................... 66

3.4 GERAÇÃO DOS DADOS ANALÍTICO-TEMPORAIS - ETAPA C ...........66

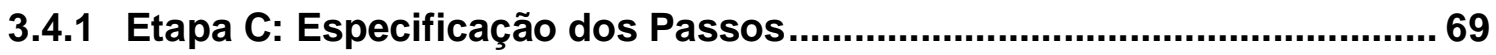

3.4.1.1 Passo C1: Geração de Gatilho para o passo B3 ...................................... 70

3.4.1.2 Passo C2: Geração de Gatilho para o Passo B4 .................................... 72

3.4.1.3 Passo C3: Geração de Procedimento Armazenado para o Passo B4 ........ 75

4 AV ALIAÇÃO DO MODELO PROPOSTO........................................78

4.1 AVALIAÇÃO DO MODELO DE BANCO DE DADOS ANALÍTICO-

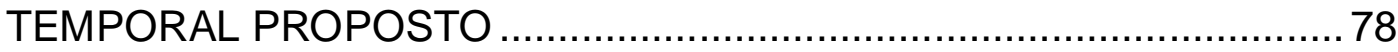

4.1.1 Processo de Tomada de Decisões ......................................................... 78

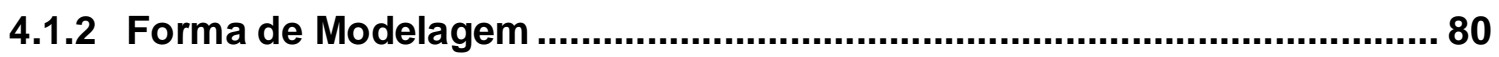

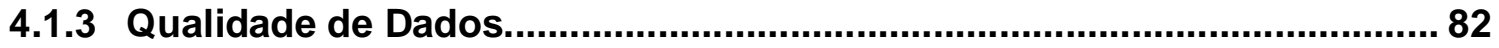

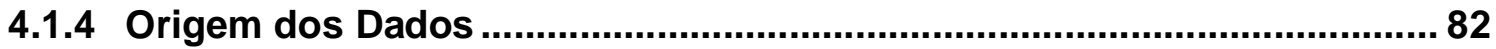

4.1.5 Extração, Transformação e Carga .............................................................. 83 


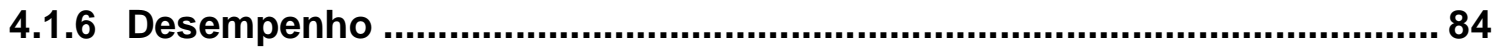

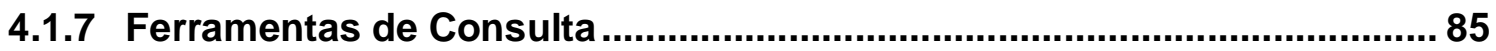

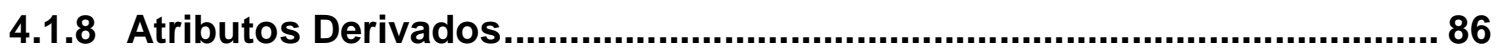

4.1.9 Histórico de Dados e Tempo de Armazenamento..................................... 87

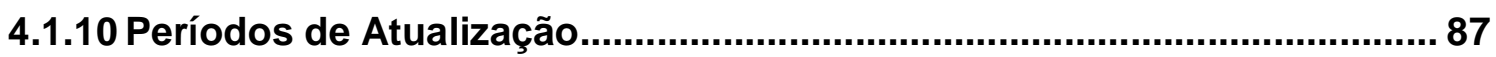

4.1.11 Sobrecarga no Ambiente Operacional ..................................................... 88

4.1.12 Modos de Atualização ................................................................................. 89

4.2 ESTUDO COMPARATIVO COM TRABALHOS CORRELATOS..............90

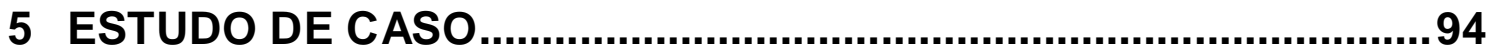

5.1 DESCRIÇÃO DAS APLICAÇÕES OPERACIONAIS ..............................94

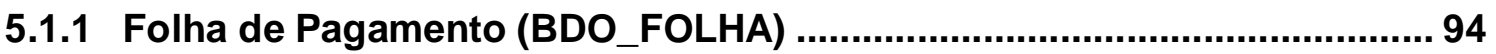

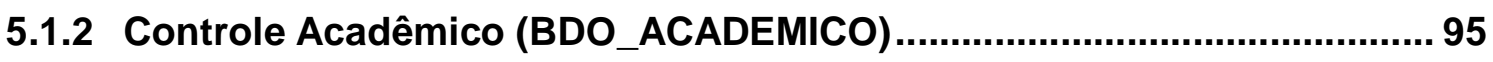

5.2 MODELAGEM DOS BANCOS DE DADOS OPERACIONAIS................ 95

5.2.1 Modelo de Dados da Folha de Pagamento ............................................... 95

5.2.2 Modelo de Dados do Controle Acadêmico ................................................ 96

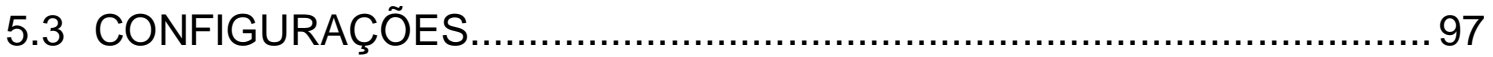

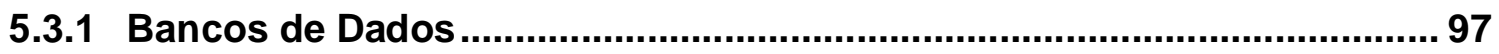

5.3.2 Funcionamento da Plataforma Oracle.................................................. 98

5.4 APLICAÇÃO DA PROPOSTA DE MODELAGEM …............................. 99

5.4.1 Aplicação da Etapa A: Mapeamento dos Modelos de Dados Operacionais em um Modelo de Dados Unificado........................................................ 100

5.4.1.1 Passo A1: Renomeação de conjuntos de entidades com nomes iguais, mas

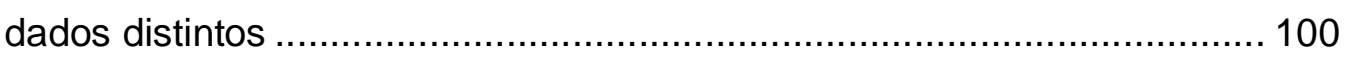

5.4.1.2 Passo A2: Renomeação de conjuntos de entidades com dados comuns,

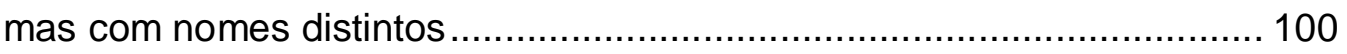

5.4.1.3 Passo A3: Renomeação de atributos com dados comuns, mas com nomes distintos 101

5.4.1.4 Passo A4: Transformação de atributos com dados comuns, mas com representação diferente de valores ....................................................... 102

5.4.1.5 Passo A5: Transformação de atributos chaves primárias ........................ 103

5.4.1.6 Passo A6: Transformação de atributos chaves estrangeiras ................... 104

5.4.1.7 Passo A7: Geração do Modelo de Dados Unificado ................................ 105 
5.4.2 Aplicação da Etapa B: Mapeamento do Modelo de Dados Unificado em um Modelo de Dados Analítico-Temporal. 106

5.4.2.1 Passo B1: Seleção dos conjuntos de entidades e atributos para o Banco de Dados Analítico-Temporal. 106

5.4.2.2 Passo B2: Criação dos conjuntos de entidades para o armazenamento dos dados analítico-temporais 108

5.4.2.3 Passo B3: Inclusão de elementos de tempo nos conjuntos de entidades. 111

5.4.2.4 Passo B4: Inclusão de atributos derivados. .......................................... 114

5.4.2.5 Passo B5: Geração do Modelo de Dados Analítico-Temporal .................. 115

5.4.3 Aplicação da Etapa C: Geração dos Dados Analítico-Temporais...........117

5.4.3.1 Passo C1: Geração de Gatilhos para o passo B3 ………....................... 117

5.4.3.2 Passo C2: Geração de Gatilhos para o Passo B4.................................. 124

5.4.3.3 Passo C3: Geração de Procedimentos Armazenados para o Passo B4 ... 124

5.4.4 Resultados Obtidos em Testes Práticos................................................. 126

5.4.4.1 Testes do Modelo Analítico-Temporal................................................. 127

5.4.4.2 Comparação entre o Modelo Proposto e o Modelo Multidimensional ....... 128

6 CONCLUSÕES........................................................................130

6.1 RESULTADOS ALCANÇADOS ....................................................... 130

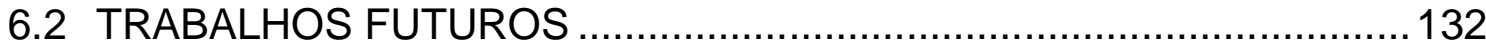

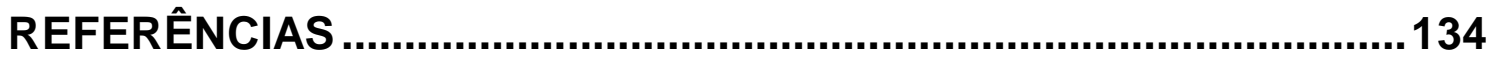

APÊNDICE A - Especificação do scripts - Etapa C - Capítulo 3 .....141

APÊNDICE B - Banco de Dados Operacional BDO_FOLHA ............144

APÊNDICE C - Banco de Dados Operacional BDO_ACADEMICO.148

APÊNDICE D - Configuração dos nomes de serviços......................153

APÊNDICE E - Banco de Dados Analítico-Temporal BDAT .............155

APÊNDICE F - Especificação dos scripts do Estudo de Caso.......158 


\section{INTRODUÇÃO}

Este trabalho insere-se na linha de pesquisa de Sistemas de Bancos de Dados; em particular, na modelagem e implementação de bancos de dados que armazenam o histórico de dados.

\subsection{JUSTIFICATIVAS E MOTIVAÇÕES}

O impacto dos sistemas de banco de dados nas atividades corporativas é crescente e irreversível. Eles fazem parte do próprio âmago das estratégias empresariais, funcionando como mecanismos de diferenciação e competição (DIAS, 2005).

Conforme Marcílio (2002), a informação tornou-se um bem valioso, sendo necessário gerenciá-la da melhor forma, de modo a se ter um efetivo controle sobre esse patrimônio peculiar.

Segundo Oliveira e Rodrigues (2004), as organizações públicas e privadas começaram a perceber o valor dos dados que têm à sua disposição, e a considerálos como um bem importante no aumento da produtividade, eficiência e competitividade. Como conseqüência, a exploração de enormes volumes de dados assume papel cada vez mais importante.

Portanto, esforços realizados para um gerenciamento eficiente da informação e dos correspondentes Sistemas de Informação são plenamente justificados, sobretudo em se considerando que as informações devem estar cada vez mais integradas, fornecendo um apoio eficiente ao processo de tomada de decisões.

Essa integração está relacionada à utilização de dados existentes em diversos bancos de dados empregados em várias áreas de uma mesma organização. Para isso, torna-se necessário solucionar questões relacionadas à Integração de Esquemas, a fim de fornecer uma unificação que possibilite a realização de análises, visando ao processo de tomada de decisões. Dessa forma, o fato de a organização possuir um histórico de dados confiável representa um importante diferencial. 
Quando se fala em confiabilidade de dados, é primordial que se apliquem as melhores práticas relacionadas à obtenção de dados com alta qualidade. Essa questão representa um fator de suma importância, podendo implicar a perda de recursos financeiros, de tempo e de oportunidades, em razão de eventuais problemas ligados à baixa qualidade desses dados (SALVADOR, 2006).

Tendo em vista todo esse panorama, é que surge esta pesquisa, no sentido de propor um modelo para projeto e implementação para um tipo de banco de dados bastante importante, que são os Bancos de Dados Analítico-Temporais (BDAT).

Dados Analítico-Temporais representam os valores que um atributo tenha assumido durante todo o seu estado evolutivo, ou seja, consistem no histórico de valores assumidos pelos dados, ao longo do tempo. Os Bancos de Dados Operacionais não são projetados para prever tais necessidades, hoje tão importantes para grande parte das aplicações.

Normalmente, a finalidade dos Bancos de Dados Operacionais é armazenar somente um único valor dos dados que, por sua vez, deve ser o mais recente. A necessidade de possuir dados analítico-temporais levou ao surgimento dos chamados Bancos de Dados Analítico-Temporais, que representam uma opção a ser utilizada para o armazenamento do estado evolutivo dos dados.

A título de exemplo, em visitas realizadas a algumas organizações públicas na região da cidade de Assis, estado de São Paulo (Vale do Paranapanema), nota-se que a maioria das aplicações operacionais utilizadas não foi projetada para o armazenamento de histórico de dados, principalmente por motivo de desempenho.

Em uma dessas organizações, mais exatamente a Usina Nova América, localizada na cidade de Tarumã, interior do estado de São Paulo, tem-se um exemplo de um Sistema de Recursos Humanos (RHS) que mantém os históricos no próprio Banco de Dados Operacional. Como o volume de dados é superior a um milhão de linhas/mês, as transações no banco de dados apresentaram grande prejuízo em seu desempenho, principalmente em razão das solicitações de recuperação de históricos.

Uma das formas disponíveis para a criação de Bancos de Dados AnalíticoTemporais dá-se por meio de Data Warehouse. No entanto, deve-se considerar a 
grande complexidade dos mecanismos de extração, transformação e carga de dados envolvidos na implementação de Data Warehouse, chegando a representar até $80 \%$ do esforço total de desenvolvimento (VASSILIADIS; SIMITSIS; SKIADOPOULOS, 2002).

Sendo assim, outra grande motivação à presente pesquisa está em propor mecanismos distintos dos tradicionalmente utilizados em ambientes de Data Warehousing para esse processo de extração, transformação e carga dos dados, visando reduzir, significativamente, o tempo total consumido nessas tarefas.

\subsection{OBJETIVOS}

O objetivo inicial deste trabalho é propor um modelo para projeto e implementação especificamente voltado para a geração de Bancos de Dados Analítico-Temporais. A origem dos dados a serem inseridos nesses bancos de dados está, exclusivamente, nos Bancos de Dados Operacionais utilizados pelas aplicações.

A esse objetivo inicial agrega-se o segundo objetivo, que é o de propor mecanismos adequados e eficientes, relativos ao processo de extração e transformação dos dados oriundos do ambiente operacional e sua respectiva carga nos Bancos de Dados Analítico-Temporais propostos.

A proposta apresentada objetiva fornecer um meio bastante eficiente aos responsáveis pelo desenvolvimento de aplicações temporais, de forma que tanto o projeto, quanto a implementação dessas aplicações, possam ser realizados de maneira bastante adequada e sistematizada.

O controle do estado evolutivo dos dados é realizado com a inclusão de "elementos de tempo" nos conjuntos de entidades a serem criados no Banco de Dados Analítico-Temporal. Esses "elementos de tempo" têm a função de representar as épocas exatas das modificações dos dados ao longo do tempo, envolvendo tanto o instante inicial de validade, como o instante em que tal dado sofrer alterações, perdendo seus valores iniciais. Esse processo repete-se tantas vezes quantas sejam as alterações sofridas por um determinado dado. 
O modelo proposto constitui-se em uma alternativa ao modelo multidimensional, tradicionalmente utilizado na modelagem de ambientes de Data Warehousing, contendo diversas particularidades. Da mesma forma, os mecanismos de extração, transformação e carga propostos representam uma alternativa altamente atraente, face aos mecanismos tradicionalmente empregados em ambientes de Data Warehousing.

\subsection{ESTRUTURA DO TRABALHO}

Este trabalho está organizado em seis capítulos. O primeiro trata da Introdução.

O Capítulo 2 apresenta conceitos e noções a respeito de Sistemas de Bancos de Dados, passando pelos Bancos de Dados Operacionais, sua modelagem e projeto. Descrevem-se os principais aspectos sobre a integração de modelos, bem como os conceitos teóricos sobre gatilhos e procedimentos armazenados. Ainda neste capítulo são apresentados os principais conceitos e noções sobre o ambiente de Data Warehousing.

Conceitos e noções sobre Bancos de Dados Analítico-Temporais, bem como o detalhamento da proposta de modelagem e implementação do Banco de Dados Analítico-Temporal são o tema do Capítulo 3. São detalhadas todas as etapas a serem seguidas para a obtenção de um modelo analítico-temporal adequado, bem como os algoritmos utilizados em sua implementação.

O Capítulo 4 apresenta uma comparação do modelo proposto com os Bancos de Dados Operacionais e com o ambiente de Data Warehousing, considerando-se os aspectos mais importantes. Ainda neste capítulo é apresentado um estudo comparativo com alguns trabalhos correlatos.

Um estudo de caso é o assunto do Capítulo 5, aplicando-se a proposta apresentada no Capítulo 3.

No sexto e último capítulo, são relatadas as considerações finais, além de possíveis estudos e pesquisas a serem desenvolvidos como conseqüência desta tese. 


\section{SISTEMAS DE BANCOS DE DADOS E DE DATA WAREHOUSING}

Neste capítulo, são apresentados os principais conceitos e noções sobre sistemas de Bancos de Dados Operacionais e seu projeto, integração de modelos, gatilhos e procedimentos armazenados, qualidade de dados, bem como uma breve descrição sobre os ambientes de Data Warehousing.

\subsection{BANCOS DE DADOS OPERACIONAIS}

Os sistemas de bancos de dados são projetados para administrar grandes volumes de informações sobre uma determinada aplicação, provendo um ambiente que seja adequado e eficiente para o armazenamento e a recuperação das mesmas (SILBERSCHATZ; KORTH; SUDARSHAN, 2006).

Segundo Date (2003, p. 06),

Um Sistema de Banco de Dados é basicamente um sistema computadorizado de manutenção de registros; em outras palavras, é um sistema computadorizado cuja finalidade geral é armazenar informações e permitir que os usuários busquem e atualizem essas informações quando as solicitar.

O maior benefício de um sistema de banco de dados é proporcionar, ao usuário, uma visão abstrata dos dados. Uma vez que a maioria dos usuários de bancos de dados não é especialista em computação, omite-se deles a complexidade da estrutura interna dos bancos de dados, graças a diversos níveis de abstração que simplificam a interação do usuário com o sistema (SILBERSCHATZ; KORTH; SUDARSHAN, 2006).

De uma maneira geral, pode-se dizer que um sistema de banco de dados é constituído por um conjunto de programas e/ou aplicações; estes, por sua vez, estão associados a um conjunto de dados por intermédio de um sistema gerenciador de banco de dados (SILBERSCHATZ; KORTH; SUDARSHAN, 2006). 
O Sistema Gerenciador de Banco de Dados (SGBD), parte integrante de um sistema de banco de dados, é um software que ajuda os usuários a criar, armazenar e processar dados para diversas aplicações (OLIVEIRA, 2002).

O Sistema Gerenciador de Banco de Dados é o responsável pelo controle de acesso aos dados, ou seja, é ele que gerencia os privilégios de cada um dos usuários, e libera, ou não, o acesso aos dados, geralmente por meio de um login e uma senha. Além disso, os sistemas gerenciadores de bancos de dados devem garantir as seguintes características: Controle de Transações, Garantia da Integridade, Garantia de Segurança e Controle de Concorrência (SILBERSCHATZ; KORTH; SUDARSHAN, 2006).

A Figura 1 ilustra uma representação simplificada de um sistema de banco de dados com as suas partes integrantes.

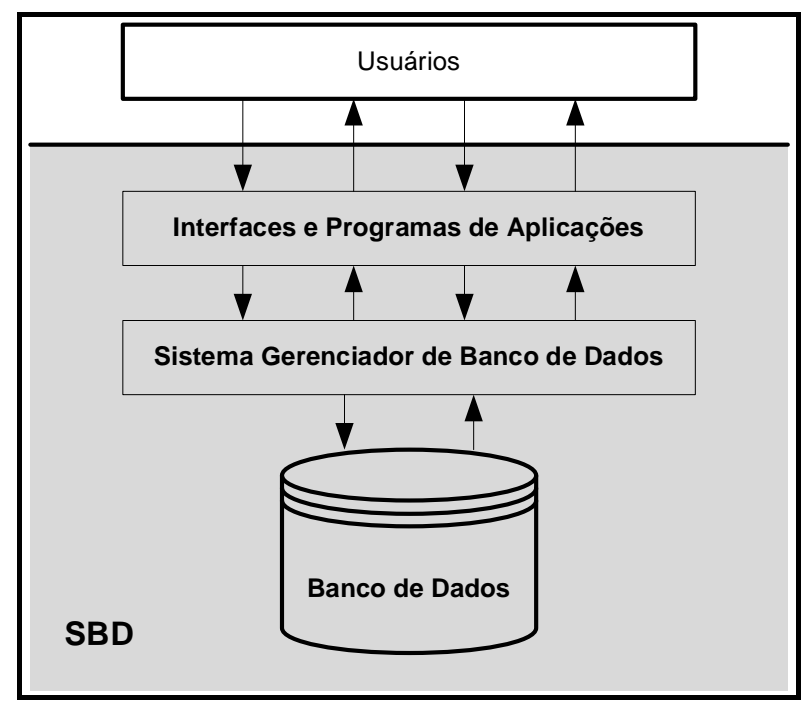

Figura 1. Representação simplificada de um Sistema de Banco de Dados

Considerando-se os Bancos de Dados Operacionais, também conhecidos por Bancos de Dados Convencionais, Tradicionais ou de Produção, verifica-se que eles são usados, extensivamente, em operações cotidianas das empresas. Seu estado é mantido por meio de modificações, assim que as proposições que eles representam não forem mais verdadeiras (COSTA NETO; SATO, 2006; DATE, 2003).

Os Bancos de Dados Operacionais são, geralmente, modelados para armazenar dados atuais (ou mais recentes), isto é, para suportar um único estado ou valor dos 
dados, não sendo comum resgatar estados anteriores. Ou seja, sempre prevalece o último estado dos dados. Quando um novo valor é introduzido, o valor do estado anterior é substituído.

Segundo Gonçalves (2003, p. 17), "os Bancos de Dados Operacionais não fornecem uma perspectiva histórica para a tomada de decisões devido às limitações de espaço e às metas para manter um bom nível de desempenho".

Nos Bancos de Dados Operacionais os dados são atualizados constantemente, dificultando um acesso preciso e oportuno que permita a realização de uma análise passível de ser rastreada. Para processar centenas ou milhares de transações por segundo, as aplicações são otimizadas, a fim de apresentarem um bom desempenho. Por outro lado, a preocupação quanto ao desempenho não é grande, quando se consideram as aplicações voltadas para a análise dos dados (SINGH, 2001).

Nota-se, assim, que os Bancos de Dados Operacionais são quase que exclusivamente, utilizados para se trabalhar com os dados atuais.

Esses tipos de bancos de dados não oferecem um suporte suficientemente adequado para aplicações com necessidades não convencionais, tais como armazenar históricos de alterações e registrar períodos de validade de dados (CORDEIRO et al., 2004).

\subsection{PROJETO DE BANCO DE DADOS}

O objetivo do projeto de bancos de dados é gerar um conjunto de relações que permita armazenar informações sem redundância desnecessária, e também recuperar facilmente informações (SILBERSCHATZ; KORTH; SUDARSHAN, 2006).

Pode-se dizer que as fases necessárias para a construção de um Banco de Dados são quatro, conforme ilustra a Figura 2 (MACHADO; ABREU, 1995; SILBERSCHATZ; KORTH; SUDARSHAN, 2006; STAIR, 1998). 


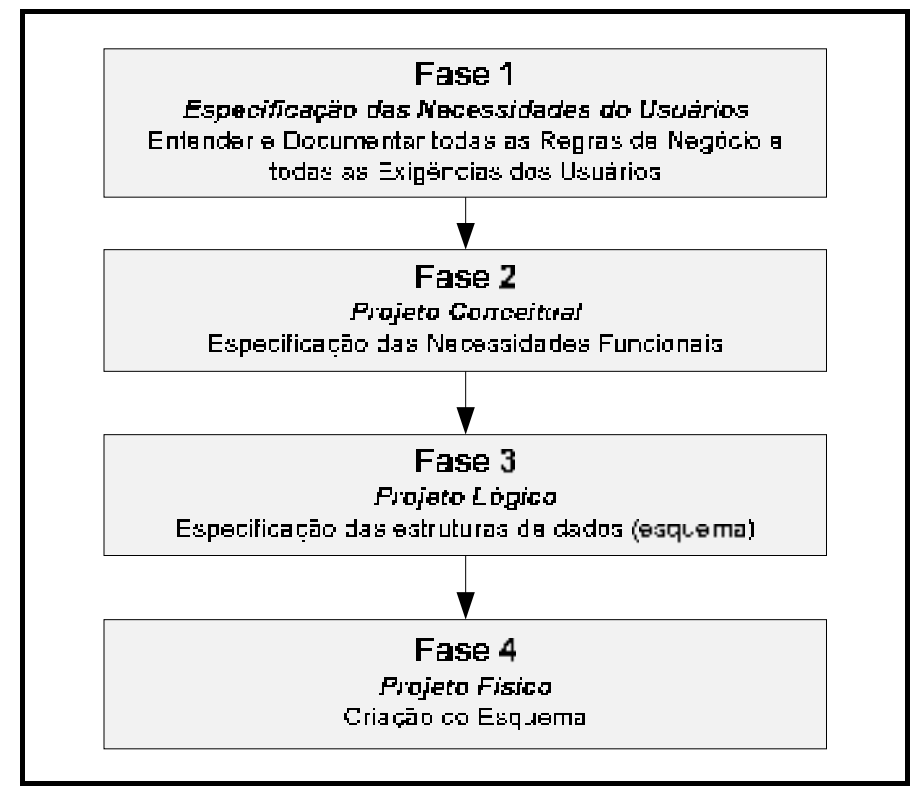

Figura 2. Fases do Projeto de um Banco de Dados

A primeira fase do projeto, conhecida por "especificação das necessidades do usuário", ou "levantamento dos requisitos", tem por finalidade caracterizar todos os dados necessários na perspectiva do usuário.

Para isso, coloca-se como primordial: levantar as necessidades dos usuários; possuir um bom entendimento da organização; conhecer a área de negócio na qual a organização está inserida; ficar atento às mudanças organizacionais, com base nas quais o banco de dados será modelado, proporcionando assim, uma maior certeza na tomada de determinadas decisões. É absolutamente essencial entender os requisitos dos usuários e adequar-se às suas necessidades a fim de obter-se um Banco de Dados bem sucedido.

Na segunda fase, o projetista seleciona o tipo de modelo de dados e, por meio da aplicação de seus conceitos, transcreve as necessidades especificadas em um esquema conceitual de banco de dados, chamado "projeto conceitual", proporcionando uma visão detalhada da organização. Nessa fase, deve-se enfocar a descrição dos dados e de seus relacionamentos, independentemente das restrições de implementação. Os detalhes físicos de armazenamento não devem ser levados em consideração nesse momento. 
A terceira fase, conhecida por "projeto lógico", tem seu início a partir do modelo conceitual, levando em consideração uma das abordagens de banco de dados possíveis, tais como a abordagem relacional e a abordagem orientada a objetos. Nesta fase são descritas as estruturas que estarão contidas no banco de dados, de acordo com as possibilidades da abordagem. Contudo, não se considera, ainda, nenhuma característica específica de um sistema gerenciador de banco de dados.

A fase de projeto lógico contempla, também, as "especificações das necessidades funcionais", nas quais os usuários descrevem os tipos de operações a serem realizadas sobre os dados.

Na quarta fase, a do "projeto físico", o projeto lógico é mapeado para o modelo de implementação de dados; modelo este, especificamente dependente dos recursos do sistema gerenciador de banco de dados que será usado. Tais recursos incluem as formas de organização de arquivos e as estruturas internas de armazenamento, tais como: tamanho de atributos, índices, tipos de atributos, nomenclaturas, dentre outros.

\subsubsection{Modelos de Dados}

A modelagem de dados responde a um conjunto de questões específicas relevantes para qualquer aplicação de processamento de dados (PRESSMAN, 2002).

São vários os fatores que tornam a modelagem de dados fundamental para a construção de Sistemas de Bancos de Dados. Um desses fatores é a necessidade de validar requisitos, e é por intermédio da modelagem que se aumenta a probabilidade de encontrar erros, de se identificar inconsistências e de se descobrir omissões, já nas fases iniciais de projeto.

Por meio da modelagem de dados, consegue-se identificar quais são os principais objetos de dados a serem processados pelo sistema; qual a composição de cada objeto de dados; que propriedades os descrevem; onde os objetos costumam ficar; quais as relações entre cada objeto e os demais; quais as relações entre os objetos e os processos que os transformam (PRESSMAN, 2002). 
Além disso, a documentação gerada pela atividade de modelagem pode servir de auxílio para analistas de sistemas, programadores, administradores de banco de dados, tanto na manutenção do banco de dados, como em futuras atualizações e adaptações.

A construção de modelos é fundamental para compreender melhor o sistema que se deseja desenvolver, ainda mais quando se trata de sistemas grandes e complexos.

A modelagem possibilita o alcance de quatro objetivos: ajuda a visualizar o sistema como ele é ou como deve ser; permite especificar a estrutura ou o comportamento de um sistema; proporciona um guia para a construção do sistema e documenta as decisões tomadas (BOOCH; RUMBAUGH; JACOBSON, 2000).

O processo de construção de um modelo é um processo incremental que, geralmente, não é finalizado em um único passo. Para se chegar a um modelo completo, muitos passos e transformações ocorrem com base no modelo inicial. Sua elaboração envolve inúmeras reuniões com os usuários, discussões entre os analistas de sistemas e de negócio, bem como mudanças de normas e leis.

Para iniciar um processo de modelagem, deve-se definir qual a principal fonte de informações. Duas fontes podem ser consideradas: "o conhecimento de pessoas", em que novos sistemas devem ser concebidos, não havendo descrição inicial dos dados; e "descrições de dados existentes", em que, para a manutenção de um sistema, usa-se como descrição inicial dos dados as descrições dos arquivos do sistema já em uso (engenharia reversa).

Um modelo de dados está sob a estrutura do banco de dados. Trata-se de um conjunto de ferramentas conceituais usadas para a descrição de dados e seus relacionamentos, da semântica de dados e das regras de consistência (SILBERSCHATZ; KORTH; SUDARSHAN, 2006).

O modelo de dados oferece uma flexibilidade substancial para o projeto de um esquema de banco de dados, proporcionando ao projetista uma base conceitual na qual se pode especificar, de modo sistemático, bem como entender e documentar, todas as regras de negócios e as exigências dos usuários do banco de dados. É 
possível especificar também como esse banco de dados será estruturado para atender plenamente a essas exigências, bem como às regras de negócio impostas.

Conforme Heuser (1999, p. 5), "um modelo de dados é uma descrição dos tipos de informações que estão armazenadas em um banco de dados". Pelo entendimento dos modelos de dados, é possível identificar quais informações estão contidas no banco de dados, ou seja, qual a descrição formal da estrutura de um banco de dados. Para se construir um modelo de dados, usa-se uma linguagem de modelagem de dados, que pode ser classificada em linguagem textual ou gráfica, de acordo com a forma de apresentar modelos (HEUSER, 1999).

Um modelo de dados deve apresentar uma estrutura de objetos que podem ser manipulados pelas linguagens textuais. Estas, por sua vez, são derivadas do SQL. Tais linguagens devem oferecer mecanismos para atualizar e consultar esses objetos, e também mecanismos para expressar restrições de integridade (EDELWEISS, 1998).

Segundo Melo, Silva e Tanaka (1997) e Silberschatz, Korth e Sudarshan (2006), a arquitetura para Banco de Dados possui três diferentes níveis, conforme apresentado na Figura 3.

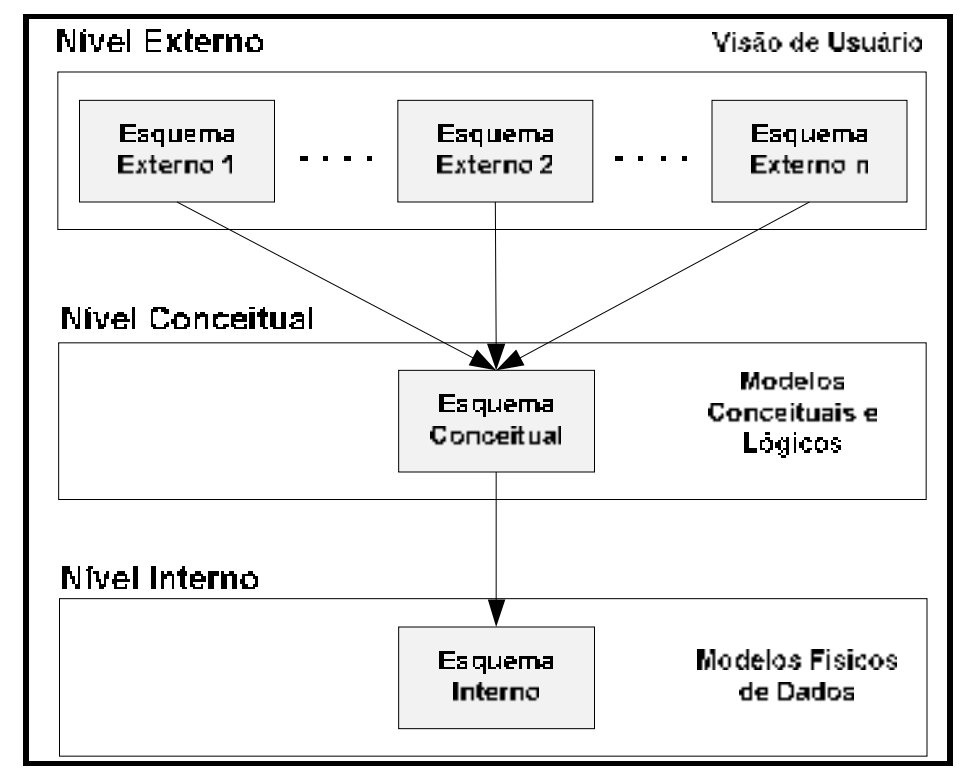

Figura 3. Arquitetura de esquemas em três níveis para um banco de dados (Melo; Silva; Tanaka, 1997, p. 6 e Silberschatz; Korth; Sudarshan, 2006, p. 4) 


\subsubsection{Esquema Interno}

O esquema interno, que é considerado o nível de abstração mais baixo e que descreve como os dados são realmente armazenados, é representado pelos modelos físicos de dados.

Por meio desses modelos, é descrita a estrutura física de armazenamento do banco de dados, a sua organização de arquivos, os seus métodos de acesso, os metadados, os arquivos de índices e outros dados do sistema.

\subsubsection{Esquema Externo}

O esquema externo, também conhecido como visões de usuário, é considerado o nível de abstração mais alto. Nele, são descritas as partes do banco de dados que são do interesse de cada grupo específico de usuários, já que em sua maioria os usuários não precisam acessar todas as informações contidas em um banco de dados. Esse nível de visão existe para simplificar a interação do usuário com os Sistemas de Bancos de Dados.

\subsubsection{Esquema Conceitual}

O esquema conceitual é representado pelos modelos conceituais e lógicos. Por meio desses modelos, é descrita a estrutura do banco de dados completo sob o ponto de vista do usuário, omitindo-se detalhes de armazenamento de dados e concentrandose na descrição de entidades, atributos, relacionamentos, operações de usuário e restrições sobre os dados. 


\subsubsection{Formas de Modelagem}

Existem diversas formas de representar graficamente os modelos de dados. Dentre tais, destacam-se os Diagramas Entidade-Relacionamento, os Diagramas IDEF1X e os Diagramas de Classes, da Orientação a Objetos.

\subsubsection{Diagramas Entidade-Relacionamento}

O diagrama entidade-relacionamento, apresentado por Peter Chen em 1976, é um dos diagramas mais comumente utilizados para modelar Bancos de Dados Relacionais. A estrutura lógica do banco de dados pode ser expressa graficamente pelo diagrama entidade-relacionamento. A relativa simplicidade e a clareza gráfica desta técnica de diagramação, explica, em grande parte, a ampla disseminação do uso do Modelo Entidade-Relacionamento (E-R).

Em um diagrama entidade-relacionamento, os dados são descritos por intermédio de conjuntos de entidades (representados graficamente por retângulos); de conjuntos de relacionamentos (representados graficamente por losangos); de conjuntos de atributos que compõem as entidades (representados graficamente por elipses); e de cardinalidades, as quais expressam o número de entidades a que outra entidade pode estar associada por meio de um conjunto de relacionamentos.

Uma entidade é formada por um conjunto de atributos (propriedades). Cada atributo deve conter um nome, acompanhado de um tipo e tamanho.

Após a elaboração dos diagramas entidade-relacionamento, pode-se iniciar a elaboração do modelo físico de dados. O modelo físico de dados deve refletir o que está graficamente representando pelos diagramas. 


\subsubsection{Diagramas IDEF1X}

Elaborado para modelagem de bases de dados, o padrão IDEF1X constitui-se de uma linguagem e de um método, que são usados para produzir modelos de dados que representam a estrutura e a semântica da informação dentro de um ambiente ou de um sistema (NIST (1993); KERN (1999)).

O IDEF1X foi publicado como padrão norte-americano pelo NIST (National Institute of Standards and Technology), em 1993. Ele pode ser considerado uma técnica a ser usada para se modelar dados de forma padronizada, consistente e de maneira previsível, com a finalidade de organizar o gerenciamento dos recursos (NIST, 1993).

As construções sintáticas básicas da linguagem IDEF1X são: entidade, relacionamento e atributo. As entidades são representadas graficamente por retângulos com uma linha divisória horizontal. São conjuntos de objetos de mesma natureza. Os relacionamentos são associações significativas entre duas ocorrências de entidades. Realizam-se pela ligação da chave primária à chave estrangeira (migração de chaves) e são representados por linhas rotuladas com um verbo ou frase verbal. Os atributos são características das entidades (KERN, 1999).

Em resumo, o IDEF1X possibilita a elaboração de modelos de dados precisos e detalhados com base em Bancos de Dados Relacionais, independentemente de qual sistema gerenciador de bancos de dados relacional será usado.

\subsubsection{Diagramas de Classes}

Os diagramas de classes representam um dos diagramas que compõem a linguagem UML (Unified Modeling Language), na elaboração da estrutura de projetos de software. A UML permite a visualização, a especificação, a construção e a documentação de artefatos que venham a fazer uso de sistemas complexos de software (BOOCH; RUMBAUGH; JACOBSON, 2000; SILBERSCHATZ; KORTH; SUDARSHAN, 2006). 
Os diagramas de classes são utilizados na modelagem de sistemas orientados a objetos. Esses diagramas mostram um conjunto de classes, interfaces, colaborações e seus relacionamentos. Geralmente são formados por uma coleção de vértices e arcos (BOOCH; RUMBAUCH; JACOBSON, 2000).

Um diagrama de classe descreve a estrutura estática de um sistema, ou seja, delineia os tipos de objetos e seus relacionamentos, mostrando como o sistema é estruturado, e não como ele se comporta (LEE; TEPFENHART, 2001).

Os diagramas de classes são basicamente elaborados com base em classes e relacionamentos. Uma classe é uma descrição de um conjunto de objetos que compartilham os mesmos atributos, operações, relacionamentos e semântica. Ela é representada graficamente por um retângulo $(\mathrm{BOOCH}$; RUMBAUGH; JACOBSON, 2000).

Cada classe deve ter um nome que a diferencie de outras classes; atributos que descrevam os valores que as instâncias podem apresentar; bem como operações que são programas de serviços. Esses programas podem ser solicitados por algum objeto da classe a fim de modificar seu comportamento.

Os relacionamentos de objetos entre classes evidenciam que tipos de vínculo existem entre objetos e definem restrições sobre esses vínculos, incluindo a quantidade relativa de instâncias vinculadas por uma associação. Isso é representado graficamente como um caminho (BOOCH; RUMBAUGH; JACOBSON, 2000; LEE; TEPFENHART, 2001).

Todos os modelos de dados desenvolvidos nesta tese são representados pelos Diagramas Entidade-Relacionamento, de acordo com as definições encontradas em (SILBERSCHATZ; KORTH; SUDARSHAN, 2006). 


\subsection{INTEGRAÇÃO DE MODELOS}

Segundo Wirti (2005), em organizações comerciais é muito comum a existência de dados mantidos em sistemas gerenciadores de banco de dados distintos, em que cada um desses sistemas pode utilizar um modelo de dados diferente.

Conforme Silberschatz, Korth e Sudarshan (2006), quando há a necessidade de integração de bases de dados distintas com diferentes modelos de dados, ocorre dificuldade em se obter um modelo conceitual comum a todos os bancos de dados envolvidos na integração.

A construção de sistemas que necessitam integrar dados de múltiplas fontes tem como principais desafios resolver a heterogeneidade da informação e apresentá-la aos usuários de forma concisa e uniforme, abstraindo suas diferenças sintáticas, estruturais e semânticas (BELIAN; SALGADO, 2004).

Segundo Oliveira, Rodrigues e Henriques (2004), a consolidação de dados, a partir de fontes dispersas, em um armazém de dados central, permite, às organizações, executarem operações de análise de dados e assim obterem informações que são de importância estratégica e tática para as suas atividades.

Para que a integração seja possível, os tipos de dados, bem como os valores contidos em cada um dos atributos, principalmente nos atributos definidos como chaves primárias devem ser sincronamente analisados para que se obtenha uma integração adequada. Para isso, é essencial que sejam discutidas também, questões relacionadas à qualidade de dados.

Existem ferramentas que, de certa forma, realizam a integração de modelos. Uma delas é a PyDbDiff (MELO et al., 2006), que tem por finalidade analisar e comparar as estruturas (metadados) de dois bancos de dados distintos, apontando suas diferenças e possíveis correções.

Essa ferramenta compara conjuntos de entidades de duas bases de dados, uma utilizada na produção de software (elaboração de novas versões) e outra voltada para o usuário final. Geralmente ocorrem muitas mudanças de estrutura durante a fase de produção das versões do software, que por sua vez já está em uso no 
cliente. Para automatizar essa tarefa de sincronização a ferramenta PyDbDiff repassa ao ambiente do cliente todas as modificações realizadas na base de dados utilizada na produção do software.

Desta forma, essa ferramenta pode ser utilizada para sincronizar bases de dados diretamente relacionadas entre si, mas não para unificar bases de dados utilizadas em diversas aplicações, sem um relacionamento direto entre elas.

Já o framework Ferb (MERGEN; HEUSER, 2006) realiza a integração de tuplas, sendo feita uma comparação do conteúdo entre duas entidades de um mesmo banco de dados. A uma das entidades atribui-se a denominação entidade origem $\left(E_{o}\right)$ e à outra, destino $\left(E_{d}\right)$. Ambas as entidades possuem os mesmos atributos. $\mathrm{A}$ partir daí, verificam-se possíveis igualdades entre os valores desses atributos, desprezando-se as tuplas duplicadas. Segundo os autores, o que ocorre é uma união de tuplas e não uma integração de modelos, já que, semanticamente, os modelos de origem e destino são idênticos.

\subsection{GATILHOS E PROCEDIMENTOS ARMAZENADOS}

Gatilhos e procedimentos armazenados são dois recursos de grande utilidade em Sistemas de Bancos de Dados (KROENKE, 1999). Eles também podem cooperar com as ferramentas de desenvolvimento de aplicação de usuários finais, adicionando recursos de processamento. Além disso, esses recursos também possibilitam declarar variáveis com base em atributos de conjuntos de entidades do próprio banco de dados, levando o código a se tornar independente de modificações físicas ocorridas com os atributos.

Com a utilização desses recursos, consegue-se uma redução no número de linhas de códigos a serem programadas por ferramentas utilizadas no desenvolvimento das aplicações dos usuários finais. Inúmeras das regras de negócio, de restrições e de integridade podem ser programadas diretamente no Banco de Dados Operacional, permitindo, às aplicações finais, conter apenas instruções básicas, sem o objetivo de garantir a integridade, toda vez que uma rotina for programada. Isso possibilita que 
as aplicações finais tornem-se mais leves, além de disporem de um código mais simples.

\subsubsection{Procedimentos Armazenados}

Um procedimento armazenado consiste em um bloco de instruções nomeado que executa uma ação. Ele pode ser armazenado no banco de dados, como um objeto de banco de dados, para execução repetida de qualquer ambiente de chamada (KOCHHAR; KRAMER, 1998).

Segundo Fanderuff (2000, p.151), "os procedimentos armazenados são 'subprogramas' que têm por objetivo executar uma ação específica, utilizando-se das instruções de processamento de dados da Linguagem SQL".

Costa (2006, p.158) salienta que procedimentos armazenados são procedimentos análogos aos existentes em linguagens de programação tradicionais, mas que terão seu código fonte armazenado no servidor de banco de dados, o qual é capaz de compilá-lo e executá-lo.

\subsubsection{Gatilhos}

Um gatilho consiste em um bloco de instruções ou subprograma acionado, de forma implícita, pela aplicação do usuário final, por meio de ferramentas de administração de bancos de dados ou pelo próprio banco de dados, sempre que ocorrer um determinado evento de inclusão, atualização ou exclusão de dados, associado a um conjunto de entidades, de acordo com a definição de um instante de tempo (KOCHHAR; KRAMER, 1998; RAMALHO, 2005).

$\mathrm{Na}$ caracterização de um gatilho, há três fatores a serem considerados (DATE, 2003):

a) especificar um evento que servirá como disparo do gatilho; 
b) especificar as condições sob as quais o gatilho deve ser executado;

c) especificar as accões que serão tomadas quando um gatilho for disparado.

A especificação do evento consiste em delimitar o "evento" ou instrução a ocorrer no Banco de Dados Operacional para que a "ação", de acordo com as "condições" avaliadas, seja executada.

Analisando o segundo fator, para que um gatilho seja programado, é necessário levantar as regras de negócio, isto é, as necessidades e "condições" as quais o gatilho deverá atender a fim de respeitar as restrições de integridade, garantindo assim a consistência dos dados.

O terceiro fator contém a definição de quais e quantas "ações" de processamento deverão ser executadas com base nos conjuntos de entidades dos Bancos de Dados Operacionais em relação ao Banco de Dados Analítico-Temporal, quando um gatilho for acionado.

A combinação das três exigências (evento, condição e ação) leva os gatilhos a serem conhecidos como regras ECA, de evento-condição-ação (COSTA, 2006; DATE, 2003).

\subsection{AMBIENTE DE DATA WAREHOUSING}

Considerando-se diversas bases de dados operacionais, normalmente ocorre 0 problema de falta de padronização entre elas, como por exemplo, a utilização de nomes iguais para designar conjuntos de entidades ou atributos diferentes. Outro problema a ser considerado é que, se o ambiente operacional for utilizado para a realização de consultas em grande volume de dados, visando a realizar análises de negócio, pode acabar por atrapalhar ou mesmo bloquear o negócio principal de uma organização. Daí nasce a idéia de se montar um ambiente separado do ambiente operacional, cuja principal função é a de proporcionar a realização de consultas que irão colaborar no processo vital de tomada de decisões estratégicas (COREY, 2001). 
Conforme Gonçalves (2003, p. 9), "o problema de inconsistência de dados e a necessidade dos usuários de tomada de decisão foram o fator chave para 0 surgimento do conceito de Data Warehousing".

Dessa forma, é importante destacar algumas definições sobre o ambiente de Data Warehousing contidas na literatura.

Segundo Corey (2001), um Data Warehouse é,

Um Banco de Dados reunido a partir de muitos sistemas destinados a suportar a produção de relatórios gerenciais e a tomada de decisão. De uma forma geral, quando as pessoas falam a respeito de armazenamento de dados, na verdade elas estão se referindo aos armazenamentos de dados e às ferramentas que, juntos, formam os modernos ambientes de produção de relatórios.

Conforme Inmon ${ }^{1}$ et al. (1996 apud COREY et al., 2001, p. 9),

Data Warehouse é um 'conjunto de dados orientado para o assunto, integrado, não volátil, variante no tempo, no apoio de decisões gerenciais'. Orientado para o assunto, integrado, não volátil e variável no tempo, são propriedades que precisam ser discutidas, visto que elas são indispensáveis quando se trata de Data Warehousing.

Segundo Kroenke (1998, p. 280)

Data Warehouse é um depósito de dados corporativo que se destina a facilitar a tomada de decisões na empresa. Um Data Warehousing não inclui apenas dados, mas também ferramentas, procedimentos, treinamentos, pessoal e outros recursos que facilitam o acesso aos dados e os tornam mais adequados aos responsáveis por tomada de decisões.

Parte das empresas mantém suas informações de duas formas: em Bancos de Dados Operacionais, que são os ambientes em que os dados são colocados em uma primeira instância; e em Data Warehouse, ambientes em que os dados são colocados, em uma segunda instância, e a partir de onde eles poderão ser consultados para análise pela emissão de relatórios (KIMBALL, 2002).

A idéia principal de um ambiente de Data Warehousing é extrair, dos Bancos de Dados Operacionais, dados pertinentes às aplicações. Em seguida, objetiva-se

\footnotetext{
${ }^{1}$ INMON, Bill. et al. Building the Data Warehouse (John Wiley \& Sons Inc., 1996).
} 
centralizá-los e padronizá-los por meio de ferramentas de ETL (Extraction, Transformation, Load), e, depois, transportá-los para o Data Warehouse, para que possam ser utilizados no processo de tomada de decisões de médio e longo prazo, conforme ilustrado na Figura 4.

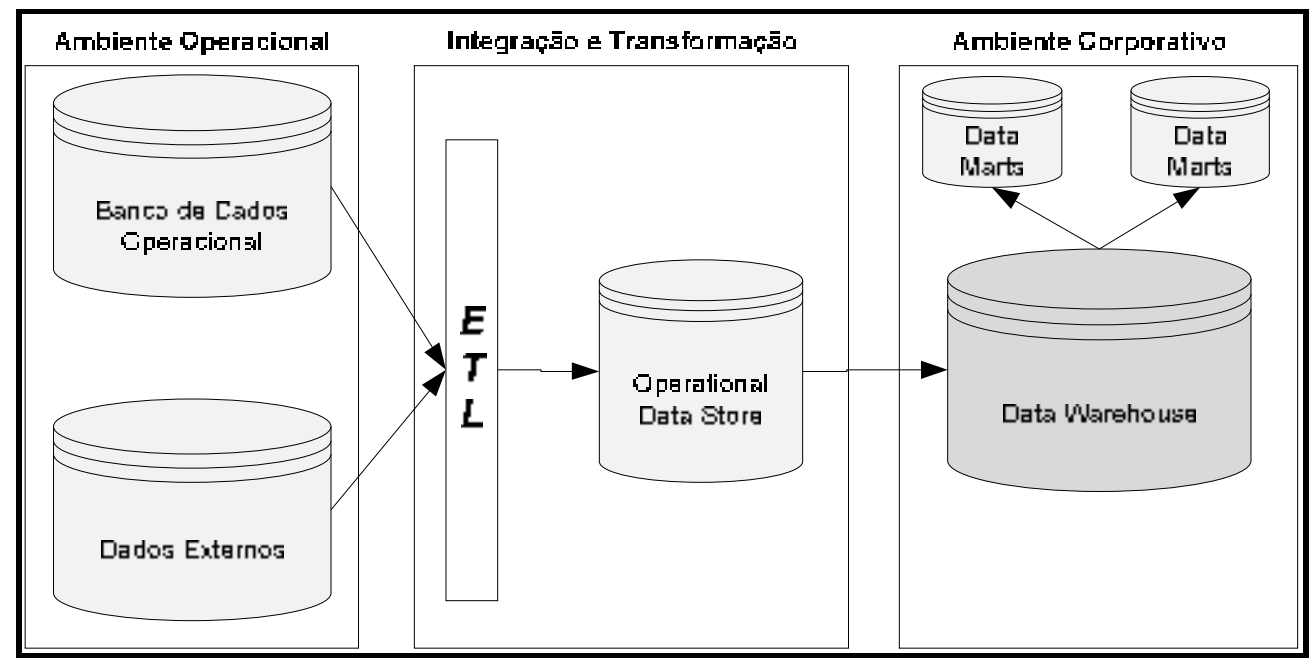

Figura 4. Ilustração de um Ambiente de Data Warehousing

As ferramentas de ETL representam uma categoria especializada de programas de software, cuja tarefa consiste, por meio da extração de dados do ambiente operacional, na eventual transformação desses dados e na carga dos dados já transformados no ambiente de Data Warehousing. Todas essas funções acabam por criar dados homogêneos e padronizados junto ao Data Warehousing (VASSILIADIS; SIMITSIS; SKIADOPOULOS, 2002).

Durante a geração de um Data Warehouse, uma das fases mais importantes referese ao processo de integração e padronização dos dados, visto que estes podem vir de diferentes fontes, podendo, inclusive, apresentar formatações bastante diferentes.

Em geral, a passagem de dados de um ambiente operacional para um ambiente corporativo constitui-se em uma tarefa bastante complexa. Muitas vezes há a necessidade de transformação e consolidação dos dados. Existem ferramentas que implementam o processo ETL (Extração, Transformação e Carga) dos dados; elas são muito úteis para auxiliar no processo de criação de um Data Warehouse (PASSOS, 2005). 
A Figura 5 ilustra o processo de ETL.

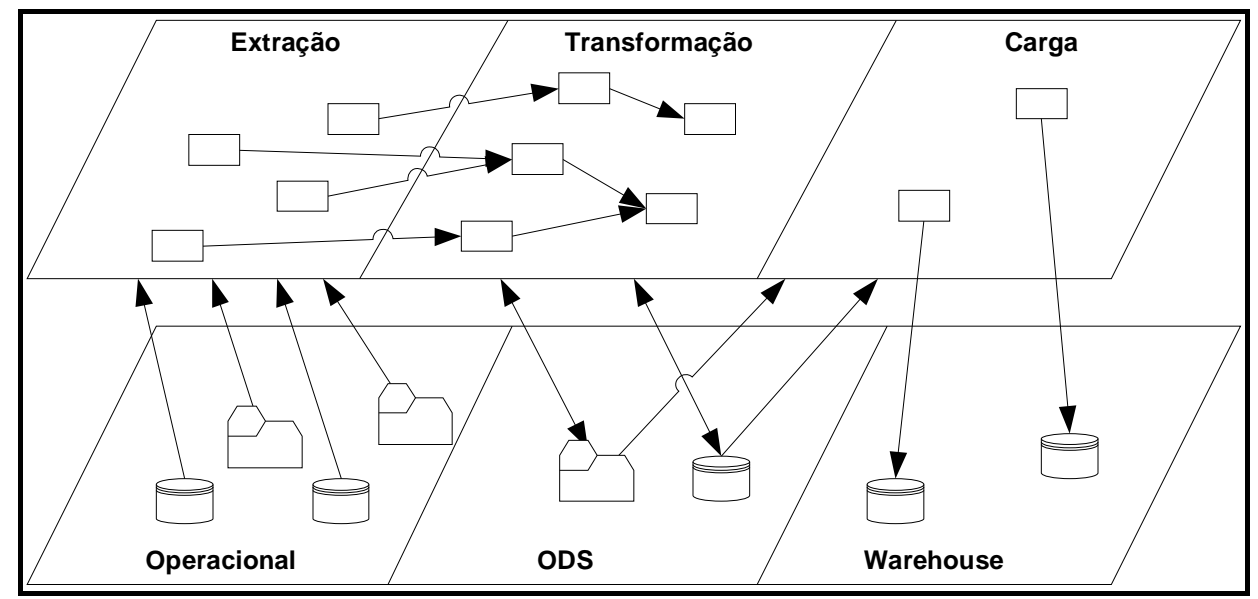

Figura 5. Processo de ETL (adaptado de VASSILIADIS; SIMITSIS; SKIADOPOULOS, 2002, p.14)

A extração representa a primeira etapa do processo de ETL e envolve a leitura e a compreensão de dados operacionais. Já a segunda etapa é constituída pela transformação, na qual podem ocorrer muitas transformações em potencial, como filtragem dos dados, combinação de dados de várias origens, cancelamento de dados duplicados, atribuição de chaves substitutas, padronização de unidades de medida, de domínios e de tipos de dados, dentre outras. A carga é a última etapa do processo de ETL, responsável por transportar os dados, já padronizados, para 0 ambiente de Data Warehousing (KIMBALL, 2002).

Os dados a serem reunidos podem estar armazenados em estruturas com formatos distintos. Essa não padronização é um fato a ser resolvido para que, durante as cargas de dados no Data Warehouse, estes possuam os mesmos formatos.

Outro aspecto muito relevante, quando se considera um ambiente de Data Warehousing, é a questão da "granularidade". Ela consiste na definição de níveis de detalhamento para o armazenamento dos dados. O nível de granularidade deve ser definido em um processo interativo com os usuários, que podem necessitar obter informações com maior ou menor nível de detalhamento. A definição do nível de granularidade incide decisivamente no espaço necessário para armazenamento do Data Warehouse. 


\subsubsection{Modelagem Multidimensional}

A modelagem multidimensional constitui-se em uma das mais utilizadas para o projeto de um Data Warehouse e é o modelo base empregado neste trabalho (ANDRADE; SANTIAGO, 2003). A estrutura fundamental do modelo multidimensional está esquematizada na Figura 6.

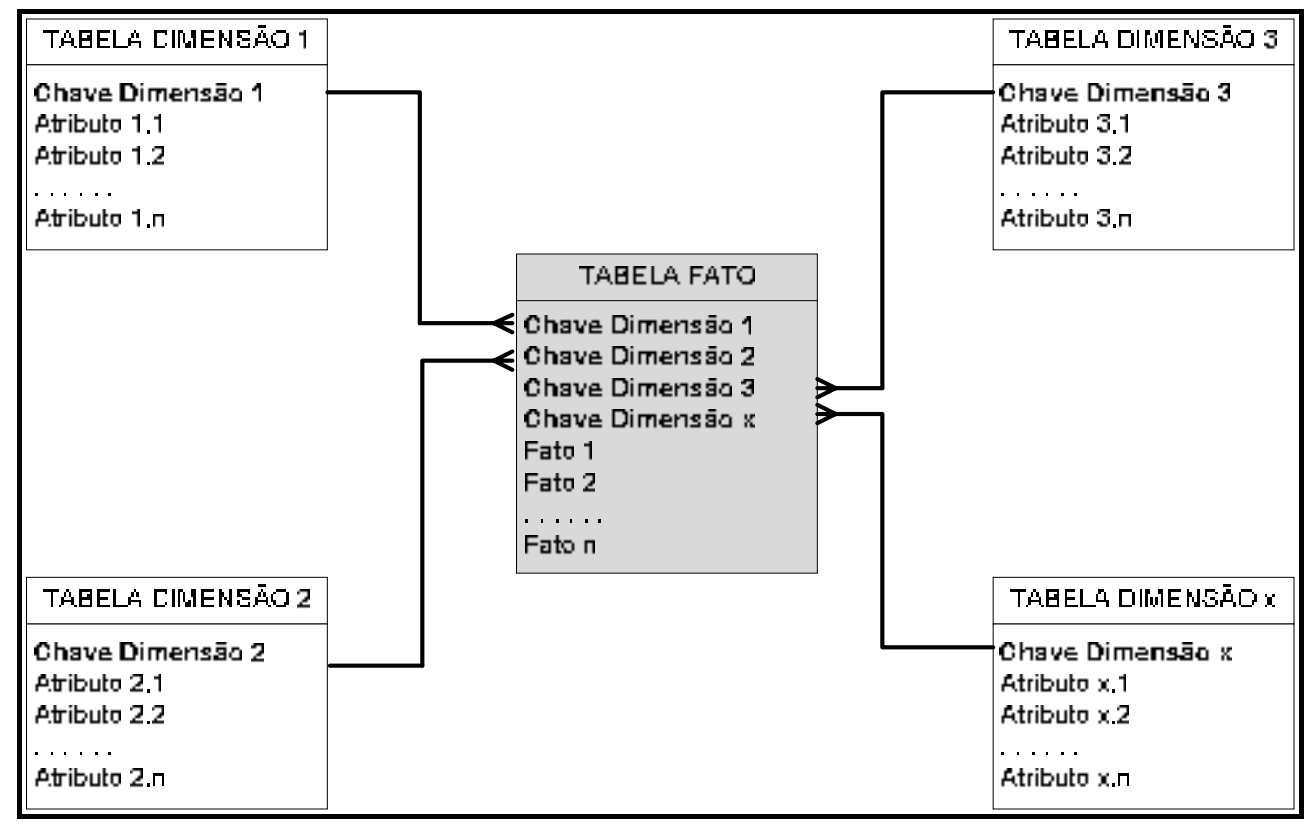

Figura 6. Estrutura básica do modelo multidimensional

Nesse modelo, nota-se a presença de dois tipos de tabelas: a tabela "fato" e as tabelas "dimensão". Conforme Kimball (2002, p. 21), "uma tabela de fatos é a principal tabela de um modelo dimensional em que as medidas numéricas de desempenho da empresa estão armazenadas".

As tabelas "fato" armazenam a maior parte das informações que um banco de dados possui, sendo, em sua maioria, dados numéricos. Esses dados são considerados a movimentação propriamente dita, ou seja, os detalhes de uma compra, de uma venda, de uma locação de fitas. Aquilo que realmente alimenta o banco de dados, está de fato armazenado nessas tabelas.

Já as tabelas "dimensão" possuem atributos com descrições que complementam o significado dos dados numéricos contidos nas tabelas "fato". Segundo Kimball (2002, 
p. 24), "as tabelas de dimensões estão sempre acompanhando uma tabela de fatos, possuindo descritores textuais da empresa".

Pode-se notar que o modelo multidimensional é não normalizado, tendo em vista que as tabelas "dimensão" podem conter redundâncias em seus valores. No entanto, essa falta de normalização implica um modelo mais simples, além de auxiliar no desempenho, quando da realização de consultas.

\subsection{QUALIDADE DE DADOS}

A qualidade dos dados armazenados em um banco de dados é um dos principais fatores a ser considerado em sua modelagem e implementação.

Conforme Pinho ${ }^{2}$ et al. (2001 apud AMARAL, 2003, p.21),

Qualidade de dados é um conceito complexo, porque possui significados diversos para diferentes pessoas. Portanto, gerar uma medida de qualidade aceitável para todos não é trivial. Para isso, é preciso definir as características da qualidade que interessam e, então, decidir como a avaliação da qualidade será feita através delas.

Para se obter uma modelagem adequada para a construção de um banco de dados, é importante que tanto os dados, quanto os esquemas dos Bancos de Dados Operacionais, estejam adequadamente modelados, oferecendo, assim, um banco de dados origem de qualidade (FERNANDES, 2004).

Segundo Salvador et al. (2006), um dado tem qualidade se satisfaz os requisitos de uso desejados; para isto, o dado deve ser:

q Preciso: é a medida de quão correto, quão livre de erros, quão próximo está esse dado do fato verdadeiro. É o princípio fundamental da qualidade de dados; se um dado não é correto, as outras dimensões são menos importantes. Para ser correto, um valor deve ser certo e deve ser representado de uma forma consistente e sem ambigüidade.

\footnotetext{
${ }^{2}$ PINHO, S.F.C. Avaliação da Qualidade de Dados pela Não Conformidade. 110 p. Dissertação (Mestrado) - COPPE, Universidade Federal do Rio de Janeiro, 2001.
} 
q Disponível em tempo: os dados estão suficientemente atualizados para as tarefas que os utilizarem.

q Relevante: os dados devem ser importantes para o tomador de decisões em um contexto, úteis e aplicáveis na tarefa em questão.

q Completo: devem os dados conter todos os fatos importantes, na amplitude e profundidade adequadas às necessidades.

q Simples/Compreendido: evita a chamada "sobrecarga de informação".

q Confiável: o dado é dependente da fonte ou método de coleta.

Ainda, conforme Salvador et al. (2006) há inúmeros os fatores que causam problemas de imprecisão em uma base de dados, destacam-se dentre eles: entrada inicial de dados com problema, degradação, mudanças e reestruturação e uso de dados.

Dentre os fatores citados, um dos mais importantes refere-se a "mudanças e reestruturações”, já que futuras mudanças ocorridas junto aos Bancos de Dados Operacionais, tais como: acréscimo de atributos, mudanças de tamanho ou formato de atributos, criação de novos conjuntos de entidades, etc., devem ser propagadas para a base de dados que armazenará os dados analítico-temporais.

Os principais problemas que afetam a qualidade de dados estão relacionados à falta de sincronização e padronização das bases de dados "origem" e "destino", quando se faz a migração dos dados. Some-se a isso, o fato de que sistemas fonte dificilmente são projetados para sofrerem mudanças. 


\section{BANCOS DE DADOS ANALÍTICO-TEMPORAIS}

Neste capítulo, são apresentados os principais conceitos e noções sobre Bancos de Dados Analítico-Temporais, bem como o detalhamento da proposta de modelagem e implementação do Banco de Dados Analítico-Temporal. São especificadas todas as etapas a serem seguidas para a obtenção de um modelo analítico-temporal adequado, bem como os algoritmos utilizados em sua implementação.

\subsection{BANCOS DE DADOS ANALÍTICO-TEMPORAIS}

Em se tratando de modelar dados analítico-temporais, um modelo de dados deve apresentar as características básicas de bancos de dados convencionais, acrescentando a possibilidade de representar dados que se alterem ao longo do tempo. Em termos gerais, bancos de dados que mantêm dados correntes, bem como dados passados, são designados Banco de Dados Analítico-Temporais (TANSEL, 1997).

Segundo Silberschatz; Korth; Sudarshan (2006, p. 610), "os Bancos de Dados que armazenam informações sobre estados do mundo real, com o passar do tempo, são chamados Banco de Dados Temporais".

Bancos de Dados Analítico-Temporais permitem armazenar e recuperar todos os estados de um dado ao longo do tempo, diferentemente dos Bancos de Dados Operacionais, em que a realidade é representada apenas pelo estado atual de um dado (EDELWEISS; OLIVEIRA, 1994; ÖZSOYOGLU; SNODGRASS, 1995).

Para se ter um melhor rendimento no processo de tomada de decisões, é necessário que se crie um banco de dados específico para tal finalidade, separado, logicamente, dos Bancos de Dados Operacionais. Com isso, torna-se possível combinar ou unir, diversos Bancos de Dados Operacionais durante o processo de extração e obtenção de dados, bem como acrescentar e excluir dados, retratar as estruturas de dados lógicas e lidar com dados "de testes", de maneira a não acessar a base de dados principal (SPRAGUE; WATSON, 1991). 
Um Banco de Dados Analítico-Temporal, além de oferecer um armazenamento mais completo e rico em relação aos Bancos de Dados Operacionais, tem como propósito específico prestar auxílio aos responsáveis pela tomada de decisões de médio e longo prazo.

A intenção é que um Banco de Dados Analítico-Temporal seja mais especializado do que um Banco de Dados Operacional, no que se refere ao aspecto de oferecer dados para análises. A especialização tem como foco principal, fornecer dados para tomadas de decisões com base no planejamento do negócio, diferentemente dos Bancos de Dados Operacionais, que visam a atender às tomadas de decisões cotidianas, com base nas funções do negócio.

Nesse sentido, para a criação de um Banco de Dados Analítico-Temporal, são necessárias adaptações, tomando-se, como ponto de partida, os modelos de dados dos Bancos de Dados Operacionais, a fim de oferecer um controle mais rico dos dados operacionais modificados ao longo do tempo.

A primeira adaptação refere-se à inclusão de "elementos de tempo" nos conjuntos de entidades a serem criados em um Banco de Dados Analítico-Temporal. Esses "elementos de tempo" têm a função de representar as datas e/ou horários da modificação de dados ao longo do tempo.

Os valores temporais a serem criados envolvem tanto o instante inicial de validade de um determinado conjunto de dados, como o instante em que tais dados sofrem alterações, perdendo seus valores iniciais. Tal processo repete-se tantas vezes quantas sejam as alterações sofridas por um determinado conjunto de dados.

A segunda adaptação diz respeito à inclusão de "atributos derivados" em alguns conjuntos de entidades a serem criados no Banco de Dados Analítico-Temporal. Esses atributos devem ter a função de armazenar valores pré-calculados, cujo objetivo é evitar a necessidade de se realizar cálculos durante a recuperação dos dados analítico-temporais. Esses atributos derivados podem, normalmente, ser obtidos por meio de operações matemáticas sobre um grupo de atributos de uma ou mais tabelas contidas no Banco de Dados Operacional. 
Assim, o processo de transferência dos dados abrange não apenas simples conversões de formatos de dados, mas também a realização de cálculos, visando à obtenção de atributos derivados.

\subsection{BANCO DE DADOS ANALÍTICO-TEMPORAL PROPOSTO}

As atividades de modelagem de um Banco de Dados Analítico-Temporal constituem um importante e exaustivo trabalho de especificação, contemplando a identificação de bancos de dados fonte e englobando todos os seus conjuntos de entidades, bem como os seus atributos. Assim como em qualquer produto de software que seja desenvolvido, a etapa de especificação é de fundamental importância. Ou seja, uma especificação bem elaborada colabora em muito para que o produto final esteja de acordo com o esperado.

A proposta de modelagem e implementação de um Banco de Dados AnalíticoTemporal aqui realizada não envolve a especificação de interfaces homem-máquina ou dados de desempenho, entre outros.

O foco central da presente pesquisa é propor e descrever uma forma de modelagem e de implementação de um Banco de Dados Analítico-Temporal a ser aplicada em organizações de pequeno e médio porte. Tal modelagem tem por função mapear Bancos de Dados Operacionais em Bancos de Dados Analítico-Temporais. Isso implica disponibilizar mecanismos que possibilitem a geração, o transporte e 0 armazenamento de dados analítico-temporais.

Com o Banco de Dados Analítico-Temporal proposto, pretende-se oferecer subsídios para o controle do histórico de dados originados dos Bancos de Dados Operacionais.

A idéia não é gerar histórico de toda a base de dados operacional, mas apenas dos dados que forem selecionados, de acordo com os critérios a serem estabelecidos. Para isso, esta proposta oferece uma forma para o mapeamento do Modelo de Dados Analítico-Temporal, bem como os recursos de programação estabelecidos 
diretamente nos Bancos de Dados Operacionais, os quais possibilitam o envio desse histórico ao Banco de Dados Analítico-Temporal.

Considerando-se os modelos de dados dos Bancos de Dados Operacionais existentes e tomando por base as especificações, é que deve ser projetado o modelo de dados do Banco de Dados Analítico-Temporal. Problemas de integração de esquemas e qualidade de dados devem ser minimizados durante a elaboração do modelo proposto.

Conforme ilustrado na Figura 7, a partir dos Bancos de Dados Operacionais, são obtidos os Modelos de Dados Operacionais. Estes, que por sua vez, são mapeados, culminando em um Modelo de Dados Analítico-Temporal. Com base nesse modelo de dados analítico-temporal, é criado o Banco de Dados Analítico-Temporal.

A forma de armazenamento adotada é de um único repositório, ou seja, os vários Bancos de Dados Operacionais devem dar origem a apenas um Banco de Dados Analítico-Temporal.

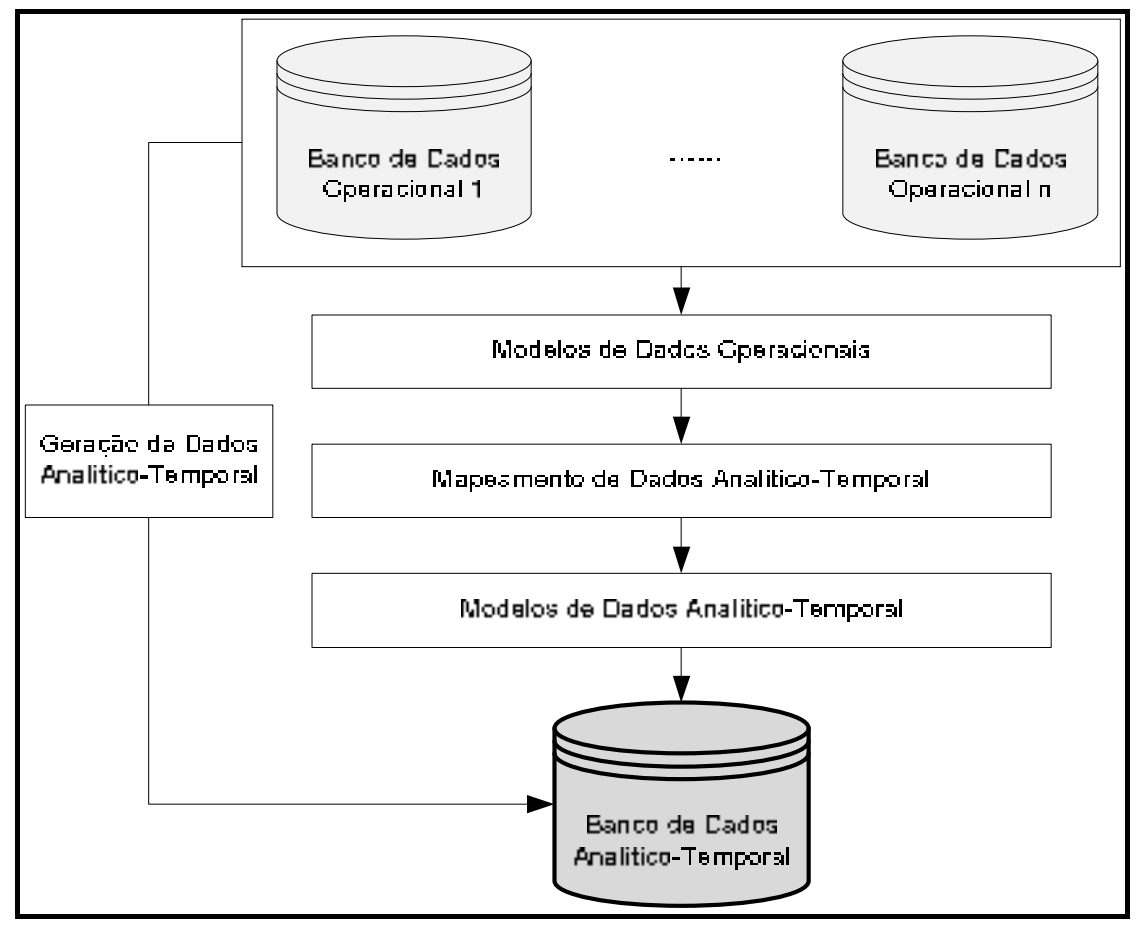

Figura 7. Diagrama Geral da Proposta de Modelagem e Implementação de Bancos de Dados Analítico-Temporais 
Tal tarefa é dividida em algumas atividades, conforme mostra a Figura 8.

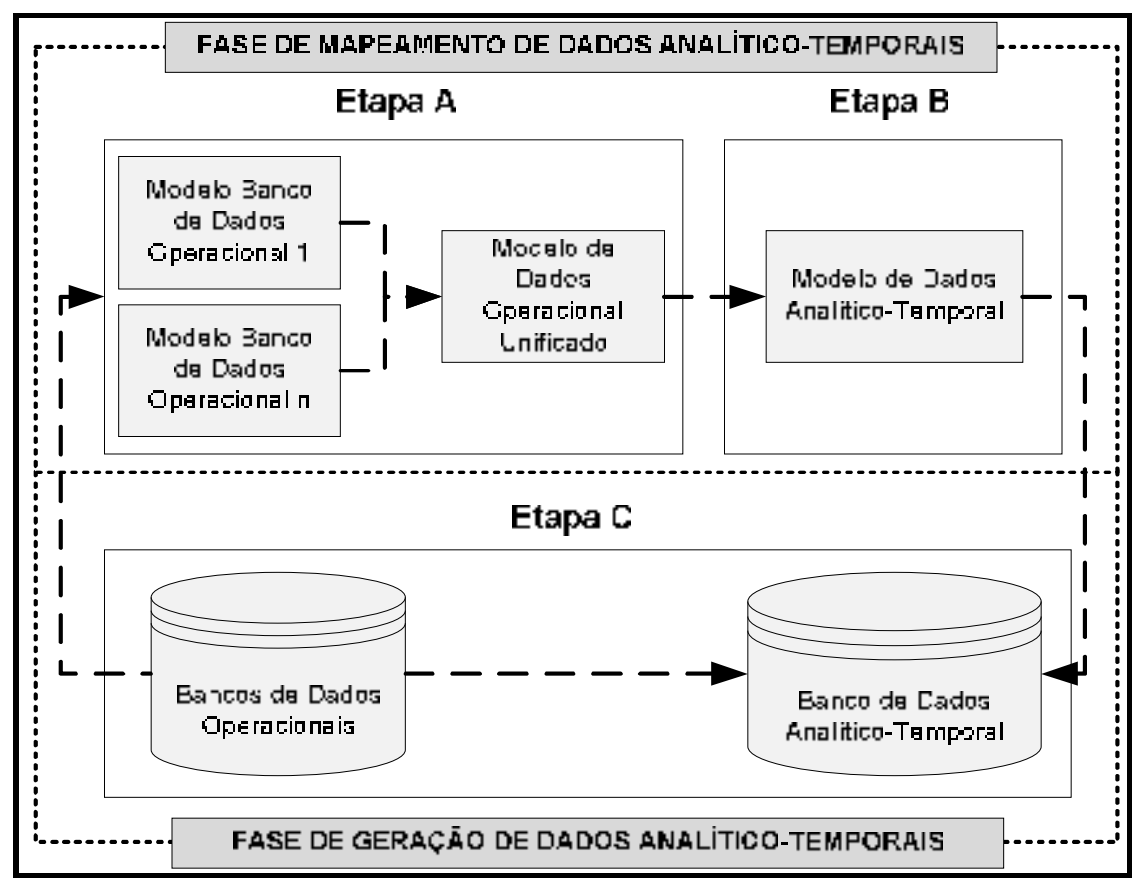

Figura 8. Etapas da Proposta de Modelagem e Implementação de Bancos de Dados Analítico-Temporais

Há a possibilidade de se trabalhar com vários Bancos de Dados Operacionais que podem possuir modelos de dados diferentes. Por essa razão, torna-se necessária a integração desses vários modelos em apenas um modelo de dados unificado. Essa necessidade também tem como alvo a padronização das estruturas operacionais, proporcionando incremento à qualidade dos dados. Tal atividade corresponde à Etapa A, da Figura 8. A partir desse Modelo de Dados Operacional Unificado, tornase possível gerar o Modelo de Dados Analítico-Temporal, correspondente à Etapa B dessa mesma figura.

A Etapa $A$ refere-se à realização de um mapeamento dos modelos de dados presentes nos Bancos de Dados Operacionais, a fim de unificá-los. Trata-se de uma ação cujo objetivo é gerar um modelo de dados chamado Modelo de Dados Operacional Unificado.

Considerando-se essa primeira atividade, as principais finalidades referem-se à integração e à qualidade dos dados. Em suma, algumas das tarefas a serem realizadas nessa etapa abrangem a renomeação de conjuntos de entidades e de 
atributos, bem como a transformação de atributos que sejam chaves primárias e a sua propagação como chaves estrangeiras.

A Etapa $B$ diz respeito à realização de um mapeamento do Modelo de Dados Operacional Unificado em um modelo de dados chamado Modelo de Dados Analítico-Temporal. Nessa segunda Etapa, há preocupações quanto a selecionar os conjuntos de entidades e atributos que comporão o Banco de Dados AnalíticoTemporal, bem como quanto a definir os conjuntos de entidades a serem criados junto ao Banco de Dados Analítico-Temporal para o armazenamento dos dados analítico-temporais.

Ainda nessa segunda Etapa, tem-se por finalidade, controlar os períodos nos quais os dados operacionais ficaram válidos, bem como registrar atributos pré-calculados (atributos derivados), a fim de evitar sobrecargas de processamento no Banco de Dados Analítico-Temporal, quando da necessidade de recuperar informações que envolvam cálculos.

Essas duas etapas constituem as atividades responsáveis pela modelagem do Banco de Dados Analítico-Temporal. O enfoque principal dessas duas etapas concentra-se em evitar o transporte dos conjuntos de entidades sem interesse para uma atividade de análise de dados. Assim, normalmente, parcela significativa dos conjuntos de entidades dos bancos de dados operacionais não faz parte desse processo.

A Etapa $C$ refere-se à especificação de gatilhos e procedimentos armazenados, os quais serão responsáveis por enviar os dados históricos dos bancos de dados operacionais para o banco de dados analítico-temporal, devendo ter por base tanto os modelos operacionais, quanto o modelo de dados analítico-temporal.

Nessa Etapa, há a preocupação em oferecer mecanismos encontrados nos próprios Sistemas Gerenciadores de Bancos de Dados com o intuito de facilitar a geração e o transporte os dados operacionais ao Banco de Dados Analítico-Temporal.

Tanto os gatilhos quanto os procedimentos armazenados devem ser criados diretamente nos Bancos de Dados Operacionais. Estes últimos não serão embutidos nos programas do usuário final. O Banco de Dados Analítico-Temporal conterá 
apenas procedimentos armazenados com a finalidade de serem utilizados para, eventualmente, consolidar os dados.

A Figura 9 contém uma analogia entre a proposta de modelagem e implementação de Bancos de Dados Analítico-Temporais e um ambiente de Data Warehousing. De acordo com a Figura 9, no Data Warehouse utiliza-se o modelo de dados multidimensional. Com base nesse modelo de dados, é que são elaborados e utilizados os processos de ETL responsáveis pelas cargas ao Data Warehouse. Na presente proposta, obtém-se o modelo de dados analítico-temporal, de acordo com as etapas A e B, e com base nesse modelo de dados são elaborados os gatilhos e procedimentos armazenados, responsáveis pelas cargas ao Banco de Dados Analítico-Temporal. Portanto, as etapas A e B da presente proposta correspondem à elaboração do modelo multidimensional de um ambiente de Data Warehousing.

Já o processo ETL, usado em Data Warehousing, corresponde à criação dos gatilhos e procedimentos armazenados. Tendo em vista o grande tempo normalmente despendido no processo ETL, esta proposta representa um ganho significativo, constituindo um importante diferencial em relação ao ambiente de Data Warehousing.

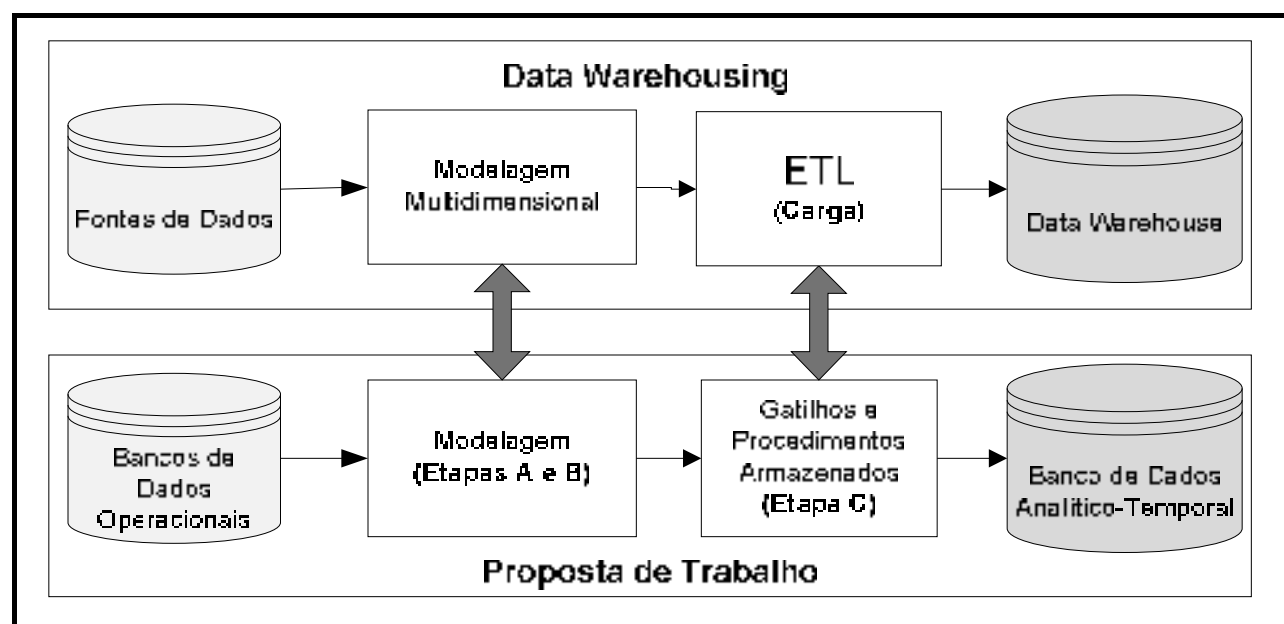

Figura 9. Proposta de Modelagem e Implementação de Bancos de Dados Analítico-Temporais x Ambiente de Data Warehousing 


\subsection{MAPEAMENTO DE DADOS ANALÍTICO-TEMPORAIS - ETAPAS A e B}

Esta fase tem por objetivo identificar e extrair, dos modelos operacionais, os conjuntos de entidades e atributos essenciais à geração de dados analíticotemporais, transformando-os em um Modelo Operacional Unificado (Etapa A) e, posteriormente, em um Modelo Analítico-Temporal (Etapa B). Esse mapeamento implica descartar todos os atributos puramente operacionais; ou seja, atributos que não se modificam com o passar do tempo, como, por exemplo, data de nascimento, sexo, etc., sempre de acordo com as necessidades da aplicação em questão.

O descarte dos atributos puramente operacionais, durante $\mathrm{o}$ processo de mapeamento, visa, primeiramente, a uma otimização do tempo de processamento, já que, para gerenciar grandes volumes de dados, demanda-se mais tempo. Em segundo lugar, esse ônus seria desnecessário, visto que, normalmente, tais atributos não serão utilizados para a finalidade básica do Banco de Dados AnalíticoTemporal, que é a tomada de decisões.

O processo de mapeamento contém diversos passos a fim de se obter o Modelo Analítico-Temporal ideal para uma aplicação específica. Tais passos são descritos nos próximos itens.

\subsubsection{Etapa A: Mapeamento dos Modelos de Dados Operacionais em um Modelo de Dados Unificado}

De maneira geral, esta etapa visa ao mapeamento dos Modelos dos Bancos de Dados Operacionais, em um Modelo de Dados Unificado, com o objetivo de integrar todos os conjuntos de entidades utilizados nos Bancos de Dados Operacionais.

Para que se consiga uma integração adequada dos Modelos de Dados Operacionais, mantendo um bom nível de qualidade dos dados, foi elaborada uma seqüência de passos a serem aplicados. 
É importante salientar que nenhuma das etapas aqui propostas tem como objetivo alterar os Modelos de Dados Operacionais, que permanecerão implementados em seu formato original.

Com a realização desta etapa, pretende-se minimizar alguns problemas, tais como: mesmos dados com nomes diferentes, dados diferentes com mesmo nome, diferentes unidades de medida, valores nulos, chaves duplicadas, etc. Esses problemas podem ocorrer principalmente pelo fato de se trabalhar com mais de um Banco de Dados Operacional.

Na Figura 10, apresenta-se a seqüência de passos proposta para a realização desta etapa.

Passo A1

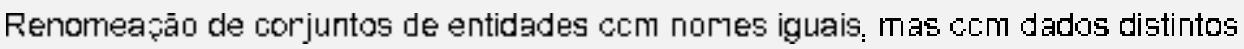

Passo A2

Reromeapa de sonjuntos de entidades corา nomes distintos, mas com dados comuns

Passo A3

Renomeaça de atributos con nome distintos: inas com dados comuns

Passo A4

Transformeçāo de atritutos com dados comuns: mas ccm diferente representaçāo de valores

Passo A5

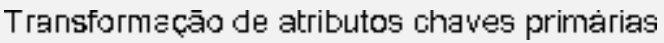

Passo A6

Transformaçāo de atributos chaves estrangeiras

Passo A7

Geraça do Modelo de Dados Urificado

Figura 10 - Passos para a Geração Modelo de Dados Unificado 


\subsubsection{Passo A1: Renomeação de conjuntos de entidades com nomes iguais, mas com dados distintos}

\section{Justificativa}

Dentre os Bancos de Dados Operacionais que virão a compor o Banco de Dados Analítico-Temporal, podem existir conjuntos de entidades que possuam os mesmos nomes, armazenando, porém, dados com finalidades diferentes. Assim, torna-se necessário identificar tais conjuntos de entidades e atribuir diferentes denominações a eles.

Dessa forma, neste passo, após tais identificações, define-se um nome alternativo na modelagem para cada um desses conjuntos de entidades, evitando-se, assim, que sejam confundidos durante o processo de mapeamento.

\section{Exemplo}

Sejam os trechos de modelos de dados da Figura 11, nos quais se pode notar que há um conjunto de entidades chamado PESSOA em cada uma das partes. No Banco de Dados Operacional 1 - $\mathrm{BDO}_{1}$, a idéia é, de fato, representar clientes de uma empresa e no $\mathrm{BDO}_{2}$ a idéia é representar funcionários que trabalhem em um projeto. Tal característica implica que os dois conjuntos de entidades possuam atributos com diferentes significados. Assim, o conjunto de entidades PESSOA, do $\mathrm{BDO}_{1}$, poderia ser identificado pelo nome alternativo "CLIENTE" e o conjunto de entidades PESSOA, do $\mathrm{BDO}_{2}$, por "FUNCIONÁRIO".

Outra opção seria usar o próprio nome do banco de dados operacional como parte integrante do nome do conjunto de entidades, na forma de prenome. Assim, os nomes dos conjuntos de entidades poderiam ser definidos por [BDO1]_PESSOA e [BDO2]_PESSOA. 


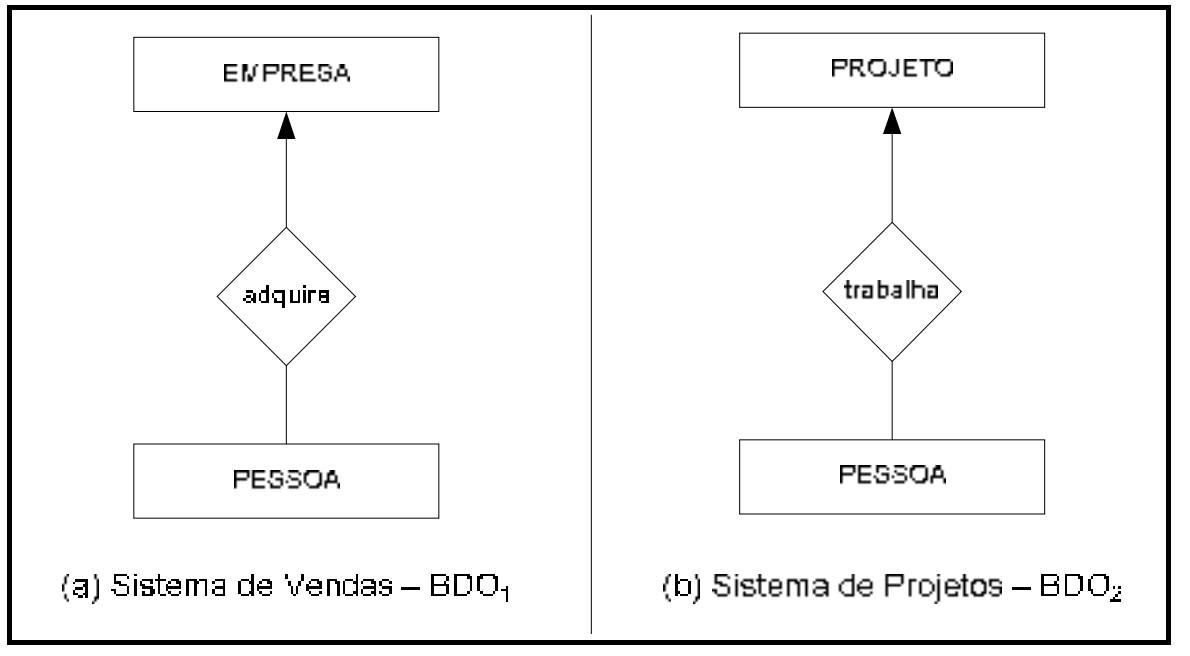

Figura 11 - Exemplo do Passo A1

\subsubsection{Passo A2: Renomeação de conjuntos de entidades com nomes distintos, mas com dados comuns}

\section{Justificativa}

Considerando-se os Bancos de Dados Operacionais que poderão a vir a compor o Banco de Dados Analítico-Temporal, podem existir conjuntos de entidades com nomes distintos, mas com tipos de dados comuns. Assim, imprescindível é identificar tais conjuntos de entidades e, eventualmente, atribuir-lhes as mesmas denominações.

Na verdade, esse é o passo no qual deve ser feito um rastreamento em todos os Modelos de Dados Operacionais, com o propósito de unificar todos os conjuntos de entidades com semelhanças em seus conteúdos e estruturas.

\section{Exemplo}

Sejam os trechos de modelos de dados da Figura 12, pertencentes ao $\mathrm{BDO}_{1}$ e ao $\mathrm{BDO}_{2}$, respectivamente. 


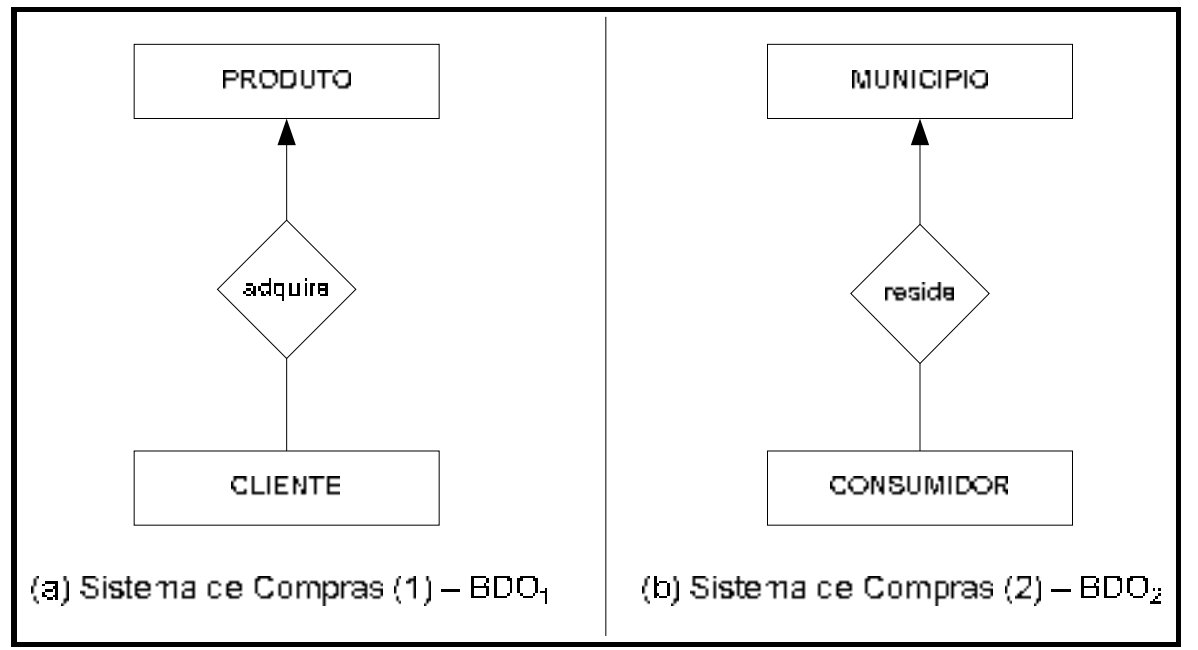

Figura 12. Exemplo de Modelos de Dados Operacionais - Passo A2

A semelhança dos Modelos de Dados Operacionais concentra-se nos conjuntos de entidades CLIENTE e CONSUMIDOR. Esses conjuntos de entidades estão sendo utilizados para armazenar dados de pessoas, que, por sua vez, são todos compradores. Portanto, os conjuntos de entidades CLIENTE, do $\mathrm{BDO}_{1}$, e CONSUMIDOR, do $\mathrm{BDO}_{2}$, podem ser unificados em apenas um conjunto de entidades, que poderia ser denominado como COMPRADOR.

Logo, os Modelos de Dados Operacionais poderiam ser unificados conforme ilustrado na Figura 13.

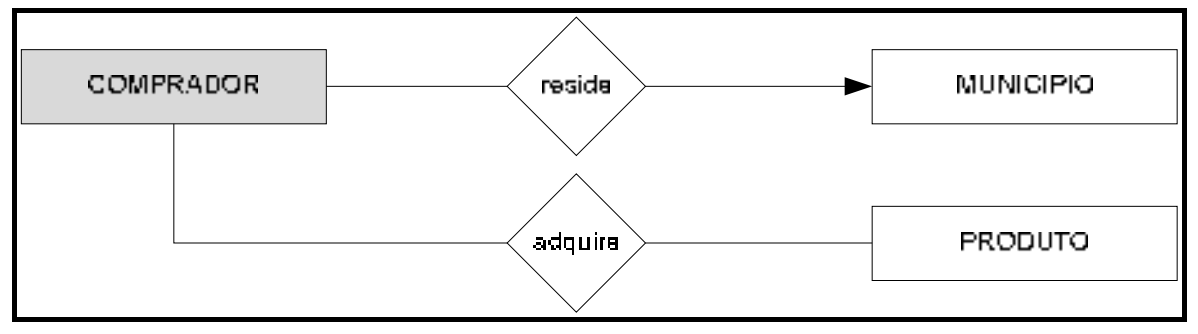

Figura 13. Exemplo do Passo A2 


\subsubsection{Passo A3: Renomeação de atributos com nomes distintos, mas com dados comuns}

\section{Justificativa}

Dentre os Bancos de Dados Operacionais que virão a compor o Banco de Dados Analítico-Temporal pode haver, nos diversos conjuntos de entidades identificados durante o Passo A2, atributos com nomes distintos, porém com dados comuns. Assim, a identificação de tais atributos é de suma importância, visando a sua unificação.

\section{Exemplo}

Sejam trechos de modelos de dados da Figura 14, pertencente ao $\mathrm{BDO}_{1}$ e ao $\mathrm{BDO}_{2}$, respectivamente.

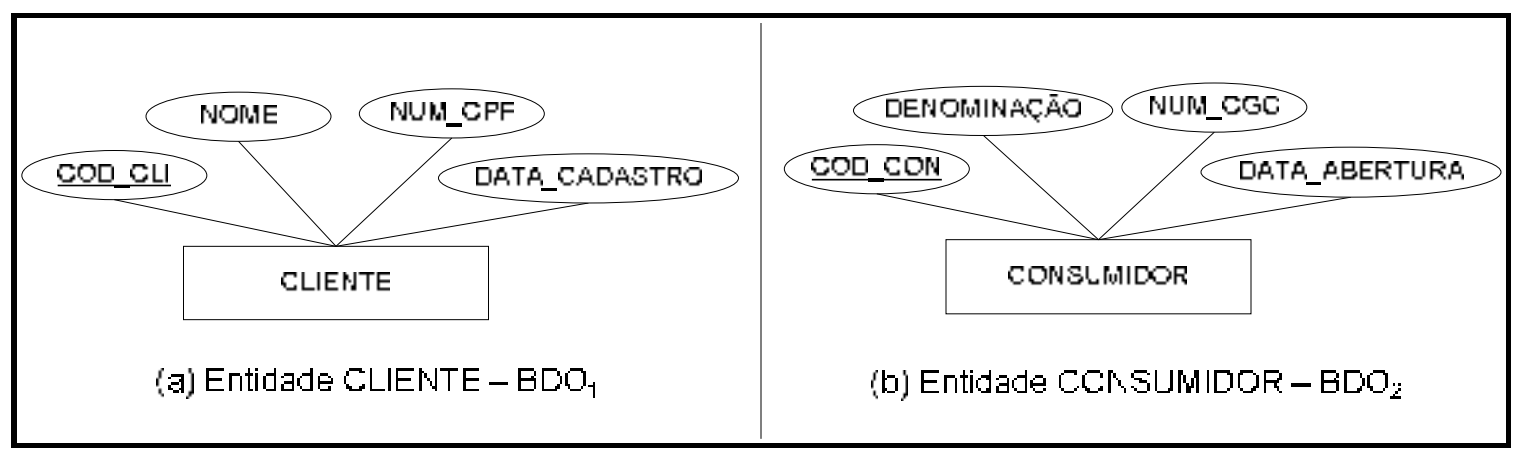

Figura 14. Exemplos de Entidades - Passo A3

Nota-se que o atributo NOME, da entidade CLIENTE, e o atributo DENOMINAÇÃO, da entidade CONSUMIDOR, apesar de não possuírem o mesmo nome de atributo, podem ser unificados por meio de uma designação comum, como, por exemplo, NOME, visto que têm a função de distinguir cada um dos clientes ou consumidores. A Figura 15 ilustra a unificação dos atributos comuns. 


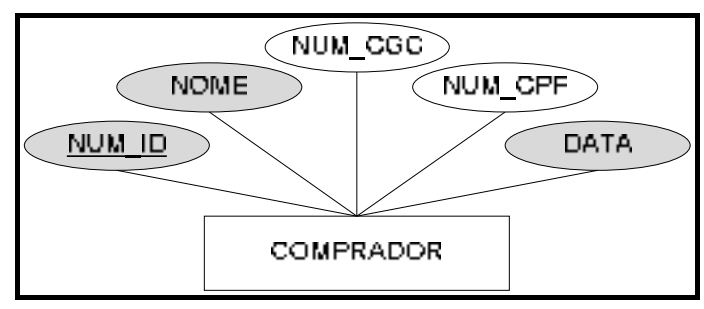

Figura 15. Exemplo do Passo A3

\subsubsection{Passo A4: Transformação de atributos com dados comuns, mas com diferente representação de valores}

\section{Justificativa}

Dentre os Bancos de Dados Operacionais a compor o Banco de Dados AnalíticoTemporal, podem existir, nos diversos conjuntos de entidades identificados, atributos que armazenam dados comuns, porém com representações diferentes em relação aos valores propriamente ditos. Torna-se, dessa forma, necessário identificar tais atributos, visando à sua padronização.

Este passo tem a função de identificar quais atributos, dos conjuntos de entidades comuns, possuem a mesma finalidade, visto que, para a geração do Modelo de Dados do Passo A3, é imprescindível analisar cada um dos atributos dos conjuntos de entidades comuns, a fim de reuni-los.

\section{Exemplo}

A representação diferente de valores entre Bancos de Dados Operacionais pode ocorrer de diversas maneiras. Um exemplo refere-se a unidades de medidas, que, em um determinado banco de dados, podem ser representadas por "centímetros", em outro por "metros", ou até mesmo em "milímetros". Dessa forma, ao fazer a transferência para o Banco de Dados Analítico-Temporal, essas unidades de medidas devem ser padronizadas. 


\subsubsection{Passo A5: Transformação de atributos chaves primárias}

\section{Justificativa}

A importância deste item está no fato de que, como é possível ocorrer a unificação de conjuntos de entidades ou de atributos, conforme descrito nos Passos A2 e A3, pode acontecer de, no momento da geração dos dados analítico-temporais, haver duplicação dos valores de atributos utilizados como chaves primárias, o que não é admissível. Dessa forma, este passo justifica-se no sentido de solucionar tal tipo de problema. Conforme já citado, este passo deve ser aplicado apenas aos conjuntos de entidades comuns e que serão unificados.

\section{Exemplo}

Sejam os trechos de modelos de dados da Figura 16, pertencente ao $\mathrm{BDO}_{1}$ e ao $\mathrm{BDO}_{2}$, respectivamente.

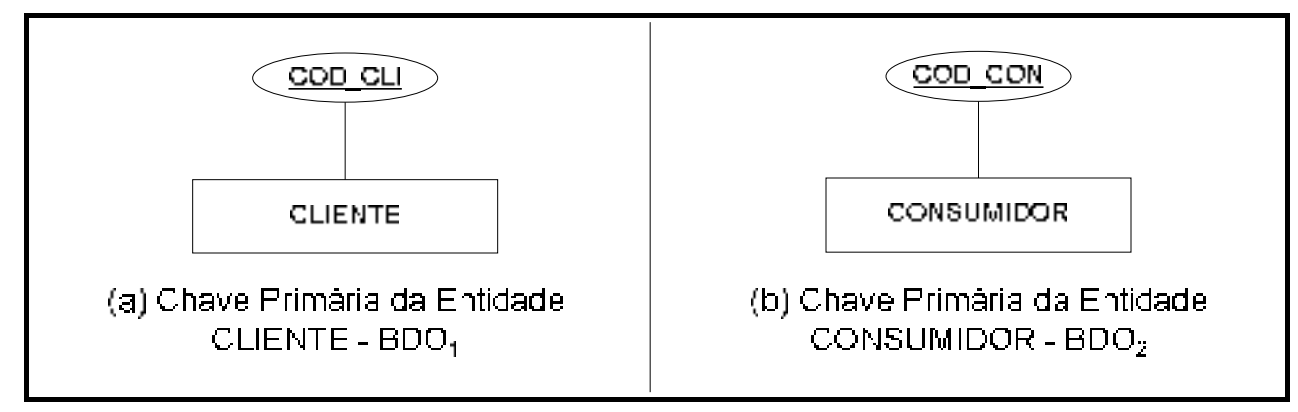

Figura 16. Trechos de Modelos de Dados - $\mathrm{BDO}_{1}$ e $\mathrm{BDO}_{2}$

O atributo COD_CLI, do conjunto de entidades CLIENTE, do $\mathrm{BDO}_{1}$, e o atributo COD_CON, do conjunto de entidades CONSUMIDOR, do $\mathrm{BDO}_{2}$, são os atributos chaves primárias desses conjuntos de entidades.

Como demonstrado no Passo A3, esses atributos podem ser unificados em um terceiro atributo. A finalidade do Passo A5 diz respeito apenas aos valores das chaves primárias, uma vez que, unidos os atributos chaves primárias, pode haver duplicidade de valores. 
Uma solução seria acrescentar, ao valor da chave primária do conjunto de entidades CLIENTE, a sigla 'CL', ou até mesmo uma sigla de identificação do banco de dados "origem", quando seus dados forem integrados ao conjunto de entidades COMPRADOR. Nesse caso, por exemplo, para o cliente '001', seria enviado o valor de chave '001CL' ou 'CL001'. Já no conjunto de entidades CONSUMIDOR, seria acrescentada a sigla ' $\mathrm{CO}$ '.

Uma segunda possibilidade seria a criação de um novo atributo para armazenar uma "chave substituta". Essa chave substituta poderia conter o nome do Banco de Dados Operacional do qual o dado teve origem, criando-se assim, uma padronização para o controle da duplicação de chaves primárias. Além do mais, o uso do próprio nome do Banco de Dados Operacional para tal controle, facilitaria a identificação da origem do dado por de ser uma solução mais genérica.

\subsubsection{Passo A6: Transformação de atributos chaves estrangeiras}

\section{Justificativa}

A importância deste item está no fato de que, caso ocorra a modificação dos valores de chaves primárias, como sugerido no Passo A5 e como tais valores podem ser utilizados em outros conjuntos de entidades como chaves estrangeiras, pode haver perda de integridade referencial. Portanto, esses novos valores devem ser propagados para todos os conjuntos de entidades, a fim de evitar a falta de integridade entre os dados.

\section{Exemplo}

A Figura 17 contém um exemplo de conversões de chaves estrangeiras, ilustrado pelo atributo CID_MUN, do conjunto de entidades COMPRADOR. 


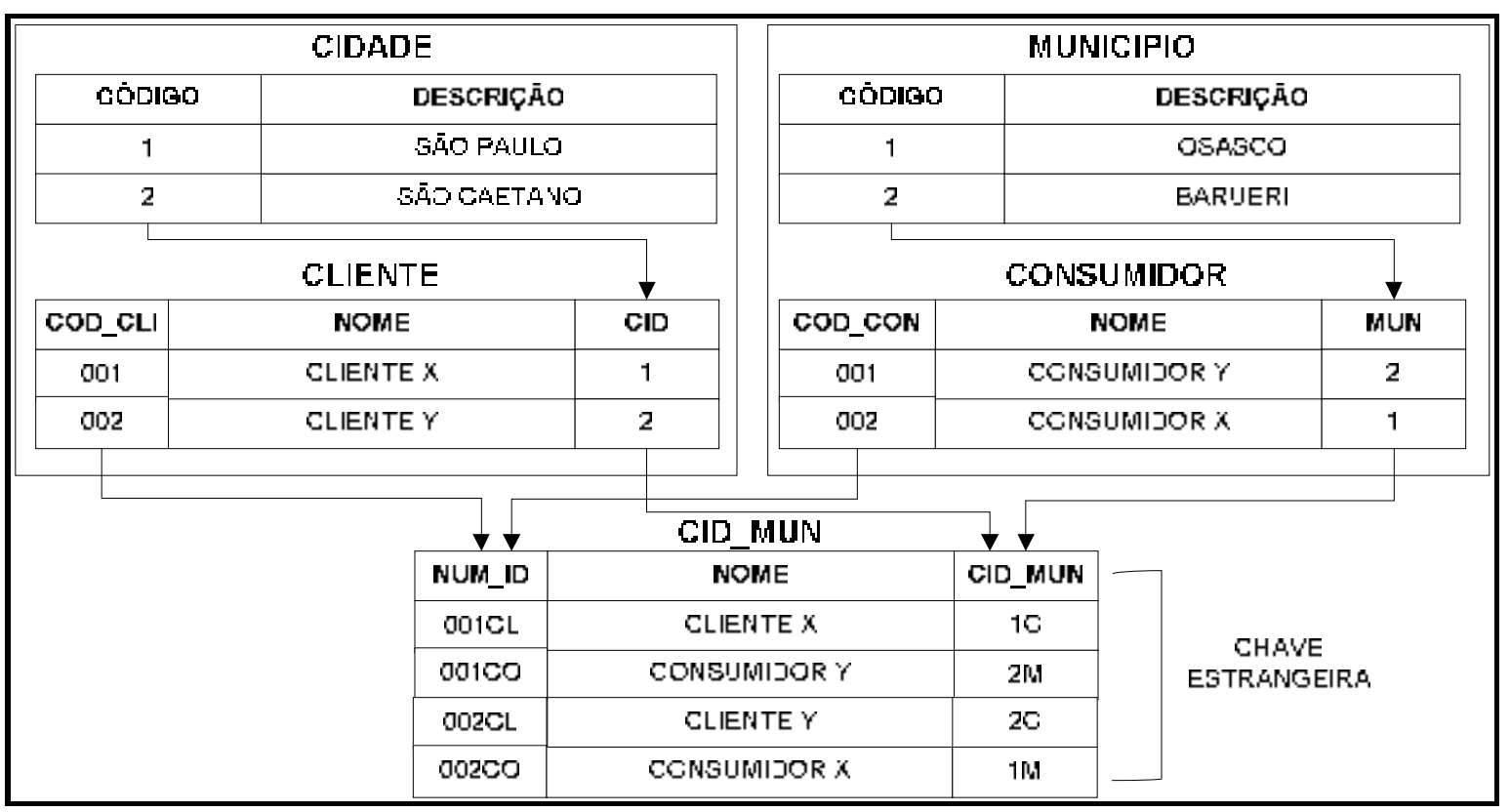

Figura 17. Ilustração do uso das Chaves Primárias como Chaves Estrangeiras

Analisando o exemplo da Figura 17, com o uso do atributo CID_MUN é possível identificar se a informação é oriunda do conjunto de entidades CIDADE e/ou MUNICIPIO. Porém, pode ocorrer duplicidade de valores, já que uma mesma informação pode estar registrada nos dois conjuntos de entidades. Por outro lado, isso não acarreta problemas já que por intermédio da chave estrangeira é possível saber qual a origem da informação. Além do mais, o conjunto de entidades CID_MUN é uma tabela intermediária da modelagem e que de fato não será implementada no Banco de Dados Analítico-Temporal, já que atributos descritivos serão armazenados junto às tabelas de fatos.

\subsubsection{Passo A7: Geração do Modelo de Dados Unificado}

Após a aplicação de todos os passos componentes desta etapa, obtém-se o Modelo de Dados Unificado, mapeado de acordo com as situações levantadas nos passos A1 a $A 6$. 
A proposta descrita nesta tese não propõe a realização de alterações nos modelos de Bancos de Dados Operacionais. As únicas modificações necessárias a serem realizadas nos Bancos de Dados Operacionais ocorrem em forma de inclusões, e são as seguintes (todas referentes à Etapa $\mathrm{C}$ desta proposta):

- de gatilhos e de procedimentos armazenados, que serão elaborados para enviar dados operacionais ao Banco de Dados Analítico-Temporal;

- de um conjunto de entidades, que conterá uma linha com a nomenclatura do Banco de Dados Operacional em questão; e

- da conexão dos Bancos de Dados Operacionais com o Banco de Dados Analítico-Temporal.

\subsubsection{Etapa B: Mapeamento do Modelo de Dados Unificado em um Modelo de Dados Analítico-Temporal}

De maneira geral, esta etapa visa ao mapeamento do Modelo de Dados Operacional Unificado, obtido ao final da Etapa A, em um Modelo de Dados Analítico-Temporal. O objetivo deste último é criar um esquema que ofereça condições para o armazenamento de dados analítico-temporais.

Os objetivos desta etapa são: selecionar os conjuntos de entidades e atributos essenciais para a geração de dados analítico-temporais; incluir atributos relativos ao tempo; adicionar atributos derivados; transformar relacionamentos entre dados em conjuntos de entidade; acomodar diferentes níveis de granularidade.

A Figura 18 apresenta a seqüência dos passos propostos para esta etapa. 


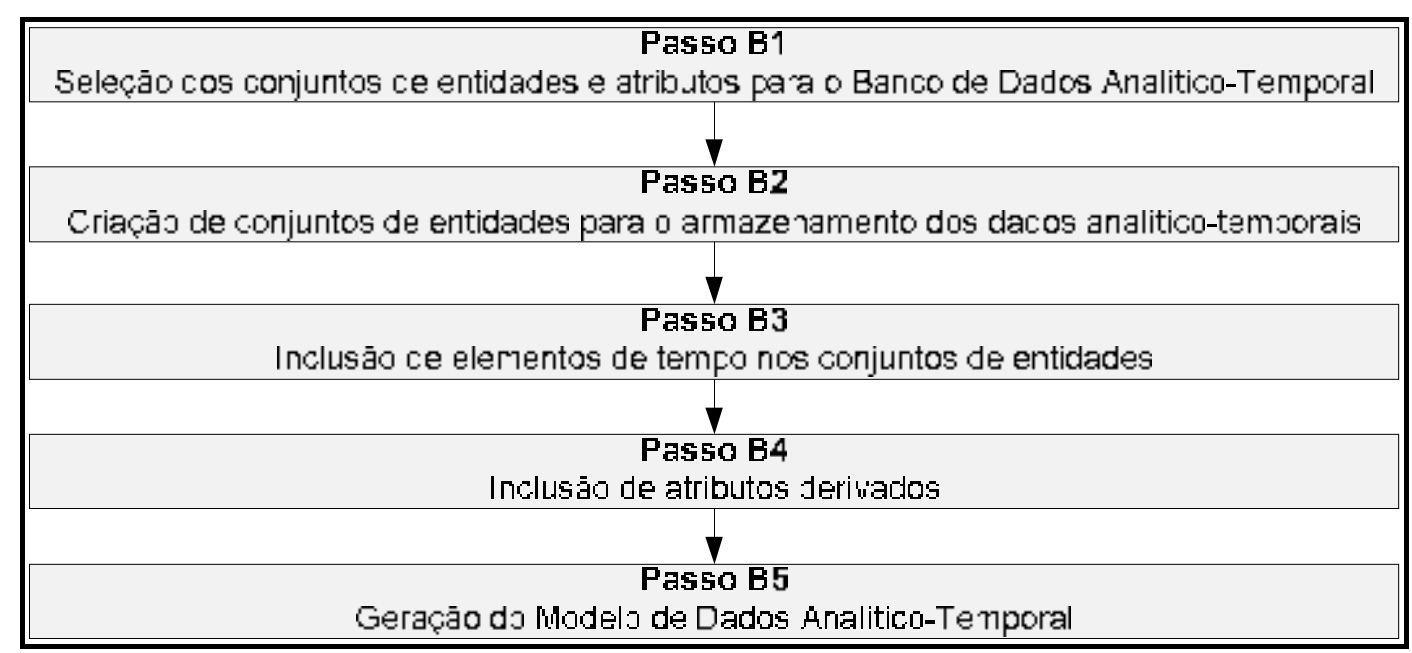

Figura 18 - Passos para a Geração do Modelo de Dados Analítico-Temporal

\subsubsection{Passo B1: Seleção dos conjuntos de entidades e atributos para o Banco de Dados Analítico-Temporal}

\section{Justificativa}

Este passo toma por base o fato de que é essencial que sejam selecionados todos os conjuntos de entidades e atributos que realmente participarão do processo de geração de dados analítico-temporais.

A primeira função deste passo é identificar, no Modelo de Dados Operacional Unificado, quais são os conjuntos de entidades e atributos puramente operacionais, para que os mesmos possam ser descartados durante a elaboração do Modelo de Dados Analítico-Temporal.

Não devem ser descartados os conjuntos de entidades que podem ter seus valores alterados ao longo do tempo, já que são, normalmente, vitais ao processo de análise. Também não devem ser totalmente descartados os conjuntos de entidades que conterão os valores descritivos, já que os mesmos podem também ser úteis na geração do banco de dados analítico-temporal.

Este passo visa a evitar a seleção de atributos que não sejam essenciais para o processo de tomada de decisões. O não descarte desses atributos pode, eventualmente, causar problemas de sobrecarga ao Banco de Dados Analítico- 
Temporal.

\section{Exemplo}

Seja o trecho de modelo de dados da Figura 19.

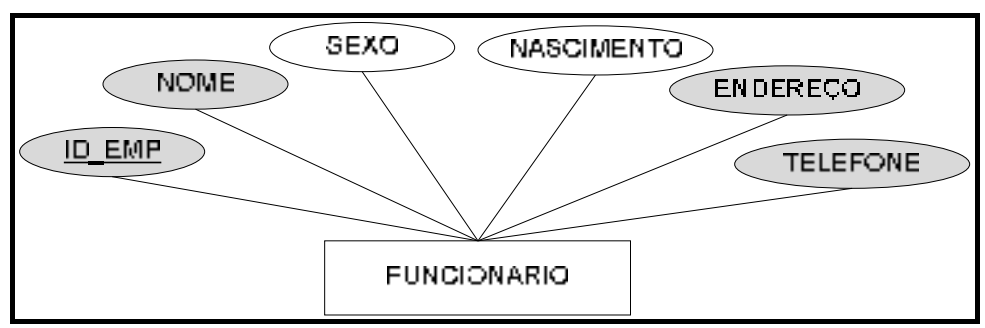

Figura 19. Exemplo de aplicação do Passo B1

Nota-se que as elipses em destaque (com cor de fundo acinzentada) identificam os atributos a serem transportados para o Banco de Dados Analítico-Temporal, já que são atributos que podem sofrer alterações ao longo do tempo, que podem ser utilizados como valores descritivos, ou atributos chaves primários que são essenciais para a localização das informações. As demais elipses identificam os atributos que não deverão participar do processo de armazenamento analítico-temporal, visto que são valores únicos. Estes, raramente, são modificados ao longo do tempo.

\subsubsection{Passo B2: Criação dos conjuntos de entidades para o armazenamento dos dados analítico-temporais}

\section{Justificativa}

A relevância deste passo assenta-se no fato de que é necessário definir as entidades para o armazenamento dos dados analítico-temporais. Sua função é oferecer um meio para a representação dos vários valores que uma entidade ou atributo pode assumir ao longo do tempo, já que nos Bancos de Dados Operacionais as representações baseiam-se em valores atuais do negócio.

O modelo adotado é o que se apresenta na Figura 20. Por esta figura, pode-se notar que o modelo utilizado difere em certa medida do modelo multidimensional, 
empregado em um ambiente de Data Warehousing. No modelo aqui proposto, há uma tabela chamada Analítico-Temporal, que contém os seguintes atributos: uma chave primária, atributos descritivos, atributos numéricos, atributos temporais e atributos derivados. Comparando-se com o modelo multidimensional, apresentado no Capítulo 2, verifica-se que, no modelo ora proposto, tudo funciona como se as tabelas "dimensão" fossem incorporadas à tabela "fato central", gerando o que aqui se denomina tabela Analítico-Temporal.

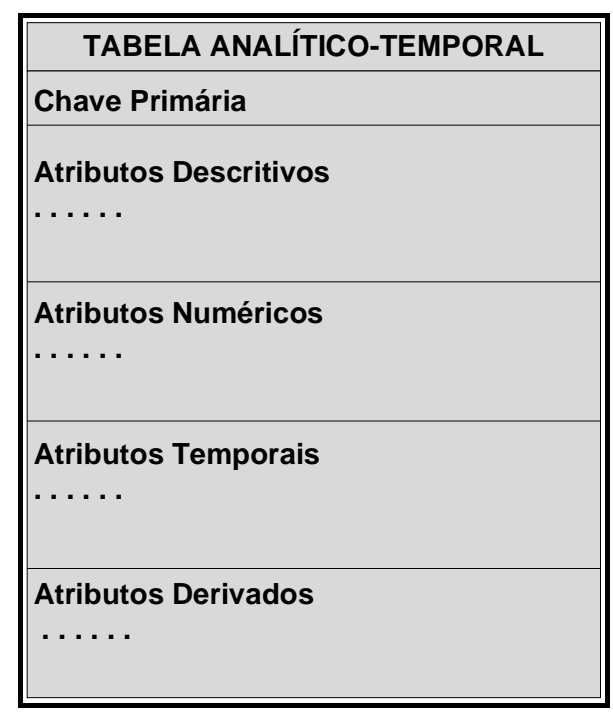

Figura 20. Modelo Analítico-Temporal

\section{Exemplo}

Seja o trecho de modelo de dados operacional da Figura 21.

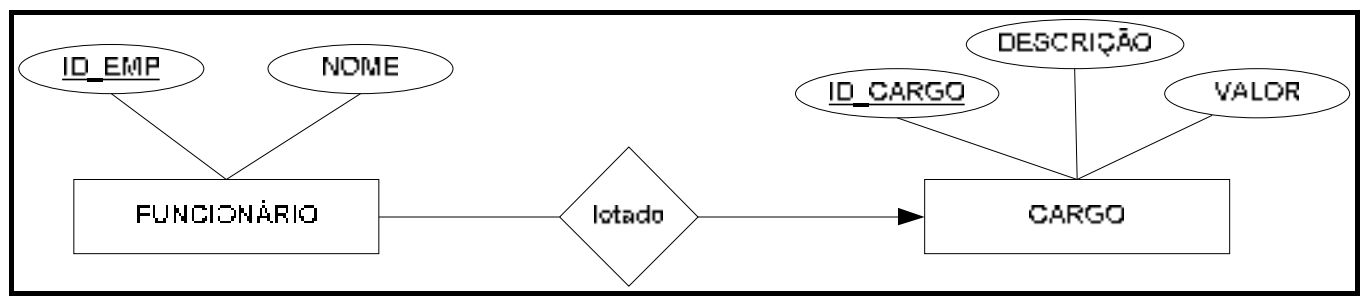

Figura 21. Modelo de Dados Operacional entre FUNCIONÁRIO e CARGO

Nota-se que o modelo de dados da Figura 21 representa o cargo atual que o funcionário possui. 
Por outro lado, em se tratando de dados analítico-temporais, essa estrutura não seria suficiente, visto que ela não suportaria mais que um cargo por funcionário, e muito menos o tempo em que o funcionário possuiu um respectivo cargo.

Com isso, surge a necessidade de se criarem novos conjuntos de entidades de dados, conforme ilustrado na Figura 22.

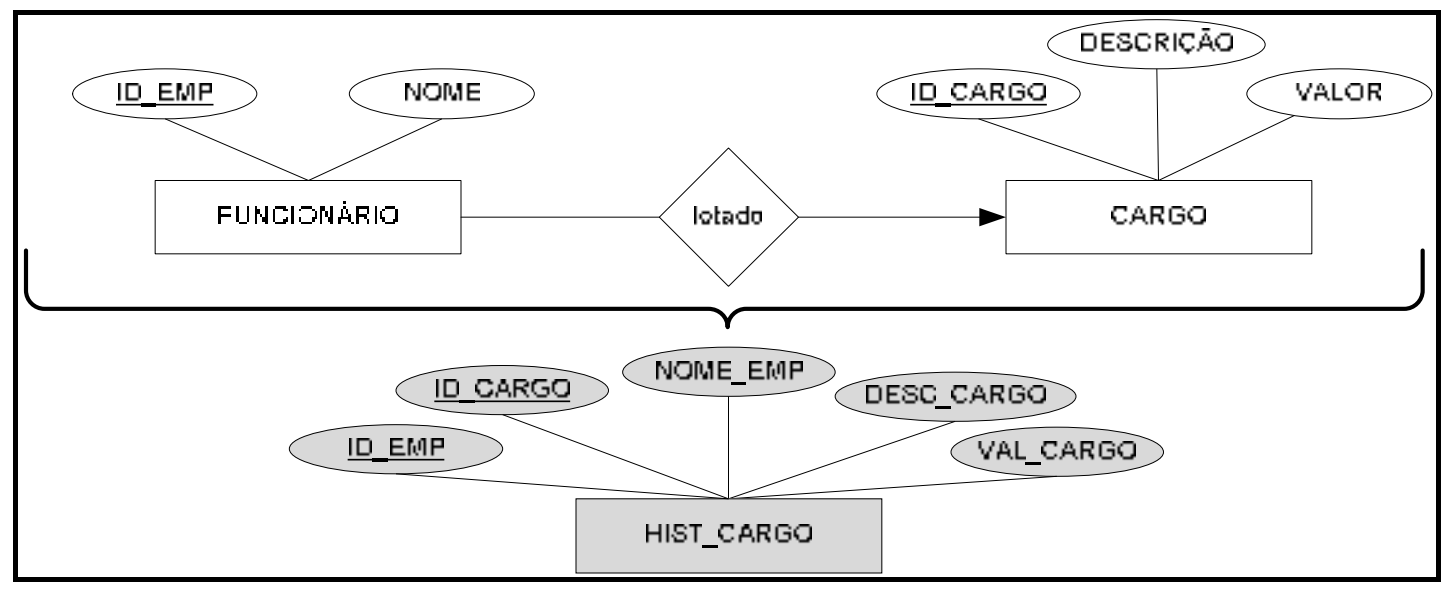

Figura 22. Exemplo do Passo B2

A tabela que seria criada no Banco de Dados Analítico-Temporal seria apenas aquela referente à entidade HIST_CARGO.

\subsubsection{Passo B3: Inclusão de elementos de tempo nos conjuntos de entidades}

\section{Justificativa}

É primordial, em alguns casos, a inclusão de atributos que controlarão os períodos nos quais os valores contidos nos conjuntos de entidades permanecerão válidos. Ou seja, em um período, determinado valor foi considerado válido. Para que isso seja possível, é necessária a inclusão de novos atributos de tempo para o controle dos períodos.

Dessa forma, a função deste passo é incluir, no Banco de Dados Analítico-Temporal, um ou mais elementos de "tempo", na estrutura de cada um dos conjuntos 
selecionados de entidades, a fim de possibilitar o armazenamento dos dados analítico-temporais, podendo, ou não, compor a chave primária existente.

Além disso, em alguns casos não basta apenas a inclusão de um elemento "tempo" na estrutura do conjunto de entidades. Pode ser necessária também, a adição de um novo conjunto de entidades, para que haja o armazenamento mais detalhado de todas as ocorrências de alteração de valores.

\section{Exemplo}

Seja o trecho de modelo de dados da Figura 23.

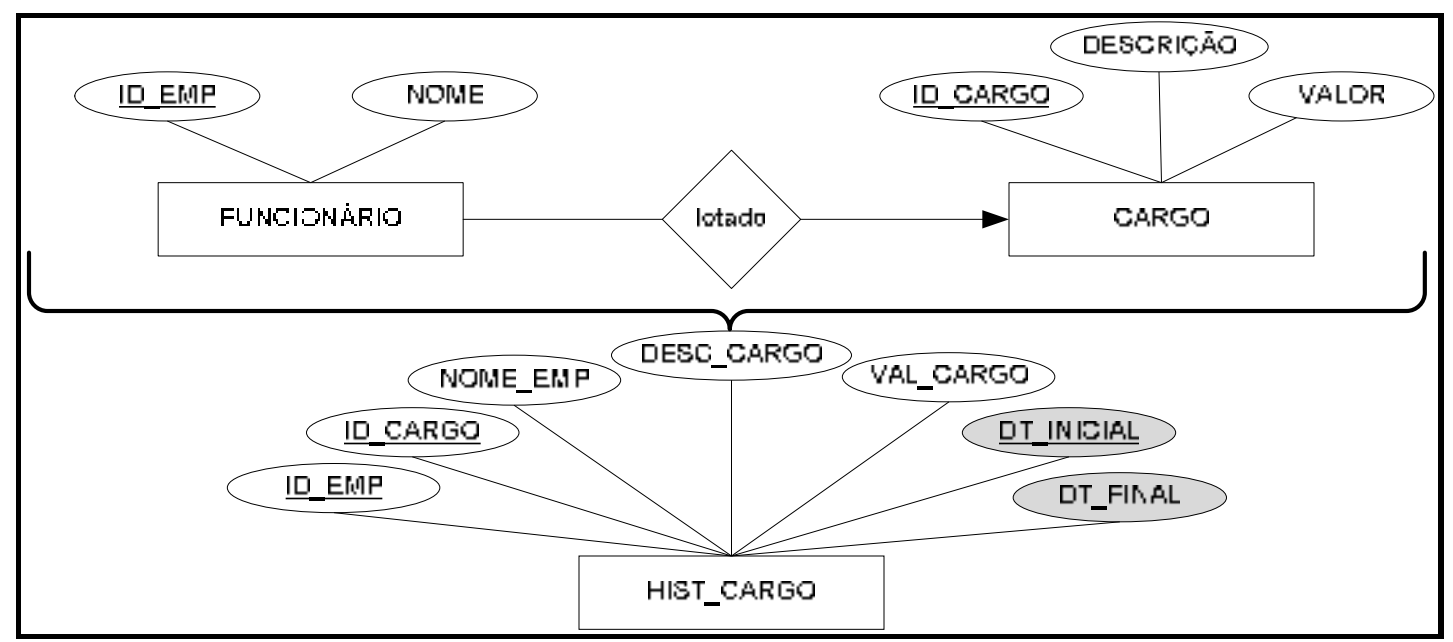

Figura 23. Exemplo do Passo B3

O objetivo é armazenar todos os cargos que um funcionário tenha ocupado na empresa, considerando-se também todos os períodos nos quais ocorreram essas mudanças. Os atributos DT_INICIAL e DT_FINAL referem-se à adição dos elementos de "tempo".

A tabela que seria criada no Banco de Dados Analítico-Temporal seria apenas aquela referente à entidade HIST_CARGO. 


\subsubsection{Passo B4: Inclusão de atributos derivados}

\section{Justificativa}

Em alguns casos, pode ser necessário realizar consultas muito complexas que impliquem acessar um grande volume de tuplas, juntamente com inúmeros cálculos. Isso poderá atrasar a obtenção das informações. Por isso, é necessário a adição de atributos derivados, já que tal procedimento pode eliminar a necessidade da realização de cálculos durante o processo de recuperação de valores.

A função deste passo é adicionar atributos totalizadores, derivados de outros atributos como, por exemplo: o total de uma venda; a idade de uma pessoa, dentre outros.

\section{Exemplo}

A Figura 24 ilustra a adição de um atributo derivado (elipse com fundo preenchido por cor cinza) em um conjunto de entidades HIST_VENDA, representando parte do Banco de Dados Analítico-Temporal. A parte de cima da figura representa parte de um modelo de dados operacional.

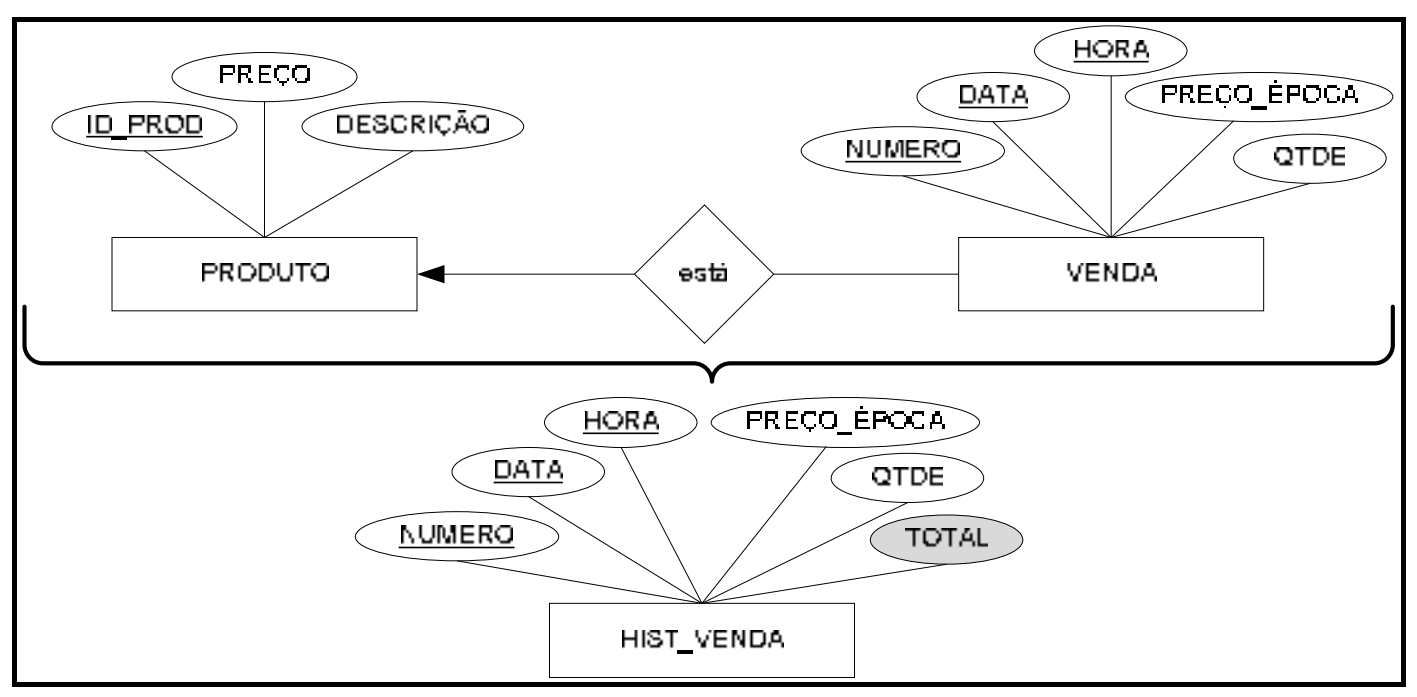

Figura 24. Exemplo 1 do Passo B4 
No exemplo, o atributo TOTAL é considerado um atributo derivado, já que se origina da multiplicação dos atributos PREÇO_EPOCA do produto com a quantidade (QTDE) vendida.

A tabela que seria criada no Banco de Dados Analítico-Temporal seria apenas aquela referente à entidade HIST_VENDA.

Como pode ocorrer a adição de atributos derivados de cálculos com base em um montante de tuplas, torna-se necessário o uso de procedimentos armazenados.

\section{Exemplo}

A Figura 25 lustra parte de um modelo de dados operacional.

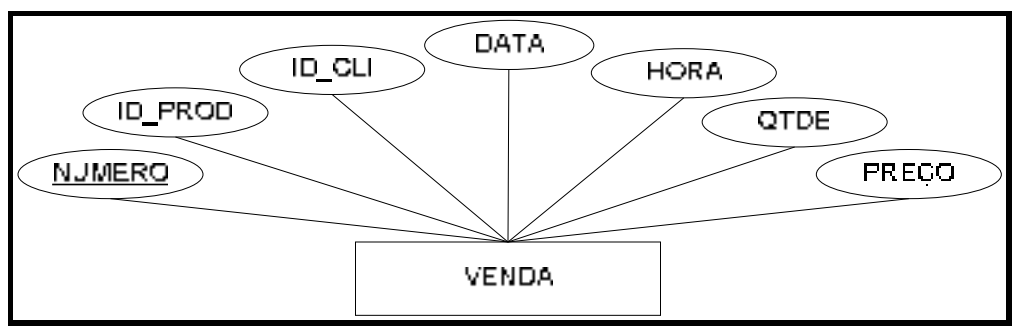

Figura 25. Entidade VENDA

Analisando o modelo de dados representado pela Figura 25, nota-se que pode ser necessário o cálculo de valores que envolvam faixas de períodos, tais como períodos semanais, mensais ou até mesmo anuais, de acordo com o agrupamento desses dados.

A Figura 26 ilustra um exemplo de cálculo cuja finalidade é agrupar e totalizar as vendas feitas mensalmente, por cliente e por produto. 


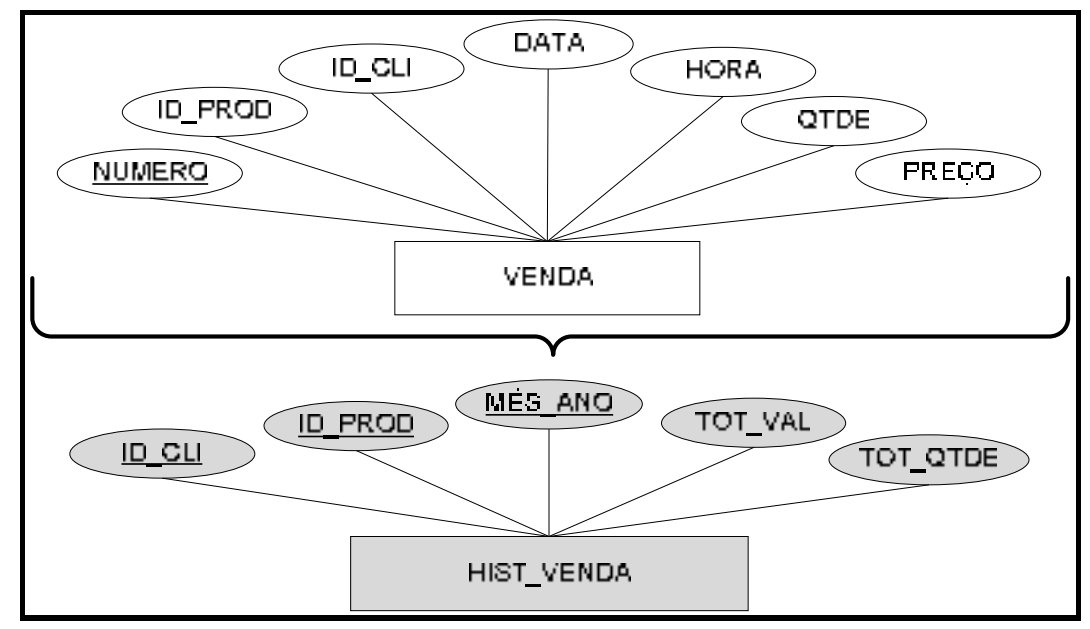

Figura 26. Exemplo 2 do Passo B4

O atributo TOT_VAL (QTDE*PREÇO) refere-se ao valor total das vendas realizadas dentro de cada mês e ano. O atributo TOT_QTDE refere-se à somatória da quantidade de produtos vendidos.

Assim, a tabela que seria criada no Banco de Dados Analítico-Temporal seria apenas aquela referente à entidade HIST_VENDA.

\subsubsection{Passo B5: Geração do Modelo de Dados Analítico-Temporal}

Após a aplicação de todos os passos componentes desta etapa, obtém-se o Modelo de Dados Analítico-Temporal. Este será utilizado para a criação do Banco de Dados Analítico-Temporal, com base no Modelo de Dados Operacional Unificado gerado na Etapa A.

\subsection{GERAÇÃO DOS DADOS ANALÍTICO-TEMPORAIS - ETAPA C}

Nesta seção, descrevem-se as atividades componentes da etapa de "Geração de Dados Analítico-Temporais" para o Banco de Dados Analítico-Temporal proposto.

Esta etapa tem por objetivo a geração, o transporte e o armazenamento de dados analítico-temporais, de forma dinâmica. Tais dados são originados dos Bancos de 
Dados Operacionais para o Banco de Dados Analítico-Temporal, por intermédio de gatilhos e procedimentos armazenados instalados nos Bancos de Dados Operacionais e de procedimentos armazenados instalados no Banco de Dados Analítico-Temporal.

Para a realização dinâmica dessa geração, é necessário algum controle sobre o Banco de Dados Operacional, que permita, a qualquer momento, a aquisição e o transporte dos dados para o Banco de Dados Analítico-Temporal. Por essa razão é que são utilizados gatilhos e procedimentos armazenados, visto que são os recursos dos Sistemas Gerenciadores de Bancos de Dados que permitem acompanhar as atualizações na base operacional e enviá-las para a base analítico-temporal (ITALIANO; FERREIRA, 2006).

Esse processo de geração, transporte e armazenamento deve ser iniciado com base nos Modelos de Dados Operacionais, bem como no Modelo de Dados AnalíticoTemporal, gerado como resultado da Etapa B.

A Figura 27 ilustra, de forma, geral como é desenvolvida esta etapa.

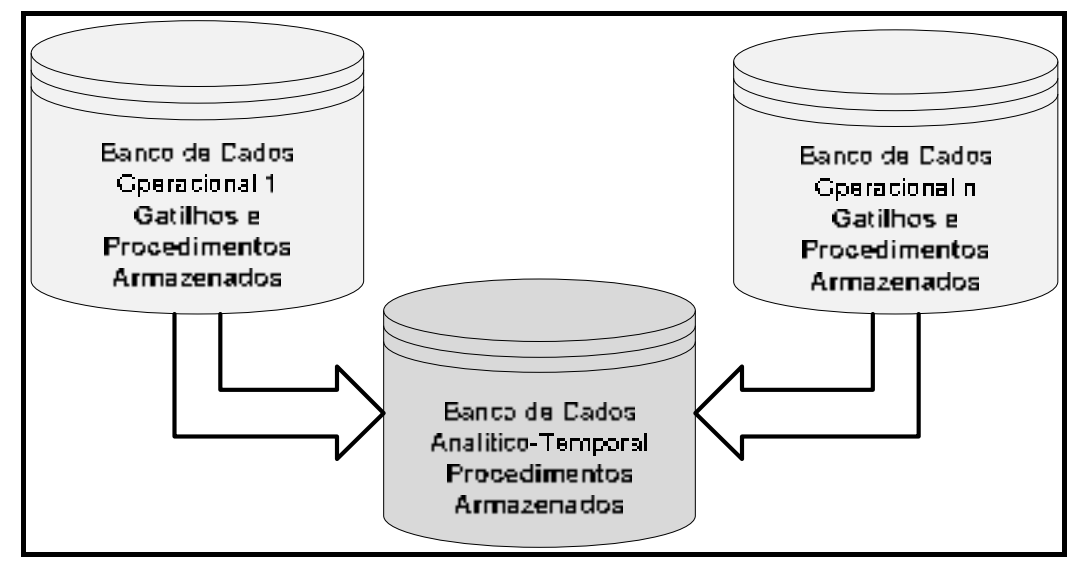

Figura 27 - Esquema Geral da Etapa C

A partir dos Modelos de Dados Analítico-Temporais é que serão criadas as estruturas que comporão 0 Banco de Dados Analítico-Temporal. Conseqüentemente, os scripts dos gatilhos e procedimentos armazenados devem ser criados com base na modelagem das etapas A e B. Além disso, deve ser elaborada a documentação de todo o processo de mapeamento, para que seja possível identificar os conjuntos de entidades origem, localizados nos Bancos de Dados Operacionais, e os conjuntos de entidades destino, localizados no Banco de 
Dados Analítico-Temporal, assim como toda a codificação dos subprogramas. Isso facilitaria a identificação da origem e do destino dos dados operacionais e/ou analítico-temporais.

A Figura 28 ilustra uma rede de comunicação entre servidores de bancos de dados, juntamente com as estações de trabalho (cliente), as quais, por sua vez, alimentam os Bancos de Dados Operacionais. O servidor que gerencia o Banco de Dados Analítico-Temporal recebe as atualizações vindas dos Bancos de Dados Operacionais.

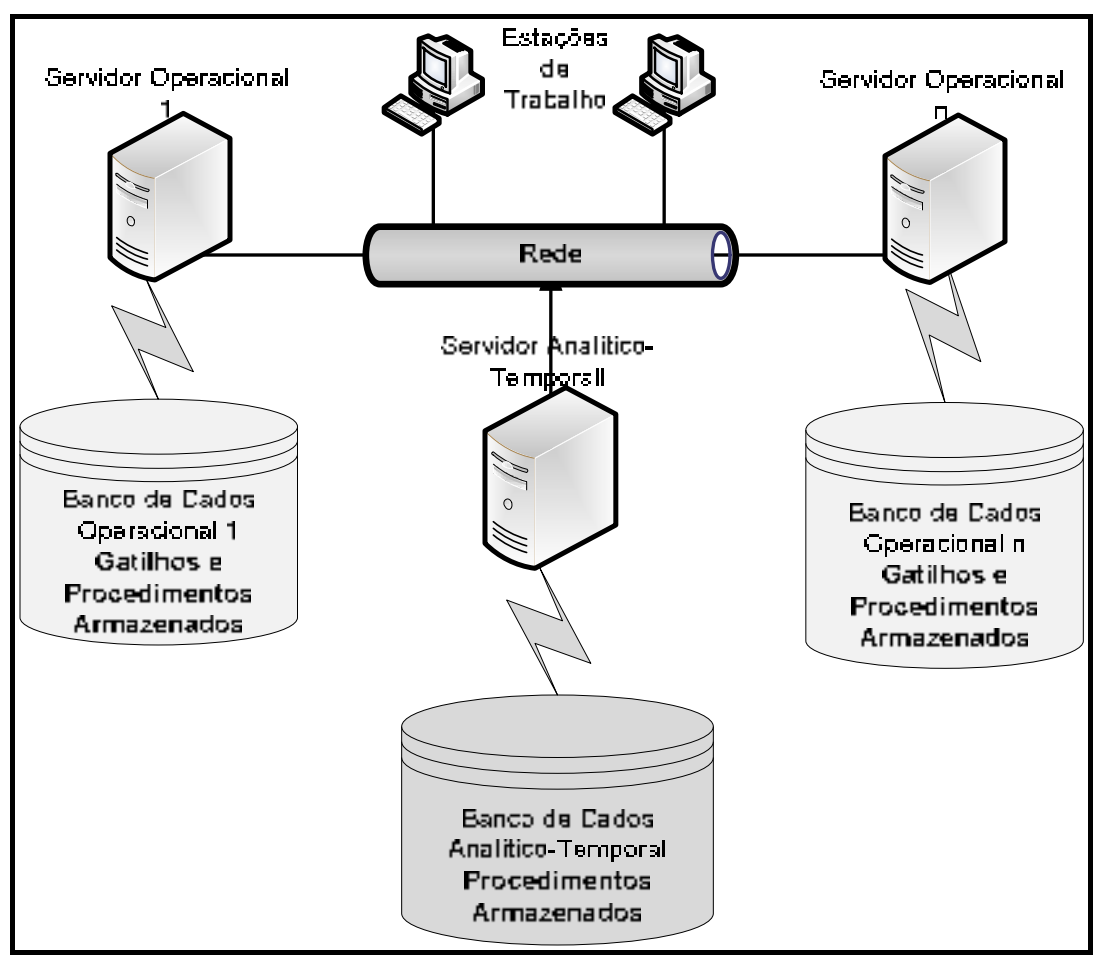

Figura 28. Esquema de Comunicação - Cliente/Servidor e/ou Servidor/Servidor

De uma maneira geral, a Figura 28 ilustra o que se pretende fazer, na prática, nesta etapa. Concebendo-se um Sistema Gerenciador de Bancos de Dados que trabalhe com a filosofia de cliente-servidor, cada cliente é uma aplicação, que solicita dados para um ou mais servidores.

As operações realizadas pelas aplicações dos usuários finais acionarão, automaticamente, os gatilhos e procedimentos armazenados programados diretamente nos Bancos de Dados Operacionais. Por meio desses mecanismos, pretende-se, transportar, remota e imediatamente, os dados para o Banco de Dados 
Analítico-Temporal, toda vez em que ocorrer alguma transação que afete as tabelas selecionadas para a geração de dados analítico-temporais. Isso poderá causar uma queda no desempenho das aplicações que utilizam os Bancos de Dados Operacionais. A análise de desempenho, porém, não faz parte do escopo da presente proposta de trabalho.

Conforme ilustrado na Figura 28, serão criados gatilhos somente nos Bancos de Dados Operacionais. Já os procedimentos armazenados poderão ser criados tanto nos Bancos de Dados Operacionais quanto no Banco de Dados Analítico-Temporal.

Os procedimentos armazenados nos Bancos de Dados Operacionais justificam-se pelo fato de que poderão ser utilizados para enviar dados já agrupados e sumarizados ao Banco de Dados Analítico-Temporal. Já no Banco de Dados Analítico-Temporal, os procedimentos armazenados são relevantes pelo fato de que podem ser utilizados para aumentar o nível de agrupamento ou até mesmo criar novos agrupamentos, caso seja necessário, sobretudo em se tratando do crescimento da base de dados analítico-temporal.

\subsubsection{Etapa C: Especificação dos Passos}

O propósito principal deste passo é desenvolver gatilhos e procedimentos armazenados genéricos, que servirão de padrão para a elaboração prática dos gatilhos e procedimentos armazenados considerados necessários para a geração de dados analítico-temporais.

Os exemplos utilizados neste item são os mesmos apresentados no desenvolvimento dos passos descritos nas Etapas A e B (Seção 3.3).

Os passos $A 1$ a A7, B1, B2 e B6 não envolvem a montagem de gatilhos e procedimentos armazenados e, por essa razão, não são detalhados nesta Etapa C.

As representações gráficas de todos os gatilhos e procedimentos armazenados são realizadas por intermédio de Fluxogramas, de acordo com as definições encontradas em Martin e McClure (1991) e em Peters e Pedrycz, (2000).

A Etapa C é composta por 3 passos, a seguir descritos. 


\subsubsection{Passo C1: Geração de Gatilho para o passo B3}

Este passo visa à criação de um gatilho para implementar o passo $\mathrm{B} 3$, anteriormente descrito, de acordo com o fluxograma da Figura 29.

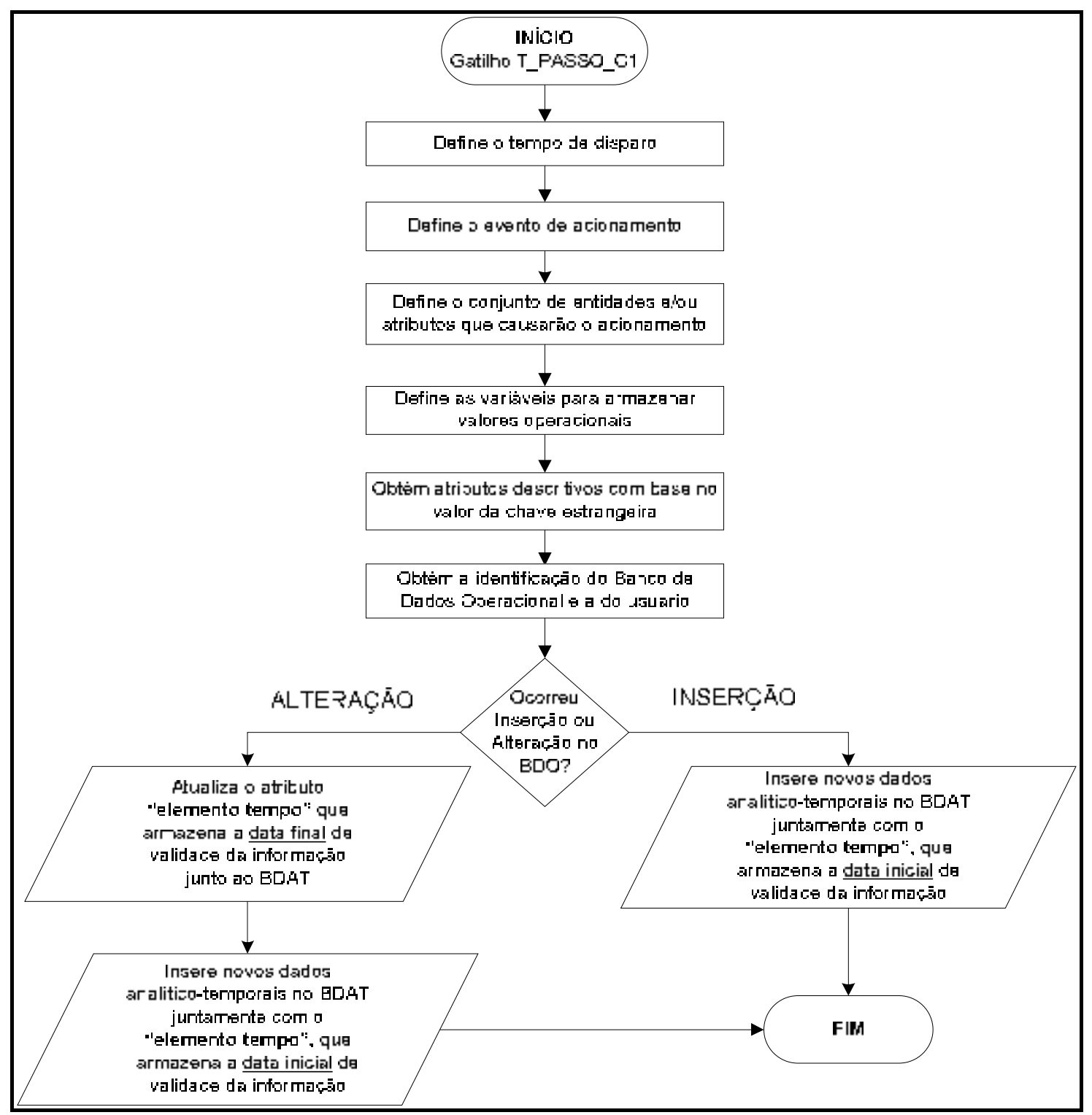

Figura 29. Fluxograma do Gatilho do Passo C1

A finalidade deste gatilho é enviar dados dos Bancos de Dados Operacionais para o Banco de Dados Analítico-Temporal. Isto, quando ocorrer alguma operação de inclusão e alteração nos conjuntos de entidades e/ou atributos dos Bancos de Dados 
Operacionais selecionados para a geração de dados analítico-temporais, bem como para o registro das épocas nas quais ocorreram as mudanças de valores dos dados operacionais, identificando-as no Banco de Dados Analítico-Temporal.

O script do gatilho genérico proposto para a realização deste passo está especificado na Figura 30.

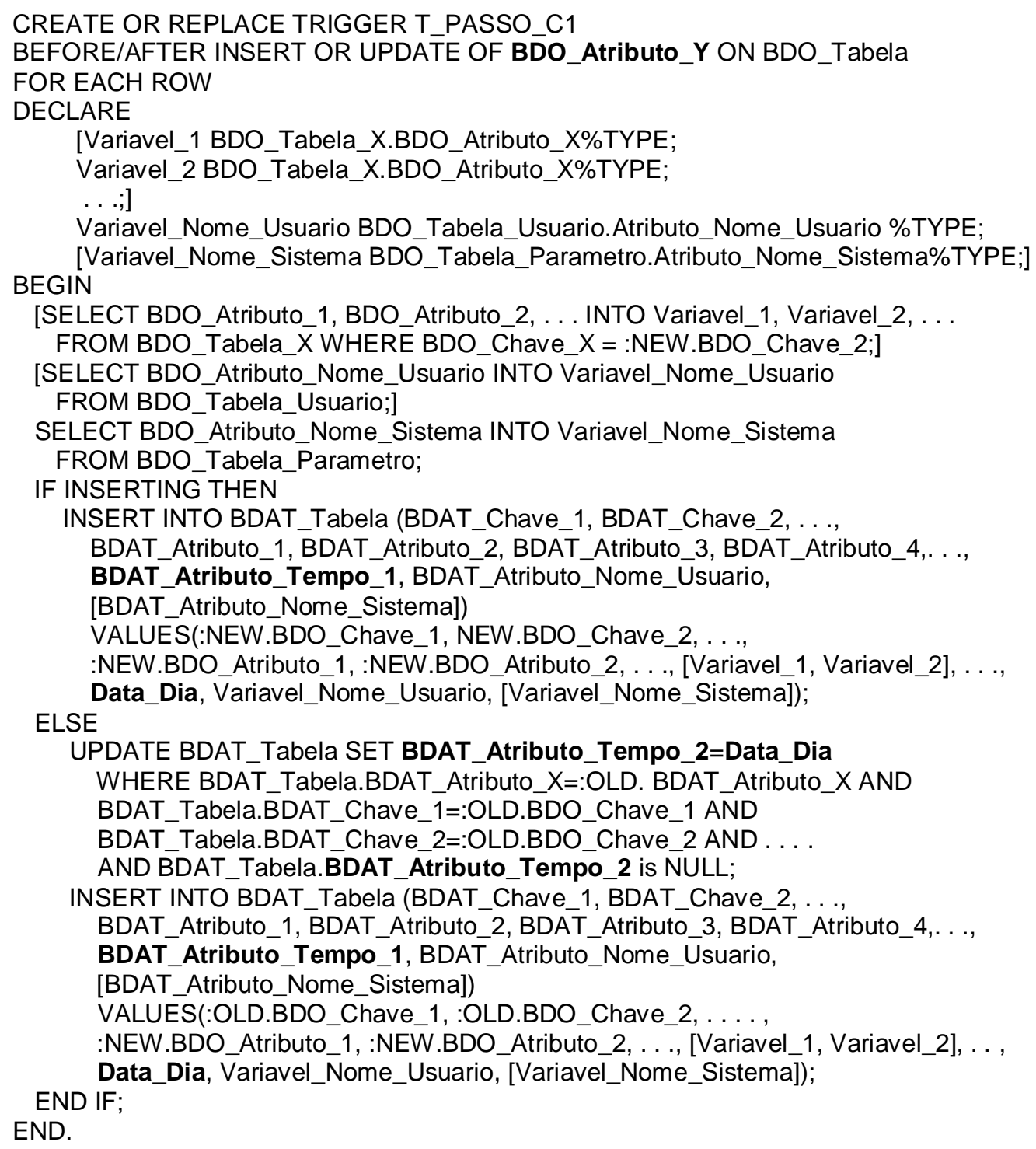

Figura 30. Especificação Genérica do Gatilho do Passo C1

$\mathrm{Na}$ Figura 31 está especificado o fluxograma para implementar o exemplo apresentado na Figura 23, cuja finalidade é armazenar no Banco de Dados Analítico-Temporal todas as mudanças de cargo que vierem a ocorrer em relação a 
cada um dos funcionários, bem como o período exato em que o funcionário ocupou determinado cargo. A especificação do gatilho pode ser encontrada no Apêndice A.

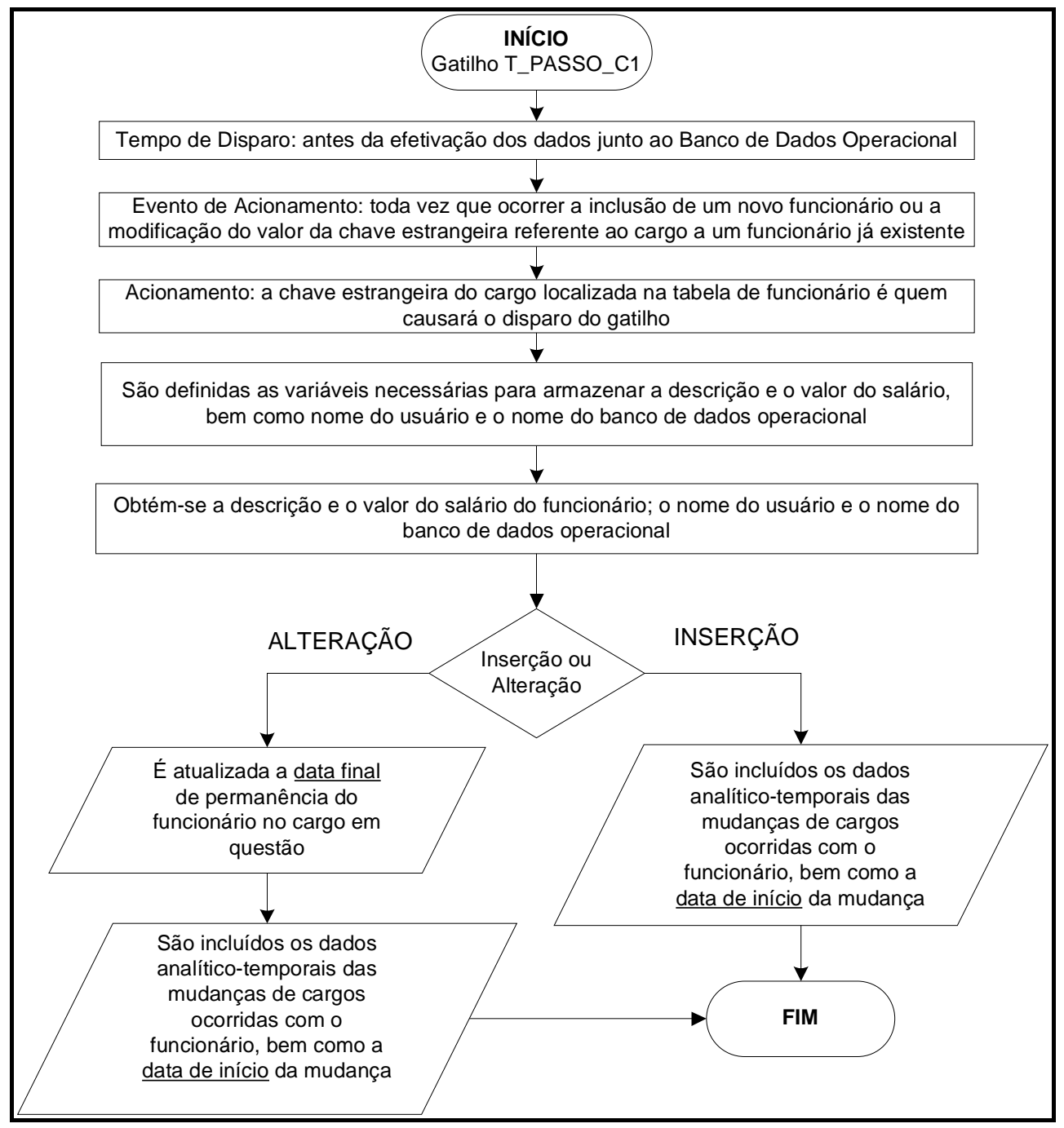

Figura 31. Fluxograma exemplo do Gatilho do Passo C1

\subsubsection{Passo C2: Geração de Gatilho para o Passo B4}

Este passo visa à criação de um gatilho para implementar o Passo B4, anteriormente descrito, de acordo com o fluxograma da Figura 32. 


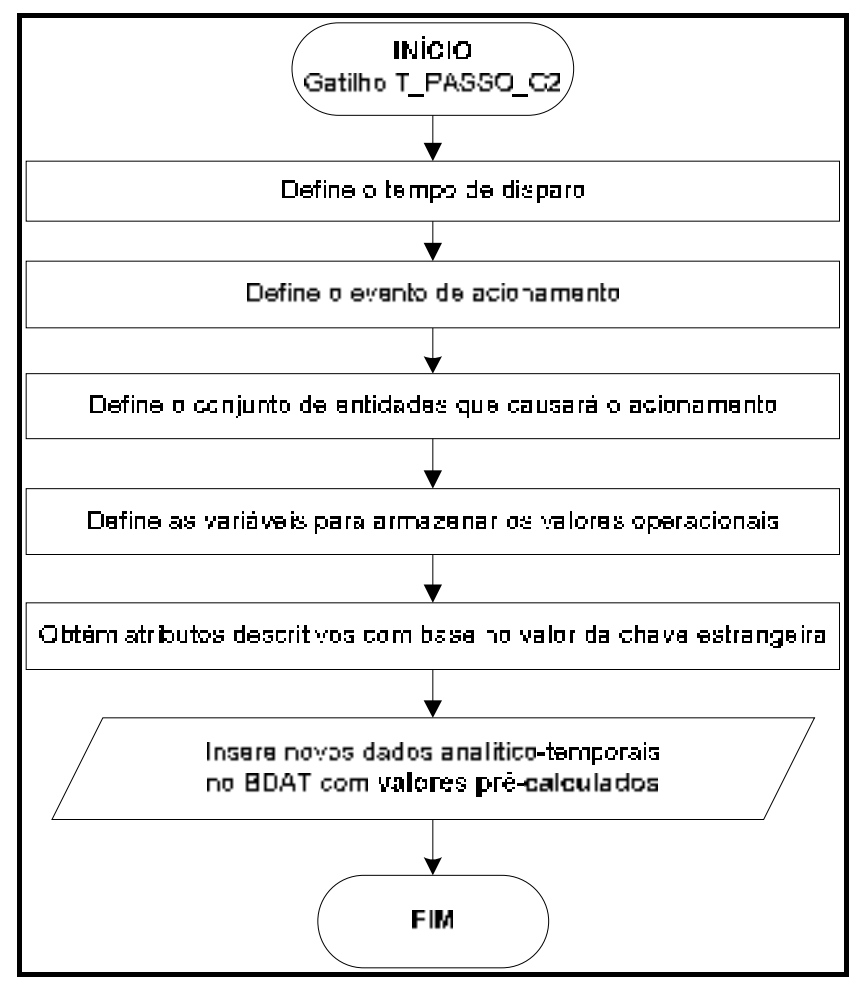

Figura 32. Fluxograma do Gatilho do Passo C2

Este gatilho visa a possibilitar o envio de valores pré-calculados, isto é, de "atributos derivados", provindos dos Bancos de Dados Operacionais para o Banco de Dados Analítico-Temporal, no caso de ocorrer alguma operação de inclusão nos conjuntos de entidades dos Bancos de Dados Operacionais.

O script do gatilho genérico proposto para a realização deste passo está especificado na Figura 33. 


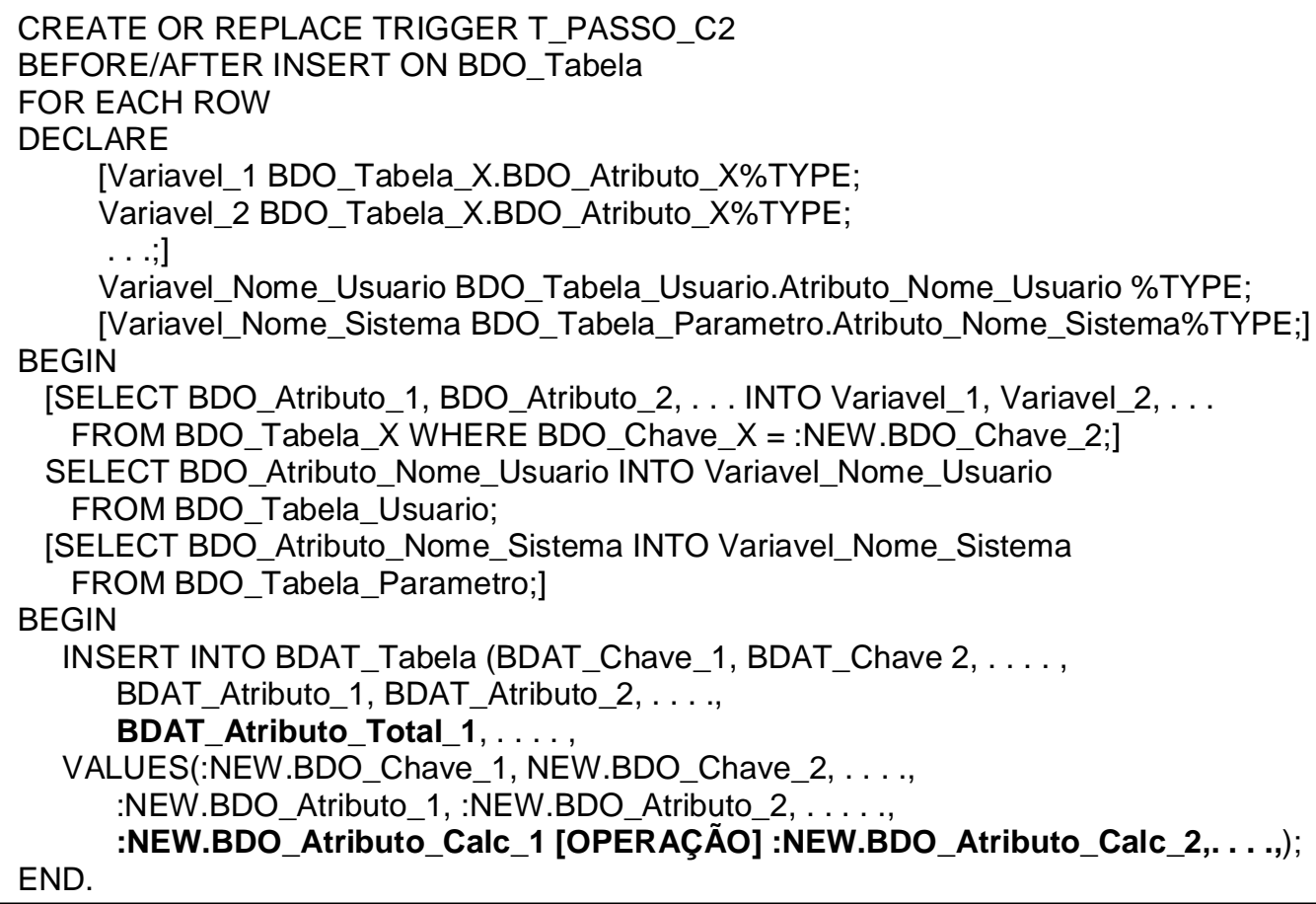

Figura 33. Especificação Genérica do Gatilho do Passo C2

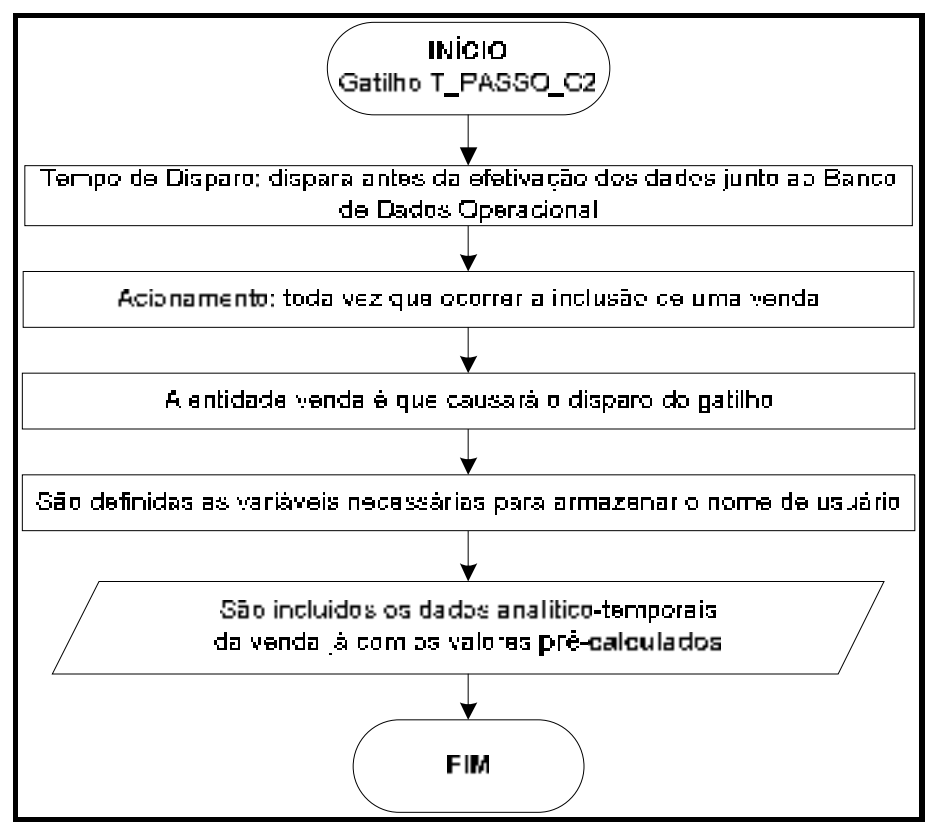

Figura 34. Fluxograma exemplo do Gatilho do Passo C2

$\mathrm{Na}$ Figura 34, está especificado o fluxograma para implementar o exemplo apresentado na Figura 24, cuja finalidade é armazenar no Banco de Dados 
Analítico-Temporal valores pré-calculados das vendas efetuadas junto ao Banco de Dados Operacional. A especificação do gatilho pode ser encontrada no Apêndice A.

\subsubsection{Passo C3: Geração de Procedimento Armazenado para o Passo B4}

Este passo destina-se à criação de procedimentos armazenados para implementar também o Passo B4, anteriormente descrito, de acordo com o fluxograma da Figura 35.

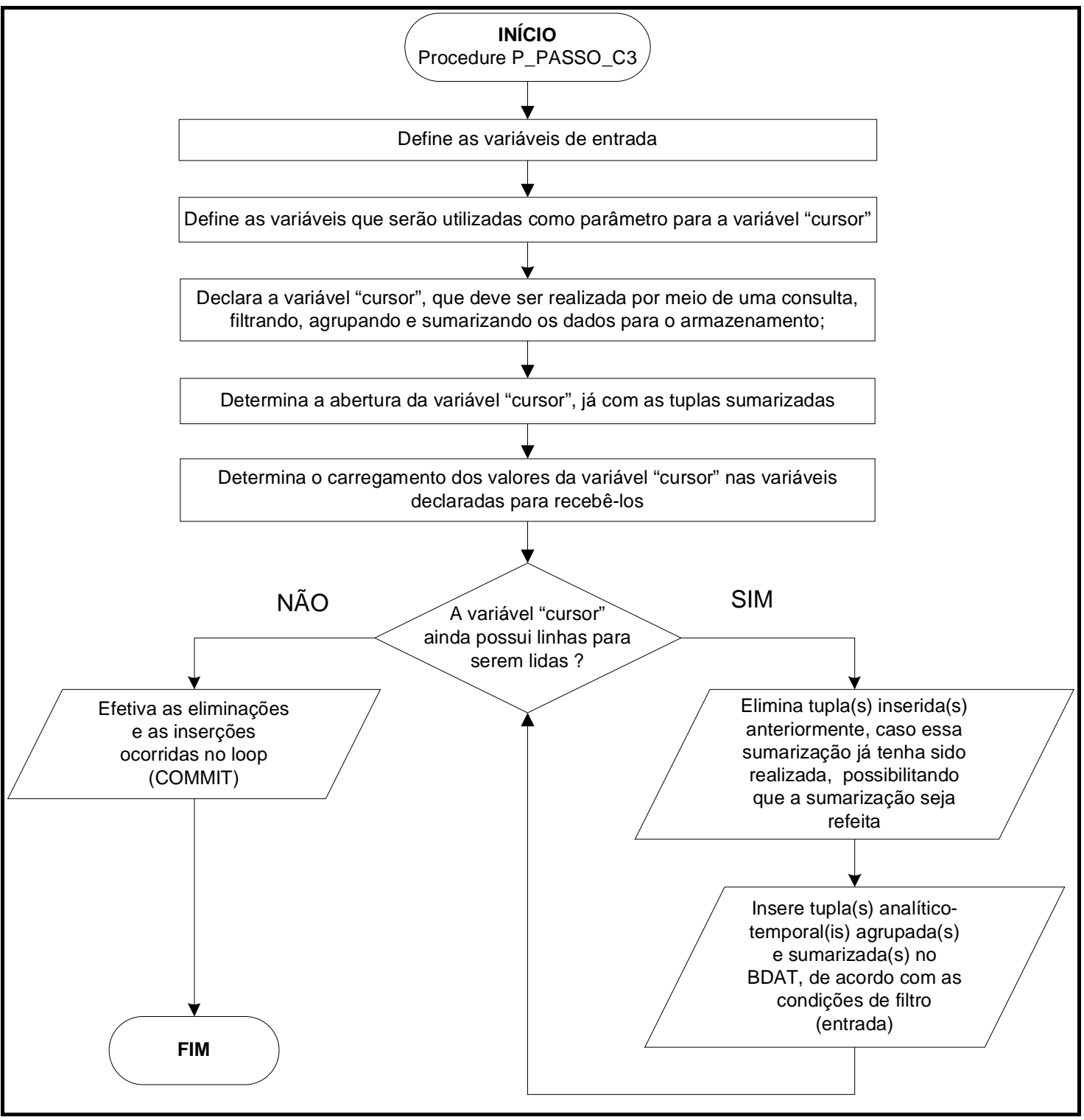

Figura 35. Fluxograma do Procedimento Armazenado do Passo C3 
Esse procedimento armazenado se destina a implementar a geração de atributos derivados, cujo cálculo e transferência dos dados não necessite ser realizados imediatamente após a ocorrência de modificações nos Bancos de Dados Operacionais. Os períodos de atualização devem ser pré-estabelecidos pelos administradores do banco de dados e analistas de negócios.

Portanto, a finalidade desse procedimento armazenado é gerar dados agrupados e totalizados, de acordo com uma periodicidade pré-estabelecida, podendo ser diária, semanal, etc.

O script do procedimento armazenado genérico proposto para a realização deste passo está especificado na Figura 36.

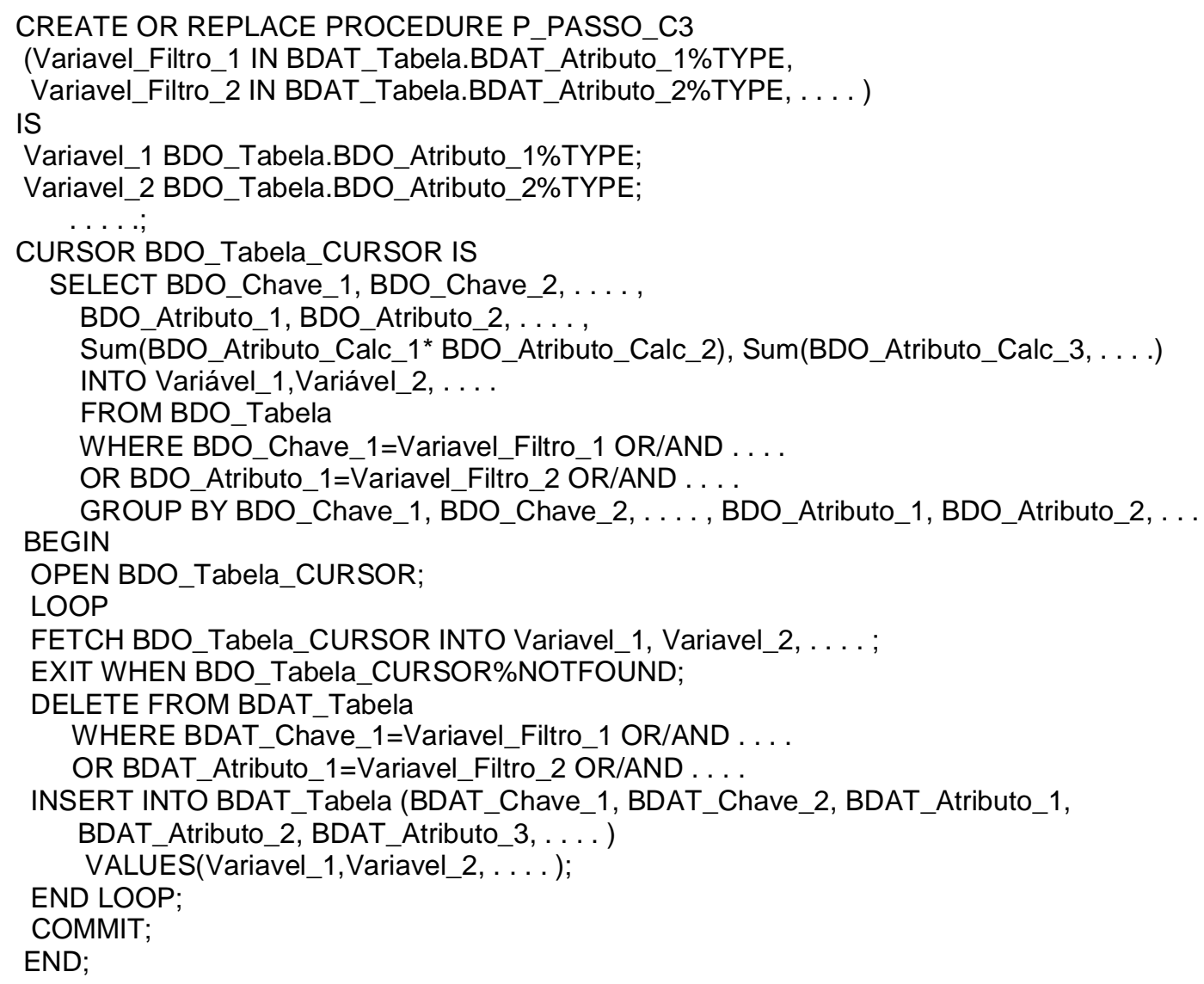

Figura 36. Especificação Genérica do Procedimento Armazenado do Passo C3

A Figura 37 especifica o fluxograma para implementar o exemplo apresentado na Figura 26, cuja finalidade é armazenar, no Banco de Dados Analítico-Temporal, as 
vendas totalizadas e agrupadas por cliente, produto, ano e mês. A especificação do procedimento armazenado pode ser encontrada no Apêndice A.

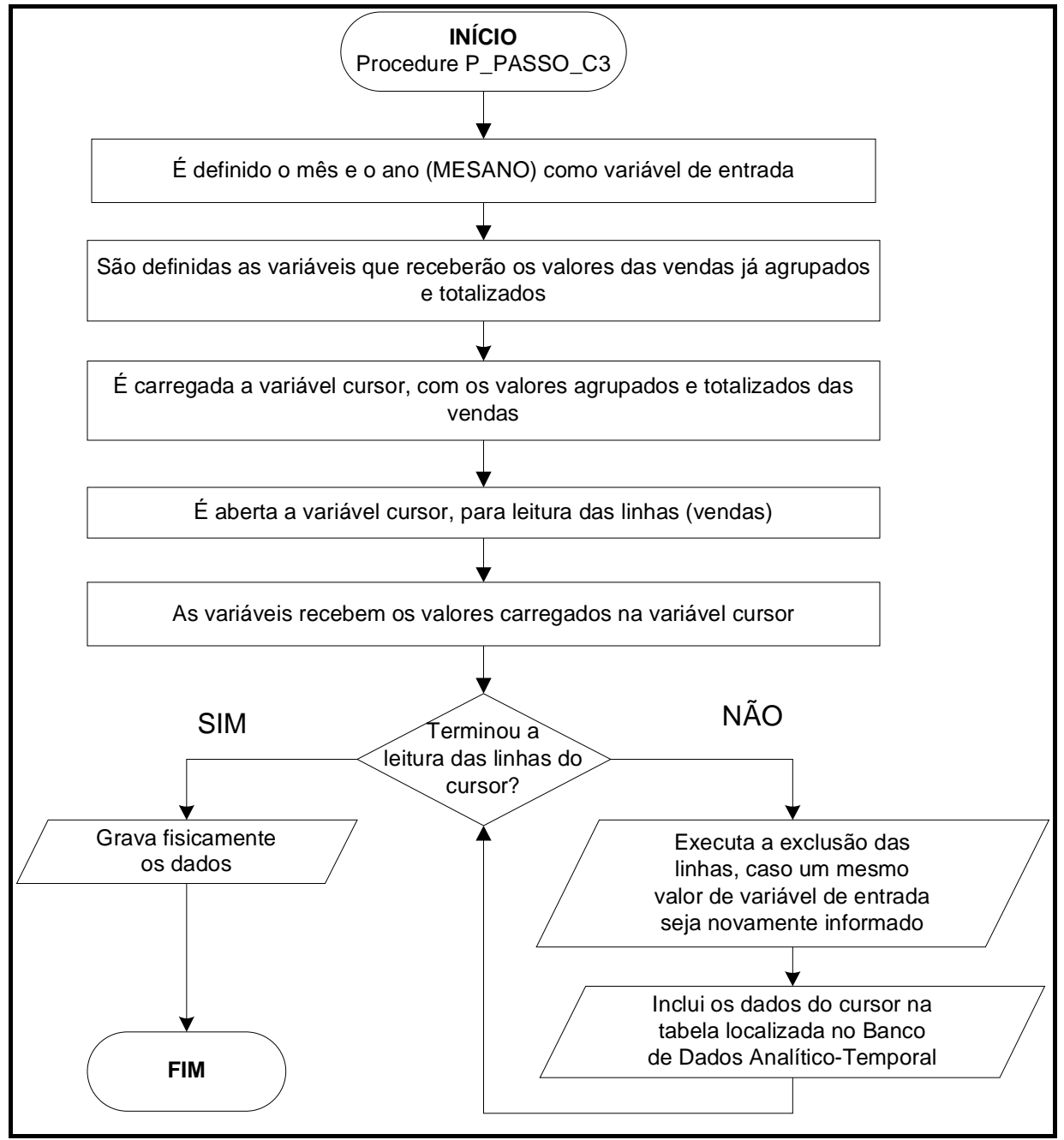

Figura 37. Fluxograma exemplo do Procedimento Armazenado do Passo C3 


\section{AVALIAÇÃO DO MODELO PROPOSTO}

Neste capítulo, é feita uma avaliação do Banco de Dados Analítico-Temporal proposto, por meio de um estudo comparativo, com os Bancos de Dados Operacionais e o ambiente de Data Warehousing. Realiza-se ainda uma comparação do modelo proposto com alguns trabalhos correlatos.

\subsection{AVALIAÇÃO DO MODELO DE BANCO DE DADOS ANALÍTICO- TEMPORAL PROPOSTO}

Neste item, é desenvolvida uma avaliação do modelo proposto, por meio de um estudo comparativo com os Bancos de Dados Operacionais e com os ambientes de Data Warehousing. Para isso, foram selecionados os aspectos mais relevantes, tanto no que se refere à finalidade desses bancos de dados, quanto no que diz respeito à modelagem propriamente dita.

\subsubsection{Processo de Tomada de Decisões}

O Banco de Dados Analítico-Temporal proposto foi modelado com o objetivo de oferecer informações para a tomada de decisões estratégicas de médio e longo prazos. Tais decisões constituem-se, basicamente, de aspectos gerenciais que necessitam abranger um grande volume de dados, tendo como base, principalmente, históricos armazenados ao longo do tempo. Normalmente, não há requisitos rígidos de desempenho para a obtenção desse tipo de dados, tendo em vista o tipo de aplicação a que se destinam.

A Figura 38 ilustra a comparação aqui desenvolvida no que concerne ao processo de tomada de decisões.

Os Bancos de Dados Operacionais são projetados para dar suporte às decisões diretamente ligadas ao negócio-fim das instituições, como, por exemplo, a venda de 
um produto, uma reserva de passagem ou o atendimento a um cliente. Esse tipo de aplicação contempla as decisões operacionais, que devem ter como base os conjuntos de dados mais recentes. Normalmente, os dados necessários a um processo de tomada de decisão operacional envolvem um número pequeno de registros e, se o Banco de Dados Operacional tiver sido adequadamente projetado, proporcionará resultados de forma rápida o suficiente para atender aos requisitos de desempenho estabelecidos.

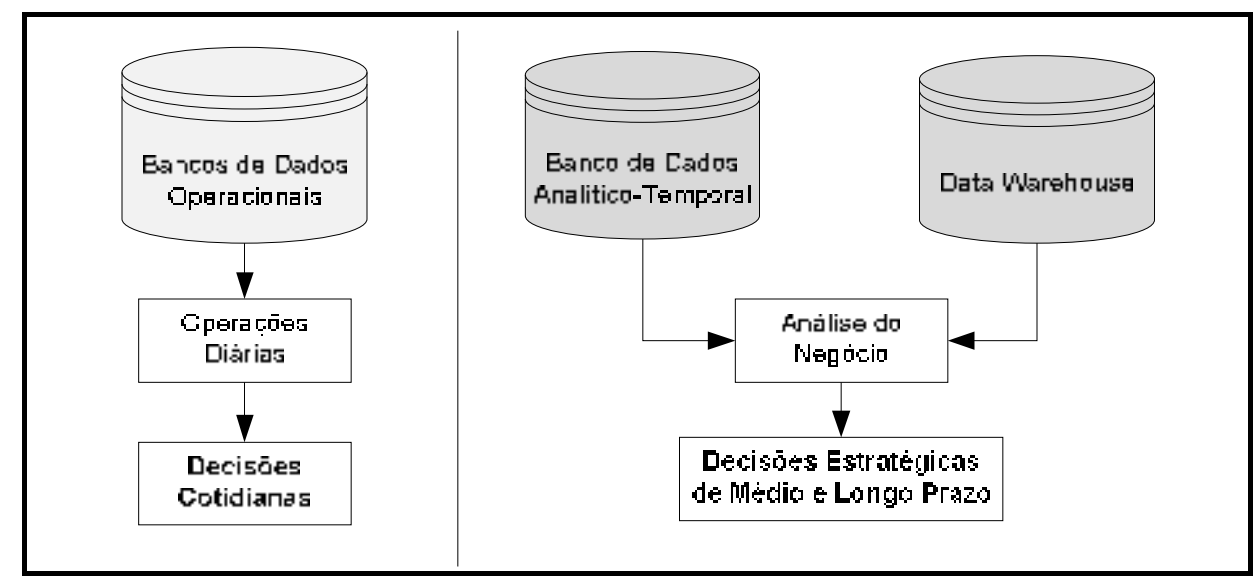

Figura 38. Comparação com relação ao processo de tomada de decisão

Comparando o modelo proposto com o ambiente de Data Warehousing, verifica-se que ambos visam a atender ao processo de tomada de decisões de médio e longo prazo. Assim, pode-se dizer que ambos os tipos de bancos de dados têm como objetivo básico, dar suporte às necessidades de obtenção de informações que possam auxiliar em decisões estratégicas, como por exemplo, o lançamento de uma nova linha de produtos, a abertura de uma nova filial ou ainda a criação de uma nova rota aérea.

Vale ressaltar que o modelo proposto é exclusivamente focado em organizações de pequeno e médio porte, diferentemente do ambiente de Data Warehousing, que além de englobar esses tipos de organizações, também se aplica a organizações de grande porte. 


\subsubsection{Forma de Modelagem}

A Figura 39 ilustra a comparação com relação à forma de modelagem entre o banco de dados proposto e os Bancos de Dados Operacionais.

Os Bancos de Dados Operacionais são projetados no sentido de evitar redundâncias de dados e garantir a integridade por intermédio de atributos "chaves estrangeiras". Noutros termos, esses bancos de dados devem atender às formas normais descritas pela teoria, sendo que, na maioria das vezes, buscam-se os graus mais altos de normalização.

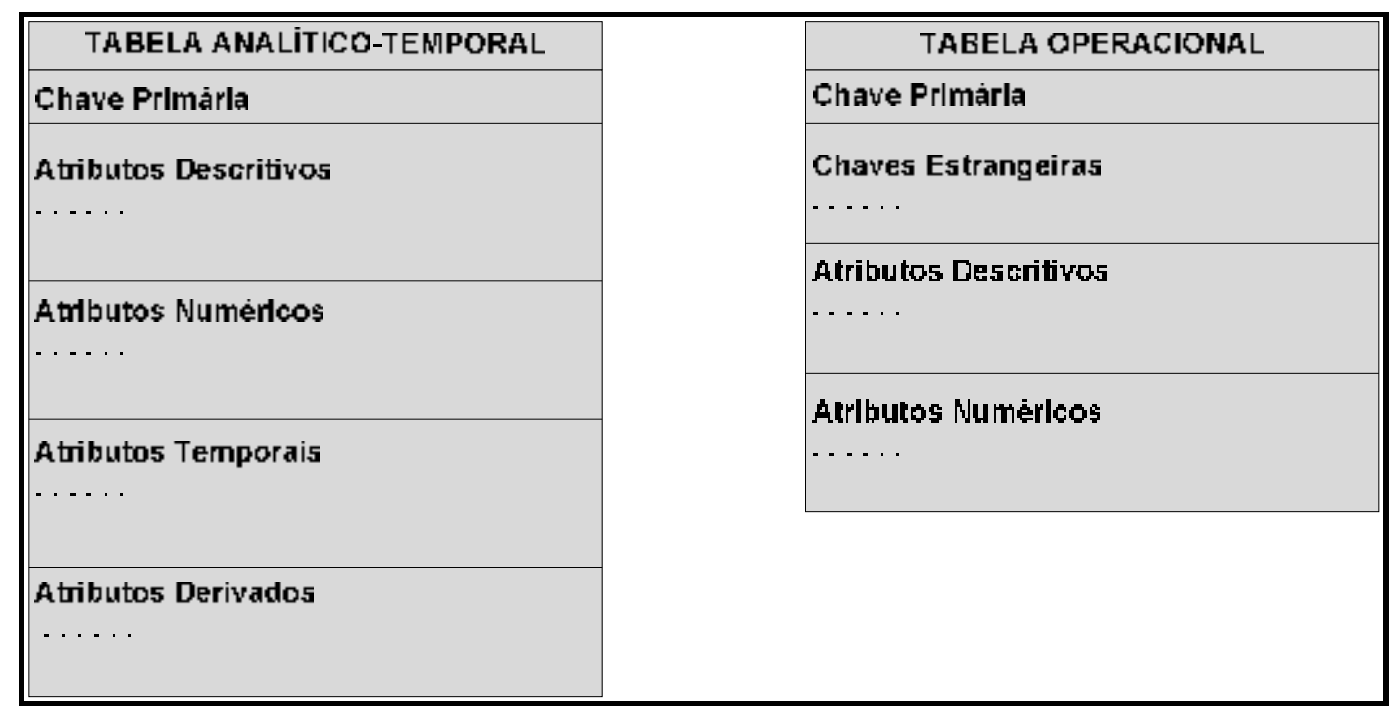

Figura 39. Comparação com relação à forma de modelagem entre o banco de dados proposto e os Bancos de Dados Operacionais

Já no Banco de Dados Analítico-Temporal proposto, as tabelas não são normalizadas. Além disso, há os atributos temporais e os atributos derivados, não necessários nos Bancos de Dados Operacionais, já que esse tipo de controle não faz parte das finalidades desse tipo de banco de dados.

A Figura 40 representa uma comparação do Banco de Dados Analítico-Temporal com os ambientes de Data Warehousing. As formas de modelagem entre esses dois bancos de dados são diferentes. 
Nos ambientes de Data Warehousing, utiliza-se, principalmente, a Modelagem Multidimensional, que faz uso de tabelas de fatos e de dimensões para projetar esse modelo. No modelo Analítico-Temporal proposto, tudo ocorre de maneira que as tabelas dimensão do modelo multidimensional estejam conjugadas com a tabela fato, gerando a chamada Tabela Analítico-Temporal. Assim, os atributos descritivos que, no modelo multidimensional, estão localizados nas tabelas "dimensão", no modelo analítico-temporal estão localizados na tabela "analítico-temporal". Os atributos numéricos do modelo analítico-temporal correspondem aos fatos do modelo multidimensional. Uma característica comum a ambos os modelos concentra-se no fato de que os mesmos não são normalizados.

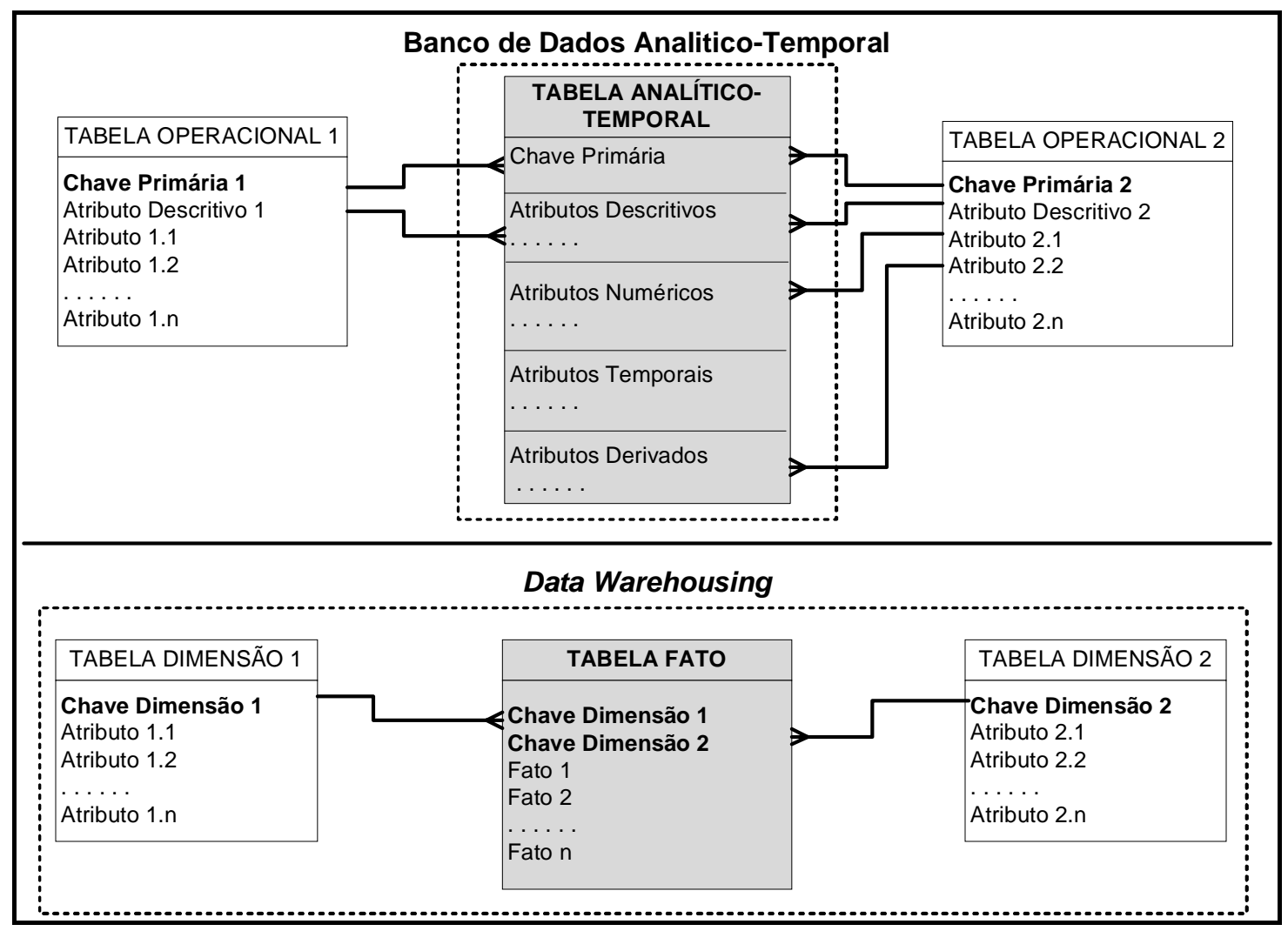

Figura 40. Comparação com relação à forma de modelagem entre o banco de dados proposto e os ambientes de Data Warehousing

Outro aspecto de destaque refere-se à facilidade de alterações nos modelos desenvolvidos, tendo em vista a boa modularidade da forma de modelagem proposta. Assim, alterações que se façam necessárias em virtude de mudanças nas especificações podem ser facilmente representadas no modelo proposto. Tal 
característica corresponde à flexibilidade de alteração de um modelo multidimensional, que pode ter, por exemplo, dimensões incluídas ou retiradas, ou ainda novos atributos numéricos inseridos na tabela fato.

\subsubsection{Qualidade de Dados}

Ao comparar o Banco de Dados Analítico-Temporal proposto com os Bancos de Dados Operacionais, nota-se que o primeiro tem por objetivo padronizar os dados, quando do processo de extração, transformação e carga, obtendo-se assim, uma melhora sensível de sua qualidade. Alguns aspectos de melhora são, por exemplo, a eliminação de dados duplicados (p.e., um mesmo cliente ser representado em vários registros), a uniformização de representações (p.e., unidades de medida), dentre outros.

Tendo em vista que a fonte dos dados é constituída pelos Bancos de Dados Operacionais, pode haver casos em que não seja possível uma plena correção de eventuais dados com problema, exigindo a implementação de políticas de correção dos dados diretamente no ambiente operacional.

Comparando o banco de dados proposto com os ambientes de Data Warehousing, nota-se uma semelhança quanto à preocupação com a qualidade dos dados. Isso

ocorre porque, nos ambiente de Data Warehousing, quando da realização do processo de extração, transformação e carga, também há as mesmas preocupações acima descritas para os Bancos de Dados Analítico-Temporais propostos, ou seja, obter dados precisos e de qualidade.

\subsubsection{Origem dos Dados}

Comparando-se o Banco de Dados Analítico-Temporal proposto com o ambiente de Data Warehousing, percebe-se que ambos os bancos de dados obtêm dados dos Bancos de Dados Operacionais. A exceção fica por conta dos ambientes de Data Warehousing, nos quais os dados podem também ter origem em fontes externas aos 
Bancos de Dados Operacionais, tais como arquivos texto, cotações de moedas, etc., o que não está previsto no Banco de Dados Analítico-Temporal aqui abordado, conforme apresentado na Figura 41.

Em se tratando de Bancos de Dados Operacionais, os dados são, em sua maioria, introduzidos de forma manual, salvo algumas exceções, tais como: importações de arquivos XML e arquivos texto e cálculos para atualização de dados.

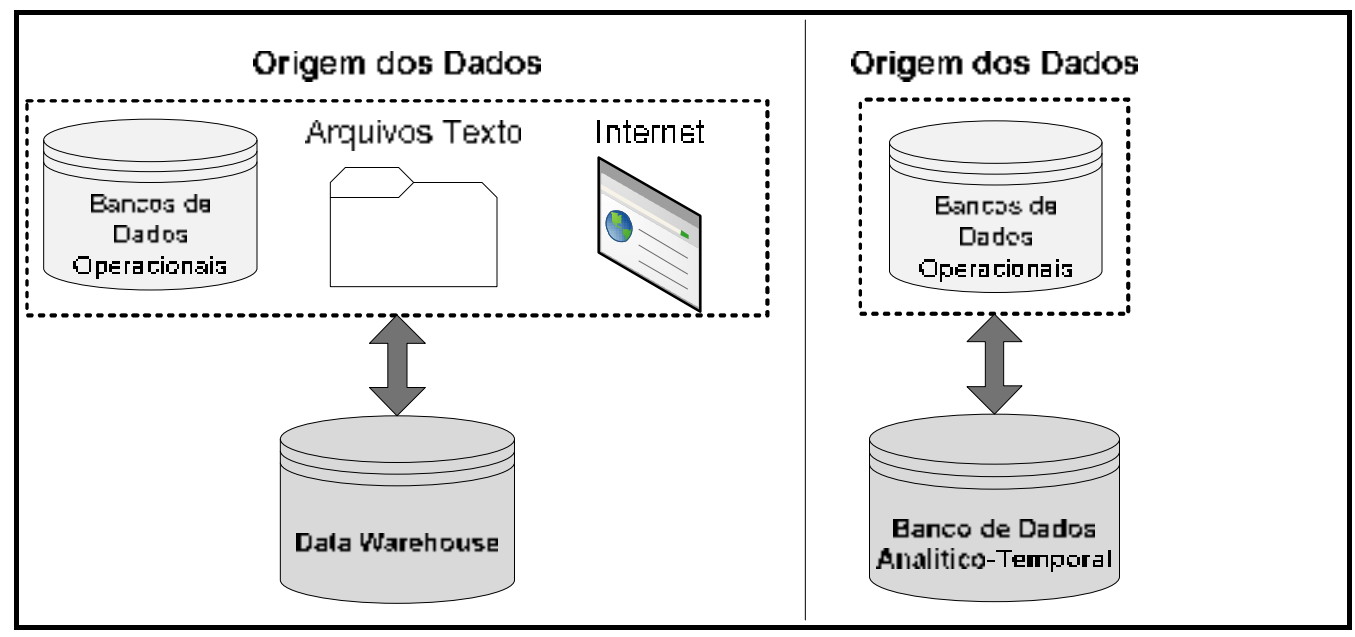

Figura 41. Comparação com relação à origem dos dados entre o banco de dados proposto e os ambientes de Data Warehousing

\subsubsection{Extração, Transformação e Carga}

Não há a necessidade da utilização de ferramentas comerciais para realizar o processo de extração dos dados dos Bancos de Dados Operacionais, bem como sua transformação e respectiva carga nos Bancos de Dados Analítico-Temporais. Tais atividades devem ser cumpridas por meio de gatilhos e procedimentos armazenados especificados, conforme esquematizado na Figura 42.

Essa característica representa um dos mais relevantes fatores a favor do Banco de Dados Analítico-Temporal proposto, tendo em vista que representa um grande ganho com relação ao tempo consumido na aplicação do processo de extração, transformação e carga em ambientes de Data Warehousing. Estatísticas mostram que esse processo pode consumir até $80 \%$ do tempo de desenvolvimento de um 
ambiente de Data Warehousing, bem como de seu orçamento. (VASSILIADIS; SIMITSIS; SKIADOPOULOS, 2002).

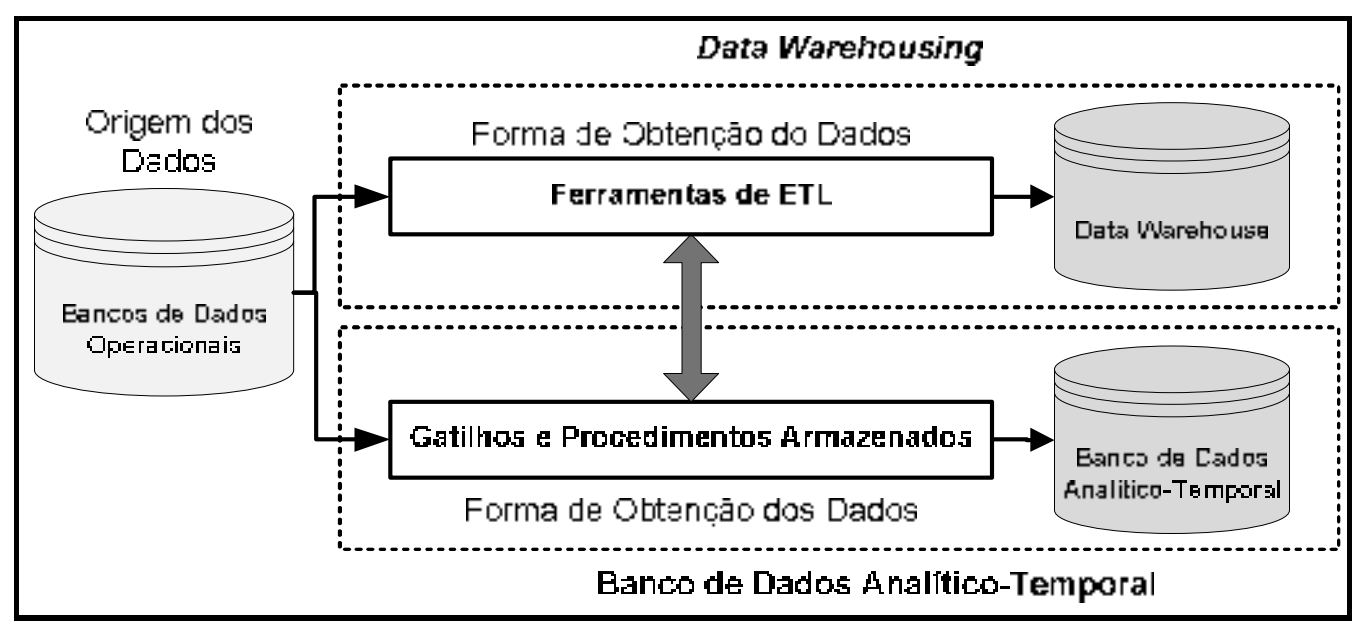

\section{Figura 42. Comparação com relação à origem e obtenção dos dados entre o banco de dados proposto e os ambientes de Data Warehousing}

Com o uso de gatilhos e procedimentos armazenados, pretende-se oferecer uma forma mais simples, disponibilizada pelos próprios Sistemas Gerenciadores de Bancos de Dados, para a geração e carga dos dados analítico-temporais.

Eventuais alterações no modelo do Banco de Dados Analítico-Temporal podem ser refletidas de forma bastante rápida nos gatilhos e procedimentos armazenados, tendo em vista a sua relativa simplicidade.

\subsubsection{Desempenho}

O modelo proposto não tem como uma de suas metas a questão de desempenho, uma vez que os problemas que procura resolver são de natureza estratégica, sem a necessidade de obtenção, quase que imediata, de respostas a consultas realizadas. Por outro lado, em se considerando os Bancos de Dados Operacionais, o aspecto de desempenho é essencial. As transações, necessariamente, devem oferecer resultados rápidos, para que se possam obter respostas rápidas o suficiente para atender às necessidades operacionais. Esse, alias, é um dos motivos que limita os 
Bancos de Dados Operacionais a não conterem um volume muito grande de dados, mantendo apenas os dados atuais.

Mesmo sem a finalidade primordial de oferecer um bom desempenho, é importante que os projetistas saibam antecipar as consultas mais freqüentes a serem feitas em um Banco de Dados Analítico-Temporal. Tal preocupação pode ser refletida nos atributos derivados presentes nas tabelas analítico-temporais, o que pode levar o Banco de Dados Analítico-Temporal a apresentar otimização em seu desempenho.

Comparando-se o banco de dados proposto com os Data Warehouses, percebe-se que se trata de bancos de dados bem similares, já que ambos devem se ocupar em oferecer dados estratégicos, sem a necessidade de respostas rápidas. Por outro lado, é possível que o banco de dados proposto poderá proporcionar um melhor desempenho, já que a Tabela Analítico-Temporal agrega também os atributos das tabelas "dimensão" (conforme já descrito) do modelo multidimensional, evitando a necessidade de realização de junções entre tabelas, quando da realização de consultas.

\subsubsection{Ferramentas de Consulta}

As ferramentas de consulta utilizadas nos ambientes de Data Warehousing são, geralmente, as ferramentas OLAP (OnLine Analytic Processing). Normalmente, tais ferramentas permitem múltiplas visualizações dos dados, refletindo a dimensão real do empreendimento, do ponto de vista do usuário.

Já nos Bancos de Dados Operacionais, o acesso aos dados é quase que exclusivamente realizado por intermédio de aplicações preparadas para os usuários finais. Dessa forma, esses usuários podem tanto manipular os dados quanto obter consultas e relatórios, por meio dessas aplicações.

No Banco de Dados Analítico-Temporal proposto, a idéia também é que sejam preparadas interfaces com os usuários, possibilitando aos mesmos o acesso às tabelas analítico-temporais. 
Portanto, o aspecto de diferenciação concentra-se na utilização de ferramentas OLAP, especificamente projetadas para uso com ambiente de Data Warehousing, não sendo adaptadas para interagir com outros ambientes.

Nessas três categorias de bancos de dados, também é possível executar diretamente instruções em SQL, desde que o ambiente em uso ofereça tal possibilidade.

A Figura 43 ilustra a comparação das ferramentas de consultas utilizadas pelos três tipos de bancos de dados.

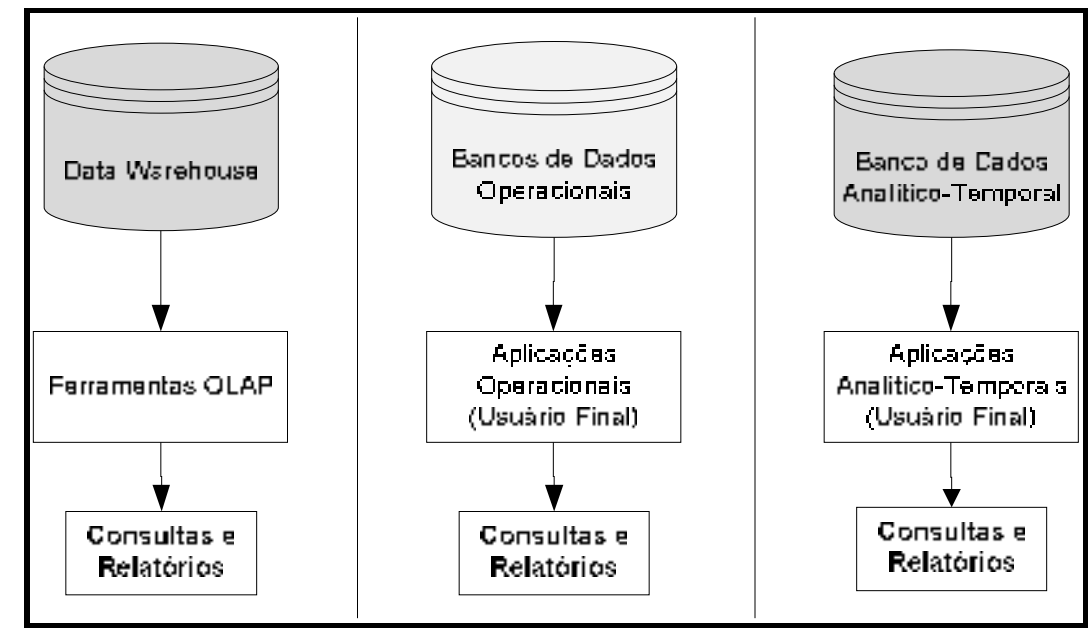

Figura 43. Comparação das ferramentas de consultas entre os três bancos de dados

\subsubsection{Atributos Derivados}

Os atributos derivados, ou ainda dados pré-calculados, podem ser comparados aos cubos dos Data Warehouses, cuja finalidade é a de, em se antecipando o cálculo das consultas mais freqüentemente realizadas, obter um ganho significativo no que se refere ao desempenho. Os atributos derivados têm o mesmo objetivo, oferecendo significativa vantagem de desempenho.

Assim, como nos ambientes de Data Warehousing, nos quais os cubos devem ser recalculados em intervalos previamente definidos, também os atributos derivados devem ter seus valores atualizados, conforme a necessidade. 
Nos Bancos de Dados Operacionais, não há a figura de atributos pré-calculados ou mesmo de cubos. O que se pode ressaltar é que esses valores de atributos derivados devem ter seus valores calculados pelos procedimentos armazenados, instalados junto aos Bancos de Dados Analítico-Temporais, aliviando uma eventual sobrecarga de processamento dos Bancos de Dados Operacionais.

\subsubsection{Histórico de Dados e Tempo de Armazenamento}

Considerando-se a questão do histórico de dados, verifica-se que tanto o Banco de Dados Analítico-Temporal, quanto os Data Warehouses, têm a função básica de armazenar dados por longos períodos de tempo, possibilitando a tarefa de tomada de decisões de médio e longo prazo, diferenciando-se principalmente na questão da forma de modelagem.

O tempo de armazenamento de cada conjunto de tabelas, tanto nos Bancos de Dados Analítico-Temporais, quanto nos Data Warehouses, vai depender do tipo de aplicação com a qual se estiver trabalhando. Mesmo após esse eventual "prazo de validade" ter expirado, os dados não devem ser simplesmente descartados, mas transferidos para um meio de armazenamento de massa.

Em se tratando de Bancos de Dados Operacionais, não faz sentido tal comparação, tendo em vista que estes últimos não são projetados para armazenar histórico de dados, uma vez que tal característica viria a atrapalhar as aplicações operacionais.

\subsubsection{Períodos de Atualização}

As atualizações ocorridas no Banco de Dados Operacional devem ser propagadas ao Banco de Dados Analítico-Temporal, imediatamente após o disparo de uma ocorrência no Banco de Dados Operacional. A idéia é a de ter um sincronismo quase que imediato entre os Bancos de Dados Analítico-Temporais e os Banco de Dados Operacionais. 
Essa atualização imediata não implica a existência de um sistema de tempo real, cujas exigências quanto à realização das atividades em tempos limites préestabelecidos é bastante rígida. Isso não ocorre no caso do tipo de atualização definido nesta tese.

Já em um ambiente de Data Warehousing, normalmente o intervalo de tempo entre duas atualizações consecutivas é bem maior, variando, por exemplo, de uma vez por dia até uma vez por mês, conforme a necessidade da aplicação.

Tal tipo de comparação não se aplica aos Bancos de Dados Operacionais, visto que estes constituem a própria fonte de dados, tanto dos Bancos de Dados AnalíticoTemporais, quanto dos Data Warehouses.

\subsubsection{Sobrecarga no Ambiente Operacional}

A forma e a freqüência de transferência dos dados dos Bancos de Dados Operacionais para o Banco de Dados Analítico-Temporal podem, de fato, causar um impacto no desempenho do ambiente operacional, tendo em vista que haverá um número maior de transações sendo efetuadas.

No entanto, considerando-se que a quantidade de registros a serem inseridos no Banco de Dados Analítico-Temporal não será grande, a cada disparo dos gatilhos inseridos no ambiente operacional, considera-se que a sobrecarga imposta não prejudique demasiadamente o seu desempenho. Além disso, é importante que sejam utilizados todos os mecanismos presentes nos Sistemas Gerenciadores de Bancos de Dados que possam vir a amenizar essa eventual sobrecarga, tais como indexação de atributos, dentre outros.

Deve-se ainda considerar que os procedimentos armazenados, responsáveis por calcular os atributos derivados, não são acionados a cada disparo dos gatilhos, amenizando consideravelmente a utilização do ambiente operacional.

As ferramentas ETL, normalmente utilizadas para o processo de extração, transformação e carga de dados para os ambientes de Data Warehousing, 
costumam, em geral, ocasionar considerável sobrecarga ao ambiente operacional. Por isso mesmo, tal processo é agendado para ocorrer nos períodos de menor utilização desse ambiente, como, por exemplo, nas madrugadas ou em finais de semana.

Conforme já comentado, os dados de origem do ambiente operacional são normalmente obtidos por digitação direta das informações. Por essa razão, fica sem sentido uma comparação quanto ao nível de sobrecarga para inserção dos dados.

\subsubsection{Modos de Atualização}

A Figura 44 ilustra a comparação relativa aos modos de atualização dos três tipos de bancos de dados aqui analisados.

A forma de utilização dos Bancos de Dados Operacionais impõe a necessidade de emprego das quatro operações básicas de um banco de dados, ou seja, inclusão, alteração, exclusão e consulta.

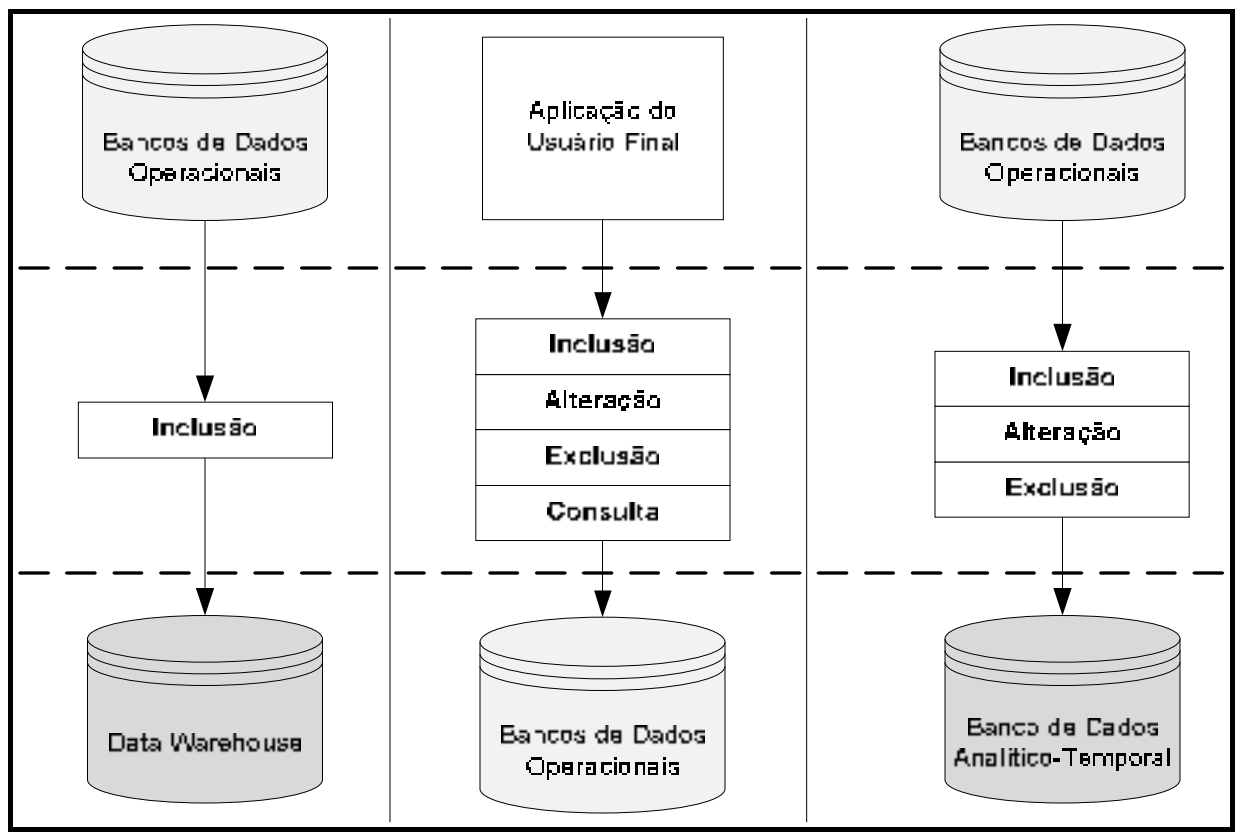

Figura 44. Modos de atualizações mais freqüentes nos três tipos de bancos de dados 
No Banco de Dados Analítico-Temporal proposto, observa-se que, além da operação de inserção, também podem ocorrer operações de alteração e de exclusão durante as atualizações, diferentemente ao que ocorre com os Data Warehouses. Nestes últimos, em geral, apenas a operação de carga é realizada. Os Data Warehouses são atualizados quase que exclusivamente por meio de inclusões de dados, não havendo, praticamente, a ocorrência de alterações. O processo de exclusão não está sendo considerado, por ocorrer quando os dados já não são mais necessários, sendo movidos para meios de armazenamento de massa.

A operação de exclusão poderá ocorrer concomitantemente a outras no Banco de Dados Analítico-Temporal, visto que, durante a execução dos procedimentos armazenados, é possível recalcular dados operacionais e reenviá-los ao Banco de Dados Analítico-Temporal. Para isso, torna-se necessário, antes do reenvio, eliminar essa faixa de dados, para que seja possível a regravação dos mesmos, evitando-se assim, a duplicação de valores.

A operação de alteração ocorrerá durante a execução dos gatilhos, já que, em determinados casos, será necessário fazer a atualização do elemento de tempo, responsável pela validade final de determinada informação.

\subsection{ESTUDO COMPARATIVO COM TRABALHOS CORRELATOS}

Esta seção tem por objetivo apresentar outros estudos feitos nessa área e mostrar em que tais pesquisas se assemelham ou diferem do presente trabalho.

Há os trabalhos que se intitulam "Sistemas de Bancos de Dados Temporais", com características e funcionalidades para o tratamento da temporalidade. Esses trabalhos, geralmente, focalizam mais a questão do controle do tempo das transações e validade dos dados. Não se tem, nesses trabalhos, a preocupação de oferecer uma metodologia para a modelagem unificada dos diversos Bancos de Dados Operacionais, bem como para a posterior modelagem de um Banco de Dados Analítico-Temporal. 
Um trabalho de proposta similar ao aqui apresentado é intitulado Implementação de Bancos de Dados Temporais com Versionamento: um estudo comparativo, de Santos (2003). O autor desenvolveu uma abordagem para a implementação de um Banco de Dados Temporal, permitindo o versionamento de esquemas e usando um banco de dados relacional, tendo como base o modelo TRM (Temporal Relational Model). Segundo o autor, o principal objetivo era avaliar as diferentes técnicas de implementação e gerenciamento de versionamento de esquemas em bancos de dados temporais.

A principal diferença entre o trabalho de Santos (2003) e a presente proposta é quanto ao gerenciamento do esquema conceitual. A presente proposta concentra-se em utilizar apenas um único esquema conceitual, não oferecendo histórico de estrutura de dados para realizar as mudanças de esquema, bem como o armazenamento dos dados no que se refere a mudanças de esquema. Já o referido trabalho concentra-se em utilizar um esquema para cada mudança ocorrida no esquema conceitual, ou seja, uma nova versão conceitual é definida toda vez em que ocorrer uma mudança no esquema conceitual, ocasionando a necessidade de adaptação dos dados junto às estruturas dos conjuntos de entidades armazenados a cada nova versão de esquema.

Outro aspecto importante de diferenciação entre os dois trabalhos é que a presente proposta possibilita também a aplicação de sumarizações e/ou totalizações de dados (alteração dos níveis de granularidade). O trabalho de Santos (2003) não trata, contudo, de tal questão.

Outros trabalhos que seguem essa mesma linha são os intitulados Gerenciador Temporal de Versões de Esquemas, de Angonese e Edelweiss (2001), e Evolução de Esquemas e Propagação de Mudanças usando o Modelo Temporal de Versões, de Galante, Edelweiss e Santos (2002). A diferença é que este último está centrado em bancos de dados orientados a objetos e no uso do modelo TVM (Temporal Version Model) para o controle de versionamento de esquemas.

Há os trabalhos de Moody e Kortnik (2000) e de Golfarelli, Maio e Rizzi (1998), nos quais podem ser encontradas formas de se converter um modelo entidaderelacionamento em um modelo multidimensional. Nesses trabalhos, as entidades 
são classificadas em três tipos: de transação (eventos que ocorrem no tempo, com medidas e quantidades), de componente (definem detalhes ou componentes das transações) e de classificação (são dependentes das entidades componentes, formando uma hierarquia). Após isso, eles identificam as hierarquias entre as entidades. Posteriormente efetuam a consolidação e a agregação dos dados.

Já no trabalho de Golfarelli, Maio e Rizzi (1998), primeiro são definidas as tabelas de fatos. Para cada tabela de fato, é montada a árvore de atributos. Depois, ela é cortada e são realizados enxertos na árvore de atributos. Em seguida, são definidas as tabelas de dimensões e os atributos para cada tabela de fatos e, finalmente são definidas as hierarquias, eliminando-se atributos sem interesse e atributos não multidimensionais.

Outra obra, muito recente, mas que também tem como foco geral preservar o histórico de um banco de dados relacional é o intitulado Bridging Relational Database History and the Web: the XML Approach de Wang, Zhou e Zaniolo (2006). Nesse trabalho, os autores observam que a preservação de artefatos digitais representa um desafio sem resposta para a sociedade de informação moderna.

O referido trabalho é muito importante, visto que despertou significativo interesse em integrar sistemas gerenciadores de bancos de dados tradicionais com o XML, devido aos sensíveis benefícios obtidos nas aplicações da Web.

Um exemplo é o projeto intitulado "AUDESP" - Auditoria Eletrônica de Órgãos Públicos, criado pelo Tribunal de Contas do Estado de São Paulo, por meio do qual todas as organizações públicas deverão fornecer suas informações fiscais (atuais e passadas) em formato XML, na Web, a partir de 2008. Em 2007, serão permitidos testes, adaptações e aprimoramentos e, a partir de 2008, será obrigatório que todas as organizações públicas atendam à exigência. A imposição está levando as empresas desenvolvedoras e fornecedoras de softwares comerciais a reestruturarem boa parte das rotinas atuais de seus programas e a desenvolverem novas rotinas em XML, bem como alterações nos modelos de dados e dos esquemas físicos, possibilitando o armazenamento dos históricos de dados (http://www.tce.sp.gov.br). 
O trabalho aqui proposto difere do trabalho de Wang, Zhou e Zaniolo (2006) e de Grandi et al. (2003), intitulado A Temporal Data Model and Management System for Normative Texts in XML Format. No presente caso, faz-se uso de gatilhos e procedimentos armazenados para o transporte dos dados analítico-temporais, mantendo-os em um outro banco de dados, separado dos dados operacionais.

Um modelo de dados existente e que também trabalha a questão do armazenamento de dados temporais é o TF-ORM ( Temporal Functionality in Objetcs with Roles Model). Ele associa informações temporais às propriedades que podem mudar de valor ao longo do tempo (EDELWEISS, 1998; HÜBLER; EDELWEISS, 2001). A principal diferença, é que TF-ORM é um modelo de dados orientado a objetos que utiliza o conceito de papéis para representar os diferentes comportamentos dos objetos. De outro lado, a presente proposta de trabalho é direcionada somente a modelos de dados relacionais.

A principal diferença está no fato de que esta pesquisa se propõe a oferecer uma metodologia para o mapeamento dos dados analítico-temporais, partindo desde a unificação dos Bancos de Dados Operacionais até a definição do modelo de dados analítico-temporal, o que culminará na construção do Banco de Dados AnalíticoTemporal. Além disso, esta proposta também se diferencia das demais em relação à forma de armazenamento dos dados analítico-temporais, visto que ela propõe armazenar os dados analítico-temporais em uma outra base de dados, definida como "Banco de Dados Analítico-Temporal" (BDAT). Outra peculiaridade deste estudo refere-se à forma de enviar os dados operacionais para o Banco de Dados Analítico-Temporal, já que são utilizados recursos oferecidos pelos próprios Bancos de Dados Relacionais, tais como gatilhos e procedimentos armazenados. Em suma, esta proposta prevê a aplicação de diferentes níveis de granularidade quanto à forma de armazenamento, diferentemente das demais concepções. 


\section{ESTUDO DE CASO}

Neste capítulo é apresentado um estudo de caso com o objetivo de aplicar a proposta de modelagem e implementação aqui apresentada.

A implementação do estudo de caso foi realizada na Fundação Educacional do Município de Assis, mais conhecida por FEMA, localizada na cidade de Assis, interior do estado de São Paulo.

\subsection{DESCRIÇÃO DAS APLICAÇÕES OPERACIONAIS}

As aplicações operacionais a serem utilizadas são: Folha de Pagamento, do setor de Recursos Humanos e Controle Acadêmico do setor de Supervisão Acadêmica. Essa escolha ocorreu após algumas discussões com a equipe de desenvolvimento de sistemas do Centro de Pesquisas em Informática (CEPEIN) e com os responsáveis pelos setores envolvidos, já que esses setores encontram muitas dificuldades quando Ihes são solicitadas, pela supervisão, informações históricas, bem como uma simples recuperação de dados anteriormente modificados.

O nome de serviço de banco de dados da aplicação de Folha de Pagamento será "BDO_FOLHA", representando o Banco de Dados Operacional $1\left(\mathrm{BDO}_{1}\right)$; o da aplicação de Controle Acadêmico será "BDO_ACADEMICO", representando o Banco de Dados Operacional $2\left(\mathrm{BDO}_{2}\right)$.

\subsubsection{Folha de Pagamento (BDO_FOLHA)}

A Folha de Pagamento é a aplicação responsável por armazenar e recuperar todas as informações cadastrais, desde os pagamentos aos funcionários, até as informações para o governo federal, referentes a recolhimento de impostos. Esta aplicação foi desenvolvida com a ferramenta Visual Basic. 


\subsubsection{Controle Acadêmico (BDO_ACADEMICO)}

O Controle Acadêmico é a aplicação responsável por armazenar e recuperar todas as informações cadastrais referentes aos alunos, professores, disciplinas, cursos, notas e faltas, etc. Ou seja, tudo o que se refere ao setor acadêmico.

Essa aplicação foi desenvolvida com a ferramenta Visual Basic, mas mantém algumas rotinas em Java, disponibilizadas no site da Instituição. São rotinas integradas, que possibilitam ao quadro discente consultar informações sobre os cursos, tais como as grades dos cursos, faltas e substituições de professores, etc., bem como médias e faltas. Para o quadro de docentes, existem rotinas que possibilitam a digitação de médias semestrais, a atualização de planos de curso, de trocas de aula, dentre outras possibilidades.

\subsection{MODELAGEM DOS BANCOS DE DADOS OPERACIONAIS}

Deve-se destacar que não são ilustrados, por completo, os modelos de dados dos referidos sistemas e, sim, partes dos mesmos. Essas partes são suficientes para ilustrar o estudo de caso. Foi reduzido tanto o número de conjunto de entidades, como a quantidade de seus respectivos atributos.

\subsubsection{Modelo de Dados da Folha de Pagamento}

A Figura 45 ilustra parte do Modelo de Dados referente ao Sistema de Folha de Pagamento, que representa o Banco de Dados Operacional "BDO_FOLHA".

Os scripts para a criação dos conjuntos de entidades do Banco de Dados Operacional BDO_FOLHA, bem como o script para a criação da conexão entre os bancos de dados, podem ser encontrados no Apêndice B. 


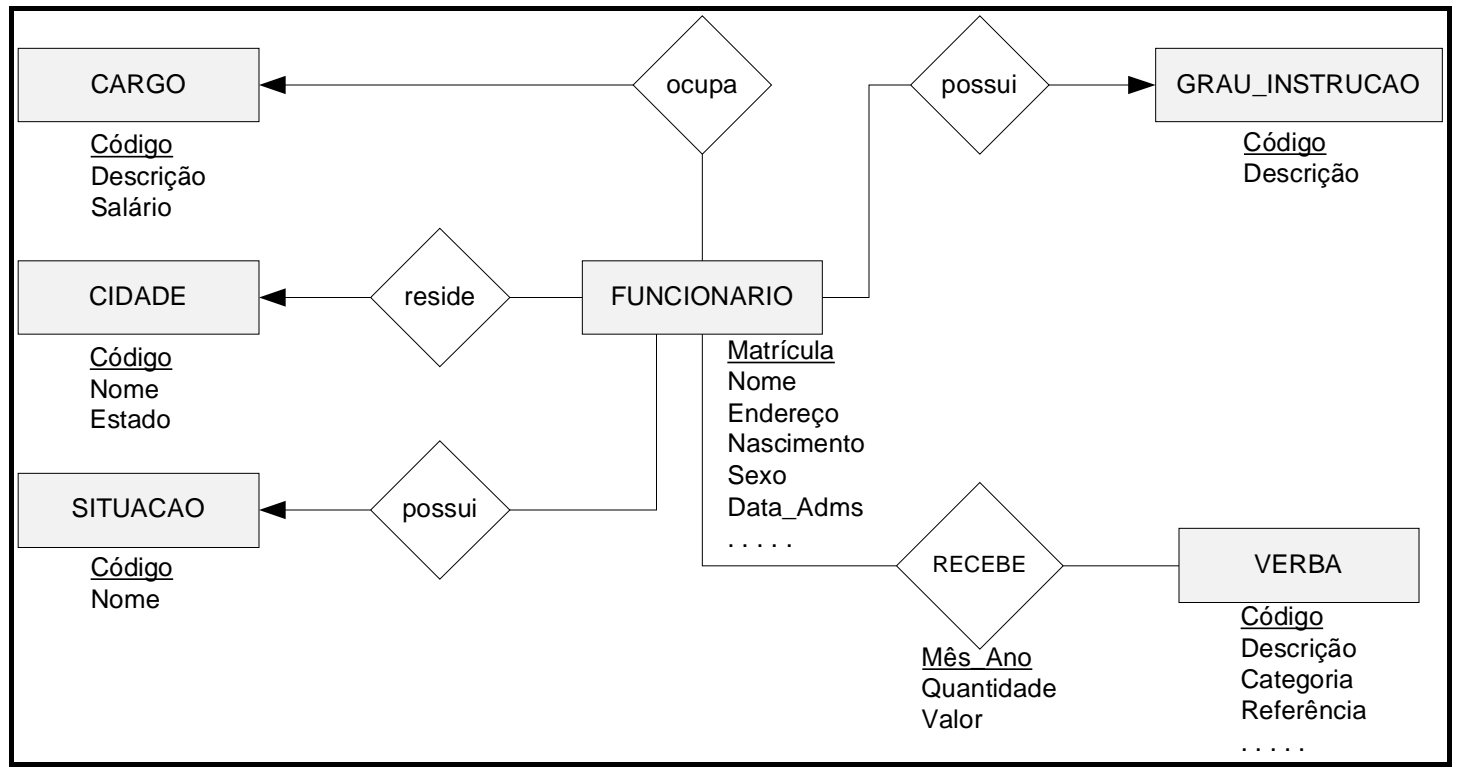

Figura 45. Parte do Modelo de Dados do Sistema de Folha de Pagamento

Os scripts para a criação dos conjuntos de entidades do Banco de Dados Operacional BDO_FOLHA, bem como o script para a criação da conexão entre os bancos de dados, podem ser encontrados no Apêndice B.

\subsubsection{Modelo de Dados do Controle Acadêmico}

A Figura 46 ilustra o Modelo de Dados referente ao Sistema Acadêmico, que representa o Banco de Dados Operacional "BDO_ACADEMICO". 


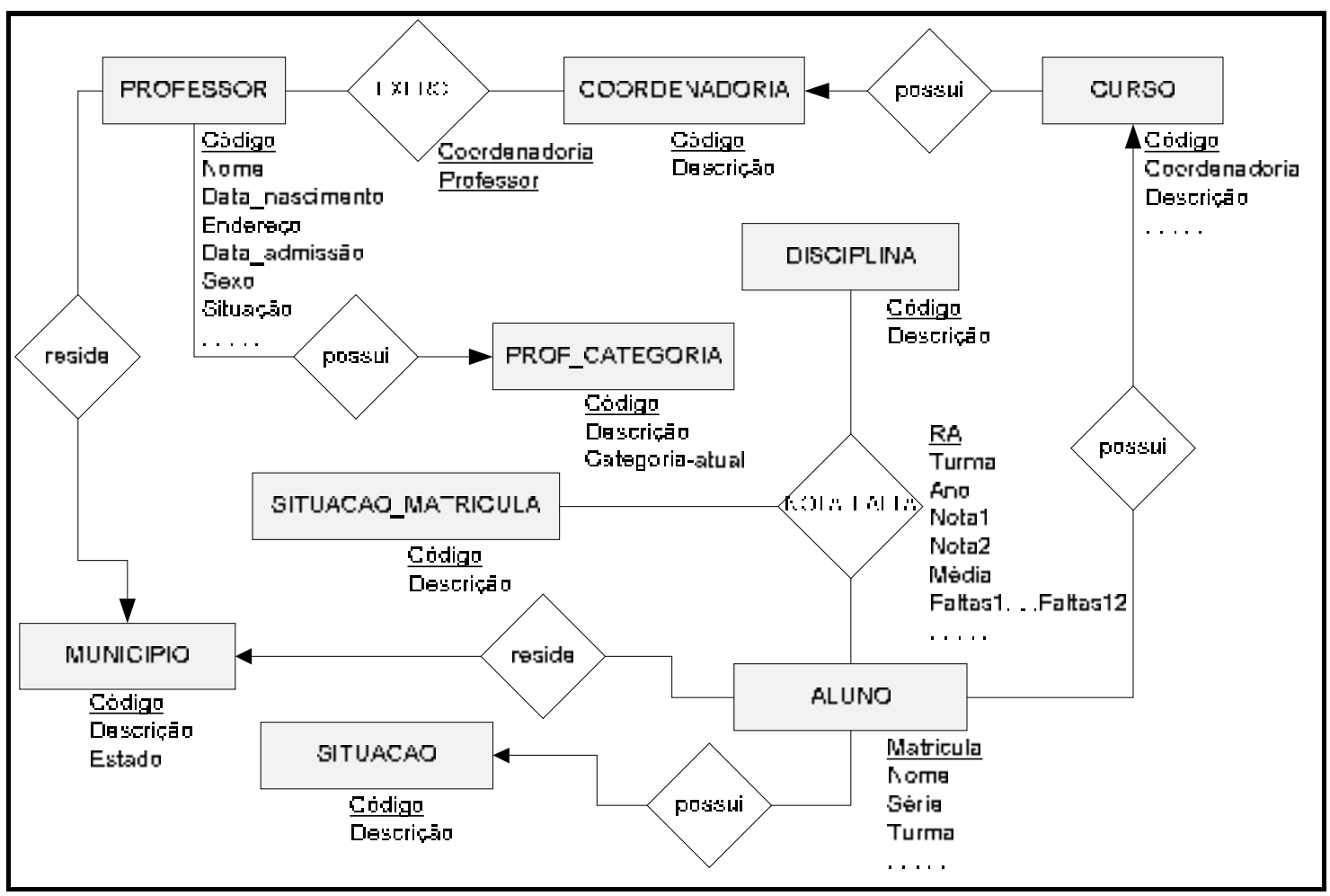

Figura 46. Parte do Modelo de Dados do Sistema Acadêmico

Os scripts para a criação dos conjuntos de entidades do Banco de Dados Operacional BDO_ACADEMICO, bem como o script para a criação da conexão entre os bancos de dados, podem ser encontrados no Apêndice C.

\subsection{CONFIGURAÇÕES}

\subsubsection{Bancos de Dados}

Para a validação prática, foi utilizado o Sistema de Banco de Dados Oracle $10 \mathrm{~g}$, por ser um Banco de Dados Relacional, que possibilita a utilização de Gatilhos e Procedimentos Armazenados.

São utilizados, no estudo de caso, dois servidores de banco de dados: um servidor contém os dois Bancos de Dados Operacionais; o outro servidor contém o Banco de Dados Analítico-Temporal proposto, conforme ilustrado na Figura 47. 


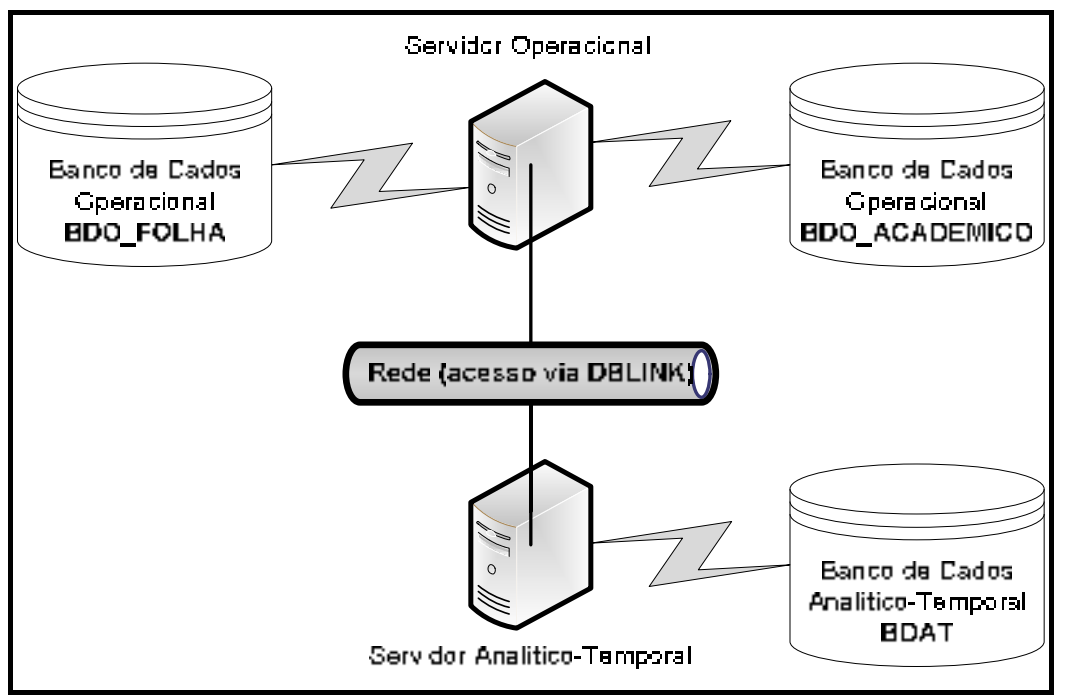

Figura 47. Estrutura de Comunicação entre os Bancos de Dados

A idéia é fazer com que os gatilhos e procedimentos armazenados enviem os dados operacionais ao Banco de Dados Analítico-Temporal, logo após terem ocorrido operações de processamento de dados nos Bancos de Dados Operacionais sobre as informações selecionadas para a geração de históricos.

Foi criado, tanto no Banco de Dados BDO_FOLHA, quanto no BDO_ACADEMICO, um conjunto de entidades definido por "PARAMETRO" (Apêndices A e B), cujo objetivo é armazenar uma tupla com a descrição abreviada do nome de cada um dos Bancos de Dados Operacionais. Essa informação é essencial para evitar a duplicação dos valores de chaves primárias junto ao Banco de Dados AnalíticoTemporal.

\subsubsection{Funcionamento da Plataforma Oracle}

O Oracle trabalha com a filosofia cliente/servidor em que cada servidor de banco de dados é um software Oracle que gerencia um Banco de Dados, e um cliente é uma aplicação que solicita dados para um ou mais servidores locais.

Cada servidor de Banco de Dados Oracle controla seu Banco de Dados Local, situado nos vários sites, mas coopera para manter a consistência do Banco de Dados Global. 
A aplicação pode, simultaneamente, acessar e/ou modificar os dados nos vários Bancos de Dados localizados nos vários sites da rede de computadores.

A comunicação entre os Bancos de Dados pode ser realizada pela criação de Database Link's. Para isso, torna-se necessário uma rede de computadores, que pode assumir qualquer uma das topologias tradicionais conhecidas.

Além disso, é necessário o uso de um software que faça a comunicação através da rede, entre os diversos sites. No caso do Oracle, é utilizado o software SQL Net (Net8). O SQL*Net realiza a comunicação entre os clientes e os servidores que operam em diferentes computadores, nos diversos sites de uma rede. Além disso, ele também permite a comunicação entre os próprios servidores para que seja possível o suporte a transações remotas e distribuídas por meio dos Bancos de Dados. Desse modo, um servidor age como cliente, enviando pedido a outro servidor.

O SQL*Net deixa transparente a conectividade necessária para transmitir requisições SQL e receber dados de aplicações que usem o sistema. O SQL Net contém informações de endereço de IP/Porta e protocolo (TCP/IP) para o estabelecimento de conexões remotas.

Os scripts com as configurações dos nomes de domínios e de serviços dos Bancos de Dados Operacional e Analítico-Temporal podem ser encontrados no Apêndice D.

\subsection{APLICAÇÃO DA PROPOSTA DE MODELAGEM}

Com base na descrição da aplicação, e principalmente nos modelos de dados operacionais, é que são aplicados todos os passos elaborados nas Etapas A e B, descritas no Capítulo 5.

Isso culmina no modelo de dados analítico-temporal, que é utilizado para criação do esquema do Banco de Dados Analítico-Temporal, cuja etapa final ocorre por meio da especificação de gatilhos e procedimentos armazenados, elaborados na Etapa C. 


\subsubsection{Aplicação da Etapa A: Mapeamento dos Modelos de Dados Operacionais em um Modelo de Dados Unificado}

A seguir, são aplicados os passos componentes da Etapa A, com o objetivo de unificar e padronizar os modelos de dados operacionais das aplicações escolhidas para o estudo de caso.

5.4.1.1 Passo A1: Renomeação de conjuntos de entidades com nomes iguais, mas dados distintos

Ao aplicar esse passo junto aos Modelos de Dados Operacionais, "BDO_FOLHA" e "BDO_ACADEMICO", verifica-se que os dois Bancos de Dados Operacionais possuem um conjunto de entidades com o mesmo nome, identificado por "SITUACAO". Contudo, eles armazenam dados com finalidades diferentes. No BDO_FOLHA, esse conjunto de entidades representa as diversas situações de trabalho em que os funcionários podem se encontrar. Já no BDO_ACADEMICO o conjunto de entidades "SITUAÇÃO" refere-se à matrícula dos alunos. Portanto, para a definição do Modelo de Dados Analítico-Temporal, esses dois conjuntos de entidades devem ser identificados por outras nomenclaturas.

Para resolver tal problema, o conjunto de entidades "SITUACAO", do Banco de Dados Operacional "BDO_FOLHA", deve ser modelado com o nome de "FOLHA_SITUACAO". Já o conjunto de entidades "SITUACAO", do Banco de Dados Operacional "BDO_ACADEMICO", deve ser modelado com o nome de “ACADEMICO_SITUACAO”.

5.4.1.2 Passo A2: Renomeação de conjuntos de entidades com dados comuns, mas com nomes distintos

Ao aplicar esse passo junto aos Modelos de Dados Operacionais, "BDO_FOLHA" e "BDO_ACADEMICO", verifica-se que os dois Bancos de Dados Operacionais possuem conjuntos de entidades com nomes distintos, mas com dados comuns, 
identificados no Banco de Dados do Sistema de Folha de Pagamento (BDO_FOLHA), por "CIDADE", "FUNCIONARIO" e "GRAU_INSTRUCAO", e, respectivamente, por "MUNICIPIO", "PROFESSOR" e "PROF_CATEGORIA", no Banco de Dados do Sistema de Controle Acadêmico (BDO_ACADEMICO).

Portanto, para a definição do Modelo de Dados Analítico-Temporal, esses conjuntos de entidades comuns devem ser identificados por outras nomenclaturas, evitando, assim, a redundância de conjuntos de entidades, bem como dos dados por eles armazenados.

Para resolver esse eventual problema, o conjunto de entidades "CIDADE", do Banco de Dados Operacional "BDO_FOLHA", bem como o conjunto de entidades "MUNICIPIO", do Banco de Dados Operacional "BDO_ACADEMICO", devem ser modelados com outra nomenclatura, por exemplo, "LOCALIDADE".

Da mesma forma, deve-se proceder para com os conjuntos de entidades "FUNCIONARIO", do Banco de Dados Operacional "BDO_FOLHA", e "PROFESSOR", do Banco de Dados Operacional "BDO_ACADEMICO", modelados, por exemplo, pela denominação de "EMPREGADO".

O mesmo deve ser feito para os conjuntos de entidades "GRAU_INSTRUCAO", do Banco de Dados Operacional "BDO_FOLHA", e "PROF_CATEGORIA", do Banco de Dados Operacional "BDO_ACADEMICO", modelados, por exemplo, pela denominação "CATEGORIA".

5.4.1.3 Passo A3: Renomeação de atributos com dados comuns, mas com nomes distintos

O presente passo somente deve ser aplicado nas entidades unificadas no Passo A2.

Considere-se que as entidades "CIDADE", do "BDO_FOLHA", e "MUNICIPIO", do "BDO_ACADEMICO", tenham os seguintes atributos:

$$
\begin{aligned}
\text { CIDADE } & =(\underline{\text { Código }}, \text { Nome }, \text { Estado }) \\
\text { MUNICIPIO } & =(\underline{\text { Código }}, \text { Descrição, Estado })
\end{aligned}
$$


A entidade "LOCALIDADE" será composta pelos atributos:

$$
\text { LOCALIDADE }=(\underline{\text { ID }}, \text { Descrição, Estado })
$$

Da mesma forma, sejam os atributos das entidades "FUNCIONARIO" e "PROFESSOR":

FUNCIONARIO = (Matricula, Nome, Nascimento, Sexo, Situação (FK), Grau_Instr (FK), Endereço, Cidade (FK), Data_admis)

PROFESSOR $=$ (Código, Nome, Data_nascimento, Sexo, Situação, Categoria, Endereço, Município, Data_admissão)

A entidade "EMPREGADO" será composta pelos atributos:

EMPREGADO = $(\underline{I D}$, Nome, Dt_nasc, Sexo, Situação $(F K)$, Categoria $(F K)$, Endereço, Localidade (FK), Dt_admis)

Finalmente, sejam os atributos das entidades "GRAU_INSTRUCAO" e "PROF_CATEGORIA":

GRAU_INSTRUCAO = $(\underline{\text { Código }}$, Descrição $)$

PROF_CATEGORIA = ( $\underline{\text { Código, }}$ Descrição, Categoria_atual)

A entidade "CATEGORIA" será composta pelos atributos:

CATEGORIA = (ID, Descrição, Categoria_atual)

5.4.1.4 Passo A4: Transformação de atributos com dados comuns, mas com representação diferente de valores

Assim como no Passo A3, nesse Passo A4, somente devem ser analisadas as entidades unificadas no Passo A2.

Dentre tais entidades, não foi detectado nenhum problema quanto a dados comuns com representação diferente de valores nos pares de entidades "CIDADE" / "MUNICIPIO" e "GRAU_INSTRUCAO" / "PROF_CATEGORIA". 
O único par de entidades com tal tipo de problema é o "FUNCIONÁRIO" I "PROFESSOR".

Nesse item, foram identificados dois atributos que representam o mesmo tipo de informação, mas com valores diferentes, conforme ilustrado na Tabela 1.

\begin{tabular}{|c|c|c|c|}
\hline $\begin{array}{c}\text { BDO_FOLHA } \\
\text { (FUNCIONARIO) }\end{array}$ & representação & $\begin{array}{c}\text { BDO_ACADEMICO } \\
\text { (PROFESSOR) }\end{array}$ & representação \\
\hline SEXO & $\begin{array}{l}\mathrm{M}-\text { masculino } \\
\mathrm{F}-\text { feminino }\end{array}$ & SEXO & $\begin{array}{l}1-\text { masculino } \\
2-\text { feminino }\end{array}$ \\
\hline SITUACAO & $\begin{array}{l}\text { A - admitido } \\
\text { D - demitido } \\
\text { F - afastado }\end{array}$ & SITUACAO & $\begin{array}{l}1-\text { ativo } \\
0-\text { inativo }\end{array}$ \\
\hline
\end{tabular}

Tabela 1. Identificação de diferentes representações de valores

Analisando a Tabela 1, nota-se que 0 atributo "SEXO", possui valores diferentes para a representação do mesmo tipo de informação. Portanto, no Banco de Dados Analítico-Temporal, essa informação deverá ser padronizada pelos valores "M" (masculino) e "F" (feminino).

Da mesma forma deve-se proceder com relação ao atributo "SITUACAO", que deverá ser padronizado pelos valores "A" (admitido), correspondente a "ativo", "D" (demitido) e "F" (afastado), correspondente a "inativo".

\subsubsection{Passo A5: Transformação de atributos chaves primárias}

Esse passo tem como base os conjuntos de entidades identificados durante a aplicação dos passos A2 e A3.

A união dos conjuntos de entidades, "CIDADE" e "MUNICIPIO" poderá causar duplicações de valores das chaves-primárias. Portanto, para a criação do conjunto de entidades que unirá os conjuntos de entidades "CIDADE" e "MUNICIPIO", dos dois Bancos de Dados Operacionais, deverá ser utilizado um novo atributo, definido como "ORIGEM". Este comporá a chave primária junto com o atributo "ID", da entidade "LOCALIDADE". Esse novo atributo receberá a sigla "FOLHA" ou a sigla "ACADEMICO", provinda do conjunto de entidades "PARAMETRO", facilitando 
assim, a identificação da origem operacional de cada tupla junto ao Banco de Dados Analítico-Temporal.

Essas siglas estarão armazenadas em cada um dos Bancos de Dados Operacionais, no conjunto de entidades "PARAMETRO", e deverão ser enviadas ao Banco de Dados Analítico-Temporal por meio dos gatilhos, que serão criados nos Bancos de Dados Operacionais.

O mesmo deve ocorrer com os conjuntos de entidades "FUNCIONARIO" I "PROFESSOR" e "GRAU_INSTRUCAO" / "PROF_CATEGORIA", que também ganham um novo atributo chamado "ORIGEM", com a mesma característica citada. Tal atributo também irá compor a chave primária das entidades "EMPREGADO" e "CATEGORIA".

\subsubsection{Passo A6: Transformação de atributos chaves estrangeiras}

Como o conjunto de entidades "FUNCIONARIO" será unido ao conjunto de entidades "PROFESSOR", em que o atributo "ORIGEM" deverá ser utilizado para identificar a origem operacional, torna-se necessário a localização dos relacionamentos de cada um desses conjuntos de entidades para saber quais serão as propagações de chaves primárias necessárias.

Analisando o Modelo de Dados do Sistema de Folha de Pagamento, verifica-se que a alteração da chave primária da entidade "FUNCIONARIO" irá causar alteração das chaves estrangeiras das tabelas "CARGO", "CIDADE", "SITUACAO" e "GRAU_INSTRUCAO" e "RECEBE". Portanto, caso esses conjuntos de entidades sejam selecionados na Etapa $\mathrm{B}$, o conjunto de entidades que for utilizado para unilos, deverá receber o atributo "ORIGEM", preenchido com o valor "FOLHA", a fim de que seja possível localizar a cidade pertencente ao Banco de Dados Operacional "BDO_FOLHA".

Da mesma forma, analisando o Modelo de Dados do Sistema de Controle Acadêmico, verifica-se que a alteração da chave primária da entidade "PROFESSOR" irá causar alterações nas chaves estrangeiras das tabelas "EXERCE", "PROF_CATEGORIA" e "MUNICIPIO". Portanto, caso esses conjuntos 
de entidades sejam selecionados na Etapa B, o conjunto de entidades utilizado para uni-los também deverá receber o atributo "ORIGEM", pelo mesmo motivo descrito. As demais renomeações de conjuntos de entidades não geram transformações de atributos de chaves estrangeiras.

\subsubsection{Passo A7: Geração do Modelo de Dados Unificado}

Após a aplicação dos passos da Etapa A, pôde-se chegar ao Modelo de Dados Operacional Unificado, conforme apresentado na Figura 48. Os conjuntos de entidades de cor mais escura correspondem às modificações realizadas com 0 intuito de unificar, generalizar e diferenciar os Modelos de Dados Operacionais.

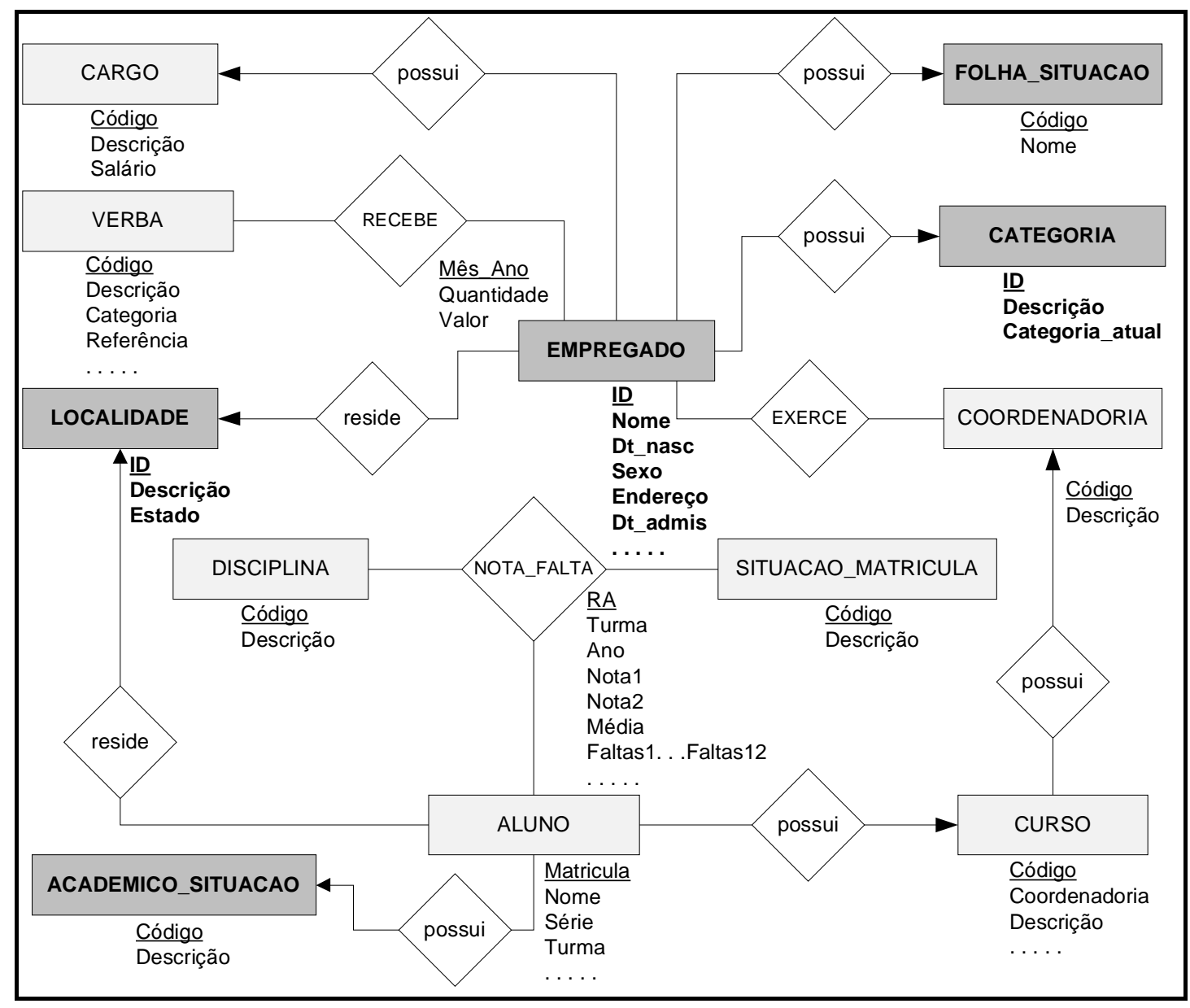

Figura 48. Modelo de Dados Operacional Unificado 


\subsubsection{Aplicação da Etapa B: Mapeamento do Modelo de Dados Unificado em um Modelo de Dados Analítico-Temporal}

5.4.2.1 Passo B1: Seleção dos conjuntos de entidades e atributos para o Banco de Dados Analítico-Temporal.

Para o setor de Recursos Humanos, o essencial é armazenar dados analíticotemporais referentes às seguintes situações:

I- Ter a possibilidade de recuperar todas as mudanças de cargos (A), de endereços (incluindo as cidades) (B) e de graus de instrução (C), ocorridas com um determinado funcionário, bem como as épocas exatas dessas mudanças.

II- Ter a possibilidade de recuperar todos os totais pagos anualmente para cada um dos funcionários de acordo com cada verba recebida.

Para o setor de Supervisão Acadêmica, o essencial é armazenar dados analíticotemporais referentes às seguintes situações:

III- Ter a possibilidade de recuperar todas as mudanças de coordenadorias (A), de categorias (titulação) (B) e de endereços (incluindo municípios) (C), ocorridas com um determinado professor, bem como as épocas exatas dessas mudanças.

IV- Ter a possibilidade de recuperar todas as alterações de médias $(A)$ e de faltas (B) ocorridas em cada disciplina com um determinado aluno, bem como as épocas exatas dessas mudanças.

Portanto, com base nessas situações é que devem ser selecionados os conjuntos de entidades operacionais e/ou atributos que fornecerão as devidas informações a serem armazenadas no Banco de Dados Analítico-Temporal, bem como a sugestão para se usarem novos conjuntos de entidades necessários para atendê-las.

As tabelas 2 e 3 contêm a justificativa da escolha de cada um dos conjuntos de entidades operacionais, bem como de seus conjuntos de relacionamentos (tabelas associativas), que devem fornecer algum tipo de informação ao Banco de Dados Analítico-Temporal, bem como a sugestão de se criar outros conjuntos de entidades necessários para tais armazenamentos. 


\section{Conjunto de Entidades:}

\begin{tabular}{|l|l|}
\hline \multicolumn{1}{|c|}{ Nomes } & \multicolumn{1}{c|}{ Justificativa de Escolha } \\
\hline CARGO & $\begin{array}{l}\text { Oferece informações sobre todos os cargos e salários que um } \\
\text { funcionário tenha assumido na Instituição. }\end{array}$ \\
\hline $\begin{array}{l}\text { FUNCIONARIO e } \\
\text { PROFESSOR } \\
\text { (EMPREGADO) }\end{array}$ & $\begin{array}{l}\text { Oferecem informações de todos os endereços, cidades, graus de } \\
\text { instruções, cargos, etc., que um funcionário e/ou professor tenha } \\
\text { ocupado na Instituição, bem como as coordenadorias, os endereços, } \\
\text { cidades, categorias (titulações) assumidas pelos professores. }\end{array}$ \\
\hline VERBA & $\begin{array}{l}\text { Fornece valores descritivos referentes aos vencimentos e descontos } \\
\text { a serem armazenamentos anualmente. }\end{array}$ \\
\hline $\begin{array}{l}\text { CIDADE e } \\
\text { MUNICIPIO } \\
\text { (LOCALIDADE) }\end{array}$ & $\begin{array}{l}\text { Fornecem valores descritivos relativos a cidades e/ou municípios em } \\
\text { que um funcionário e/ou professor tenha residido. }\end{array}$ \\
\hline $\begin{array}{l}\text { GRAU_INSTRUCAO e } \\
\text { PROF_CATEGORIA } \\
\text { (CATEGORIA) }\end{array}$ & $\begin{array}{l}\text { Fornecem valores descritivos referentes a graus de instruções e/ou } \\
\text { categorias que um funcionário e/ou professor tenha assumido. }\end{array}$ \\
\hline COORDENADORIA & $\begin{array}{l}\text { Fornece valores descritivos sobre as coordenadorias ocupadas pelos } \\
\text { professores. }\end{array}$ \\
\hline ALUNO & $\begin{array}{l}\text { Fornece valores descritivos referentes aos alunos, para o auxílio às } \\
\text { modificações das notas e faltas. }\end{array}$ \\
\hline DISCIPLINA & $\begin{array}{l}\text { Fornece valores descritivos referentes às disciplinas, para o auxílio às } \\
\text { modificações das notas e faltas. }\end{array}$ \\
\hline $\begin{array}{l}\text { SITUACAO } \\
\text { (ACADEMICO_SITUACAO) } \\
\text { (FOLHA_SITUACAO) }\end{array}$ & $\begin{array}{l}\text { Fornecem valores descritivos referentes às situações que cada um } \\
\text { dos funcionários e/ou alunos tenha ocupado. Esse conjunto de } \\
\text { entidades existe nos dois bancos de dados operacionais. }\end{array}$ \\
\hline
\end{tabular}

Tabela 2. Seleção dos conjuntos de entidades

\section{Conjunto de Relacionamentos:}

\begin{tabular}{|l|l|}
\hline \multicolumn{1}{|c|}{ Nomes } & \multicolumn{1}{c|}{ Justificativa de Escolha } \\
\hline RECEBE & $\begin{array}{l}\text { Oferece informações dos valores pagos anualmente aos funcionários da } \\
\text { Instituição. }\end{array}$ \\
\hline EXERCE & $\begin{array}{l}\text { Oferece informações de todas as coordenadorias que um professor veio a } \\
\text { ocupar. }\end{array}$ \\
\hline NOTA_FALTA & $\begin{array}{l}\text { Oferece informações de todas as mudanças de notas e de faltas por } \\
\text { disciplina ocorridas com os alunos. }\end{array}$ \\
\hline
\end{tabular}

Tabela 3. Seleção dos conjuntos de relacionamentos

Não foram selecionados os conjuntos de entidades SITUAÇÃO_MATRICULA e CURSO. 
5.4.2.2 Passo B2: Criação dos conjuntos de entidades para o armazenamento dos dados analítico-temporais

Na Figura 49 é apresentado o modelo de dados necessário para armazenar as mudanças de cargo e salário ocorridas com os funcionários, em resposta às questões colocadas no Passo B1, item I-A.

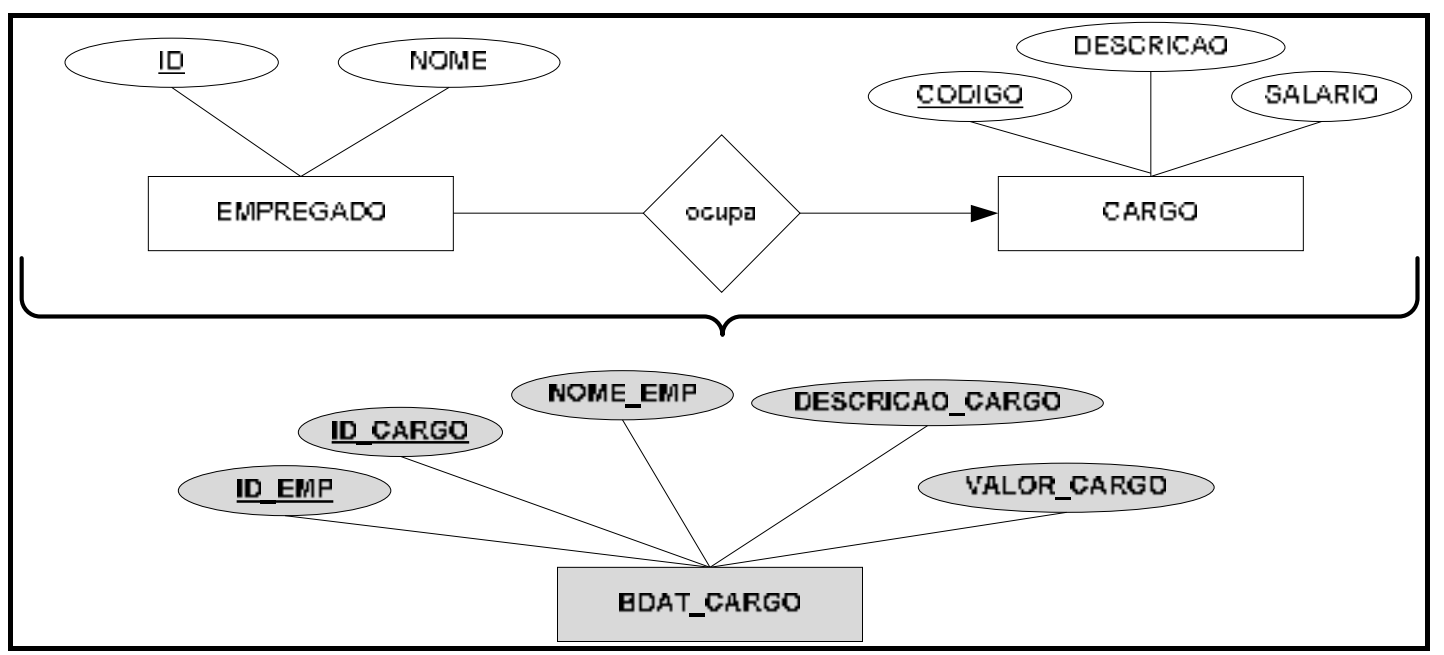

Figura 49. Modelo de Dados BDAT_CARGO

Na Figura 50, tem-se o modelo de dados necessário para armazenar as mudanças de grau de instrução ocorridas com os funcionários, bem como as mudanças de categoria dos professores, em resposta às questões colocadas no Passo B1, itens IC e III-B.

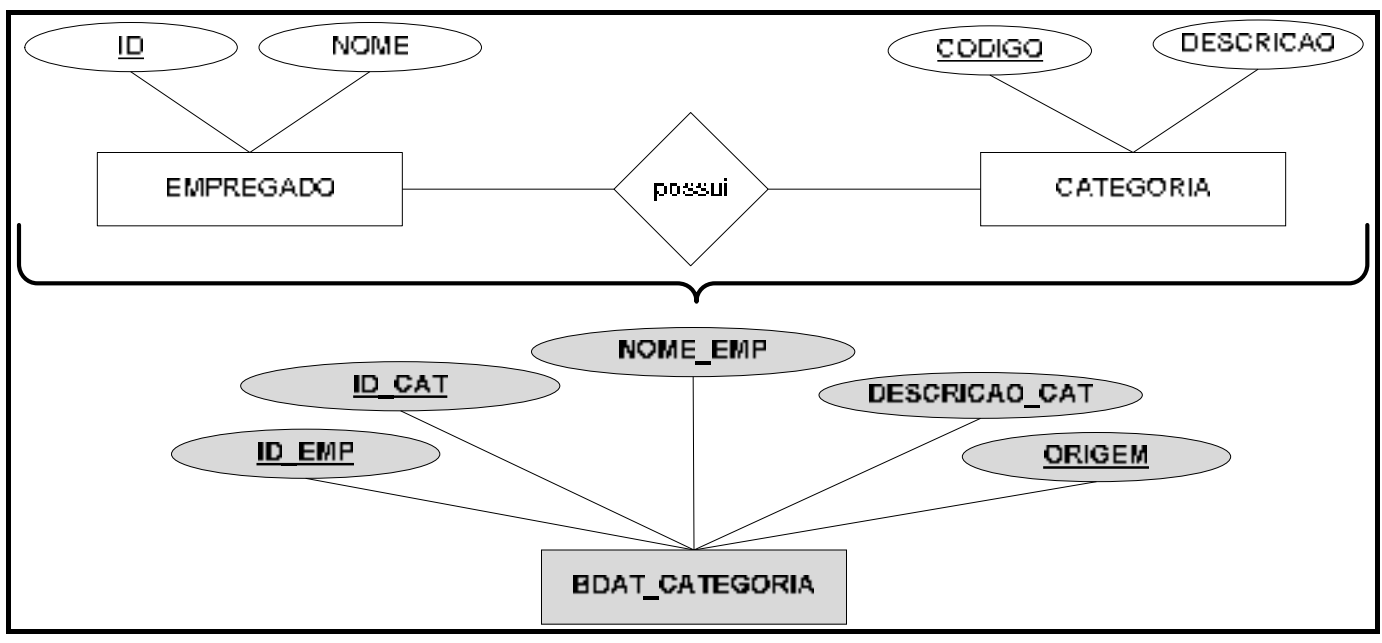

Figura 50. Modelo de Dados BDAT_CATEGORIA 
$\mathrm{Na}$ Figura 51, é apresentado o modelo de dados necessário para armazenar as mudanças de coordenadoria ocorridas com os professores, em resposta às questões propostas no Passo B1, item III-A.

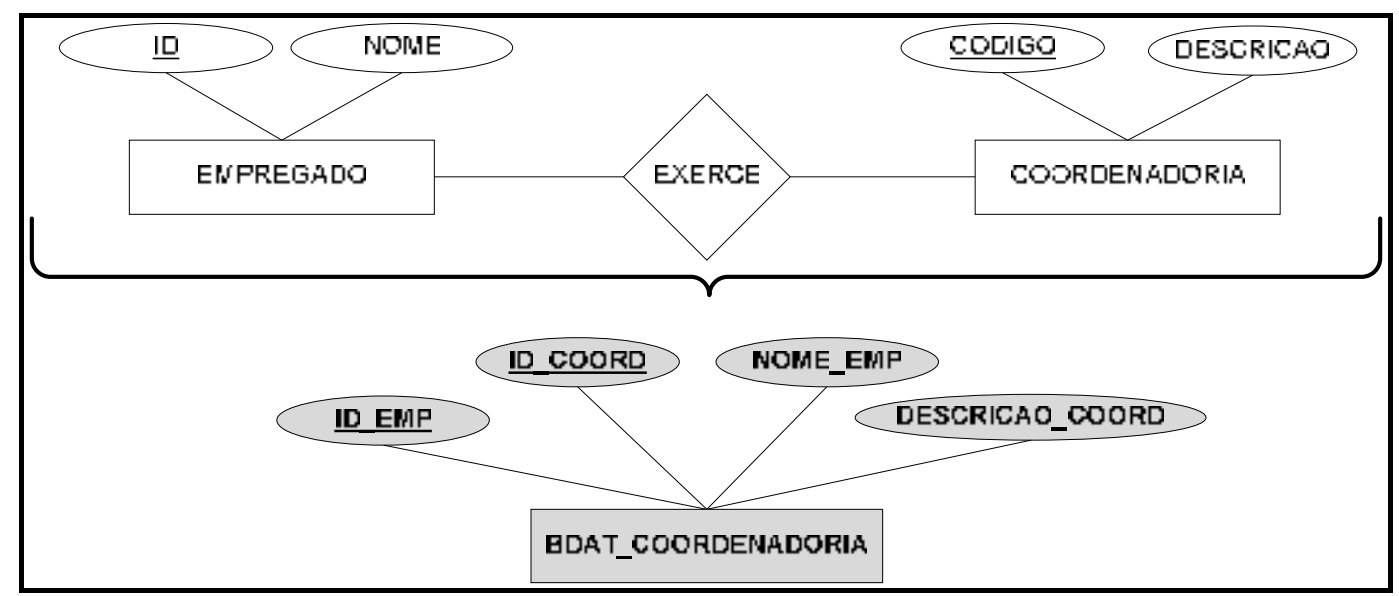

Figura 51. Modelo de Dados BDAT_COORDENADORIA

$\mathrm{Na}$ Figura 52, apresenta-se o modelo de dados necessário para armazenar os valores anuais pagos aos funcionários, em resposta às questões colocadas no Passo B1, item II.

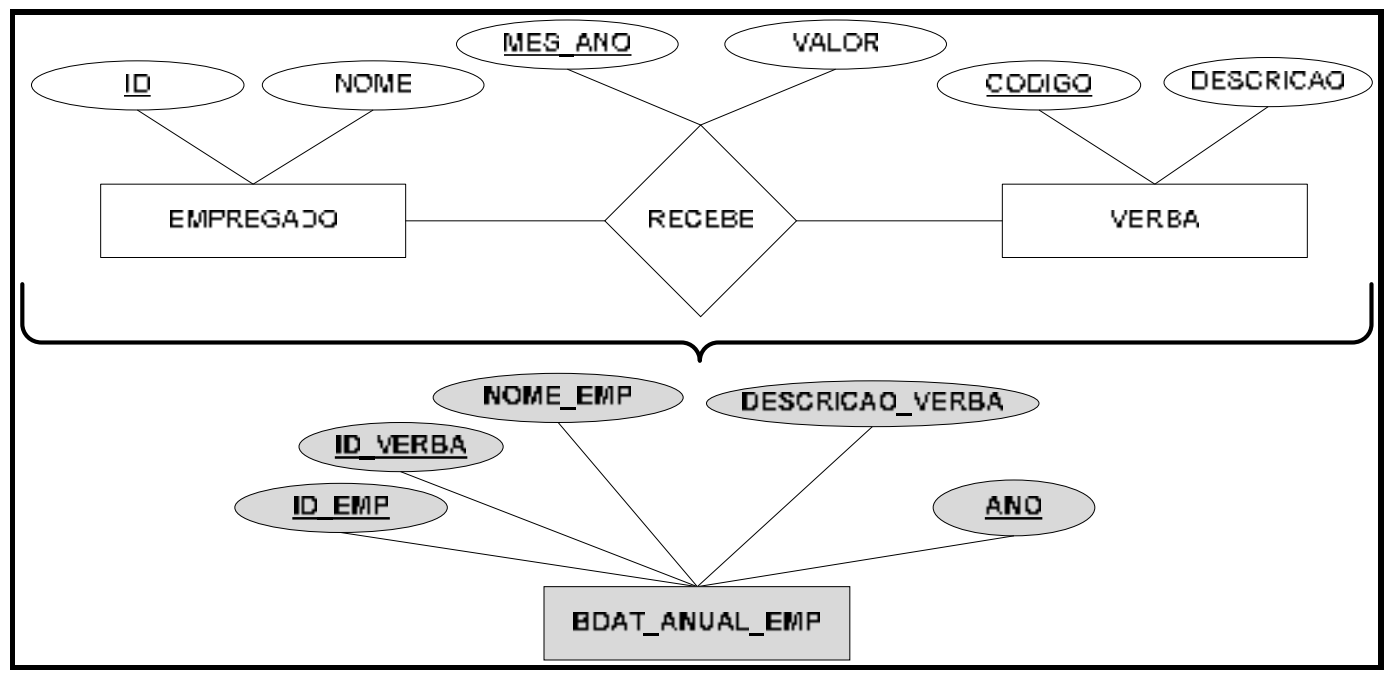

Figura 52. Modelo de Dados BDAT_ANUAL_EMP 
Na Figura 53, tem-se o modelo de dados necessário para armazenar as alterações dos valores das médias semestrais dos alunos, em resposta às questões propostas no Passo B1, item IV-A.

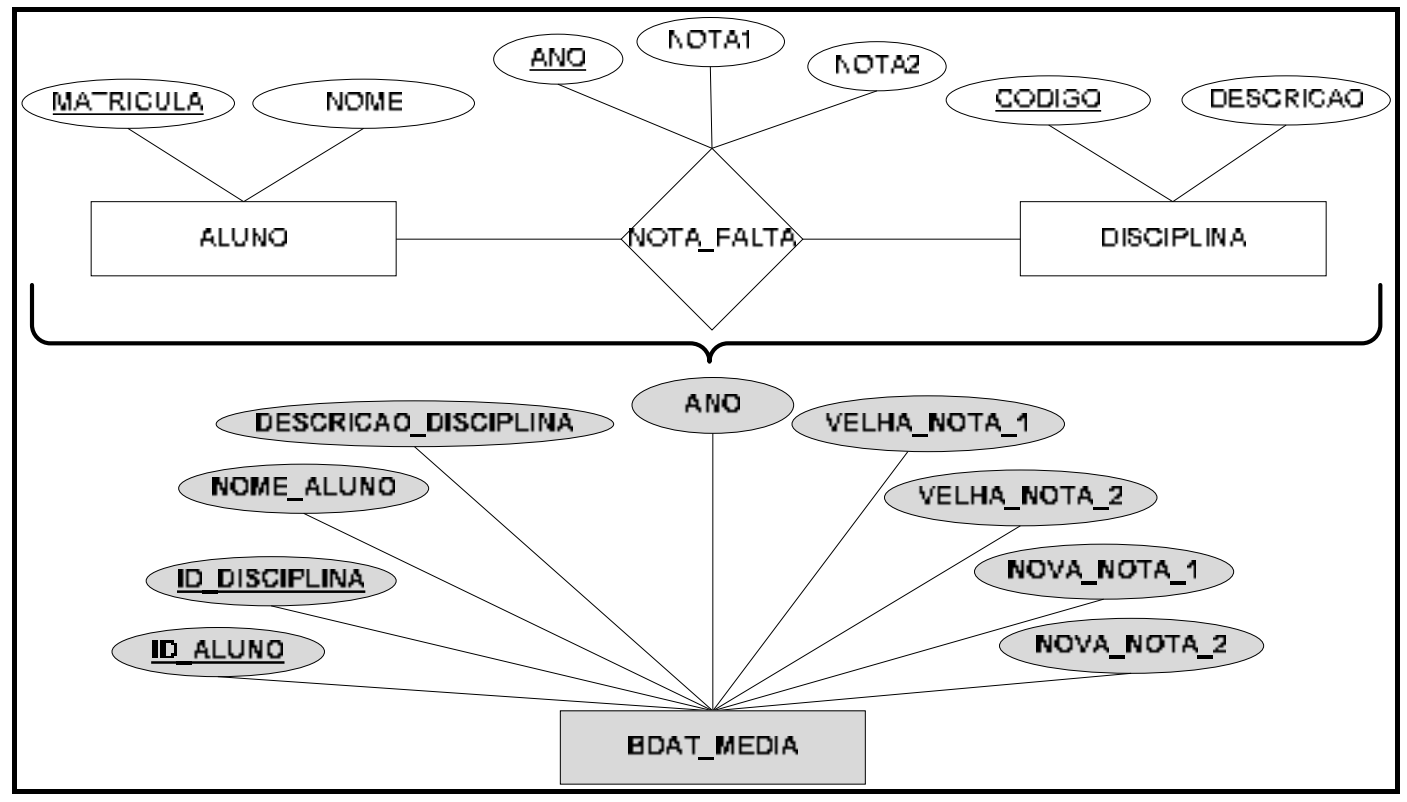

Figura 53. Modelo de Dados BDAT_MEDIA

Na Figura 54, há o modelo de dados necessário para armazenar a quantidade anual de faltas dos alunos, em resposta às questões colocadas no Passo B1, item IV-B.

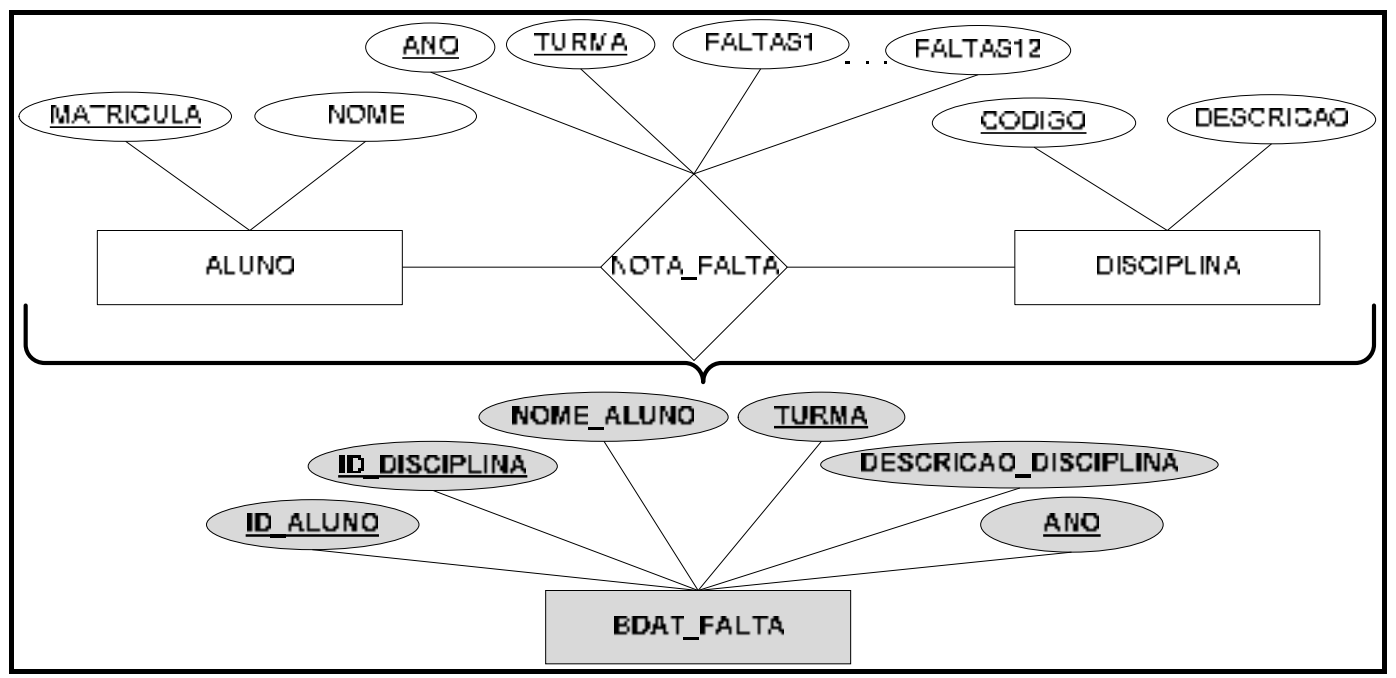

Figura 54. Modelo de Dados BDAT_FALTA 
A Figura 55 apresenta o modelo de dados necessário para armazenar as mudanças de endereço ocorridas com os funcionários e/ou professores, em resposta às questões propostas no Passo B1, itens I-B e III-C.

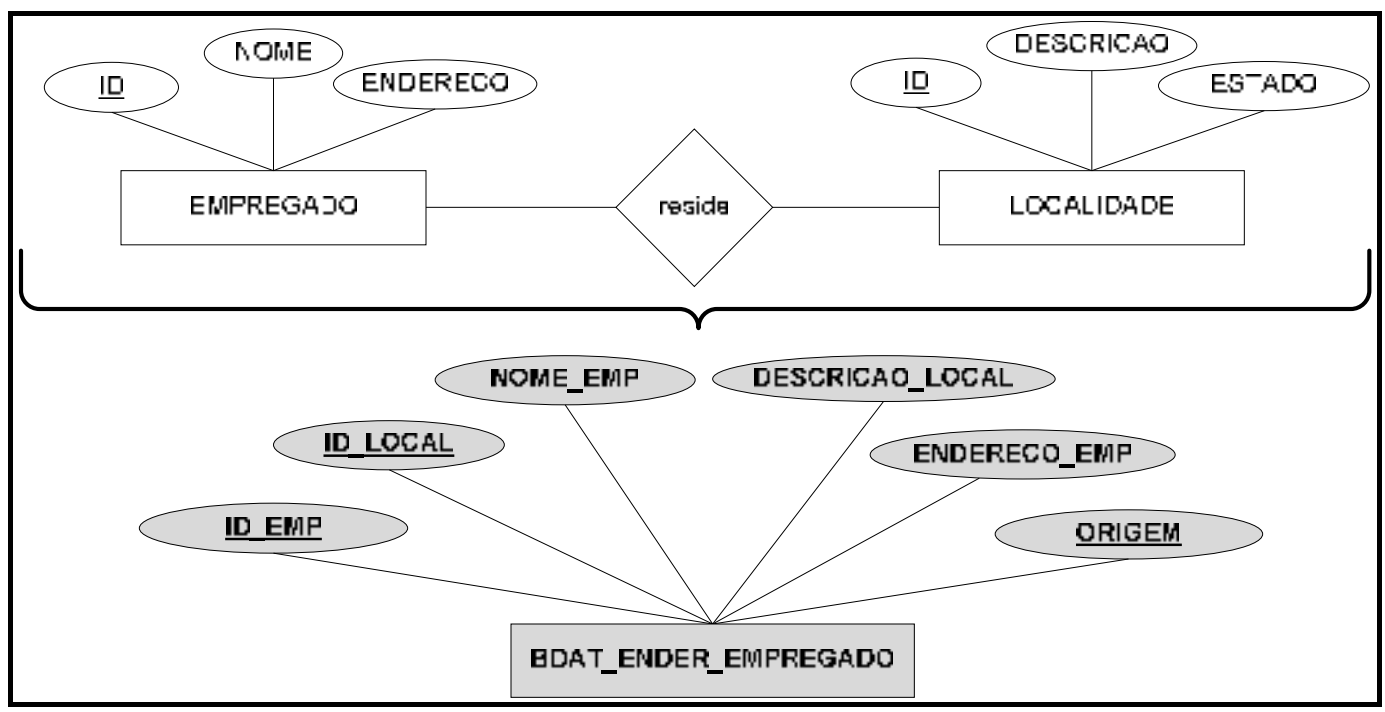

Figura 55. Modelo de Dados BDAT_ENDER_EMPREGADO

O acréscimo do atributo "ORIGEM" deu-se em função da necessidade de realizar a união dos dados provindos dos dois Bancos de Dados Operacionais. Esse atributo é primordial, já que, por meio dele, é possível saber qual a origem operacional do dado em questão. Trata-se do atributo a ser informado pelo conjunto de entidades "PARAMETRO", criado em cada um dos bancos de dados operacionais.

\subsubsection{Passo B3: Inclusão de elementos de tempo nos conjuntos de entidades}

A finalidade desse passo é incluir elementos de "tempo" nos modelos de dados identificados nos passos B1 e B2. A idéia inicial é saber qual foi o período exato em que os dados permaneceram válidos, ou seja, o momento em que eles foram os dados atuais.

Portanto, com base nesse passo, serão acrescentados os elementos de "tempo", de acordo com os modelos de dados definidos nos passos B1 e B2. As elipses com fundo preenchido representam os elementos de "tempo". 
As entidades criadas no passo $B 2$ e que devem ter os elementos de tempo incluídos são: BDAT_CARGO, BDAT_CATEGORIA, BDAT COORDENARIA, BDAT_MEDIA e BDAT_ENDER_EMPREGADO, conforme indicam as figuras 56 a 60 .

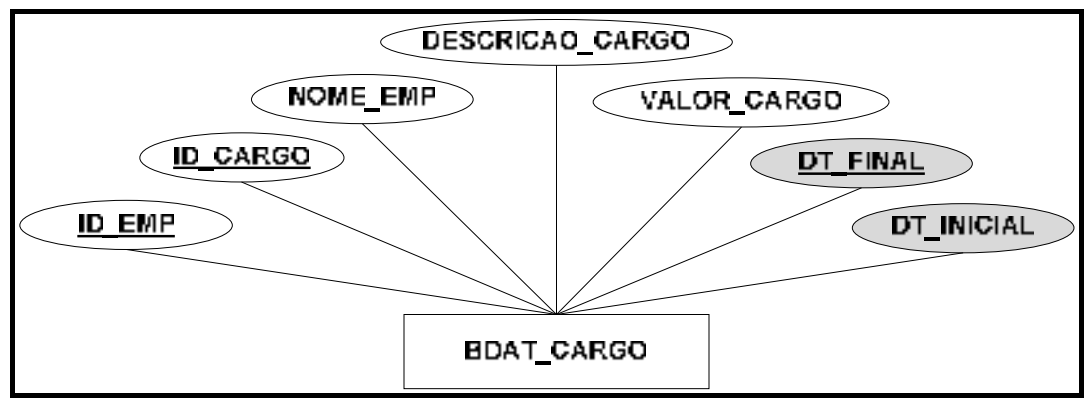

Figura 56. Modelo de Dados BDAT_CARGO com Elementos de Tempo

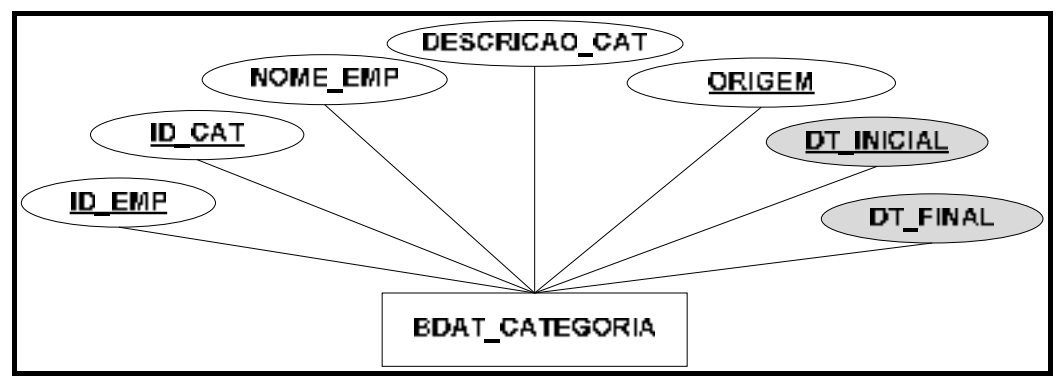

Figura 57. Modelo de Dados BDAT_CATEGORIA com Elementos de Tempo

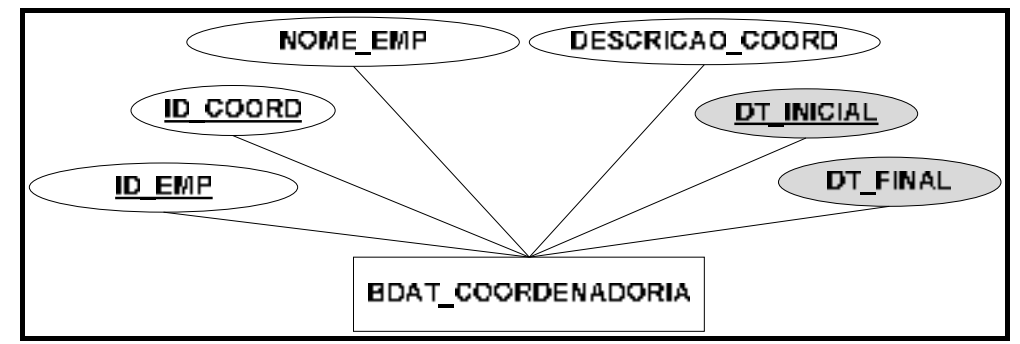

Figura 58. Modelo de Dados BDAT_COORDENADORIA com dos Elementos de Tempo 


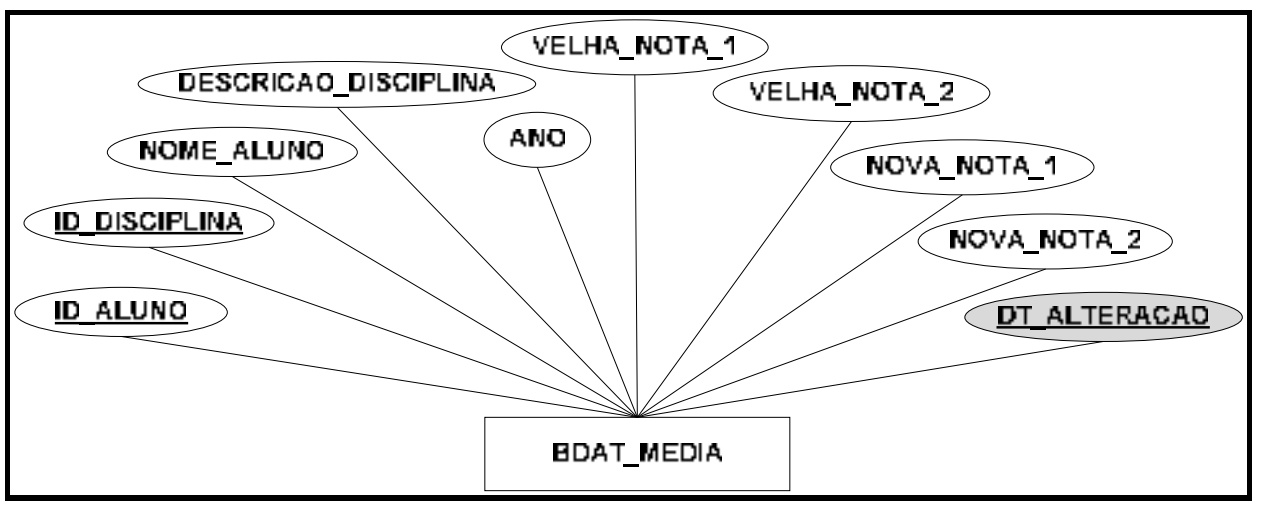

Figura 59. Modelo de Dados BDAT_MEDIA com Elemento de Tempo

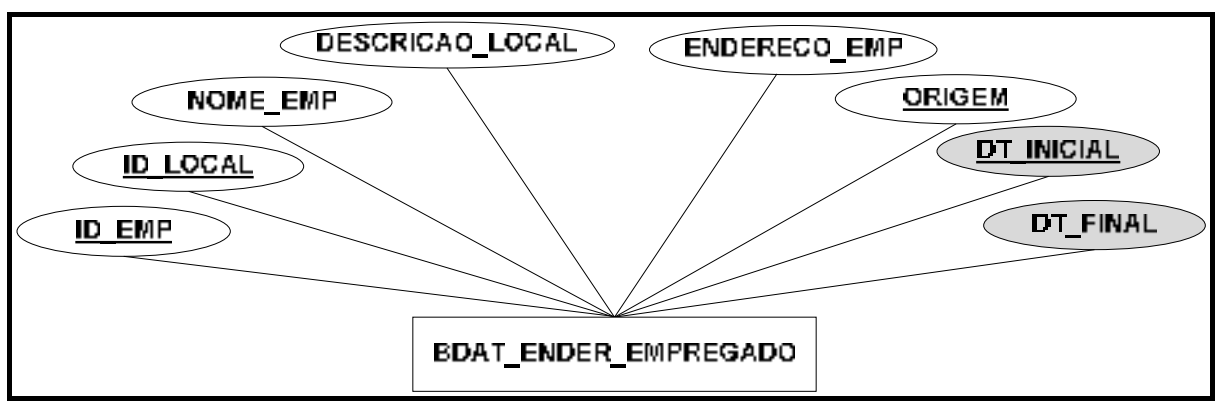

Figura 60. Modelo de Dados BDAT_ENDER_EMPREGADO com Elementos de Tempo

O horário das modificações será armazenado juntamente com os elementos de tempo "DT_INICIAL", "DT_FINAL" e/ou "DT_ALTERACAO”. O horário de ocorrência das alterações também deve ser incluído nos campos de data, em função da possibilidade de ocorrência de mais de uma alteração no mesmo dia.

No modelo de dados responsável por armazenar os pagamentos anuais dos funcionários (BDAT_ANUAL_EMP), bem como no responsável por armazenar a quantidade anual de faltas dos alunos por disciplina (BDAT_FALTA), não foram acrescentados os elementos de "tempo". Isso, pelo fato de que tais modelos serão utilizados para o armazenamento de valores sumarizados. Portanto, sua finalidade é armazenar valores agrupados e totalizados, e não controlar as épocas das mudanças de valores, diferentemente dos demais modelos de dados apresentados. 
5.4.2.4 Passo B4: Inclusão de atributos derivados.

A finalidade desse passo é adicionar atributos derivados juntos aos modelos de dados apresentados nos passos B1 e B2. A idéia inicial é evitar a realização de cálculos quando da necessidade de recuperação de informações. As elipses com fundo preenchido representam os atributos derivados.

As entidades criadas no passo B2, e complementadas no passo B3 que necessitam da criação de atributos derivados são: BDAT_MEDIA, BDAT_FALTA e BDAT_ANUAL_EMP, conforme indicam as figuras 61 a 63.

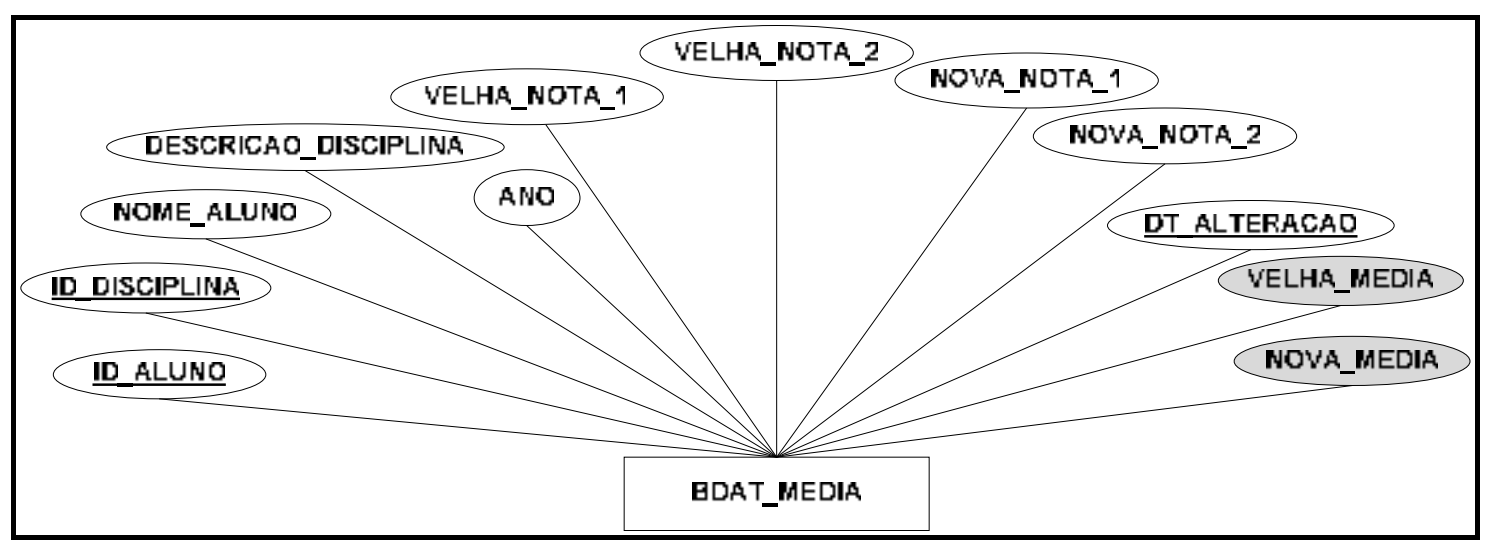

Figura 61. Modelo de Dados BDAT_MEDIA com Elemento Tempo e Atributos Derivados

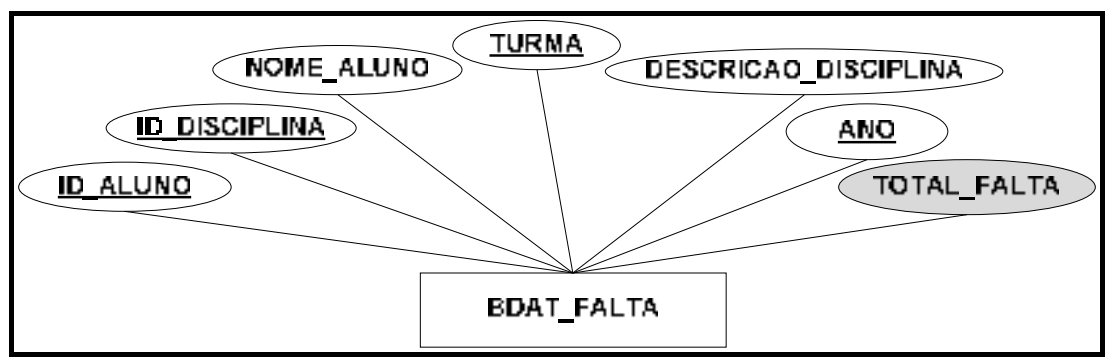

Figura 62. Modelo de Dados BDAT_FALTA com atributo derivado 


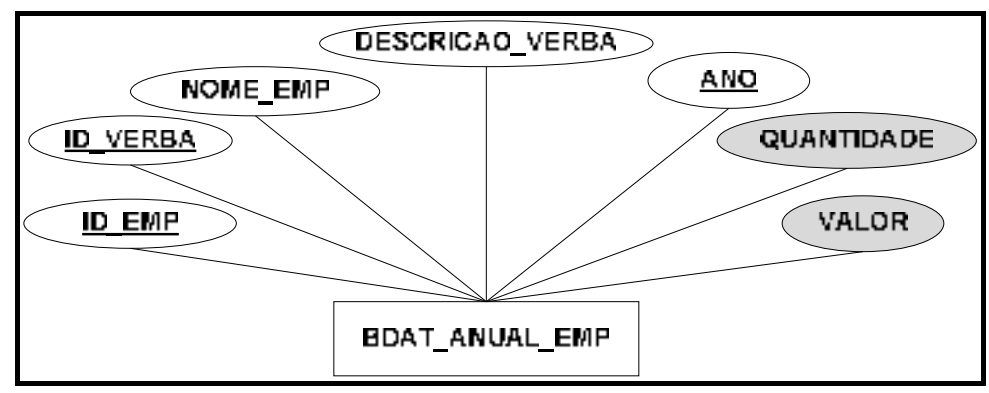

Figura 63. Modelo de Dados BDAT_ANUAL_EMP com atributos derivados

Nos demais modelos de dados apresentados nos Passos B2/B3, não foram acrescentados atributos "derivados", pelo fato de esses modelos não necessitarem armazenar valores pré-calculados.

\subsubsection{Passo B5: Geração do Modelo de Dados Analítico-Temporal}

Após a aplicação dos passos da Etapa B, pôde-se chegar ao modelo de dados necessário para que se possa ter um controle razoável das modificações efetuadas junto aos Bancos de Dados Operacionais "BDO_FOLHA" e "BDO_ACADEMICO", conforme apresentado na Figura 64. Os atributos não foram contemplados na figura, uma vez que os mesmos já foram apresentados durante a aplicação dos passos.

As entidades criadas em conseqüência do Modelo de Dados Analítico-Temporal estão representadas na Figura 64, em tracejado.

Segue uma descrição simplificada das tabelas resultantes do mapeamento. Essas tabelas é que formarão o Banco de Dados Analítico-Temporal.

- BDAT_CARGO = (ID EMP, ID CARGO,NOME_EMP, DESCRICAO_CARGO, VALOR_CARGO, ID_USUAARIO_BDO, DT INICIAL, DT_FINAL);

- BDAT_CATEGORIA = (ID EMP, ID CAT, NOME_EMP, DESCRICAO_CAT, ID_USUARIO_BDO, ORIGEM, DT INICIAL, DT_FINAL);

- BDAT_COORDENADORIA = (ID EMP, ID COORD, NOME_EMP, DESCRICAO_COORD, ID_USUARIO_BDO, DT INICIAL, DT_FINAL);

- BDAT_ANUAL_EMP = (ID EMP, ID VERBA, NOME_EMP, DESCRICAO_VERBA, $\underline{\text { ANO}}$, QUANTIDADE, VALOR); 
- BDAT_MEDIA = (ID ALUNO, ID DISCIPLINA, NOME_ALUNO, DESCRICAO_DISCIPLINA, ANO, VELHA_NOTA_1, VELHA_NOTA_2, NOVA_NOTA_1, NOVA_NOTA_2, ID_USUARIO_BDO, DT ALTERACĀO, VELHA_MEDIA, $\bar{T}$, NOVA_MEDIA);

- BDAT_FALTA = (ID ALUNO, ID DISCIPLINA, NOME_ALUNO, DESCRICAO_DISCIPLINA, $\underline{\text { ANO }}$, TOTAL_FALTA, TURMA);

- BDAT_ENDER_EMPREGADO $=($ ID EMP, ID LOCAL, NOME_EMP, DESCRICAO_LOCAL, ID_USUARIO_BDO, ENDERECO_EMP, ORIGEM, DT INICIAL, DT_FINAL);

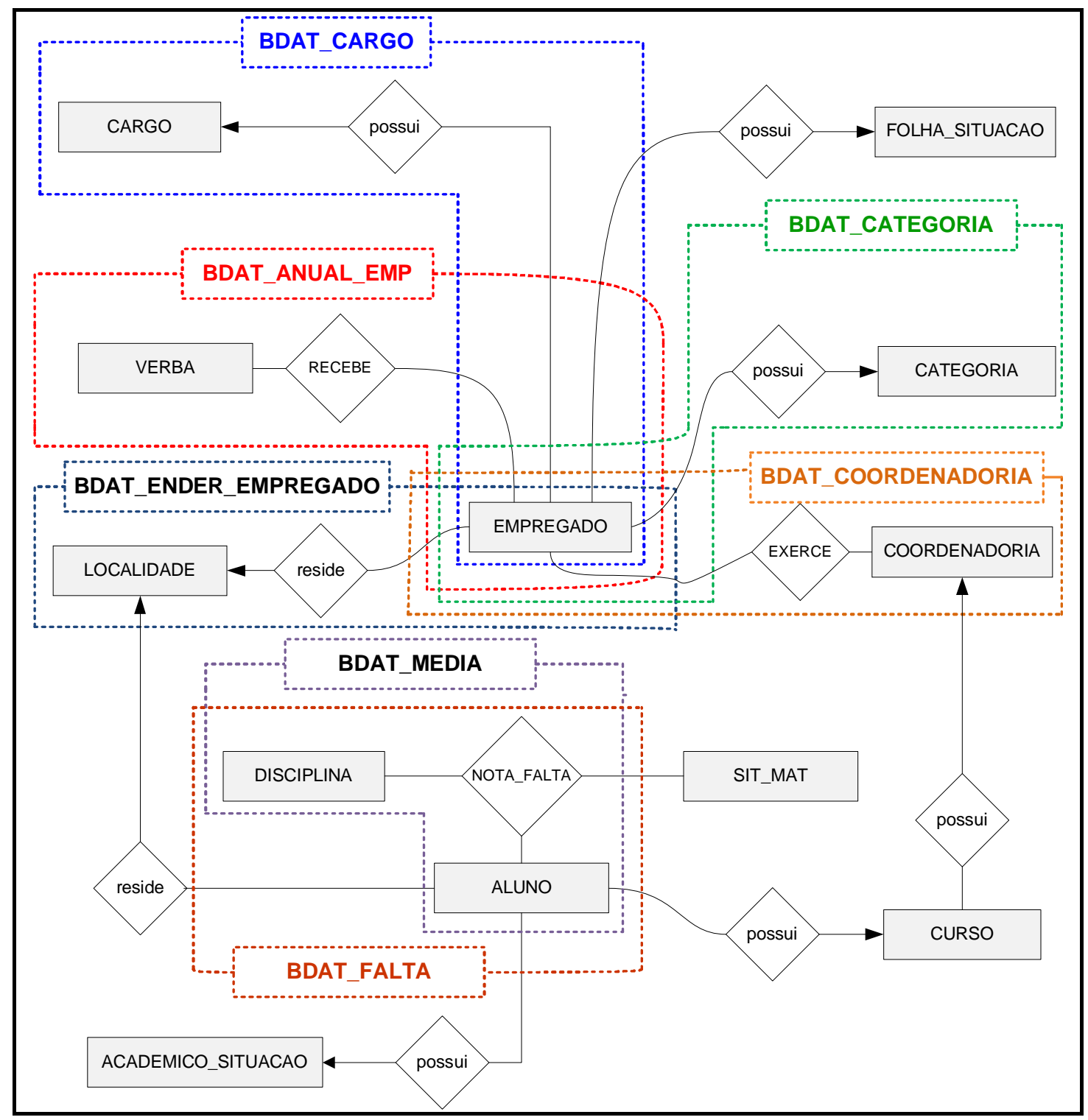

Figura 64. Modelo de Dados Analítico-Temporal

$\mathrm{Na}$ próxima seção, são descritos alguns exemplos práticos de gatilhos e procedimentos armazenados (subprogramas). A idéia inicial é criar, pelo menos, um subprograma para cada uma das especificações elaboradas na Etapa C, a fim de 
demonstrar, na prática, exemplos reais de como se aplicam as especificações genéricas de gatilhos e procedimentos armazenados propostos.

\subsubsection{Aplicação da Etapa C: Geração dos Dados Analítico-Temporais}

A seguir, com base no resultado da Etapa B, serão aplicados os passos elaborados durante o desenvolvimento da Etapa $\mathrm{C}$, com o objetivo de gerar, transportar e armazenar os dados analítico-temporais.

As especificações dos scripts para a criação do modelo de dados analítico-temporal podem ser encontradas no Apêndice $E$.

\subsubsection{Passo C1: Geração de Gatilhos para o passo B3}

O primeiro gatilho foi programado com base no modelo de dados apresentado na Figura 56. Definido como "PASSO_C1_BDAT_CARGO", sua finalidade é enviar dados referentes às mudanças de cargos ocorridas com os funcionários, toda vez que houver uma operação de inclusão ou de alteração, conforme ilustrado no fluxograma da Figura 65. A especificação do gatilho pode ser encontrada no Apêndice F. 


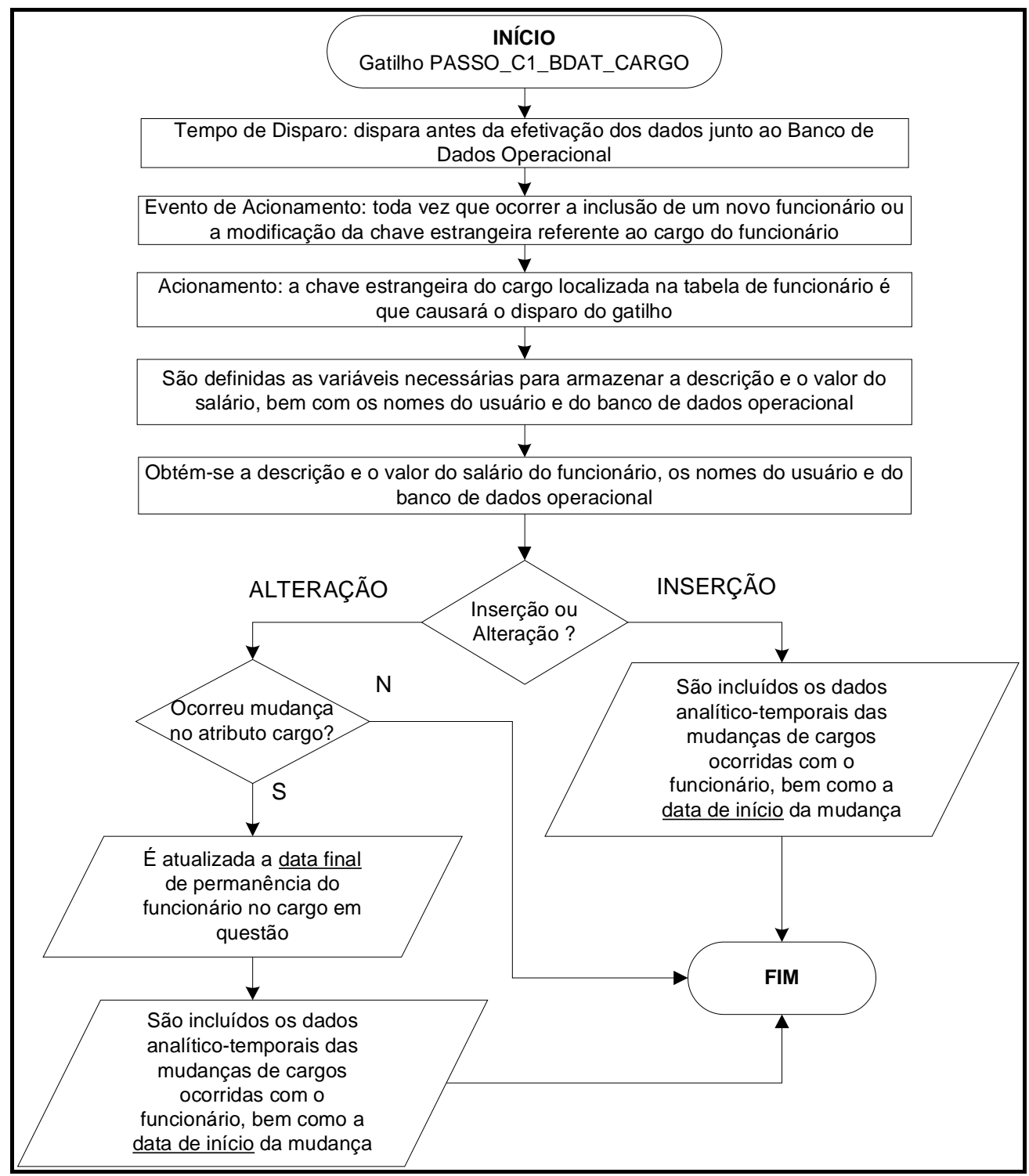

Figura 65. Fluxograma do gatilho do PASSO_C1_BDAT_CARGO

Os próximos dois gatilhos foram programados com base no modelo de dados apresentado na Figura 57. A finalidade é enviar dados referentes às mudanças de grau de instrução ocorridas com os funcionários, bem como das mudanças de categoria dos professores, toda vez que houver a inclusão ou a alteração de um funcionário e/ou de um professor.

Como, tanto os dados dos funcionários quanto os dados dos professores serão enviados para um mesmo conjunto de entidades junto ao Banco de Dados AnalíticoTemporal (BDAT), colocou-se, no script desses dois gatilhos, uma instrução para buscar o nome do sistema (PARAMETRO). Este, por sua vez, envia os dados, para 
que os mesmos possam servir, futuramente, para identificar a origem operacional dos dados.

Portanto, são dois gatilhos, o "PASSO_C1_BDAT_CAT1", que foi criado junto ao "BDO_FOLHA" e o "PASSO_C1_BDAT_CAT2, criado junto ao "BDO_ACADEMICO", conforme fluxogramas das figuras 66 e 67 . As especificações desses dois gatilhos podem ser encontradas no Apêndice F.

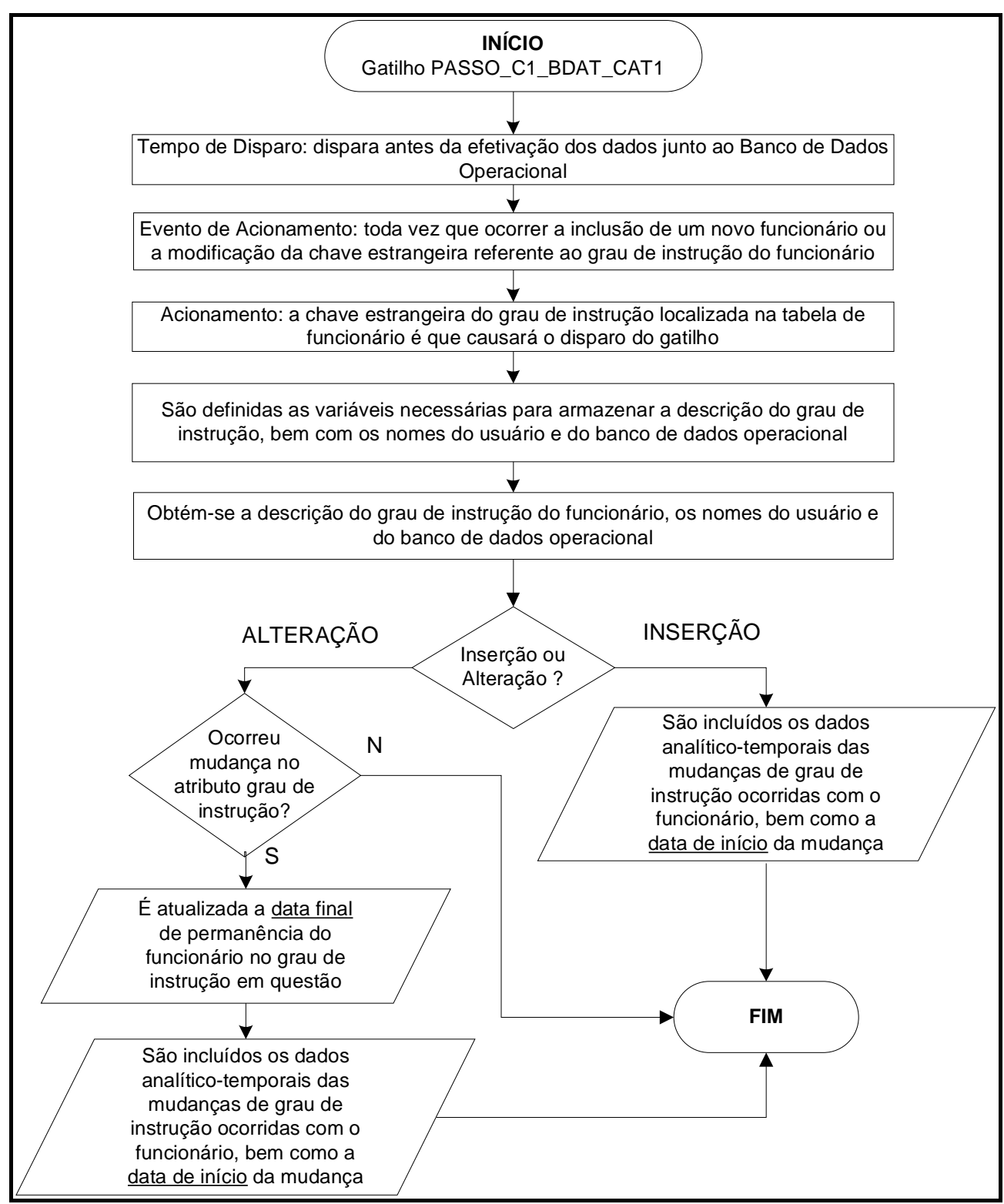

Figura 66. Fluxograma do gatilho do PASSO_C1_BDAT_CAT1 


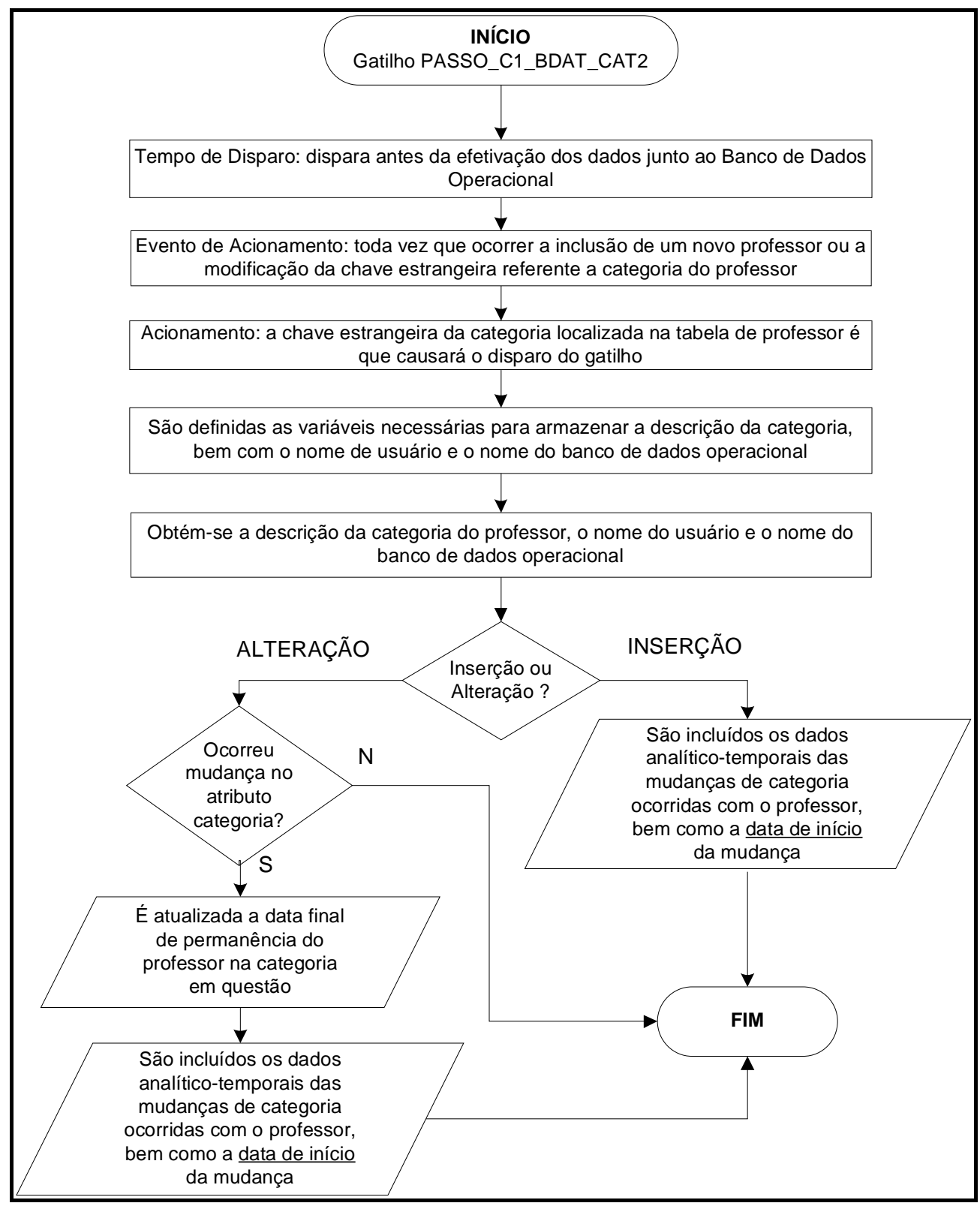

Figura 67. Fluxograma do gatilho do PASSO_C1_BDAT_CAT2

O próximo gatilho foi programado com base no modelo de dados apresentado na Figura 58. Definido por "PASSO_C1_BDAT_COORDENADORIA", sua finalidade é enviar dados referentes às mudanças de coordenadoria, toda vez que houver a inclusão de uma nova coordenadoria ou a alteração das coordenadorias existentes, conforme ilustrado no fluxograma da Figura 68. A especificação do gatilho pode ser encontrada no Apêndice F. 


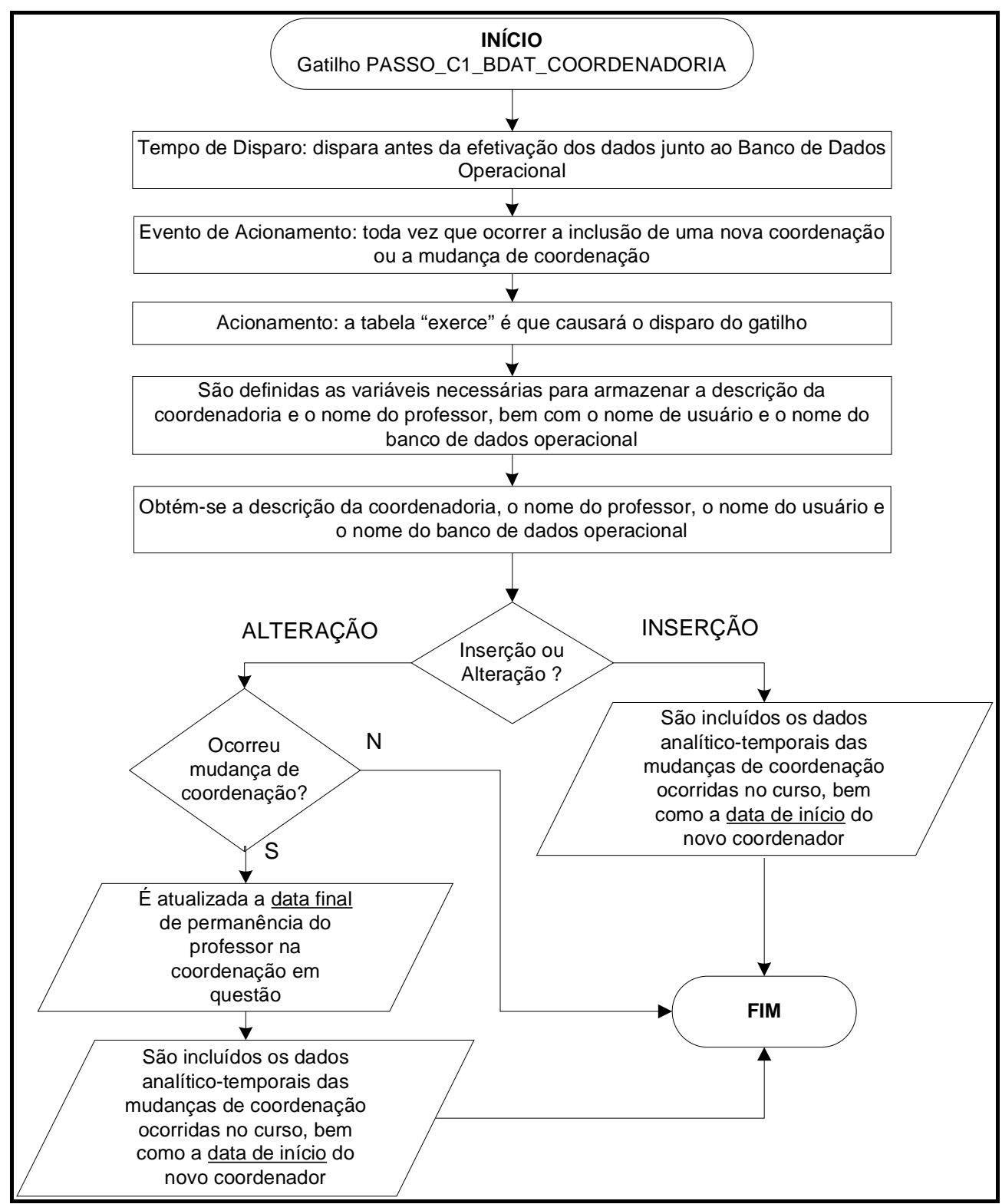

Figura 68. Fluxograma do gatilho do PASSO_C1_BDAT_COORDENADORIA

O próximo gatilho foi programado com base no modelo de dados apresentado na Figura 60. São dois gatilhos, o "PASSO_C1_BDAT_ENDER_EMP1" e o "PASSO_C1_BDAT_ENDER_EMP2". Sua finalidade é enviar dados referentes às mudanças de endereços ocorridas com funcionários e/ou professores.

A Figura 69 ilustra o gatilho "PASSO_C1_BDAT_ENDER_EMP1", criado junto ao Banco de Dados Operacional "BDO_FOLHA". A Figura 70 ilustra o gatilho "PASSO_C1_BDAT_ENDER_EMP2", criado junto ao Banco de Dados Operacional 
"BDO_ACADEMICO". As especificações dos gatilhos podem ser encontradas no Apêndice F.

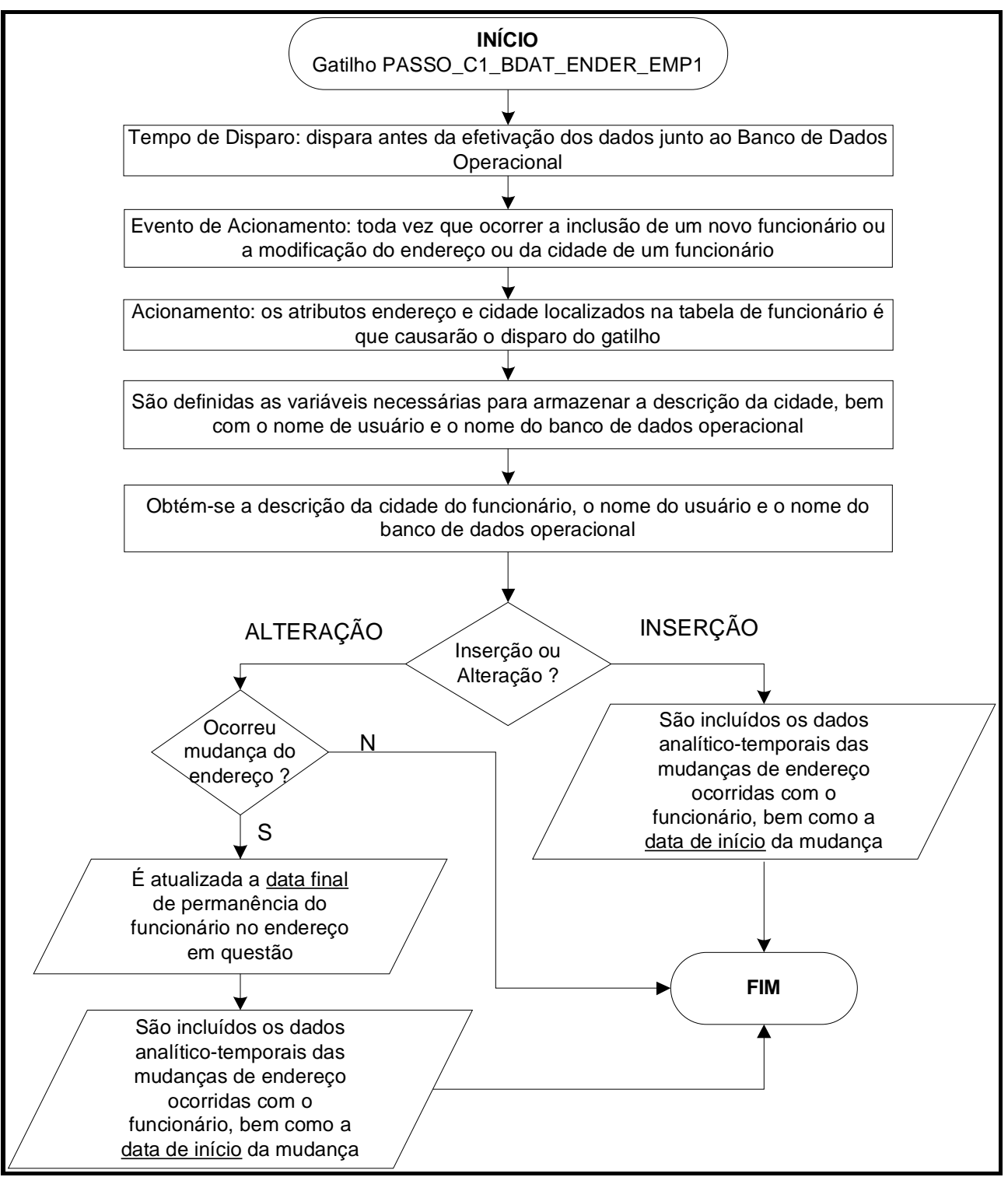

Figura 69. Fluxograma do gatilho do PASSO_C1_BDAT_ENDER_EMP1 


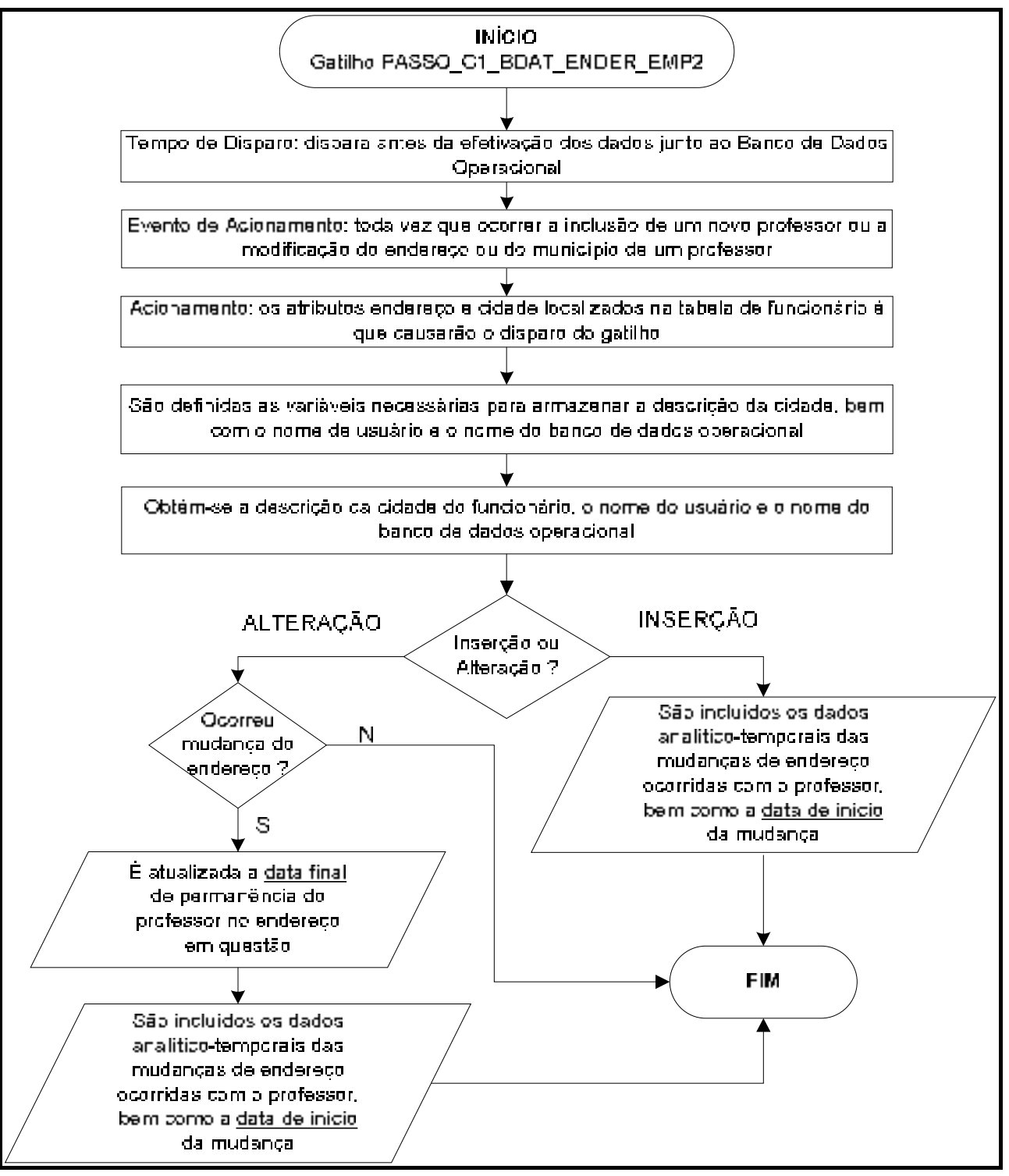

Figura 70. Fluxograma do gatilho do PASSO_C1_BDAT_ENDER_EMP2 


\subsubsection{Passo C2: Geração de Gatilhos para o Passo B4}

A finalidade deste passo é programar gatilhos responsáveis por enviar dados operacionais pré-calculados (atributos derivados) ao Banco de Dados AnalíticoTemporal.

O gatilho "PASSO_C2_BDAT_MEDIA" foi programado com base no modelo de dados apresentados na Figura 61. Sua finalidade é enviar dados pré-calculados todas as vezes que ocorrerem alteração de notas dos alunos, conforme fluxograma ilustrado na Figura 71. A especificação do gatilho pode ser encontrada no Apêndice F.

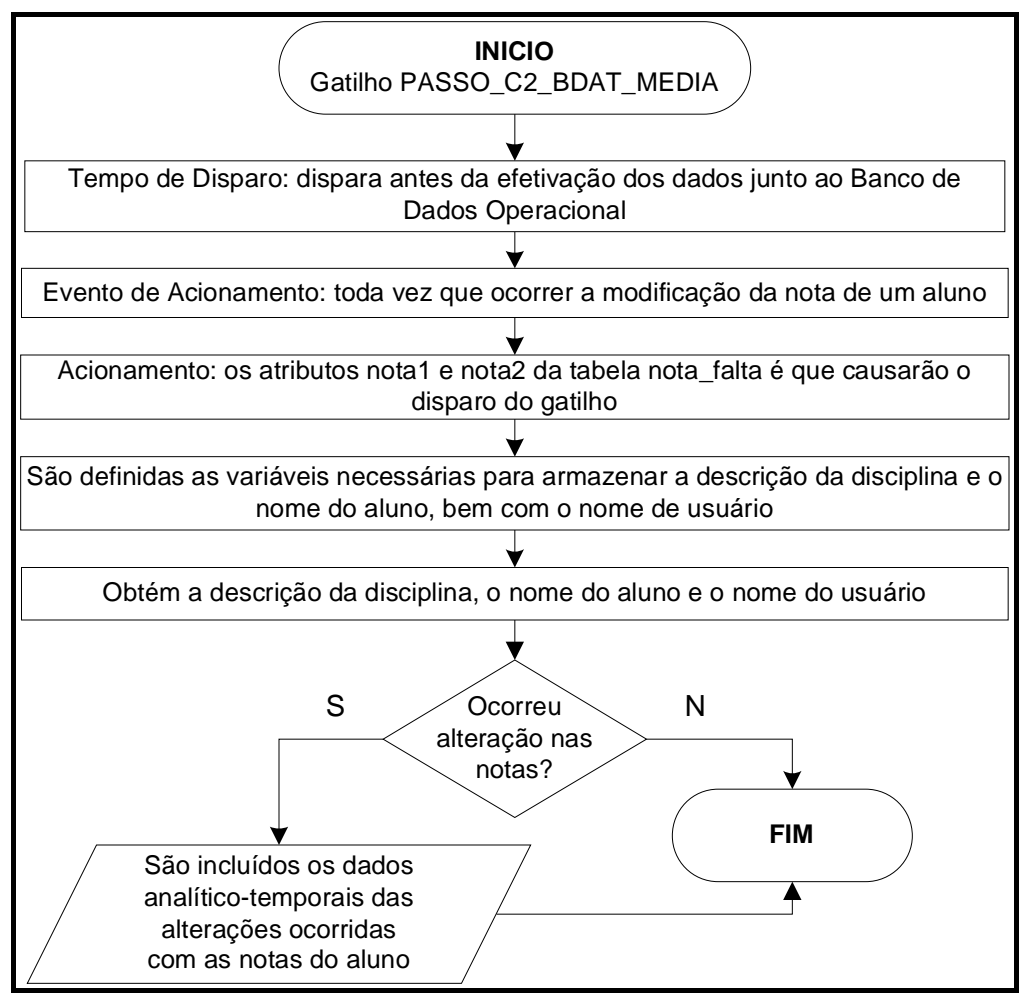

Figura 71. Fluxograma do gatilho do PASSO_C2_BDAT_MEDIA

\subsubsection{Passo C3: Geração de Procedimentos Armazenados para o Passo B4}

O procedimento armazenado "PASSO_C3_BDAT_ANUAL_EMP" foi programado com base no modelo de dados apresentados na Figura 63. Sua finalidade é agrupar 
e totalizar dados referentes aos pagamentos efetuados, anualmente, aos empregados, conforme fluxograma ilustrado na Figura 72. A especificação do gatilho pode ser encontrada no Apêndice F.

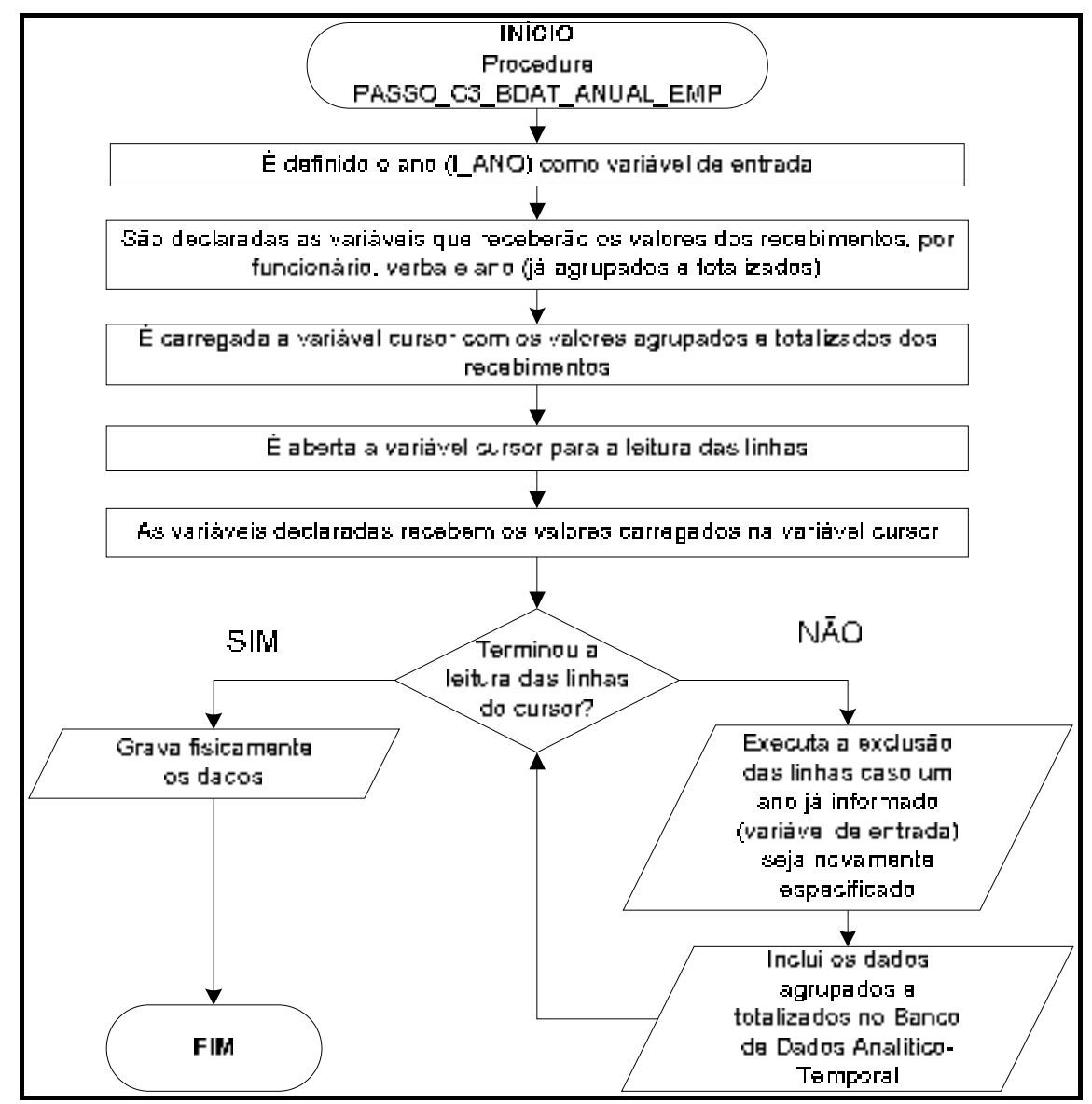

Figura 72. Fluxograma do Procedimento Armazenado do
PASSO_C3_BDAT_ANUAL_EMP

Já o procedimento armazenado "PASSO_C3_BDAT_FALTA" foi programado com base no modelo de dados apresentados na Figura 62. Sua finalidade é agrupar e totalizar dados referentes às faltas anuais dos alunos, conforme fluxograma ilustrado na Figura 73. A especificação do gatilho pode ser encontrada no Apêndice F. 


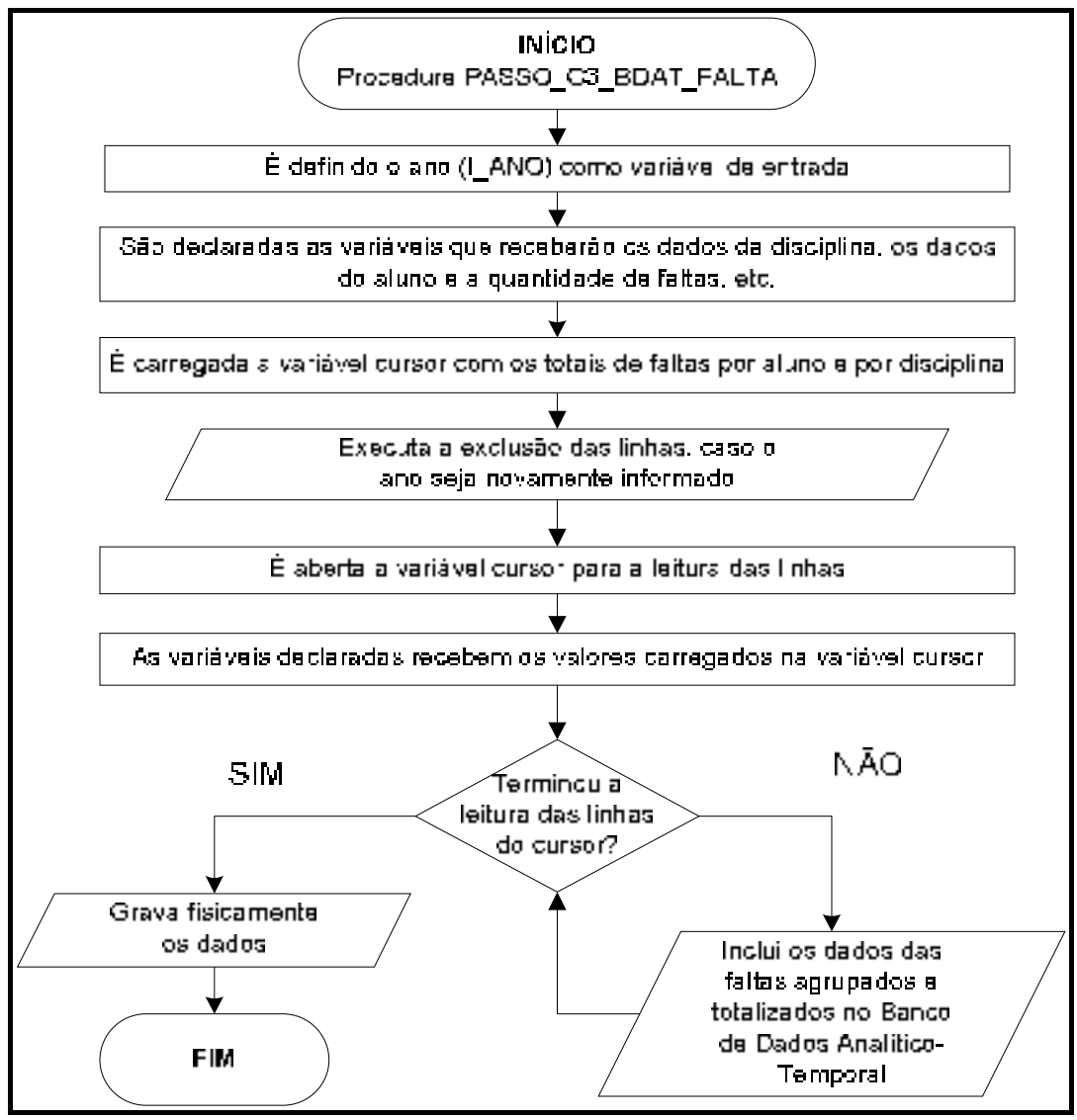

Figura 73. Fluxograma do Procedimento Armazenado do PASSO_C3_BDAT_FALTA

\subsubsection{Resultados Obtidos em Testes Práticos}

Foram realizados alguns testes práticos junto ao modelo implementado como resultado do estudo de caso. A principal motivação para a realização desses testes refere-se a, por um lado, verificar uma implementação real do modelo proposto e por outro lado, verificar qual a sobrecarga causada nos Bancos de Dados Operacionais em razão da criação de gatilhos e de procedimentos armazenados. Uma outra classe de testes refere-se a realizar um estudo comparativo relacionado a questões de desempenho, entre o modelo proposto e o ambiente de Data Warehousing, 


\subsubsection{Testes do Modelo Analítico-Temporal}

Com vista a realizar testes no Modelo Analítico-Temporal proposto, foram simulados alguns cenários. As simulações foram feitas com base em alterações de salários dos funcionários junto ao Banco de Dados Operacional (BDO_FOLHA).

10 Cenário: sem criação de gatilhos e de procedimentos armazenados, ou seja, com o Banco de Dados Operacional original:

- Transação 01: para atualizar o salário de apenas um funcionário, o Sistema Gerenciador de Banco de Dados consumiu, em média, 1 ms.

- Transação 02: para atualizar o salário de todos os funcionários, o Sistema Gerenciador de Banco de Dados consumiu, em média, 3 ms.

20 Cenário: com criação de um gatilho para gerar históricos de mudanças de salários dos funcionários, bem como com a criação de conexão entre os bancos de dados, ou seja, com a implantação da presente proposta. Nesse cenário, partiu-se de uma instância vazia, ou seja, o Banco de Dados Analítico-Temporal ainda não possuía nenhuma tupla armazenada:

- Transação 01: para atualizar o salário de apenas um funcionário, o Sistema Gerenciador de Banco de Dados consumiu, em média, 3 ms.

- Transação 02: para atualizar o salário de todos os funcionários o Sistema Gerenciador de Banco de Dados consumiu, em média, 1.020 ms.

30 Cenário: Idem ao Cenário 02, exceptuando-se o fato de que se partiu de uma instância inicial de 155 tuplas de históricos de mudança de salário (já havia 155 tuplas no Banco de Dados Analítico-Temporal):

- Transação 01: para atualizar o salário de apenas um funcionário, o Sistema Gerenciador de Banco de Dados consumiu, em média, 4 ms.

- Transação 02: para atualizar o salário de todos os funcionários, o Sistema Gerenciador de Banco de Dados consumiu, em média, 1.021 ms. 
Analisando-se os resultados obtidos, pode-se concluir que, de fato, ocorre uma sobrecarga nos Bancos de Dados Operacionais, já que é aí que esses os gatilhos estão instalados. No entanto, há alguns fatores atenuantes. Em primeiro lugar, considerando-se as atualizações isoladas, o tempo absoluto ainda se situa dentro de valores bastante aceitáveis. Em segundo lugar, a situação de atualização de toda uma base de valores é tarefa raramente realizada, ou ainda realizada em datas previamente conhecidas. Esses fatores acabam por minorar, assim, a grande sobrecarga observada com os resultados dos testes aqui apresentados.

5.4.4.2 Comparação entre o Modelo Proposto e o Modelo Multidimensional

De forma a possibilitar uma comparação do modelo proposto com o modelo multidimensional, utilizado no ambiente de Data Warehousing, foi modelado um problema conforme apresentado na Figura 74.

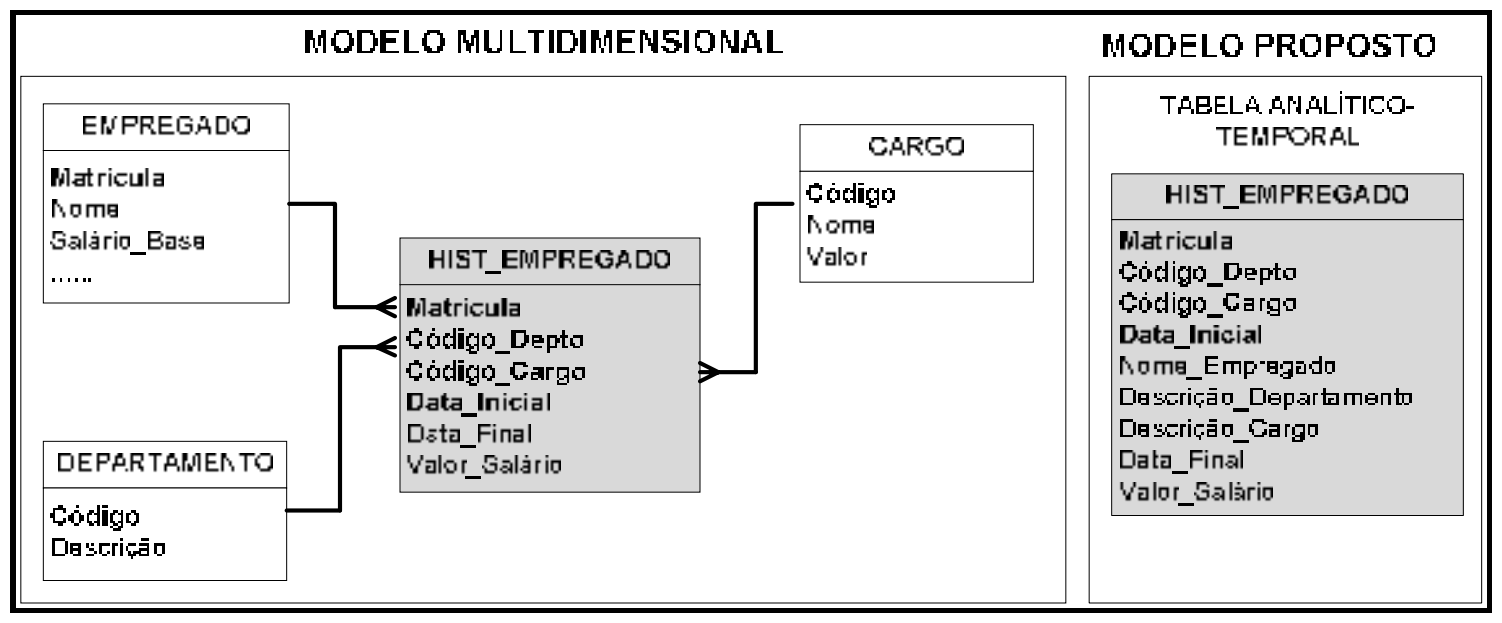

Figura 74. Modelos de Dados utilizados em testes

O Modelo Multidimensional foi implementado, considerando o mesmo número de tuplas do modelo analítico-temporal, ou seja, em ambos os modelos a tabela HIST_EMPREGADO testada continha 10.000 tuplas.

Com base nesses modelos de dados, foram simulados alguns cenários obtendo-se os seguintes resultados: 
10 Cenário: filtrar e totalizar 3.000 tuplas:

- Modelo Analítico-Temporal: apresentou um tempo total de, em média, 6 ms.

- Modelo Multidimensional: apresentou um tempo total de,_em média, $10.5 \mathrm{~ms}$.

2ํㅡㄹ Cenário: filtrar e totalizar 1.000 tuplas:

- Modelo Analítico-Temporal: apresentou um tempo total de, em média, 3.5 ms.

- Modelo Multidimensional: apresentou um tempo total de, em média, 9 ms.

3o Cenário: filtrar e totalizar 10 tuplas:

- Modelo Analítico-Temporal: apresentou um tempo total de, em média, 3.4 ms.

- Modelo Multidimensional: apresentou um tempo total de, em média, 6.5 ms.

4ํㅡㄹ Cenário: filtrar e totalizar 01 tupla:

- Modelo Analítico-Temporal: apresentou um tempo total de, em média, 3.3 ms.

- Modelo Multidimensional: apresentou um tempo total de, em média, 6.4 ms.

Analisando-se os resultados obtidos, pode-se concluir que, de fato, a recuperação de informações com base no modelo proposto é mais rápida em relação ao modelo multidimensional utilizado em ambientes de Data Warehousing. Atribui-se a esse melhor desempenho, o fato de que no modelo proposto não existe a necessidade de acessar outras tabelas, visto que as informações estão todas contidas na tabela analítico-temporal, enquanto que no modelo multidimensional, existe a necessidade desse acesso, já que os atributos descritivos estão armazenados nas tabelas de dimensões. 


\section{CONCLUSÕES}

A metodologia apresentada nesta tese tem a finalidade de servir como condutor para a modelagem e implementação de Bancos de Dados Analítico-Temporais. O modelo proposto objetiva ser completo, no sentido de abranger todas as atividades importantes na definição de um banco de dados desse tipo.

Nesse sentido, o conjunto das atividades propostas constitui-se em uma importante contribuição aos desenvolvedores de tal tipo de sistemas, considerando-se as significativas vantagens de tempo no desenvolvimento e implementação do modelo proposto.

Uma das atividades mais relevantes diz respeito à identificação dos dados a serem aproveitados, total ou parcialmente em um Banco de Dados Analítico-Temporal.

Questões relacionadas à qualidade e integração dos dados estão também contempladas na modelagem sugerida, tendo em vista que os principais problemas encontrados nos Bancos de Dados Operacionais são considerados e resolvidos, quando da fase inicial da modelagem. Tal tipo de problema ocorre, principalmente, quando há a necessidade de integrar mais do que um Banco de Dados Operacional para formar o Banco de Dados Analítico-Temporal. Além disso, considera-se ser este último um dos fatores mais importantes da referida tese.

Finalmente, a forma de extração, transformação e carga dos dados, dos Bancos de Dados Operacionais para os Bancos de Dados Analítico-Temporais, por meio de gatilhos e procedimentos armazenados, representa um ganho considerável em relação ao processo tradicionalmente utilizado em ambientes de Data Warehousing.

\subsection{RESULTADOS ALCANÇADOS}

Pode-se dizer que os objetivos inicialmente estabelecidos para este trabalho foram alcançados, já que a proposição de uma nova forma de modelagem voltada para a geração de Bancos de Dados Analítico-Temporais, bem como a proposição de 
implementação de mecanismos de extração, transformação e carga dos dados, foram apresentados.

Considerando tais objetivos, é possível apontar os principais resultados obtidos com a forma de modelagem aqui proposta.

O primeiro resultado refere-se à eficácia do modelo proposto, já que, por meio das duas primeiras atividades as quais tratam das questões de modelagem de dados, consegue-se obter um Modelo de Dados Analítico-Temporal bastante adequado para atender às necessidades relacionadas ao processo de tomada de decisões de médio e longo prazos.

Comparativamente com o processo de ETL utilizado nos ambientes de Data Warehousing, é possível que o uso de gatilhos e procedimentos armazenados para a geração e carga dos dados analítico-temporais seja uma forma mais simples, menos complexa, mais rápida e adequada, já que os dados serão obtidos, única e exclusivamente, de Bancos de Dados Operacionais, os quais dão suporte para o uso de gatilhos e procedimentos armazenados.

A questão da qualidade dos dados também merece destaque como um dos importantes resultados produzidos, pois tanto no processo de modelagem, quanto nos processos de extração, transformação e carga propostos, os dados passam por um processo de melhoria de sua qualidade, eliminando-se, por exemplo, dados com mesmo nome, mas com diferentes significados.

Outro resultado positivo a ser considerado refere-se a que a estrutura dos Bancos de Dados Operacionais não é afetada, sendo necessária apenas a inserção de gatilhos e procedimentos armazenados, além de alguns pequenos detalhes necessários à operacionalização dos mesmos. Nessa mesma linha, não são necessárias alterações nos programas utilizados pelos usuários finais.

Um resultado bastante interessante está ligado aos períodos de atualizações sugeridos pelo modelo proposto. A maioria das atualizações deve ser propagada ao Banco de Dados Analítico-Temporal, logo após uma ação de modificação ter sido submetida aos Bancos de Dados Operacionais, obtendo-se assim, um sincronismo quase que imediato, entre os Bancos de Dados Analítico-Temporais e os Banco de Dados Operacionais. 
No que se refere à sobrecarga de processamento no ambiente operacional, pode-se dizer que os testes realizados, de fato, indicaram tal problema. No entanto, considerando-se que a quantidade de registros a serem inseridos no Banco de Dados Analítico-Temporal não será grande, a cada disparo dos gatilhos inseridos no ambiente operacional, entende-se que a sobrecarga imposta não prejudique sensivelmente o seu desempenho. Além do mais, os procedimentos armazenados, responsáveis por calcular informações derivadas, serão acionados em períodos agendados, amenizando, assim, a utilização do ambiente operacional.

Além do mais, a sobrecarga não depende exclusivamente dos Sistemas de Bancos de Dados, mas também de outros aspectos envolvidos em sua implantação, tais como: topologias de rede, configurações dos equipamentos, elaboração adequada dos programas e da análise de dados, etc.

Outro resultado de destaque refere-se à facilidade de alterações no modelo desenvolvido, tendo em vista a boa modularidade da forma de modelagem proposta. Assim, alterações que se façam necessárias, em virtude de mudanças nas especificações, podem ser facilmente representadas no modelo proposto.

\subsection{TRABALHOS FUTUROS}

Uma primeira sugestão de trabalhos futuros refere-se à possibilidade de que sejam desenvolvidas ferramentas computacionais para automatizar a implantação do modelo proposto, permitindo a desenvolvedores assumirem uma tarefa de verificação dos resultados obtidos pelas ferramentas.

O primeiro tipo de ferramenta computacional a ser desenvolvida diz respeito ao auxílio às atividades de modelagem (etapas A e B). Essa ferramenta seria usada para o mapeamento dos dados analítico-temporais, com base nos Modelos de Dados Operacionais, tendo como resultado final um esboço do Modelo de Dados Analítico-Temporal.

O segundo tipo de ferramenta computacional a ser desenvolvido está ligado à terceira atividade relacionada à criação automatizada dos gatilhos e procedimentos armazenados (Etapa C), com base nos Modelos de Dados Operacionais e Analítico- 
Temporais. Essa ferramenta teria a função de gerar, automaticamente, uma précodificação dos gatilhos e dos procedimentos armazenados, com base nos esquemas dos Bancos de Dados Operacionais e no Banco de Dados AnalíticoTemporal.

Outra sugestão de trabalhos futuros refere-se à possibilidade de se ter uma documentação automatizada dos metadados relativos aos dados transferidos para 0 Banco de Dados Analítico-Temporal, tendo em vista que um registro preciso dos metadados é de vital importância para eventuais manutenções do modelo proposto.

A criação de ferramentas do tipo OLAP, com base no o tipo de modelagem proposta, que possibilitariam uma exploração plena do ambiente proposto, facilitando sobremaneira a tarefa de geração de relatórios a partir do Banco de Dados AnalíticoTemporal, se configura em outra possibilidade de desenvolvimento de futuros trabalhos.

Uma última sugestão de trabalhos futuros a ser desenvolvida é o aprimoramento do modelo proposto em relação ao tratamento de falhas de comunicação entre os Bancos de Dados Operacionais e o Banco de Dados Analítico-Temporal, já que caso isso ocorra, acarretará na não atualização do Banco de Dados Analítico-Temporal, visto que os gatilhos são preparados para propagar as atualizações no ato em que as mesmas ocorrem junto aos Bancos de Dados Operacionais. 


\section{REFERÊNCIAS}

AMARAL, Glenda Carla Moura. AQUAWARE: Um ambiente de suporte à qualidade de dados em data warehouse. 2003. 164 p. Dissertação (Mestrado) Instituto de Matemática - Universidade Federal do Rio de Janeiro, Rio de Janeiro, 2003.

ANDRADE, Fábio Bahia; SANTIAGO, Luciano Diniz Guerra. Introdução aos conceitos de modelagem multidimensional aplicados a data warehouses. Faculdade Ruy Barbosa, Revista CienteFico, Salvador, v.2, julho-dezembro, 2003. 12 p.

ANGONESE, Silvio Fernando; EDELWEISS, Nina. Gerenciador temporal de versões de esquemas. In CONFERENCIA LATINOAMERICANA DE INFORMÁTICA, 27. 2001, Mérida, Venezuela. Anais CLEl'2001. Mérida, 2001. 12 p.

BERLIAN, Rosalie Barreto; SALGADO, Ana Carolina. Aspectos semânticos em um sistema de integração de informações na web. In: WORKSHOP DE WEB SEMÂNTICA, 1., 2004, Brasília. Workshop Proceedings., 2004. 6 p.

BOOCH, Grady; RUMBAUGH, James; JACOBSON, Ivar. UML, guia do usuário. Rio de Janeiro. Editora: Campus Ltda, 2000.

CORDEIRO, Robson Leonardo Ferreira; SANTOS, Clesio Saraiva dos; EDELWEISS, Nina; GALANTE, Renata de Matos. Classificação de restrições de integridade em bancos de dados temporais de versões. In: BRAZILIAN SYMPOSIUM ON DATABASES, 19., 2004, Brasília. Anais/Proceedings SBBD’2004. Brasilia, 2004. p. 336-377.

COREY, Michael; ABBEY, Michael; ABRAMSON, lan; TAUB, Ben. Oracle 8i Data Warehouse. Rio de Janeiro: Editora Campus (Autorizado por Oracle Press), 2001.

COSTA, Rogério Luís de C. SQL: guia prático. 2. ed. Rio de Janeiro: Editora Brasport, 2006.

COSTA NETO, José Craveiro, SATO, Liria Matsumoto. Construção de um ambiente de dados sobre um sistema de arquivos paralelos. In: BOLETIM TÉCNICO. Escola Politécnica da USP, Departamento de Engenharia da Computação e Sistemas Digitais, São Paulo, 2002, 12 p. 
DATE, Christopher J.; Introdução a Sistemas de Banco de Dados. Tradução de Daniel Vieira. 8. ed. Rio de Janeiro: Editora Elsevier, 2003.

DIAS, Fernando Skackauskas. Estudo exploratório da avaliação de sistemas de informação. In: SIMPÓSIO MINEIRO DE SISTEMA DE INFORMAÇÃO, 2005, Belo Horizonte, Anais SBC - SMSI. Belo Horizonte, 2005. 8 p.

EDELWEISS, Nina. Bancos de dados temporais: teoria e prática. In: JORNADA DE ATUALIZAĈÃO EM INFORMÁTICA, 17. CONGRESSO NACIONAL DA SBC, 18, 1998. Recife: Sociedade Brasileira de Computação. v.2. Editora H.P. Moura. Anais do XVIII Congresso Nacional da Sociedade Brasileira de Computação "Rumo à Sociedade do Conhecimento", Recife, 1998. p. 225-282.

EDELWEISS, Nina; OLIVEIRA. José Palazzo M. Modelagem de aspectos temporais de sistemas de informação. Universidade Federal de Pernambuco. Livro Texto da Escola de Computação, 9., Recife, 1994. 162 p.

FANDERUFF, Damaris. Oracle8i - Utilizando SQL*Plus e PL/SQL. 1. ed. São Paulo: Editora Makron Books, 2000.

FERNANDES, Sérgio Antonio de Souza. 0 projecto de data warehouses: a tecnologia ROLAP versus MOLAP. Lisboa, Portugal, janeiro, 2004. 13 p.

GALANTE, Renata de Matos; EDELWEISS, Nina; SANTOS, Clesio Saraiva dos. Evolução de esquemas e propagação de mudanças usando o modelo temporal de versões. CONFERENCIA LATINOAMERICANA DE INFORMÁTICA, 28, 2002, Editora da Universidad de la Republica Montevideo. Anais do CLEl'2002. Montevideo, 2002. $12 \mathrm{p}$.

GOLFARELLI, Mateo; MAIO, Dario; RIZZI, Stefano. Conceptual Design of Data Warehouses from E/R Schemes. In: HAWAII INTERNATIONAL HIERARQUIAS CONFERENCE ON SYSTEMS SCIENCES, 1998, Hawaii. Proceedings. Hawaii, 1998. $10 \mathrm{p}$.

GONÇALVES, Márcio. Extração de Dados para Data Warehouse. Rio de Janeiro: Editora Axcel Bookes do Brasil, 2003.

GRANDI, Fabio; MANDREOLI, Federica; TIBERIO, Paolo; BERGONZINI, Marco. A temporal data model and management system for normative texts in XML format. In: INTERNATIONAL WORKSHOP ON WEB INFORMATION AND DATA 
MANAGEMENT, 1, 2003, New Orleans, USA. ACM - WIDM'03. New Orleans, 2003. p. 29-36.

HEUSER, Carlos Alberto. Projeto de Banco de Dados. 3. ed. Porto Alegre: Editora Sagra Luzzato (Instituto de Informática da UFRGS), 1999.

HÜBLER, Patrícia Nogueira; EDELWEISS, Nina. Definição de um gerenciador para o modelo de dados TF-ORM. In: CONCURSO DE TESES E DISSERTAÇÕES DO CONGRESSO DA SBC, 37, 2001, Fortaleza. Anais SBC. 2001. 6 p.

INMON, Bill. Building the Data Warehouse. 2. ed. New York: Wiley Computer Publishing, 1996.

ITALIANO, Isabel Cristina; FERREIRA, João Eduardo. Synchronization options for data warehouse designs. IEEE Computer Magazine, Revista do IEEE Computer Society, março, 2006. p. 53-57.

LEE, Richard C.; TEPFENHART, William M. UML e C++: guia prático de desenvolvimento orientado a objeto. São Paulo: Editora Makron Books, 2001.

KERN, Vinícius Medina. Modelagem de informação com IDEF1X: linguagem, método, princípio do consenso. Revista Alcance, Itajaí, Editora da UNIVALI, v.3, novembro, 1999. p. 99-107.

KIMBALL, Ralph. Data Warehouse Toolkit: o guia completo para modelagem dimensional. Rio de Janeiro: Editora Campus, 2002.

KOCHHAR, Neena; KRAMER, Debby. Introduction to Oracle: SQL and PL/SQL Using Procedure Builder. v.3. São Paulo: Editora Oracle Education, 1998.

KROENKE, David M. Banco de Dados: Fundamentos, Projeto e Implementação. 6. ed. Rio de Janeiro: Editora LTC - Livros Técnicos e Científicos S.A,1999.

MACHADO, Felipe Nery R; ABREU, Mauricio. Projeto de Banco de Dados: uma visão prática. São Paulo: Editora Érica Ltda, 1995.

MANUAIS DA ORACLE UNIVERSITY - Introdução ao oracle: SQL e SQL *Plus. São Paulo: Editora Oracle Corporation, 2000. 
MARCÍLIO, Dalton Luiz. Análise e metodologia de integração de esquemas parte 1. Companhia de Informática do Paraná - CELEPAR - Estado do Paraná AEN (Agência Estadual de Notícias). Disponível em $<$ www.pr.gov.br/batebyte/edicoes/2002/bb123/analise.htm>. Acesso em: 21 mar. 2007.

MARTIN, James; McCLURE, Carma. Técnicas Estruturadas e CASE. Tradução de Lúcia Faria Silva. Revisão Técnica de Ronald Stevis Cassiolato. São Paulo: Editora Makron, McGraw-Hill, 1991.

MELO, Álvaro Nunes Lemos de; SILVA, Juliano Tonezer da Silva; CERVI, Cristiano Roberto; PAVAN, Willingthon. PyDbDiff - uma ferramenta para comparação de estruturas de bancos de dados. In: ESCOLA REGIONAL DE BANCO DE DADOS ERBD, 2, 2006, Passo Fundo, Universidade de Passo Fundo. Anais da II Escola Regional de Banco de Dados, abril, 2006. 6 p.

MELO, Rubens Nascimento; SILVA, Sidney Dias da; TANAKA, Asterio Kyoshi. Banco de Dados em Aplicações Cliente-Servidor. Rio de Janeiro: Editora Infobook, 1997.

MERGEN, Sérgio Luis Sardi; HEUSER, Carlos Alberto. Ferb: um framework para casamento de esquemas. In: ESCOLA REGIONAL DE BANCO DE DADOS - ERBD, 2, 2006, Passo Fundo, Universidade de Passo Fundo. Anais da II Escola Regional de Banco de Dados, abril, 2006. 6 p.

MOODY, Daniel L.; KORTINK, Mark A. R. From enterprise models to dimensional models: a methodology for data warehouse and data mart design. In: INTERNATIONAL WORKSHOP ON DESIGN AND MANAGEMENT OF DATA WAREHOUSE, 28., p.2, 2000, Stockholm. Proceedings of the International Workshop on Design and Management of Data Warehouse. Stockholm, june, 2000. p. 1-12.

NIST (National Institute of Standards and Technology). Federal Information Processing Standards Publication 184. Integration definition for information modeling (IDEF1X). Formalization was written by Robert G Brown. Gaithersburg, MD (USA), december, 1993. 184 p.

OLIVEIRA, Paulo Jorge; RODRIGUES, Fátima; HENRIQUES, Pedro Rangel. Limpeza de dados - uma visão geral. In: SIMPÓSIO DOUTORAL DO DEPARTAMENTO DE INFORMÁTICA, 1., 2004. Málaga. Proceedings of Data Gadgets 2004 Workshop-Bringing Up Emerging Solutions for Data Warehousing Systems, Málaga, Espanha, 2004. p. 39-51. 
OLIVEIRA, Wilson José de. Data Warehouse. 1. ed. Florianópolis: Editora Visual Books, 2002.

ÖZSOYOGLU, G.; SNODGRASS, R. T. Temporal and real-time databases: a survey. IEEE Transactions on Knowledge and Data Engineering, New York. Revista do IEEE Computer Society. v.7, n.4, p.513, 1995.

PASSOS, Emmanuel; GOLDSCHMIDT, Ronaldo. Data Mining: um guia prático. 1. ed. Rio de Janeiro: Editora Elsevier, 2005.

PETERS, James F.; PEDRYCZ, Witold. Software engineering: an engineering approach. New York: Library of Congress Cataloging-in-Publication Data, John Wiley \& Sons, 2000.

PINHO, Selma Foligne Crespio. Avaliação da qualidade de dados pela não conformidade. 2001. 110 p. Dissertação (Mestrado) - COPPE, Universidade Federal do Rio de Janeiro, Rio de Janeiro, 2001.

PINHEIRO, Sandro Favin; FORNARI, Miguel Rodrigues. Implementação de um modelo conceitual temporal e espacial utilizando o SGBD oracle. In: Seminário de Computação, 11, 2002. Blumenau. Anais do XI SEMINCO - Seminário de Computação, Blumenau, setembro, 2002. p. 25-38.

PRADELLA, Jorge Antônio Pinto. Bancos de dados ativos temporais. Curso de Pós-Graduação em Ciência da Computação. Professores: Nina Edelweiss e Clésio Saraiva dos Santos . Instituto de Informática. Universidade Federal do Rio Grande do Sul. Disponível em

<http://www.inf.ufrgs.br/ clesio/cmp151/cmp15120031/seminarios/artigo_jorge.pdf>.

Acesso em: 03 nov. 2004.

PRESSMAN, Roger S. Engenharia de Software. 5. ed. Rio de Janeiro: Editora McGraw Hill, 2002

RAMALHO, José Antonio. Oracle 10g: Ideal para quem deseja iniciar o aprendizado do Oracle. São Paulo: Editora Pioneira Thomson Learning, 2005.

SALVADOR, Valéria Farinazzo Martins; BRITTO, Mozart; MOURA JR., Lincoln de Assis; ALMEIDA JUNIOR, Jorge Rady. Qualidade de dados para gestão de conhecimento na área de saúde. In: CONGRESSO BRASILEIRO DE INFORMÁTICA EM SAÚDE, 10, 2006. Florianópolis. Anais do X Congresso Brasileiro de Informática em Saúde, v.1, outubro, 2006. p. 548-553. 
SANTOS, Constância da Silva. Implementação de bancos de dados temporais com versionamento de esquemas: um estudo comparativo. 2003. 68 p. Dissertação (Mestrado) - Instituto de Informática, Universidade Federal de Rio Grande do Sul, Porto Alegre, 2003.

SILBERSCHATZ, Abraham; KORTH, Henry F.; SUDARSHAN, S. Sistemas de Bancos de Dados. 5. ed. Tradução de Daniel Vieira. Rio de Janeiro: Editora Elsevier, 2006.

SINGH, Harry S. Data Warehouse: Conceitos, Tecnologias, Implementação e Gerenciamento. Tradução de Mônica Rosemberg. Revisão Técnica de José Davi Furlan. São Paulo: Editora Makron Books, 2001.

SOUZA, Solange Nice Alves de; CAMPOS, Edit Grassiani Lino; SANTOS, André Roberto Doreto dos. Uma ferramenta para a definição de consultas baseada em entidades e papéis. Revista IEEE América Latina. v.4, junho, 2006. p. 277-282.

SPRAGUE, Ralph H. Jr.; WATSON, Hugh J. Sistema de apoio à decisão: colocando a teoria em prática. 2. ed. Tradução de Anna Beatriz Gonçalves Rodrigues Silva. Rio de Janeiro: Editora Campus, 1991.

STAIR, Ralph M. Princípios de Sistemas de Informação: uma abordagem gerencial. 2 ed. Florida State University. Tradução de Maria Lúcia Lecker Vieira, Dalton Conde de Alencar. Rio de Janeiro: Editora LTC - Livros Técnicos e Científicos S.A., 1998.

TANSEL, Abdullah Uz. Temporal relational data model. Revista IEEE Computer Society (IEEE Transactions on Knowledge e Data Engineering), v.9, n.3, may/june, 1997. p. 464-479.

TRIBUNAL DE CONTAS DO ESTADO DE SÃO PAULO. Disponível em: (http://www.tce.sp.gov.brl. Acesso em: 06/02/2007.

VASSILIADIS, Panos; SIMITSIS, Alkis; SKIADOPOULOS, Spiros. Conceptual modeling for ETL processes. In: WORKSHOP ON DATA WAREHOUSING AND OLAP. Proceedings of the 5th ACM international workshop on Data Warehousing and OLAP. McLean, Virginia, USA, 2002. p. 14-21.

WANG, Fusheng; ZHOU, Xin; ZANIOLO, Carlo. Bridging relational database history and the web: the XML approach. In: WORKSHOP ON WEB INFORMATION AND DATA MANAGEMENT. Proceedings of the eighth ACM international workshop 
on Web information and data management - ACM - WIDM'06. Arlington, Virginia, USA, 2006. p. 3-10.

WIRTI, Carla Lia. Estudo de Técnicas para Casamento de Esquemas Relacionais. In: CONGRESSO SUL CATARINENSE DE COMPUTAÇÃO, 1. Promoção UNESC. Apoio SBC e FAPESC. Campus UNESC, Criciúma, Santa Catarina, Brasil, 28 de setembro - 01 de outubro, 2005. 4 p. 


\section{APÊNDICE A}

Especificação dos scripts utilizados para implementar os exemplos de fluxogramas apresentados na Etapa C do Capítulo 3 


\section{Especificação prática do Gatilho do Passo C1 - (T_PASSO_C1), apresentado pelo Fluxograma da Figura 31}

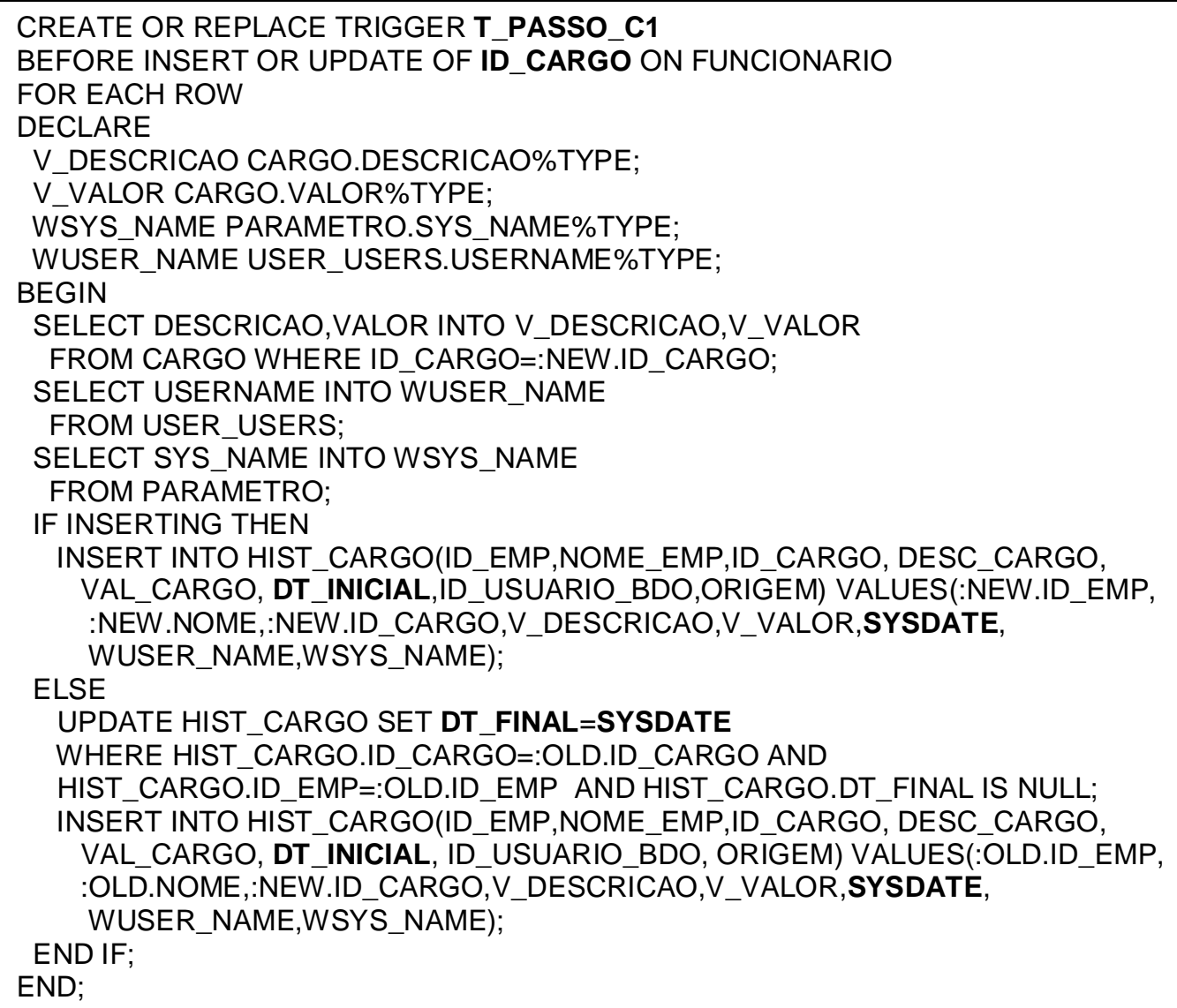

\section{Especificação prática do Gatilho do Passo C2 - (T_PASSO_C2), apresentado pelo Fluxograma da Figura 34}

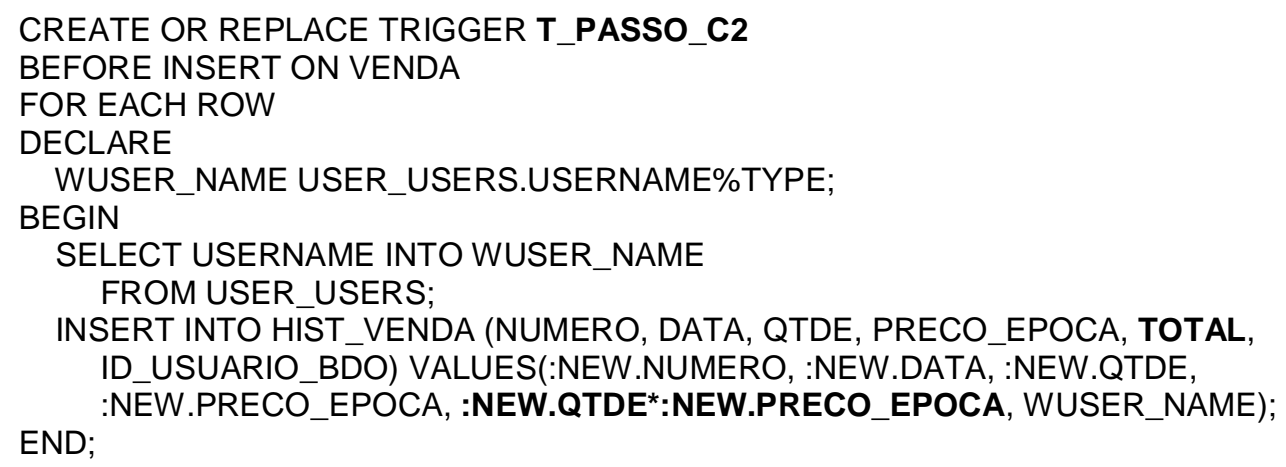




\section{Especificação prática do Procedimento Armazenado do Passo C3 - (P_PASSO_C3), apresentado pelo Fluxograma da Figura 37}

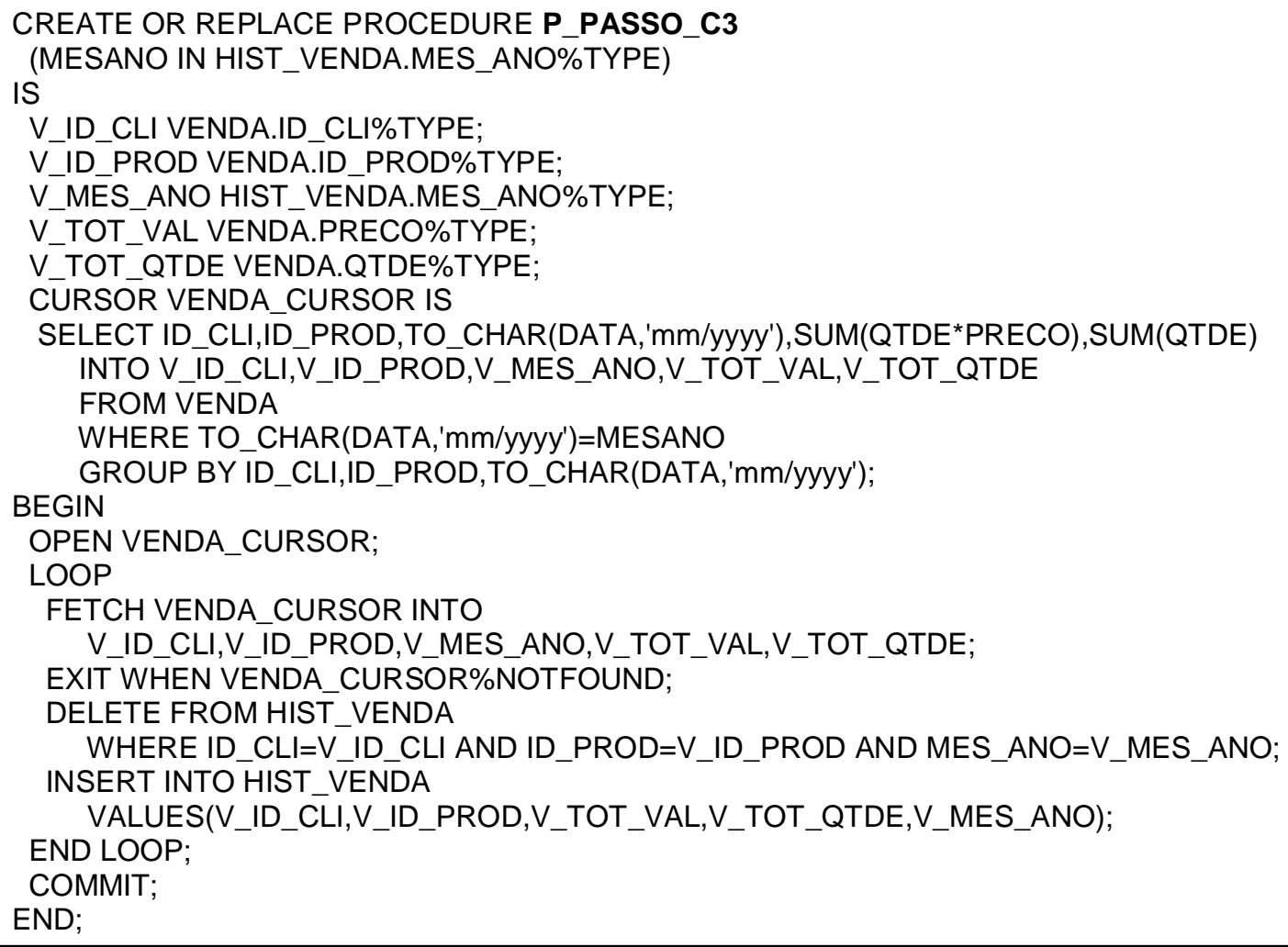




\section{APÊNDICE B}

Scripts para a criação do Banco de Dados Operacional (BDO_FOLHA) utilizado pelo setor de Recursos Humanos 


\section{Conjunto de entidades FUNCIONARIO - Cadastro de Funcionários}

CREATE TABLE FUNCIONARIO

(MATRICULA NUMBER(5),SITUACAO CHAR(1),NOME VARCHAR2(30),

CARGO NUMBER(3),GRAU_INSTR NUMBER(2),CIDADE NUMBER(3), ENDERECO

VARCHAR2(30),

NASCIMENTO DATE NOT NULL,SEXO CHAR(1),DATA_ADMIS DATE,

CONSTRAINT FUNCIONARIO_PK PRIMARY KEY(MATRICULA),

CONSTRAINT FUNCIONARIO_CARGO_FK FOREIGN KEY(CARGO) REFERENCES

CARGO(CODIGO),

CONSTRAINT FUNCIONARIO_GRAU_FK FOREIGN KEY(GRAU_INSTR) REFERENCES

GRAU_INSTRUCAO(CODIGO),

CONSTRAINT FUNCIONARIO_CIDADE_FK FOREIGN KEY(CIDADE) REFERENCES

CIDADE(CODIGO),

CONSTRAINT FUNCIONARIO_SITUACAO_FK FOREIGN KEY(SITUACAO) REFERENCES

SITUACAO(CODIGO),

CONSTRAINT FUNCIONARIO_SEXO_CK CHECK(SEXO='M' OR SEXO='F'));

\section{Conjunto de entidades CARGO - Cadastro de Cargos}

CREATE TABLE CARGO

(CODIGO NUMBER(3),DESCRICAO VARCHAR2(25),

SALARIO NUMBER $(10,2)$ NOT NULL,

CONSTRAINT CARGO_PK PRIMARY KEY(CODIGO));

\section{Conjunto de entidades CIDADE - Cadastro de Cidades}

CREATE TABLE CIDADE

(CODIGO NUMBER(3),DESCRICAO VARCHAR2(25),ESTADO CHAR(2),

CONSTRAINT CIDADE_PK PRIMARY KEY(CODIGO));

\section{Conjunto de entidades GRAU_INSTRUCAO - Cadastro de Graus de Instrução}


Conjunto de entidades SITUACAO - Cadastro de Tipos de Situação de Funcionários

CREATE TABLE SITUACAO

(CODIGO CHAR(1),NOME VARCHAR2(50),

CONSTRAINT SITUACAO_PK PRIMARY KEY(CODIGO));

\section{Conjunto de entidades RECEBE - Pagamentos Mensal/Anuais dos} Funcionários

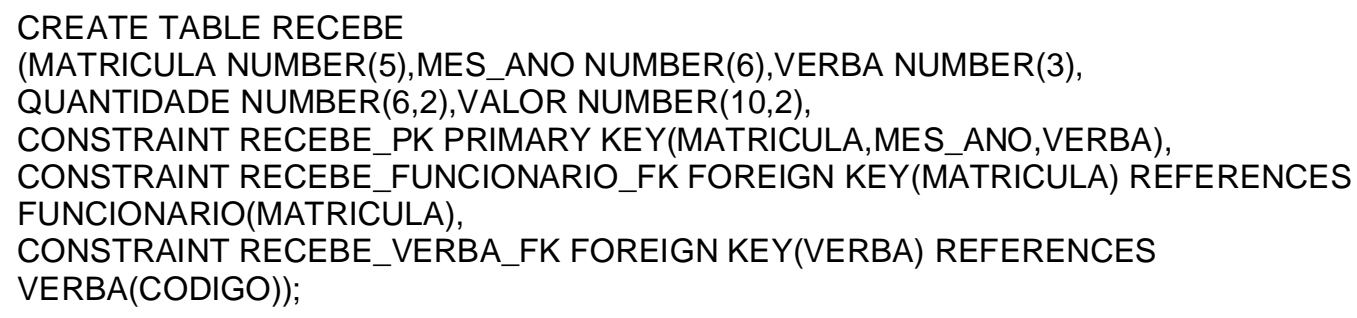

\section{Conjunto de entidades VERBA - Cadastro de Tipos de Vencimentos} e Descontos

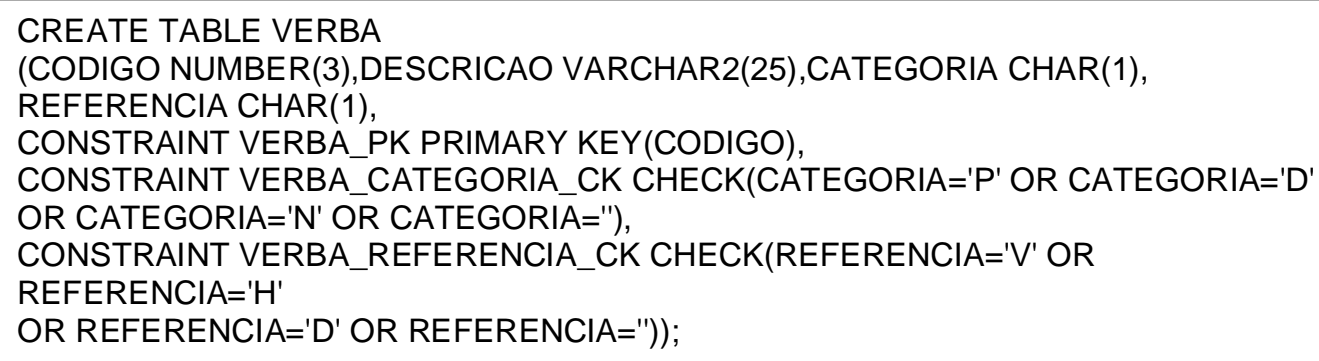

Conjunto de entidades PARAMETRO - Cadastro da Origem do Sistema

CREATE TABLE PARAMETRO

(SYS_NAME VARCHAR2(10));

INSERT INTO PARAMETRO VALUES('FOLHA');

'O atributo SYS_NAME deve ser preenchido com a palavra "FOLHA". 
Criação do DBLINK para conexão entre o BDO_FOLHA e o BDAT

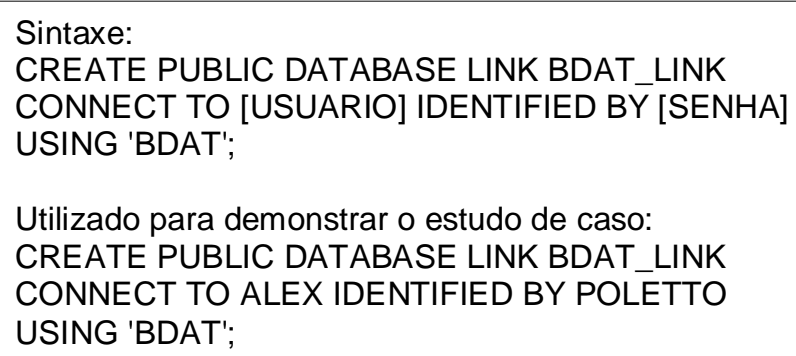




\section{APÊNDICE C}

Scripts para a criação do Banco de Dados Operacional (BDO_ACADEMICO) utilizado pelo setor Acadêmico 


\section{Conjunto de entidades ALUNO - Cadastro de Alunos}

CREATE TABLE ALUNO

(MATRICULA CHAR(10),NOME VARCHAR2(70), CURSO CHAR(3),SERIE CHAR(1), TURMA CHAR(1),MUNICIPIO NUMBER(3),SITUACAO_MATRICULA NUMBER(3), CONSTRAINT ALUNO_PK PRIMARY KEY(MATRICULA),

CONSTRAINT ALUNO_CURSO_FK FOREIGN KEY(CURSO) REFERENCES

CURSO(CODIGO),

CONSTRAINT ALUNO_MUNICIPIO_FK FOREIGN KEY(MUNICIPIO) REFERENCES

MUNICIPIO(CODIGO),

CONSTRAINT ALUNO_SITUACAO_FK FOREIGN

KEY(SITUACAO MATRICULA)REFERENCES SITUACAO(CODIGO),

CONSTRAINT ALUNO_TURMA_CK CHECK(TURMA='1' OR TURMA='2'));

\section{Conjunto de entidades NOTA_FALTA - Cadastro de Médias e Faltas}

CREATE TABLE NOTA_FALTA

(RA CHAR(10),COD_TURMA CHAR(10),ANO CHAR(4),DISCIPLINA CHAR(4),

SITUACAO CHAR(1),NOTA1 NUMBER(5,2),NOTA2 NUMBER(5,2),MEDIA NUMBER(5,2),

FALTAS1 NUMBER(3), FALTAS2 NUMBER(3),FALTAS3 NUMBER(3),

FALTAS4 NUMBER(3),FALTAS5 NUMBER(3), FALTAS6 NUMBER(3),

FALTAS7 NUMBER(3),FALTAS8 NUMBER(3), FALTAS9 NUMBER(3),

FALTAS10 NUMBER(3),FALTAS11 NUMBER(3),FALTAS12 NUMBER(3),

CONSTRAINT NOTA_FALTA_PK PRIMARY KEY(RA,COD_TURMA,ANO),

CONSTRAINT NOTA_FALTA_ALUNO_FK FOREIGN KEY(RA) REFERENCES

ALUNO(MATRICULA),

CONSTRAINT NOTA_FALTA_SIT_MAT_FK FOREIGN KEY(SITUACAO) REFERENCES

SIT_MAT(CODIGO),

CON̄STRAINT NOTA_FALTA_DISCIPLINA_FK FOREIGN KEY(DISCIPLINA)

REFERENCES DISCIPLINA(CODIGO));

\section{Conjunto de entidades EXERCE - Cadastro de Coordenadores}

\section{CREATE TABLE EXERCE}

(COORDENADORIA NUMBER(3),PROFESSOR NUMBER(4),

CONSTRAINT EXERCE_PK PRIMARY KEY(COORDENADORIA,PROFESSOR),

CONSTRAINT EXERCE_COORDENADORIA_FK FOREIGN KEY(COORDENADORIA)

REFERENCES COORDENADORIA(CODIGO),

CONSTRAINT EXERCE_PROFESSOR_FK FOREIGN KEY(PROFESSOR)

REFERENCES PROFESSOR(CODIGO)); 


\section{Conjunto de entidades COORDENADORIA - Cadastro de} Coordenadorias

CREATE TABLE COORDENADORIA (CODIGO NUMBER(2),DESCRICAO VARCHAR2(35),

CONSTRAINT COORDENADORIA_PK PRIMARY KEY(CODIGO));

\section{Conjunto de entidades CURSO - Cadastro de Cursos}

\section{CREATE TABLE CURSO}

(CODIGO CHAR(3),COORDENADORIA NUMBER(2),DESCRICAO VARCHAR2(70), CONSTRAINT CURSO_PK PRIMARY KEY(CODIGO),

CONSTRAINT CURSO_COORDENADORIA_FK FOREIGN KEY(COORDENADORIA) REFERENCES COORDENADORIA(CODIGŌ));

\section{Conjunto de entidades DISCIPLINA - Cadastro de Disciplinas}

\section{Conjunto de entidades MUNICIPIO - Cadastro de Municípios}

\section{Conjunto de entidades PROF_CATEGORIA - Cadastro de Categorias}




\section{Conjunto de entidades PROFESSOR - Cadastro de Docentes}

CREATE TABLE PROFESSOR

(CODIGO NUMBER(4),NOME VARCHAR2(40),DATA_NASCIMENTO DATE,

CATEGORIA NUMBER(2), ENDERECO VARCHAR2(70),MUNICIPIO NUMBER(3),

DATA_ADMISSAO DATE,SEXO CHAR(1),SITUACAO CHAR(1),

CONSTRAINT PROFESSOR_PK PRIMARY KEY(CODIGO),

CONSTRAINT PROFESSOR_CATEGORIA_FK FOREIGN KEY(CATEGORIA)

REFERENCES PROF_CATEGORIA(CODIGO),

CONSTRAINT PROFESSOR_MUNICIPIO_FK FOREIGN KEY(MUNICIPIO) REFERENCES

MUNICIPIO(CODIGO));

\section{Conjunto de entidades SITUACAO_MATRICULA - Cadastro de} Situação de Matriculas

CREATE TABLE SITUACAO_MATRICULA

(CODIGO CHAR(1),DESCRICAO VARCHAR2(20),

CONSTRAINT SIT_MAT_PK PRIMARY KEY(CODIGO));

\section{Conjunto de entidades SITUACAO - Cadastro de Situação de Alunos}

Conjunto de entidades PARAMETRO - Cadastro da Origem do Sistema

CREATE TABLE PARAMETRO

(SYS_NAME VARCHAR2(10));

INSERT INTO PARAMETRO VALUES('ACADEMICO');

'O atributo SYS_NAME deve ser preenchido com a palavra "ACADEMICO". 
Criação do DBLINK para conexão entre o BDO_ACADEMICO e o BDAT

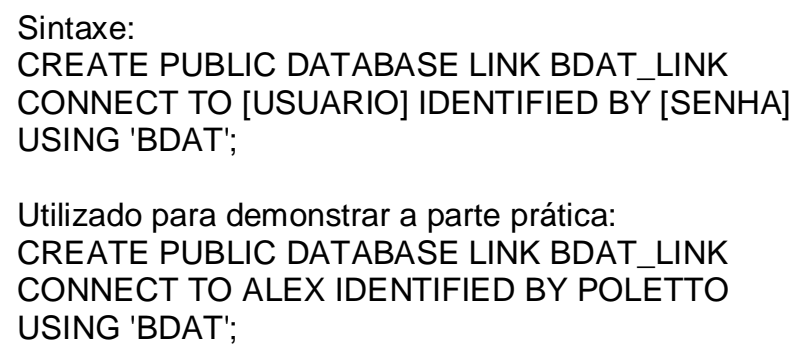




\section{APÊNDICE D}

Scripts para a configuração dos nomes de serviços dos Bancos de Dados Operacionais e do Banco de Dados Analítico-Temporal 


\section{Exemplo de configuração de nomes de domínios}

NAMES.DEFAULT DOMAIN = maq1. server01.com. br SQLNET.AUTHENTICATION_SERVICES= (NTS)

\section{Exemplo de configuração de nomes de serviços}

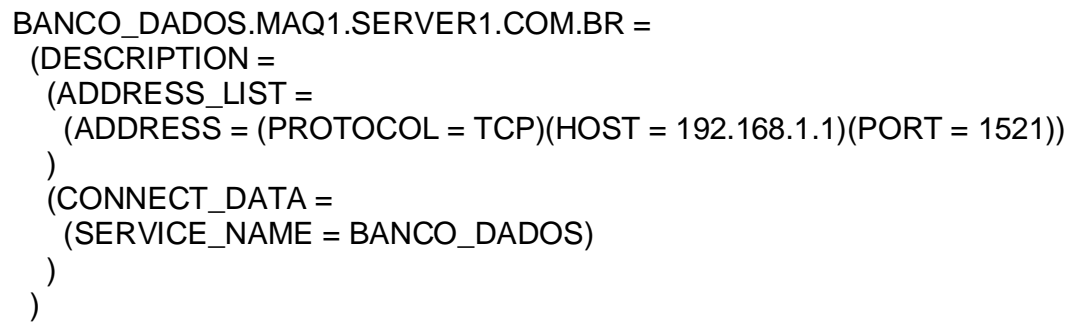

Configuração dos nomes de serviços que foram utilizados no estudo de caso. Foi utilizado apenas um computador para ilustrar o estudo de caso

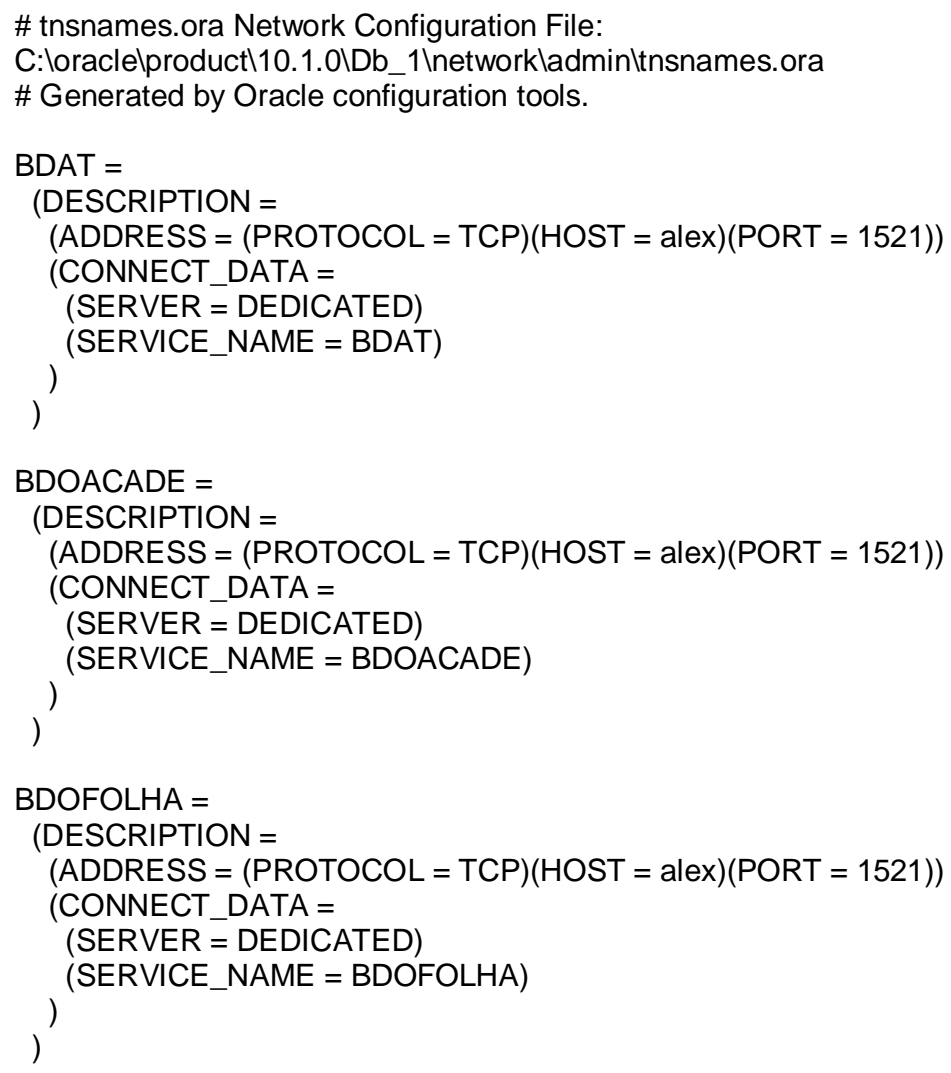




\section{APÊNDICE E}

Scripts para a criação do Banco de Dados Analítico-Temporal (BDAT) utilizado para armazenar os dados analítico-temporais 
Conjunto de entidades BDAT_ANUAL_EMP - utilizado para armazenar os pagamentos dos funcionários agrupados $\mathrm{e}$ totalizados por ano, verba e funcionário

CREATE TABLE BDAT_ANUAL_EMP

(ID_EMP NUMBER(5),ID_VERBA NUMBER(3),NOME_EMP VARCHAR2(35),

DESSCRICAO_VERBA VARCHAR2(40),ANO CHAR(4),

VALOR NUMBER(10,2),QUANTIDADE NUMBER(7,2),

CONSTRAINT BDAT_ANUAL_EMP_PK PRIMARY KEY(ID_EMP,ID_VERBA,ANO));

Conjunto de entidades BDAT_CARGO - utilizado para armazenar as mudanças de cargos ocorridas com os funcionários

CREATE TABLE BDAT_CARGO

(ID_EMP NUMBER(5),ID_CARGO NUMBER(3),NOME_EMP VARCHAR2(30),

DESSCRICAO_CARGO VARCHAR2(25),VALOR_CARGO NUMBER(10,2),

ID_USUARIO_BDO VARCHAR2(30),DT_INICIAL DATE,DT_FINAL DATE,

CONSTRAINT BDAT_CARGO_PK PRIMARY KEY(ID_EMP,ID_CARGO,DT_INICIAL));

Conjunto de entidades BDAT_CATEGORIA utilizado para armazenar as mudanças de graus de instruções e/ou categorias ocorridas com os funcionários e/ou professores

CREATE TABLE BDAT_CATEGORIA

(ID_EMP NUMBER(5),ID_CAT NUMBER(2),NOME_EMP VARCHAR2(40),

DESCRICAO_CAT VARCHAR2(100),ID_USUARIO_BDO VARCHAR2(30),

ORIGEM VARCHAR2(10),DT_INICIAL DATE,DT_FINAL DATE,

CONSTRAINT BDAT_CATEGORIA_PK PRIMARY KEY(ID_EMP, ID_CAT, ORIGEM,

DT_INICIAL));

Conjunto de entidades BDAT_COORDENADORIA - utilizado para armazenar as mudanças de coordenadorias ocorridas com os professores

CREATE TABLE BDAT COORDENADORIA

(ID_EMP NUMBER(4),NOME_EMP VARCHAR2(40),ID_COORD NUMBER(3),

DESTCRICAO_COORD VARCHAR2(35),ID_USUARIO_BDO VARCHAR2(30),

DT_INICIAL DATE,DT_FINAL DATE,

CONSTRAINT BDAT_COORDENADORIA_PK PRIMARY KEY(ID_EMP, ID_COORD,

DT_INICIAL)); 


\section{Conjunto de entidades BDAT_ENDER_EMPREGADO - utilizado para armazenar as mudanças de endereço ocorridas com os funcionários e/ou professores}

CREATE TABLE BDAT_ENDER_EMPREGADO

(ID_EMP NUMBER(5),ID_LOCAL NUMBER(3),NOME_EMP VARCHAR2(40),

DESSCRICAO_LOCAL VARCHAR2(40),ENDERECO_EMP VARCHAR2(70),

ID_USUARIO_BDO VARCHAR2(30),ORIGEM VARCHAR2(10),

DT̄_INICIAL DATE,DT_FINAL DATE,

CONSTRAINT BDAT_EMPREGADO_PK PRIMARY KEY(ID_EMP, ID_LOCAL, ORIGEM, DT_INICIAL));

\section{Conjunto de entidades BDAT_FALTA - utilizado para armazenar os totais anuais de faltas ocorridas com os alunos}

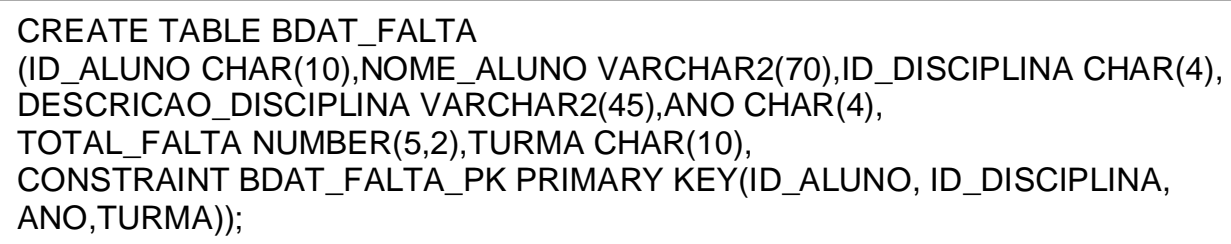

Conjunto de entidades BDAT_MEDIA - utilizado para armazenar as mudanças de notas semestrais ocorridas com os alunos

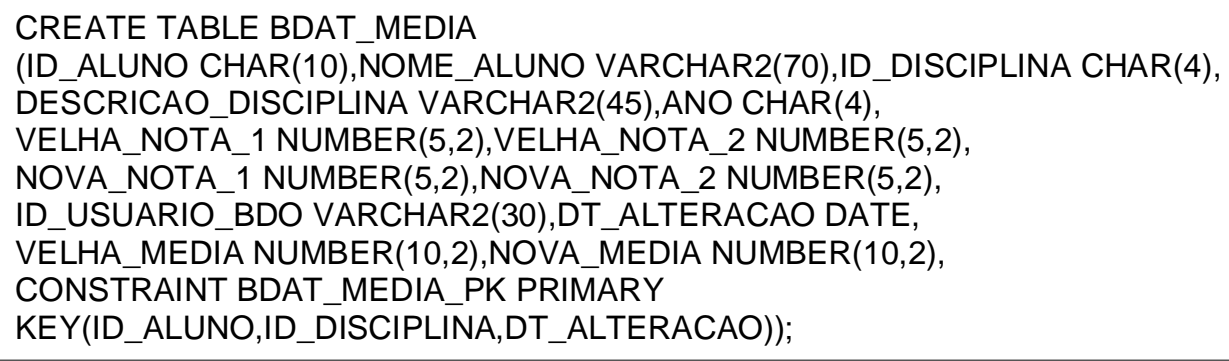




\section{APÊNDICE F}

Especificação dos Scripts utilizados no Estudo de Caso 


\section{Especificação do Gatilho PASSO_C1_BDAT_CARGO (Fluxograma da Figura 65 )}

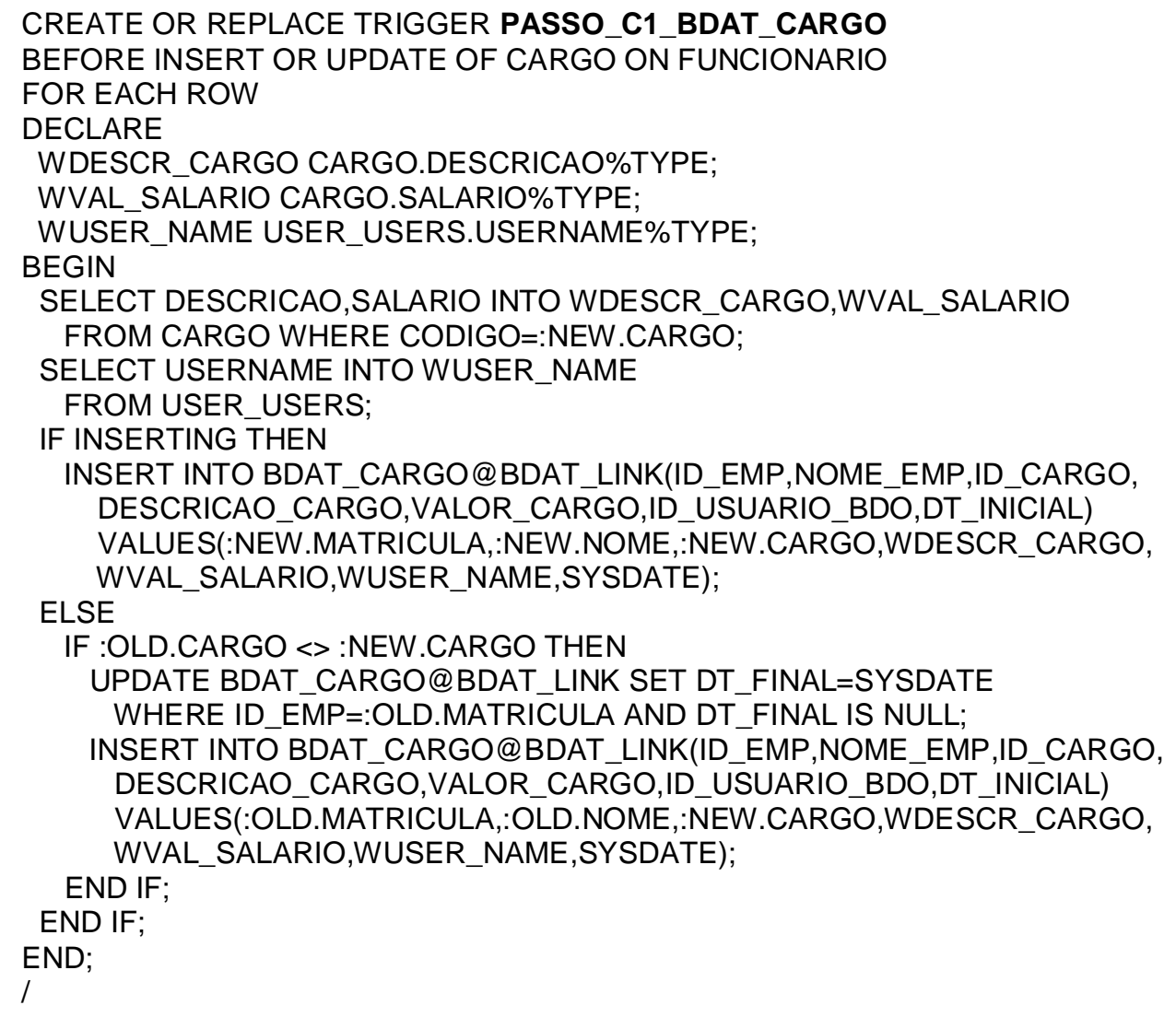




\section{Especificação do Gatilho PASSO_C1_BDAT_CAT1 (Fluxograma da Figura $6 \overline{6}$ )}

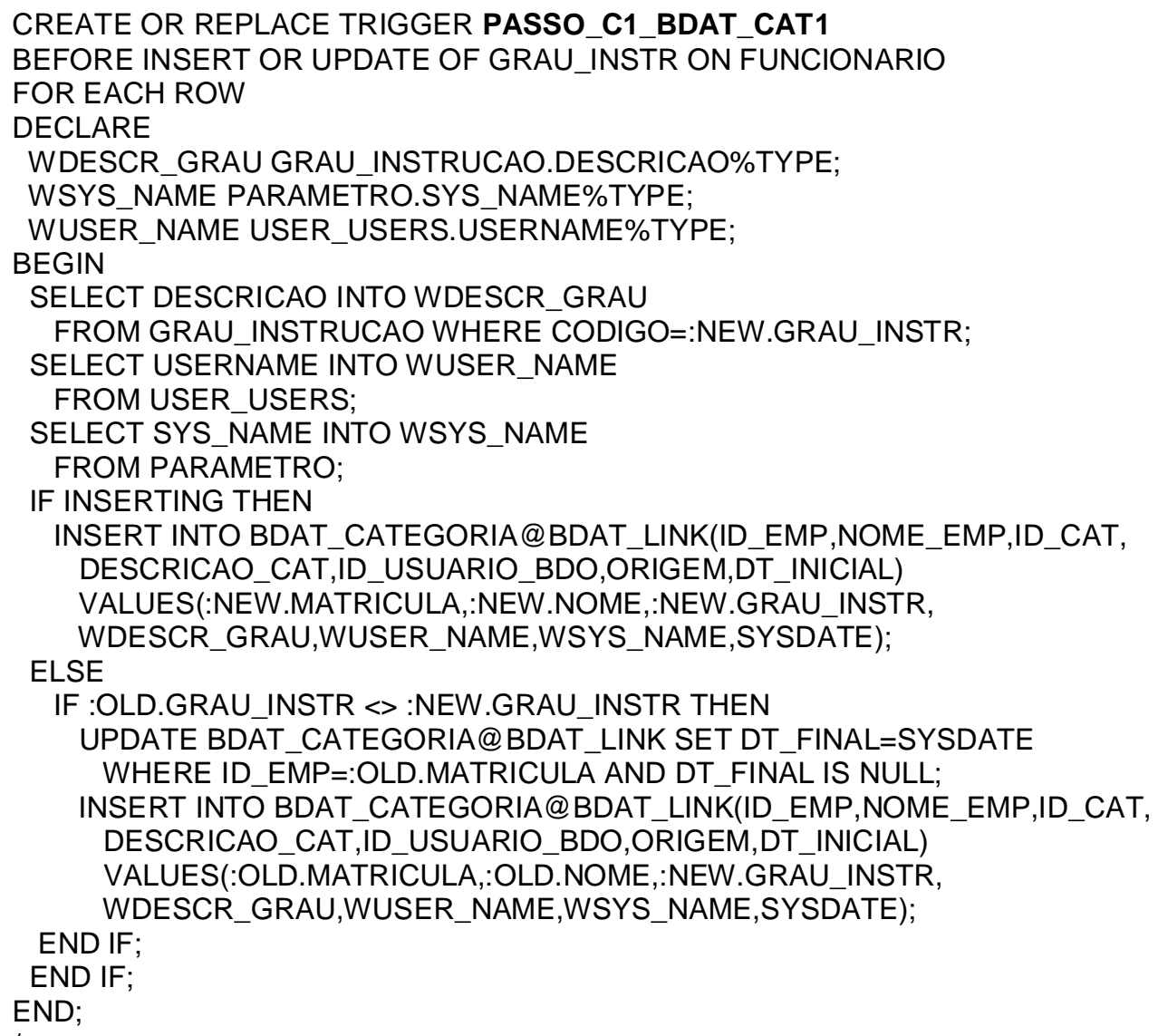




\section{Especificação do Gatilho PASSO_C1_BDAT_CAT2 (Fluxograma da Figura $6 \overline{7}$ )}

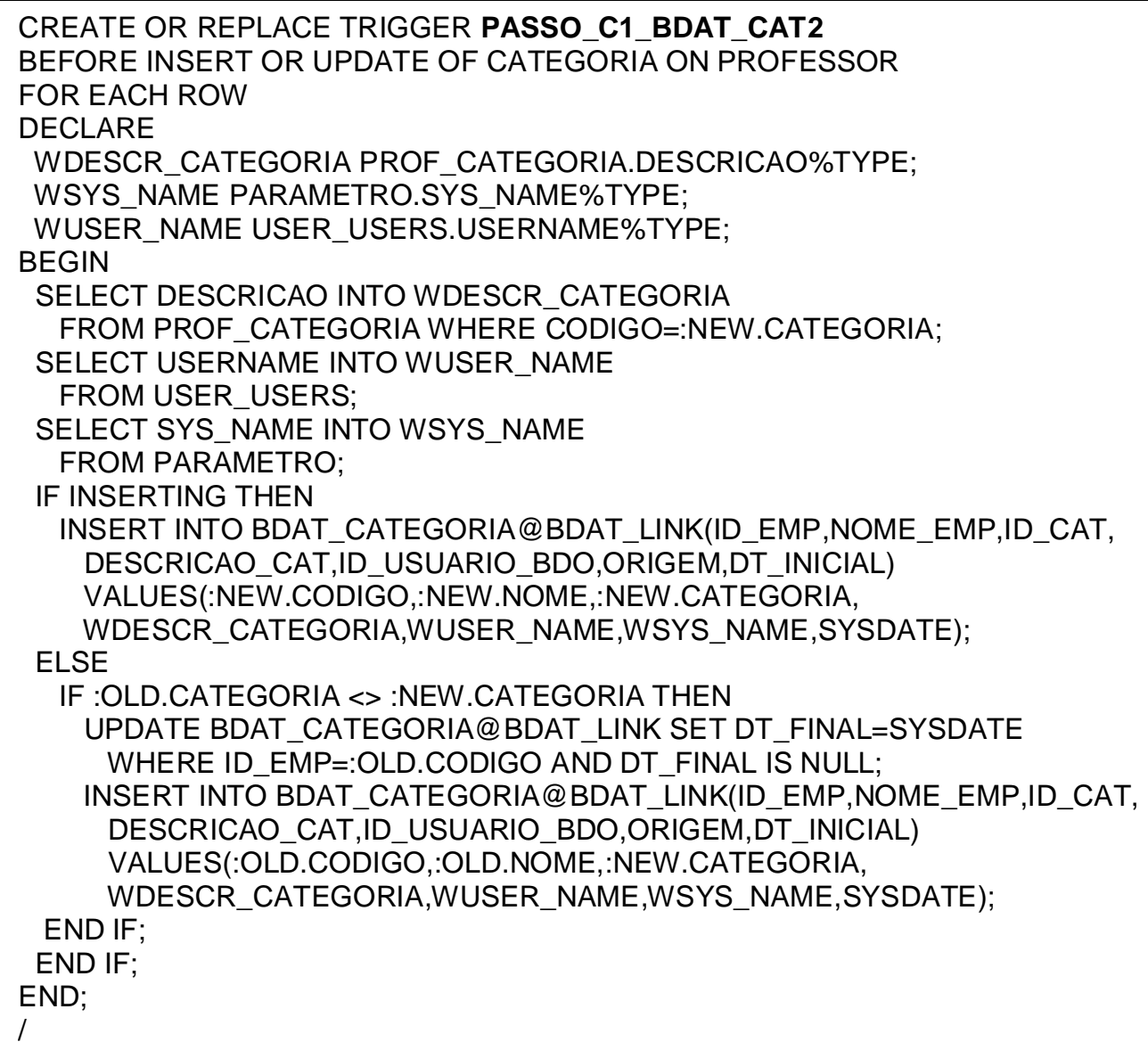




\section{Especificação do Gatilho PASSO_C1_BDAT_COORDENADORIA (Fluxograma da Figura 68)}

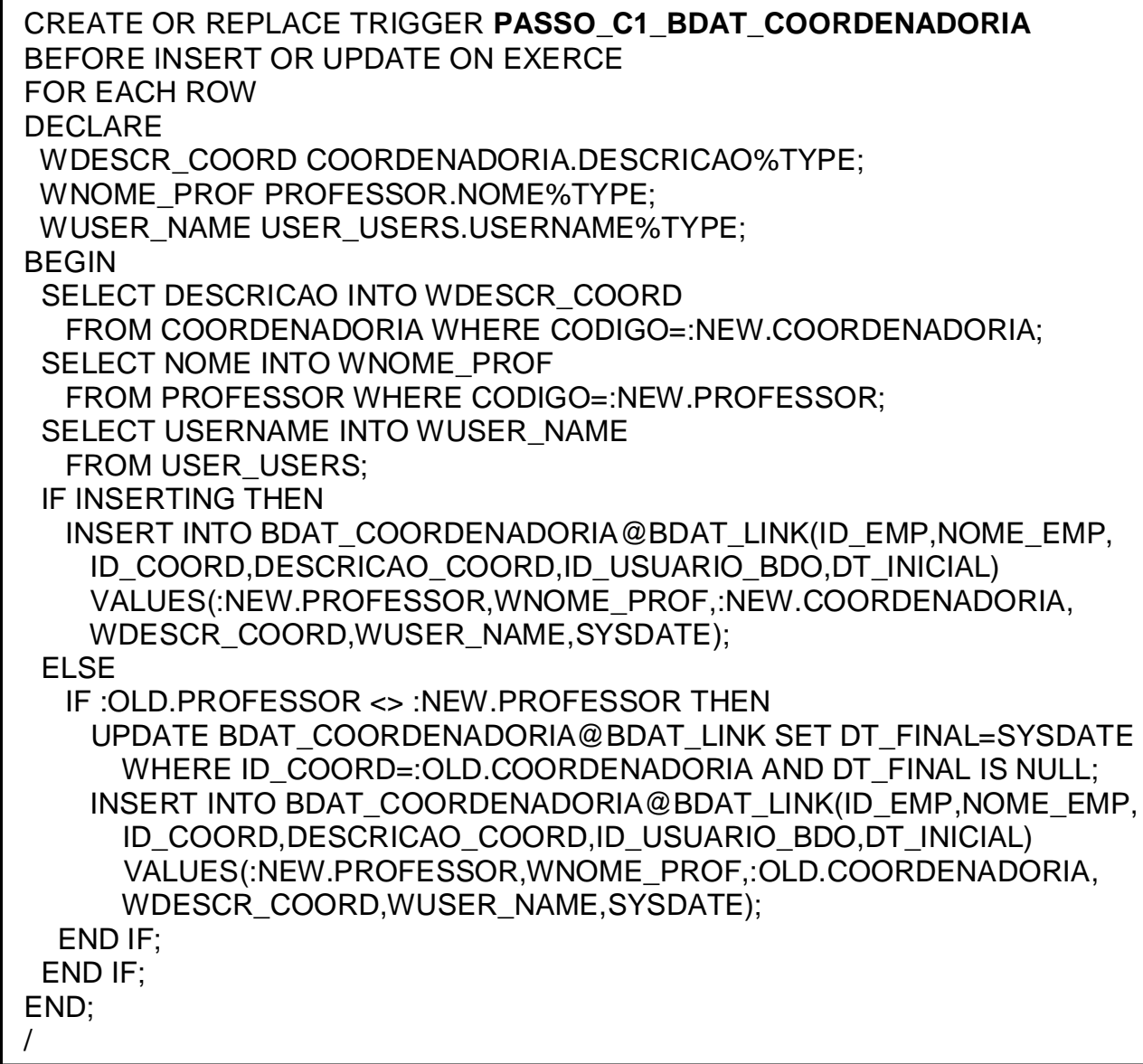




\section{Especificação do Gatilho PASSO_C1_BDAT_ENDER_EMP1 (Fluxograma da Figura 69)}

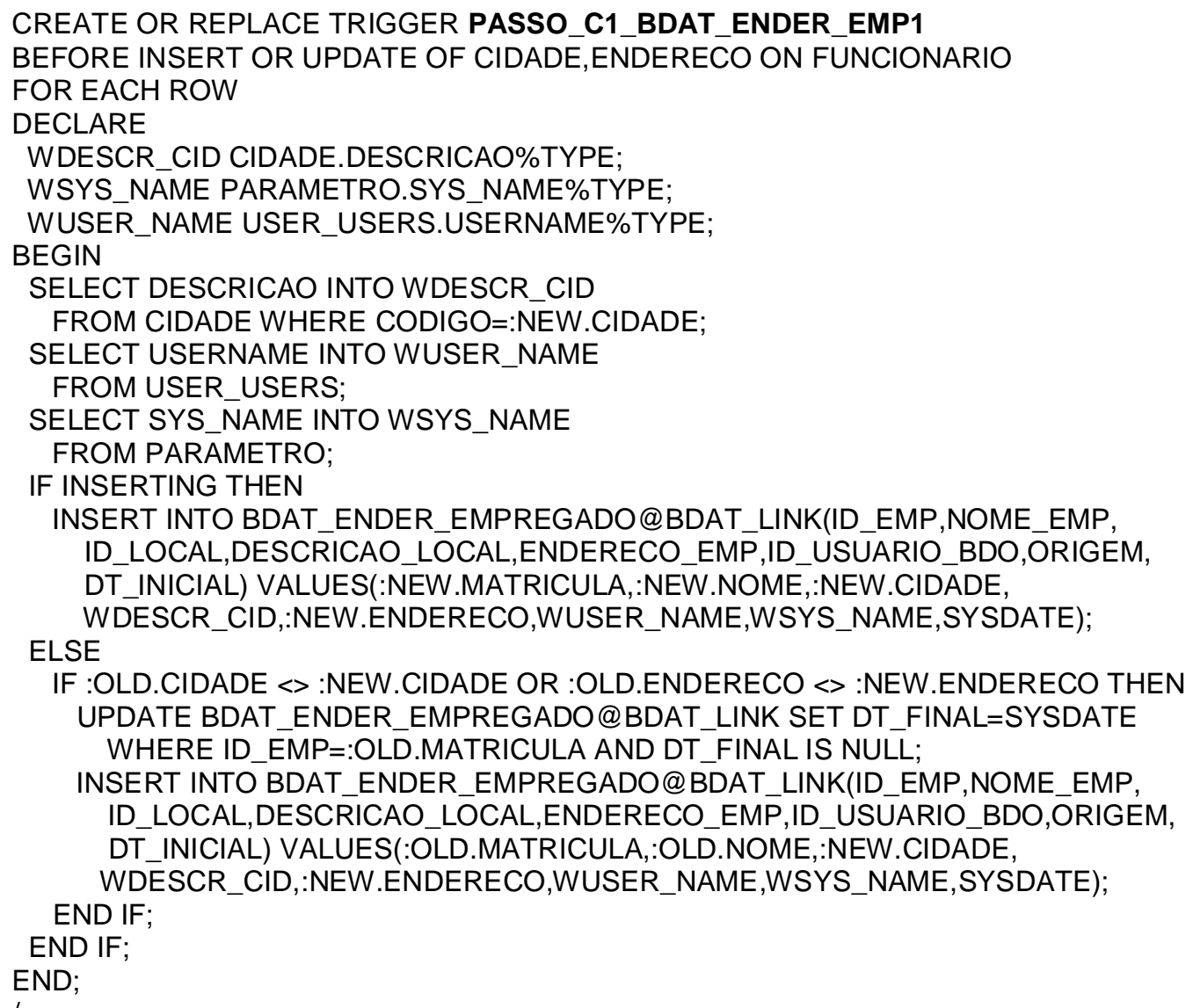




\section{Especificação do Gatilho PASSO_C1_BDAT_ENDER_EMP2 (Fluxograma da Figura 70)}

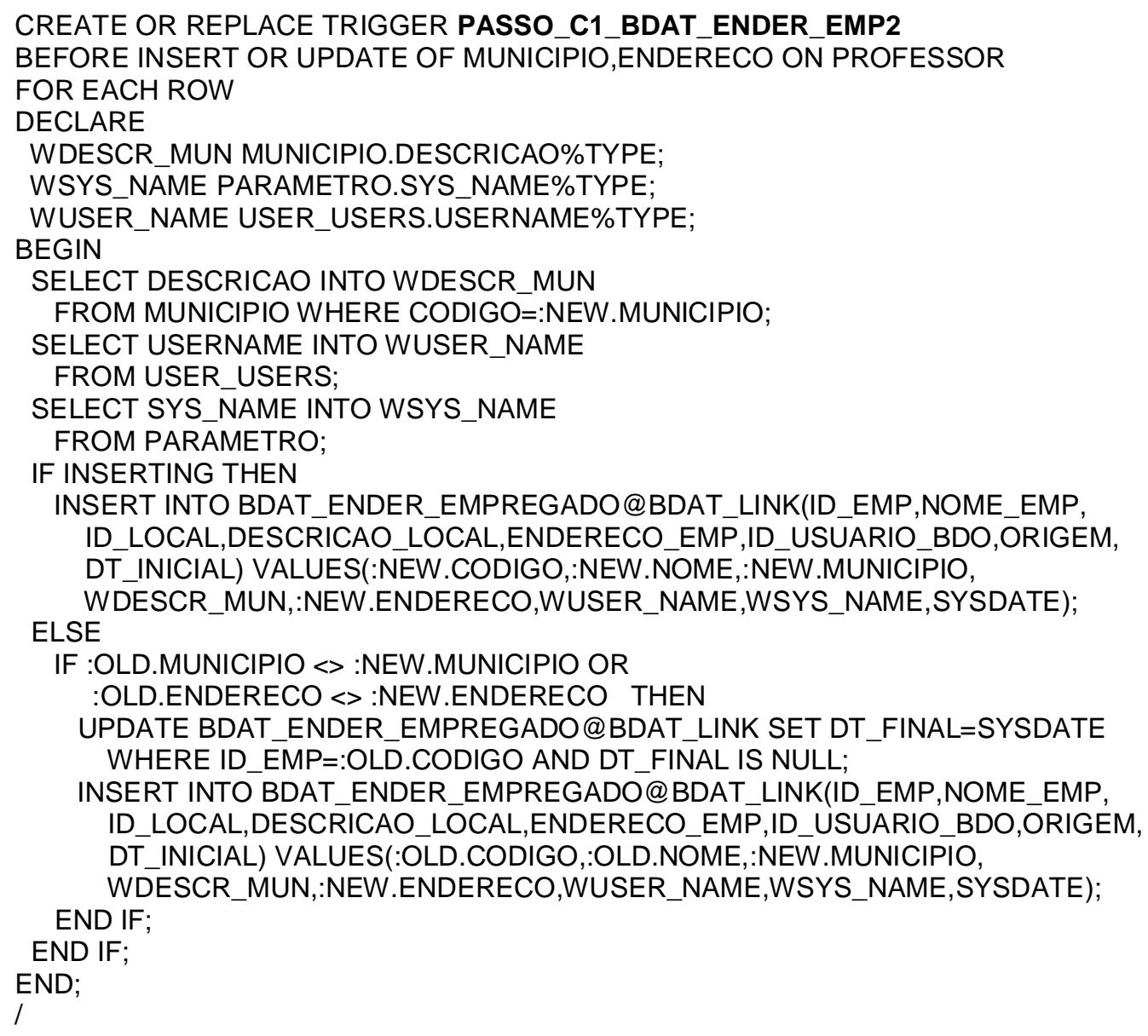




\section{Especificação do Gatilho PASSO_C2_BDAT_MEDIA (Fluxograma da Figura 71)}

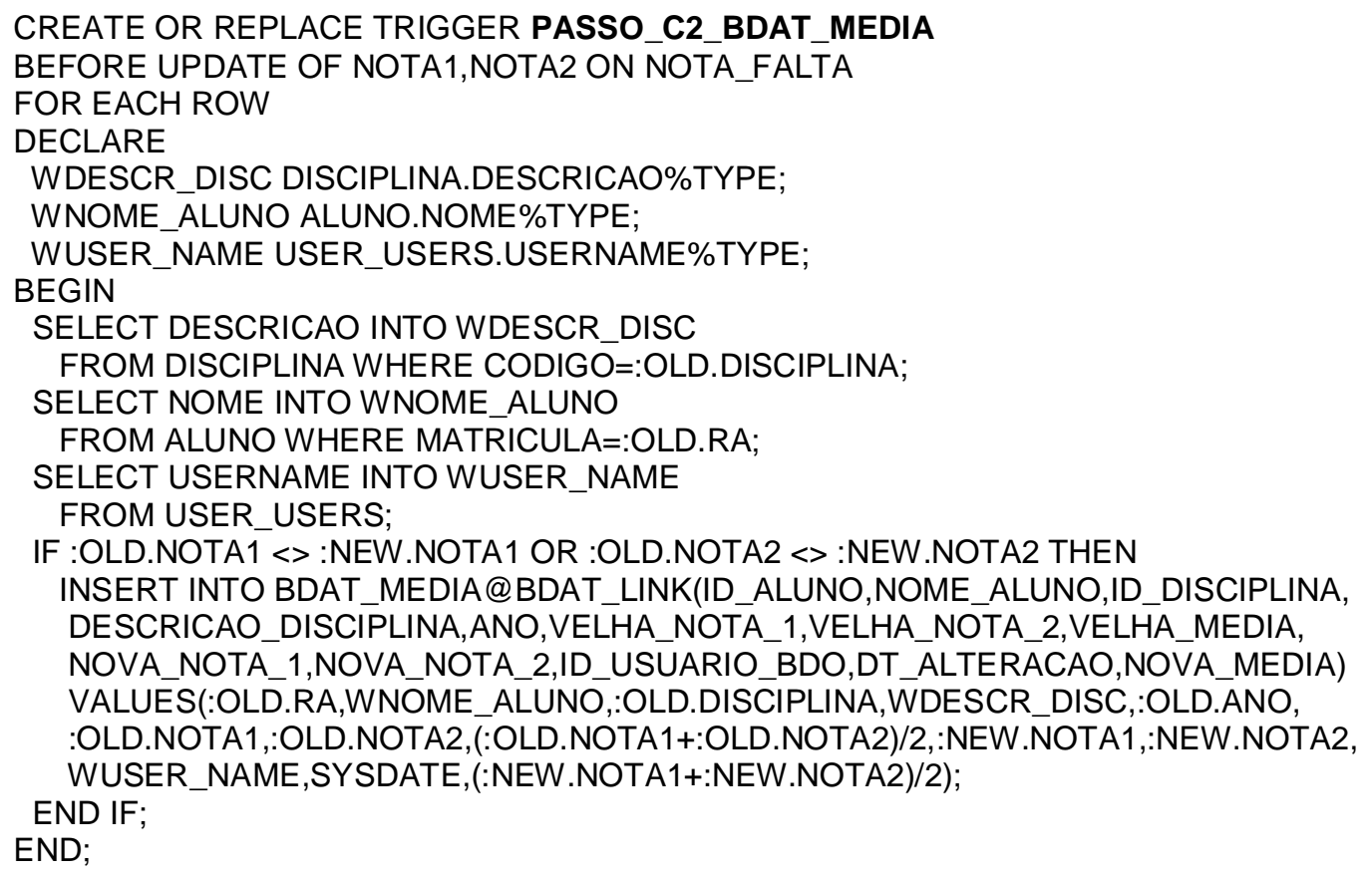




\section{Especificação do Procedimento PASSO_C3_BDAT_ANUAL_EMP (Fluxograma da Figura $7 \overline{2}$ )}

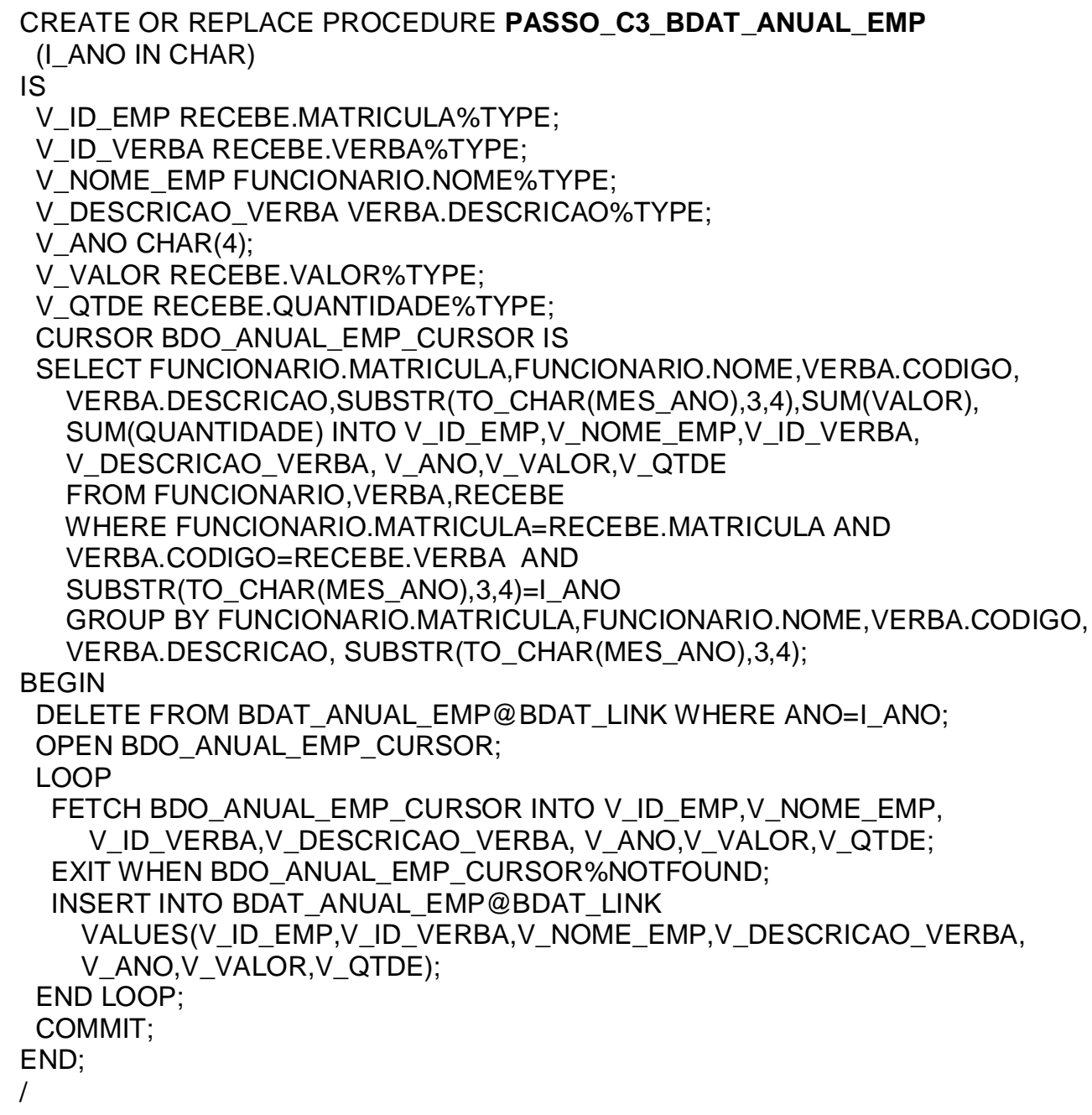




\section{Especificação do Procedimento PASSO_C3_BDAT_FALTA (Fluxograma da Figura 73)}

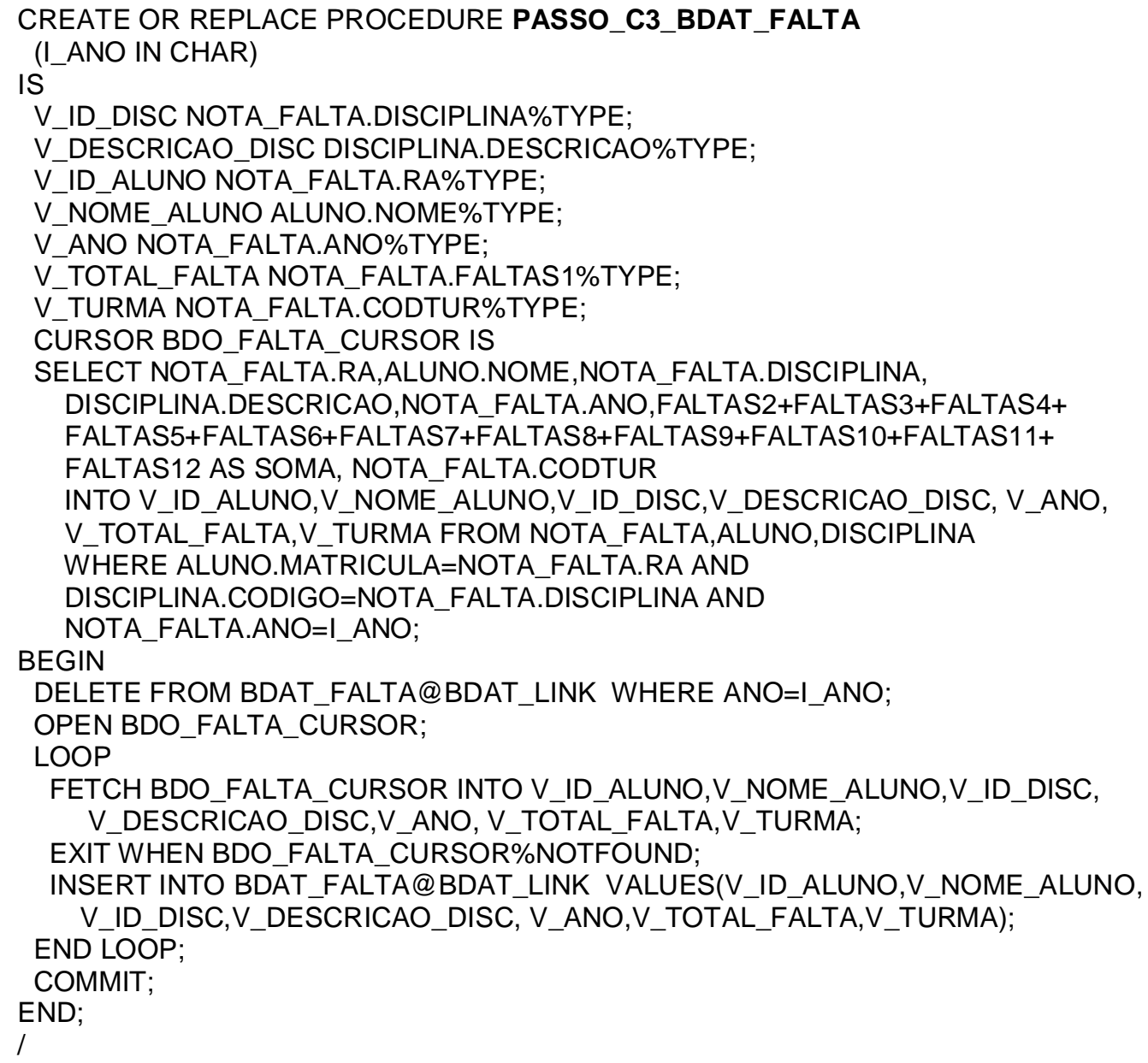

